Universidad deValladolid

PROGRAMA DE DOCTORADO EN ECONOMÍA

TESIS DOCTORAL:

\title{
MODELLING ENERGY TRANSITIONS TO A LOW CARBON ECONOMY
}

\author{
Presentada por Jaime Nieto Vega para optar \\ al grado de
}

Doctor por la Universidad de Valladolid

Dirigida por:

Óscar Carpintero Redondo

Luis Javier Miguel González 


\section{Table of Contents}

LIST OF TABLES 6

ABSTRACT

1.1. JUSTIFICATION AND MOTIVATION

1.1.1. THE ENERGY TRANSITION AND THE LIMITS TO GROWTH.

1.1.2. SUSTAINABILITY TRANSITIONS AND ENERGY-ECONOMY-ENVIRONMENT MODELLING

1.2. OBJECTIVES

1.3. THEORETICAL FRAMEWORK

1.3.1. ECOLOGICAL ECONOMICS.

1.3.2. POST-KEYNESIAN ECONOMICS.

1.4. METHODOLOGICAL FraMEWORK

1.5. STRUCTURE

\section{LESS THAN $2^{\circ} \mathrm{C}$ ? AN ECONOMIC-ENVIRONMENTAL EVALUATION OF THE PARIS}

2.1. INTRODUCTION

2.2. Methodology

2.3. TOWARDS A NEW LANDSCAPE: THE INDCS IN DETAIL

2.3.1. QUALITY OF INFORMATION

2.3.2. MITIGATION POLICIES: ENERGY, INDUSTRY, AGRICULTURE, WASTE AND LULUCF

2.3.3. FINANCE, EQUITY AND LEADERSHIP OF THE TRANSITION 
2.3.4. REDUCING EMISSIONS? 65

$\begin{array}{ll}\text { 2.3.5. THE TOP } 12 \text { POLLUTERS PATHWAY } & 67\end{array}$

2.4. ECONOMIC AND ENVIRONMENTAL FEATURES OF INDCS 68

2.4.1. SOCIO-ECONOMIC IMPACT 68

2.4.2. DEMAND SIDE MANAGEMENT POLICIES

2.4.3. SUBSTITUTION OF NON-RENEWABLE ENERGIES 71

2.4.4. THE ROLE OF TECHNOLOGY

2.4.5. TRANSITION EQUITY

2.4.6. COMPLIANCE WITH THE OBJECTIVES OF EMISSIONS REDUCTIONS 74

2.5. CONCLUSIONS 76

3. MACROECONOMIC MODELLING UNDER ENERGY CONSTRAINTS: GLOBAL LOW CARBON

TRANSITION SCENARIOS. $\quad 79$

3.1. INTRODUCTION

3.2. THEORETICAL FRAMEWORK: LIMITS, ECONOMIC STRUCTURE AND SYSTEM DYNAMICS 81

3.3. MOdELLING A FEASIBLE WORLD ECONOMY. METHODOLOGY 86

3.3.1. THE ECONOMY MODULE

3.3.2. ENERGY MOdULE 95

3.4. LOW-CARBON ECONOMIES COPING WITH THE LIMITS. RESULTS. $\quad 98$

3.4.1. EMISSIONS AND GDP GROWTH UNDER ENERGY CONSTRAINTS 100

3.4.2. STRUCTURAL CHANGE AND THE UNCERTAIN PATHWAYS TOWARDS SUSTAINABILITY 105

$\begin{array}{ll}\text { 4.5. CONCLUDING REMARKS AND POLICY IMPLICATIONS } & 109\end{array}$

4. A SYSTEM DYNAMICS-ECOLOGICAL MACROECONOMICS MODEL: THE ENERGY

TRANSITION IN THE EU.

$\begin{array}{ll}\text { 4.1. INTRODUCTION } & 113\end{array}$

4.2. Methodology 115

4.2.1. General OVerview 115

$\begin{array}{ll}\text { 4.2.2. THE ECONOMY MOdULE } & 119\end{array}$

4.2.3. DEFINITION OF SCENARIOS 125

$\begin{array}{ll}\text { 4.3. RESULTS } & 129\end{array}$

$\begin{array}{ll}\text { 4.4. DISCUSSION } & 135\end{array}$

4.4.1. AN ECOLOGICAL MACROECONOMICS CONTRIBUTION TO POST-KEYNESIAN THEORY 135 
$\begin{array}{ll}\text { 5.1. MAIN FINDINGS } & 144\end{array}$

5.2. POLICY AND THEORY IMPLICATIONS

$\begin{array}{ll}\text { 5.3. LiMitATIONS AND FUTURE DEVELOPMENT. } & 150\end{array}$

\begin{tabular}{lr} 
REFERENCES & 152 \\
\hline
\end{tabular}

\begin{tabular}{lr} 
SUPPLEMENTARY MATERIALS & 177 \\
\hline
\end{tabular}

$\begin{array}{ll}\text { APPENDIX 1. METHODOLOGICAL APPENDIX FOR INDCS REVISION } & 177\end{array}$

$\begin{array}{ll}\text { APPENDIX 2. MEDEAS-WORLD ANALYSIS } & 180\end{array}$

$\begin{array}{ll}\text { APPENDIX 2.A. LIST OF INDUSTRIES } & 180\end{array}$

APPENDIX 2.B. TARGET MATRICES FOR THE WORLD MODEL. 181

APPENDIX 2.C. DIRECT AND INDIRECT EFFECTS 186

APPENDIX 2.D. WORLD ECONOMY MODULE VIEWS

APPENDIX 3. MEDEAS-EUROPE ANALYSIS $\quad 191$

APPENDIX 3.A. SCENARIOS ASSUMPTIONS

APPENDIX 3.B. ENERgy RoAdMAP 2050: PrimARY ENERGy USE REDUCTION TARGETS TO 2030 AND PROJECTIONS TO 2050.

APPENDIX 3.C. METHODOLOGY ANNEX ON NOTATION. 195

APPENDIX 3.D. TARGET MATRICES FOR THE EUROPEAN MODEL. 196

\section{List of Figures}

Figure 1. Stylized net global CO2 emissions. Billion tonnes CO per year (GtCO/yr)....... 16

Figure 2 Greenhouse Gas Emissions by Economic Sectors............................................... 18

Figure 3. 'Ecological ceiling', 'social foundation' and the 'safe and just space for humanity'.

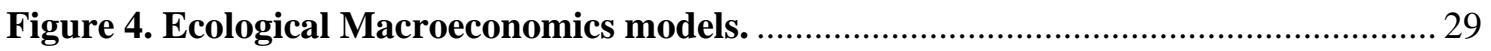

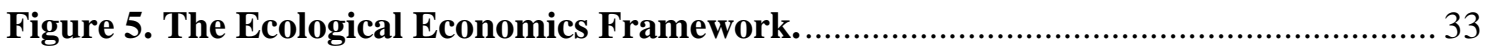


Figure 6. Optimisation and simulation IAMs and their interaction with economics. 37

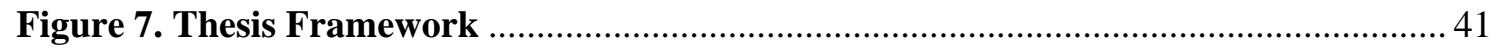

Figure 8. Top 15 policies. Differences of each policy with respect to the global mean by

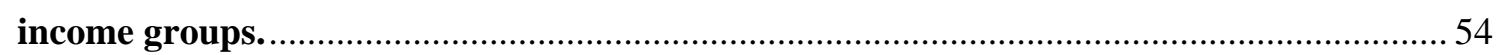

Figure 9. Sectoral relevance by income groups. Differences with respect to global sectoral mean.

Figure 10. Emissions variations by income level and different scenarios from baseline 20052015 to 2030 66

Figure 11. General overview of system dynamics structure based on stocks, flows and feedbacks. 83

Figure 12. Negative feedback loop between GDP growth and energy availability............. 84

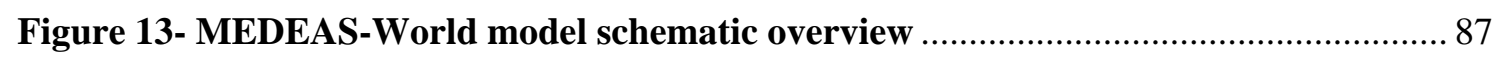

Figure 14. Economy module structure and main energy inputs ......................................... 89

Figure 15. From interregional Input-Output tables (IOT) to a World IOT ....................... 92

Figure 16. Simplified influence diagram of the Economy module...................................... 97

Figure 17. Emissions change by scenarios. From 2005-2015 mean to 2030 and 2050....... 102

Figure 18. GDP growth scenarios (3-yr mobile average).............................................. 103

Figure 19. Direct and indirect contribution to energy demand variation by final end-use

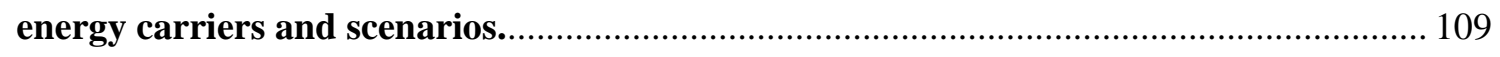

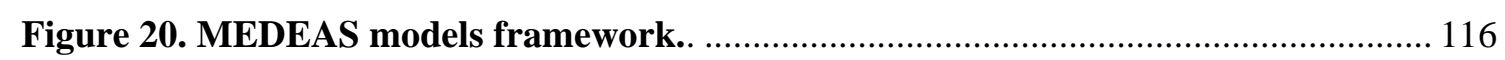

Figure 21. Simplified influences diagram of main interactions between Energy, Economy

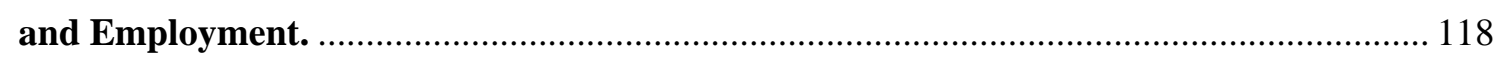

Figure 22. Schematic overview of the Economy module and main interactions. .............. 120

Figure 23. Two-Regions Europe-Rest of the World simplified Input-Output framework.

Figure 24. Sequential (a) and storylines (b) scenarios framework. .................................. 127

Figure 25. Sequential scenarios for the Energy Roadmap 2050. Key variables. ............... 131

Figure 26. Storyline scenarios. Main results. Source: own elaboration............................... 132

Figure 27. Kaleckian employment model extended with energy supply constraints. ....... 137

Figure 28. 'DEM-ECON. Investment and Households' View in MEDEAS-World............ 187

Figure 29. 'ECON. Economic structure - A matrix evolution' view in MEDEAS-World. 188

Figure 30. 'DEM ECON - Income. Labour and capital compensation' view in MEDEAS-

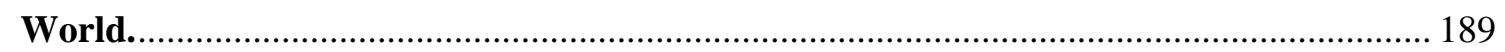

Figure 31. 'ECON. Confrontation demand with limits' view in MEDEAS-World. ........... 190

Figure 32. Ref2016 and EUCO scenarios. Primary Energy production and net imports pathways and projections. 194 


\section{List of Tables}

Table 1. Sustainability transitions: summary of main approaches. ......................................... 23

Table 2. Historical socioecological regimes............................................................................................. 24

Table 3. Classification of Integrated Assessment Models ............................................................. 26

Table 4. Ecological Macroeconomics models and how they deal with feedbacks. ................ 28

Table 5. Information criteria ..................................................................................................................... 48

Table 6. Overview of main policies in INDCs...............................................................50

Table 7 (continuation of Table 6). Overview of main policies in INDCs................................. 51

Table 8. Top 15 Policies in the INCDs....................................................................................52

Table 9. Overview of policies by country ................................................................................56

Table 10. Financial allocation by income group (billions US\$). Totals and effort related to

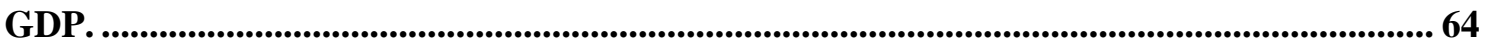

Table 11. Overview of Top 12 polluter. Information, emissions and financial resources. . 67

Table 12. Overview of main results (excluding policies)................................................................. 75

Table 13. Overview of the most relevant scenario inputs. ...................................................99

Table 14. Energy sensitivity to final demand growth by resources (EJ/trillion USD)...... 106

Table 15. Summary of main results: Import Dependency, Renewables share on TPES,

GDP, Employment and GHG emissions by Scenarios............................................................ 134

Table 16. List of industries ..................................................................................................................... 180

Table 17. BAU final A matrix (World level) and different year's sum of columns (share of intermediate products on total output) ................................................................................................. 183

Table 18. Green growth scenario target A matrix (World level) ............................................ 184

Table 19. Post growth scenario A matrix (World level) ........................................................... 185

Table 20. Detailed scenarios summary for European model.................................................. 191

Table 21. Main changes in target matrices ............................................................................ 196 


\section{Abstract}

The escalation of the global temperature, as well as the increasing perception of the climate change impacts, have led the international community to the signature of the Paris Agreement. The bold dependency on non-renewable energy resources by the economy is, simultaneously, a problem both from its availability side and from its use as main greenhouse gases emitter. Therefore, the main challenges of the transition to sustainability would lie on the fact that it would be the first transition towards a more sustainable regime and to make this transformation compatible with the maintenance of social welfare. With this objective, the Integrated Assessment Models (IAMs) are a powerful analysis tool in order to evaluate the complex energy-economy-environment (3E) relationships. After a revision of the IAM's state of the art, it is verified that optimisation models are dominant, with a stylised representation of the economy, and poorly integrated with the biophysical systems. Conventional models tend to present an unidirectional relationships with the environment due to the lack of feedbacks and the disregard or underestimation of resources' availability.

This thesis is developed with the purpose of filling this gap in the literature and discussing the usual results of conventional models. Therefore, its objectives would be the revision of the national transition plans, on a global scale, to determine their policy targets, emissions objectives and means of implementation, in order to comprehend their underlying principles. With this framework, an Ecological Macroeconomics model is developed and integrated in a well disaggregated and highly-integrated IAM: MEDEAS. With the objective, in turn, of analysing the macroeconomic impacts of energy transitions, including the effects of a potential energy supply scarcity, the main novelty of this model is its energy-economy feedback. With this inspiration, two economic models are constructed, one at the global and the other European level. These models are based on the combination of two methodologies: energy-extended Input-Output Analysis (IOA) and System Dynamics (SD). The IOA framework enables the accountability not only of direct (both monetary and energy) but also indirect carriers of the final demand of goods and services. Moreover, SD allows modelling complex systems rich in non-linear relationships, feedbacks, tipping points, time delays and stock-flow structures.

This thesis' results show, firstly, an insufficient preparation of the national commitments (INDCs) to meet the Paris Agreement's targets. This way, the underlying general philosophy of these plans relies on a Green Growth background understood as a combination of a so-called inclusive economic growth with energy efficiency gains and substitution of fossil fuel for renewable-based technologies. However, the emissions variation commitments, once estimated in absolute terms, result in an overall increase between $19.3 \%$ (if external North-South funds are 
received) and $25.8 \%$ (if not received) by 2030 . These external funds represent no less than $41.4 \%$ of the total funding of the Paris Agreement's national commitments.

Once established the framework of the dominant sustainability transition policies, it is applied to the MEDEAS model and its Economy module. Three different scenarios are defined as Business as Usual (BAU), Green Growth (GG) and Post-Growth. The simulation of the BAU scenario at the global level, shows an important increase in the GHG emissions, that would only slightly decrease after the economic downturn driven by the insufficient energy supply. On the other hand, the GG scenario, despite the strong efforts to shift the energy mix towards renewables, is not able to achieve significant GHG emissions reductions. Conversely, the Post-Growth scenario is the only one to achieve significant GHG emissions avoiding resources tensions. On the light of these results, industrial policy and the inclusion of IOA prove to be paramount, given that the capacity to explain the total energy use variation of the indirect effects of final demand (those related with inter-industry spill-overs) represents more than two times that of the direct carriers in some cases.

Finally, at European level, an Employment sub-module is constructed and integrated, allowing the inclusion of policies such as the working time reduction (WTR) and the evaluation of different labour productivity growth scenarios. In addition, the European Commission's primary energy demand with correlative energy efficiency gains scenarios are assessed (Ref16, EUCO+27, EUCO+33, EUCO+40). The outcomes of this analysis show important GDP and employment reductions in all the scenarios, especially in EUCO+40. In fact, this is the only scenario achieving significant GHG emissions reduction, although at the expense of the macroeconomic indicators. It is observed that different socioeconomic stimulus have a negligible effect on GDP once the energy limits are imposed. Employment would only recover significantly after the implementation of the WTR policy along with an increase in salaries. As a consequence, only the PG scenario is able to combine a significant GHG emissions (70\% by 2050) with the maintenance of employment.

Therefore, on the light of these results, the main theoretical and policy implications of this thesis are related to the following elements:

- Multilateral agreements like Oil Depletion Protocol or Leaving fossil fuels underground could contribute to overcome the weaknesses of the current unilateral and voluntary-based strategy.

- Efficiency and substitution of fossil fuels by renewables alone (GG narrative) could be ineffective due to rebound effect or the energy trap: the necessity to carry on relying on fossil fuels during the process of unfolding the renewable energy technologies. 
- Likewise, promoting labour productivity growth prior to knowing the implications of the energy restriction could be either ineffective in terms of GDP (best case) or harmful for employment (productivity trap).

- Retaking industrial policy could be a powerful tool to achieve a socially and effective energy transition towards sustainability.

- The incorporation of absolute limits from the energy side could contribute to a more complete economic growth theory, as well as to improve the IAMs' realism.

- The Kaleckian theory of employment would be nuanced if energy restrictions are regarded. This way, wages or aggregate demand incentives would be ineffective to create employment even below full-employment.

- In order to overcome this limit, a WTR policy addressing the great productivity gains of the last decades could contribute to ease the potential adverse social effects during the energy transition.

- Demand management policies contributing to obtain similar welfare and energy services levels with lower final energy demand would contribute to overcome a possible GDP decline.

- Moving from a Degrowth rhetoric to a Post-Growth one would address more effectively the socioecological challenges of the future: a shift from GDP as a policy target towards equality and sustainability, while recognizing the necessity to expand the material base of the least developed countries. 


\section{Resumen de la tesis}

La escalada del aumento de la temperatura global, así como la percepción cada vez más vívida de los impactos del cambio climático, han llevado a la comunidad internacional a la firma de diferentes Tratados como el Acuerdo de París. La fuerte dependencia de la utilización de recursos energéticos no renovables por parte de la economía es, al mismo tiempo, un problema por el lado de su disponibilidad y por el de su uso, como principales emisores de gases de efecto invernadero. De hecho, los principales retos de esta transición recaerían en que esta sería la primera que abunda en una mayor sostenibilidad, así como en hacer compatible esta transformación con el mantenimiento del bienestar social. Con este objetivo en mente, los Modelos de Evaluación Integrada (MEI) constituyen una poderosa herramienta para analizar las complejas relaciones entre economía, energía y medio ambiente (Energy-Economy-Environment o 3E en inglés). Tras una revisión del estado del arte en lo referente a los MEIs, se constata que abundan los modelos de optimización con una representación de la economía muy estilizada, que además adolecen de una gran falta de integración con los sistemas naturales. Los modelos convencionales tienden a presentar una influencia unidireccional sobre el medio ambiente, debido a la ausencia de realimentaciones y la desatención o minusvaloración de la disponibilidad de recursos.

Con el propósito de cubrir esta carencia de la literatura y discutir los resultados tradicionalmente obtenidos en los modelos convencionales se desarrolla esta tesis. Los objetivos de la misma pasarían, por tanto, por una revisión a escala global de los planes de transición nacionales para determinar las políticas, objetivos de emisiones, medio de implementación que nos ayude a entender la filosofía subyacente general de las mismas. Con este marco, se desarrolla un modelo de Macroeconomía Ecológica para su incorporación a un MEI desagregado y de alta integración entre sus dimensiones: MEDEAS. Con el objetivo, a su vez, de analizar los impactos macroeconómicos de las transiciones energéticas y los posibles efectos de una escasez en el flujo de suministro energético, la principal novedad de este nuevo modelo es la inclusión de una realimentación energía-economía. Con estos mimbres se elaboran dos modelos, uno a escala global y otro a escala europea. Estos modelos estarían basados en la combinación de la metodología Input-Output extendida a la energía, con la Dinámica de Sistemas. El marco Input Output permite contabilizar no solo los acarreos directos (monetarios y energéticos) de la demanda final de bienes y servicios, sino también los indirectos. Por otro lado, la Dinámica de Sistemas permite el modelado de sistemas complejos en los que abundan las relaciones no lineales, las realimentaciones, los puntos de inflexión, retardos temporales y las estructuras basadas en flujos y stocks. 
Los resultados arrojados por esta tesis muestran, en primer lugar, una insuficiente preparación de los compromisos nacionales (INDCs) para lograr los objetivos del Acuerdo París. Así, la filosofía general de estos planes podría definirse como de Crecimiento Verde (o Green Growth) caracterizada por una combinación de un denominado crecimiento económico inclusivo con mejoras de la eficiencia energética y sustitución de las tecnologías dependientes de los combustibles fósiles por las renovables. A pesar de ello, los compromisos en materia de variación de emisiones, una vez estimados en términos absolutos, arrojarían un aumento de las mismas entre un 19.3\% (condicionado a recepción de financiación Norte-Sur) y un 25.8\% (de no recibirse) para el año 2030. Esta financiación Norte-Sur, representaría nada menos que el $41.4 \%$ de todos los recursos financieros requeridos en los compromisos nacionales.

Una vez establecido el marco de políticas de transición hacia la sostenibilidad dominante, se procede a la aplicación del mismo al modelo MEDEAS y su módulo de Economía. En este sentido, se diseñan tres escenarios denominados como Business as Usual (BAU), Green Growth (GG) y Post-Growth (PG). La simulación del escenario BAU muestra un aumento muy importante en las emisiones de gases de efecto invernadero, que sólo se verían ligeramente minoradas tras el declive económico motivado por el insuficiente suministro de energía (fundamentalmente líquidos). El escenario GG, por su parte, a pesar de los esfuerzos en materia de transición energética, sería incapaz de lograr reducciones significativas de emisiones. Contrariamente, el escenario PG es el único en el que se alcanzan reducciones significativas de emisiones evitando tensiones por el lado de los recursos. A la luz de estos resultados, se prueban como fundamentales las políticas industriales y la inclusión del análisis Input-Output, dado que la capacidad para explicar la variación en el uso total de energía de los efectos indirectos de la demanda final (aquellos relacionados con los efectos de arrastre inter-industriales) representan más del doble que los efectos directos en algunos casos.

Por último, a escala europea, se añade un sub-módulo de empleo que permite añadir políticas como la reducción de la jornada laboral y evaluar escenarios de crecimiento de la productividad del trabajo. Además, se evalúan los escenarios de la Comisión Europea de reducción del uso de energía final con incrementos correlativos de eficiencia (Ref16, EUCO+27, EUCO+33 y EUCO+40). Los resultados muestran importantes reducciones del PIB y el empleo en todos los escenarios, especialmente en el EUCO+40, que sería el único en lograr reducciones de calado en las emisiones, aunque a costa de los indicadores socioeconómicos. Se observa que la inclusión de diversos estímulos socioeconómicos apenas afectaría al PIB una vez que los límites energéticos son establecidos, revelando la jerarquía existente entre los sistemas biofísicos y la economía. El empleo sólo lograría recuperarse de manera significativa después de la aplicación de una reducción de la jornada laboral junto con un incremento correspondiente de los salarios. 
No obstante, tan sólo el escenario PG es capaz de combinar una reducción importante en las emisiones (70\% en 2050) con el mantenimiento del empleo.

Por lo tanto, a la luz de estos resultados, las principales implicaciones de esta tesis tendrían que ver con los siguientes elementos:

- Acuerdos multilaterales como el Protocolo de Agotamiento del Petróleo o Mantener los combustibles fósiles bajo tierra podrían contribuir a superar las carencias de la estrategia unilateral y voluntaria.

- Las políticas de eficiencia con transición a renovables por sí solas (narrativa GG) podrían ser inefectivas por elementos como el efecto rebote o la trampa de la energía: la necesidad de seguir consumiendo combustibles fósiles durante el proceso de instalación de las tecnologías renovables.

- En el mismo sentido, promover incrementos de la productividad del trabajo antes de conocer las implicaciones de las restricciones energéticas, podría ser ineficaz en términos de PIB (en el mejor de los casos) y dañino para el mantenimiento del empleo (trampa de la productividad).

- La recuperación de la política industrial podría ser una herramienta muy poderosa para lograr una transición hacia la sostenibilidad efectiva y socialmente justa.

- La incorporación de límites absolutos por el lado de la energía, podría contribuir a una teoría del crecimiento económico más completa, así como a mejorar el realismo de los Modelos de Evaluación Integrada.

- La teoría Kaleckiana del empleo quedaría matizada si incluyéramos restricciones energéticas, haciendo subidas de salarios o aumentos de la demanda agregada inefectivos para crear empleo incluso por debajo del pleno empleo.

- Para vencer estas fricciones, una reducción de la jornada laboral que dé respuesta a los grandes incrementos de productividad vividos en las últimas décadas podría contribuir a paliar los posibles efectos sociales adversos durante la transición.

- Políticas de gestión de la demanda que contribuyan a obtener niveles similares de bienestar y de servicios energéticos, con una menor demanda de energía final contribuirían a superar un posible declive en el PIB.

- Pasar de una retórica del decrecimiento a otra post-crecimiento (post-growth) daría una respuesta más efectiva a los retos socioecológicos del futuro: trasladando los objetivos de política económica del PIB a la equidad y la sostenibilidad y, al mismo tiempo, reconociendo la necesidad de ampliación de la base material de las economías de los países menos desarrollados. 


\section{Agradecimientos/Acknowledgments}

Esta tesis doctoral es fruto de la combinación de trabajo personal con trabajo colectivo. En esta interacción tan fructífera que ha supuesto un proceso de aprendizaje apasionante en el que el interés por la investigación no ha dejado de crecer, me gustaría expresar mis agradecimientos especiales:

A Óscar, por su confianza en mí y por haber sido más que un director de tesis: por su apoyo, sus consejos, su rigor, buena disposición y bondad; por sus respuestas y también por sus preguntas y, sobre todo, por haberme acompañado más que dirigido en esta aventura. A Luis Javier (Epi) también por su confianza en mí, su espíritu incansable, entusiasmo contagioso por la investigación, sus buenas ideas y su acompañamiento.

Mención especial al GEEDS, un magnífico grupo de compañeros/as, fuente inagotable de aprendizaje y ejemplo de vinculación con la sociedad. A Nacho e Íñigo en particular, por su generosidad y los desvelos compartidos. A Paula, Carlos, Marga, Fernando, Carmen, Santiago, Noelia, David, Gonzalo, Chema, Pablo y, sobre todo a Luis Fernando (Chapi), por su buena disposición, generosidad con su tiempo, sus consejos y apoyo, especialmente en la fase final de la tesis. Gracias también a la sección de Estructura del Departamento de Economía Aplicada por su gran acogida durante estos años.

No puedo olvidarme de Ramiro y Luis que, junto a Óscar, Chapi y Pablo han sido mis compañeros de café durante la tesis. Sin vosotros, esto habría sido mucho más aburrido, sin duda alguna.

I would also like to express my gratitude to my colleagues at University of Leeds, especially at the Sustainability Research Institute. Particularly to Paul and John for their confidence and for how much I have learned from them. This learning process is extensive to all the good friends that I made during my visit to Leeds and afterwards. Without this experience, this thesis (and my life) would not be the same.

Por último, y quizá más relevante. Mi máxima gratitud a todas las personas importantes en mi vida que me han acompañado en esta aventura. En particular a Paula, por su infinita paciencia y cariño, y por haber hecho de Leeds una experiencia inolvidable. Por estar ahí en todo momento. A mis padres: por todo. A mi hermano, a mi abuela, y a toda mi familia. 
This PhD thesis has been developed under the support of the European project H2020-LCE-2015-2 (691287) Guiding European Policy toward a lowcarbon economy. Modelling Energy System Development under Environmental and Socioeconomic constraints (MEDEAS) and the support of MODESLOW project: MODElling and Simulation of scenarios towards a LOW-carbon transition: the Spanish case (ECO2017-85110-R) funded by the "Spanish National Research, Development and Innovation Program" (Ministry of Economy and Innovation, Spain). 
"Sin embargo, la única forma de desterrar la escasez pasa, precisamente, por aumentar $\mathrm{y}$ no reducir- el universo de lo útil en general $-\mathrm{y}$ no el de las riquezas en particular- y por configurar las necesidades de forma que puedan colmarse con cargo a lo útil que es abundante y renovable, y aprovechar lo mejor posible las riquezas ya existentes, reduciendo al máximo la necesidad de obtener nuevas riquezas. O, dicho de otra manera, la abundancia sólo puede alcanzarse reduciendo, y no ampliando, la esfera de la producción -y del consumo- de riquezas y construyendo ésta sobre la energía y materias primas abundantes y renovables.”

Naredo, J.M. (1987)

“We are often asked, 'Were the Limits to Growth predictions correct?' Note that this is the media's language, not ours! We still see our research as an effort to identify different possible futures. We are not trying to predict the future. We are sketching alternative scenarios for humanity as we move toward 2100 . Nonetheless it is useful to reflect on the lessons of the past 30 years. [...] For those who respect numbers, we can report that the highly aggregated scenarios of World3 still appear, after 30 years, to be surprisingly accurate".

(Meadows, Randers and Meadows, 2002)

"Yet, while the need for transformation is now widely recognised, this is generally interpreted as being totally consistent with maintaining the same social, ecological and economic structure as today. That is a structure of social inequity [and] ecological exploitation.”

Spash, C. (2016) 


\section{Introduction}

\subsection{Justification and motivation}

\subsubsection{The energy transition and the limits to growth.}

Few issues are able to reach such a unanimous consensus as human-induced climate change does among the scientific community. The IPCC, the United Nations body for assessing the science related to climate change, warns in its special report (IPCC, 2018): "Human activities are estimated to have caused approximately $1.0^{\circ} \mathrm{C}$ of global warming above pre-industrial levels, [...]. Global warming is likely to reach $1.5^{\circ} \mathrm{C}$ between 2030 and 2052 if it continues to increase at the current rate". According to the same report, the consequences of increasing $1.5^{\circ} \mathrm{C}$ or $1.5^{\circ} \mathrm{C}-2^{\circ} \mathrm{C}$ are potentially disastrous: more extreme weather events, a rise in sea level or high biodiversity losses, which could lead to health costs, premature deaths, forced population displacement, higher risks and costs in food production, etc. However, increases in the global temperature beyond $2^{\circ} \mathrm{C}-3^{\circ} \mathrm{C}$ are very likely to be incompatible with human life at all. Although the more pessimistic IPCC scenario (RCP 8.5 ) predicts that it is more unlikely than likely to stay below $4^{\circ} \mathrm{C}$ (IPCC, 2014), climate scientists also know the necessary GHG reduction so as not to exceed $1.5^{\circ} \mathrm{C}-2^{\circ} \mathrm{C}$. In order to keep global temperatures within this -hazardous but humancompatible- range, net zero emissions should be reached from 2040 to 2055, describing the trajectory shown in Figure 1.

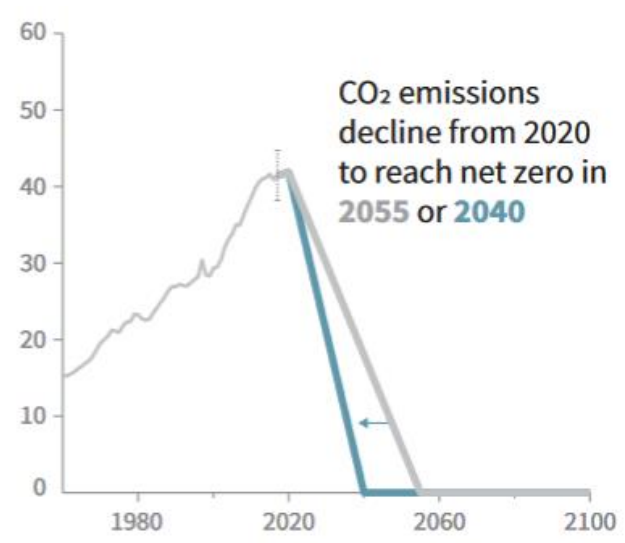

Figure 1. Stylized net global CO2 emissions. Billion tonnes CO per year (GtCO/yr). Source: IPCC (2018).

Given the enormous effort that such a steep shrinkage in GHG emissions would involve, the international community reached the Paris Agreement in 2015 in order to "hold the increase 
in the global average temperature to well below $2^{\circ} \mathrm{C}$ above pre-industrial levels". However, this was not the first attempt to undertake global action for the same purpose. Despite human-induced climate change responsibilities being unevenly distributed -it has been mainly caused by developed countries- its consequences are a global threat to the whole of humanity. Thus, tackling climate change requires the commitment of all countries across the world. This was addressed through global governance, promoted by the United Nations Framework Convention on Climate Change (UNFCCC), which was established in 1992. The Kyoto Protocol (1997) was signed 5 years after that in Japan. The protocol followed a multilateral approach whereby a binding GHG emissions reduction goal was set for all signing countries, recognizing different responsibilities by imposing harsher objectives on developed countries.

However, an ex post analysis of compliance to the Kyoto Protocol shows that only 36 countries fully participated and that 9 emitted higher levels than their commitment (Shishlov, Morel and Bellassen, 2016). As a result, the new rounds of the Conference of Parties (COPs), where all the UNFCCC countries meet periodically, looked for a new approach to climate governance. COP21 witnessed the signature of the Paris Agreement (2015) by 188 countries amounting to nearly $98 \%$ of the global emissions. This time, commitments were voluntary and individually set out by the parties. The only exception made by the obligation of Annex I parties, i.e., developed countries, was to present absolute reductions in GHG emissions. This different approach will have climatic, environmental and financial implications that are assessed in this thesis (Chapter 2).

Globally, around $76 \%$ of GHG emissions are, directly or indirectly, energy-related (Figure 2). The economic sectors breakdown typically used by the IPCC -and UNFCC overallcovers Electricity and heat production, Buildings, Transport, Industry, Other energy and Agriculture, Forestry and Other Land Use (AFOLU). Among these, only AFOLU is not energyrelated, since it has to do with pasture and livestock emissions, as well as the increase or reduction of forest cover-due to its carbon capture capacity. The remaining economic sectors are accounted for according to their current and historical necessity to burn fossil fuels to provide energy services. 


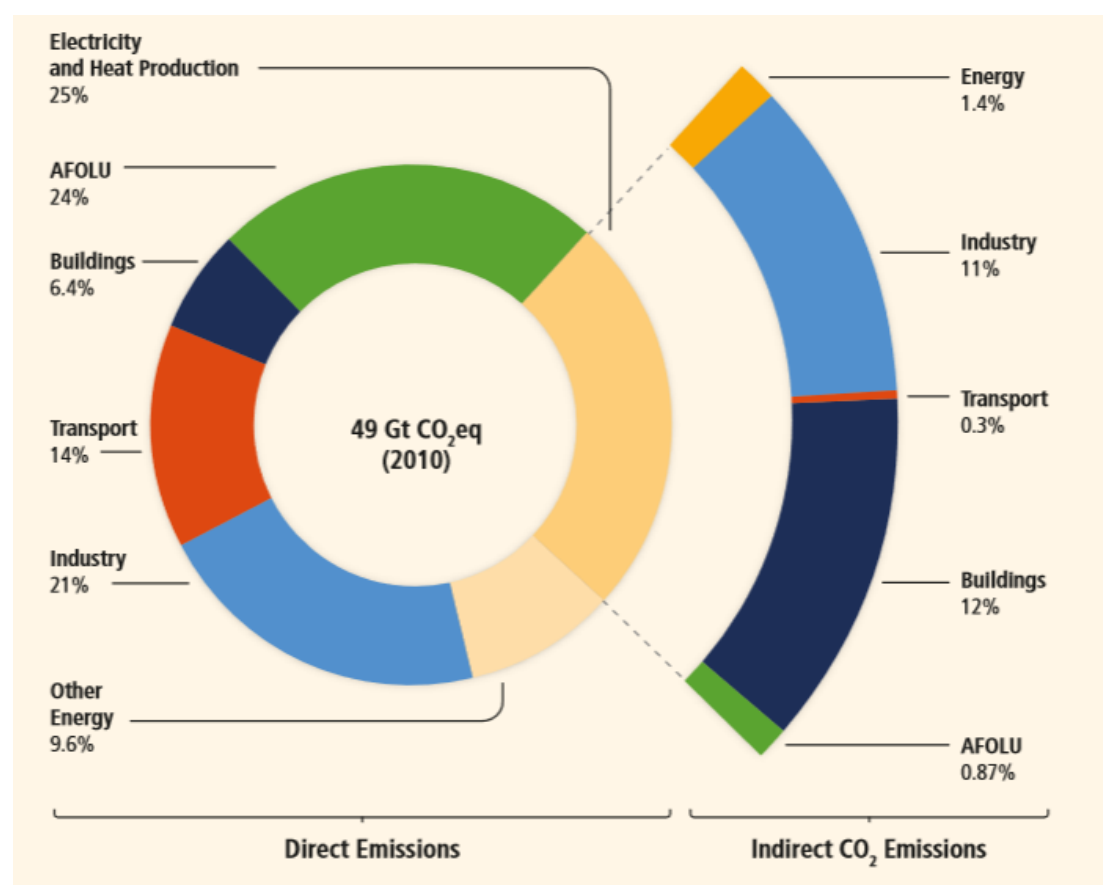

Figure 2 Greenhouse Gas Emissions by Economic Sectors. Source: IPCC (2014).

Therefore, energy systems emerge as a key dimension in sustainability transitions if significant GHG emissions reductions are to be achieved. Certainly, given the abovementioned, reaching net zero by 2040-2055 implies a rapid and huge transformation of the global energy systems. Moreover, there is a close relationship between energy and economics (Ayres and Warr, 2009; Charles A. S. Hall and Klitgaard, 2012), which has bolstered the appearance of a growing body of energy-economy-environment (EEE) models (Scrieciu, Rezai and Mechler, 2013; Dagoumas and Koltsaklis, 2019; Gómez-Plana, González-Eguino and Rodrigues, 2019), discussed below.

Therefore, given that energy is the fundamental variable to tackle climate change, we can state that the global environmental challenges have to do with two different dimensions: waste (mainly GHG emissions) and resources (energy). The idea of limits -the rise in global temperatures and sufficient supply of resources, respectively- are crucial for both the climate and energy dimensions. More precisely, non-renewable energy resources (NRER) are the main contributors to human-induced climate change; namely: oil, gas and coal. By definition, these resources are all exhaustible and the aim is for them to simultaneously disappear from the energy mix, if transition policies are taken seriously. Nevertheless, it is known that an energy transition towards sustainability will necessarily require NRER use, at least while deploying all renewable technologies. Therefore, tensions between NRER use (demand) and phase-out (supply) could emerge on the way to sustainability. 
As a consequence, the subjection of NRER extraction to geological limits is a crucial aspect of the energy transition. In 1956, the geophysicist M.K. Hubert predicted the zenith of the US oil domestic extraction between 1965 and 1970 (Hubbert, 1956). Although Hubbert's model has been generalized to other resources (Mason et al., 2011; Prior et al., 2012), it has also been updated to incorporate the idea of multi-cycle Hubbert curves as new resources are turned into recoverable reserves (Reynolds, 2014). Considering the more important NRER (around 33\% of total primary energy supply), three relevant issues have to be taken into consideration:

1. New oil field discoveries are increasingly smaller (Hook and Hirsch R. and Aleklett, 2009) and the small oil fields' depletion rate is higher than the bigger ones (Hook M. and Aleklett, 2008).

2. Conventional oil extraction peaked by 2005 (IEA, 2010) and non-conventional oil is replacing it in the energy mix. As the extraction of non-conventional resources (also applicable to natural gas) is more expensive than the conventional ones, both in monetary (Aguilera, 2014) and energy (Hall, Lambert and Balogh, 2014) terms, extraction costs are likely to rise.

3. Oil demand -as well as coal and natural gas- is rising in order to supply the development processes of emerging countries. Meanwhile, the developed countries' demand is not being reduced despite the claims to cut NRER use.

In Capellán-Pérez et al. (2017) a wide literature review of depletion (Hubbert) curves for conventional and non-conventional oil and gas, coal and uranium, can be found in section 2.3.3. There, different maximum extraction curves are depicted, according to several levels of certainty, commonly separated between levels of confidence. So, if we assume that the world economy is gradually phasing-out, but still demanding NRER as the energy transition is completed, the economic system might face turmoil. In fact, the energy-economy nexus has been widely studied, showing a close connection between access to high-quality energy resources and sustained economic growth (Stern, 2011; Charles A S Hall and Klitgaard, 2012; Foxon, 2017).

The idea of an economy constrained by the biophysical environment in not new. Apart from the theoretical aspects of scarcity posed by the classical political economy -discussed in section 1.3.1- the pioneering work The limits to growth (LTG) done by Meadows et al., (1972) dealt with this important issue. Based on World3, a system dynamics Integrated Assessment Model (IAM), in a report to the Club of Rome, they warned about the limits that the global economy will have to face in the future. These limits were multidimensional and involved five factors: population, agricultural production, non-renewable resource depletion, industrial output, and pollution generation. Despite the harsh critique that the study raised (Cole et al., 1973; Nordhaus, 1973), it was rapidly addressed by Forrester, Low and Mass (1974). Then, the debate 
quietens down for a couple of decades, emerging again after the publication of Beyond the limits, where Meadows, Meadows and Randers (1992) updated the limits to growth. The same year, Nordhaus critiqued the new results of the model (Nordhaus, 1992) and the debate froze again. It was in 2002 when the original authors of LTG published the 30-year update (Meadows, Randers and Meadows, 2002), afterwards supported by Turner, G. (2008) and Bardi, U. (2011). The results obtained in The limits of growth were tested in the light of the real facts, showing an impressive match between the real data and the projections in the reference scenario. As Turner, G. (2008) put it:

"Given the high profile of the LTG and the implications of their findings, it is surprising that such a comparison has not been made previously. This may be due to the effectiveness of the many false criticisms attempting to discredit the LTG. As shown, the observed historical data for 1970-2000 most closely match the simulated results of the LTG "standard run" scenario for almost all the outputs reported"

The vision of LTG dealt with the idea that perpetual growth in a finite planet is not possible. Today, this point of view regains importance as NRER become scarcer in a growing economy, at a time when the path to sustainability is beginning. Thus, renewed interest in the biophysical limits to the economy recently developed into the concept of planetary boundaries introduced by Rockström et al. (2009). Biophysical constraints to the economic system were not strange when the planetary boundaries concept was put forward in 2009. Multidimensionality is also present here, taking into consideration 9 different biophysical boundaries that should not be crossed: climate change, novel entities, stratospheric ozone depletion, atmospheric aerosol loading, ocean acidification, biogeochemical flows, freshwater use, land-system change and biosphere integrity. By 2015, four of these boundaries had already been trespassed: climate change, loss of biosphere integrity, land-system change and altered biogeochemical cycles (phosphorus and nitrogen) (Steffen and Rockström, 2015). According to the authors, two of these (climate change and loss of biodiversity) are "core boundaries", i.e., ones that would "drive the Earth System into a new state". This would suggest that the economy cannot simply run free, unrestrained, but on the contrary, that this kind of performance would lead to unprecedented consequences for the planet and, hence, the economy.

More recently, Raworth (2017) added a 'social foundation' to that 'ecological ceiling' of the planetary boundaries, leaving a ring on the inside where the 'safe and just space for humanity' would fall. Accordingly, the author specifies that, above the 'ecological ceiling' the economy would be in a state of 'overshoot', while below the 'social foundation' would be in a shortfall (see Figure 3). The social foundation implies widespread access to water, food, energy, health, 
education, political voice, housing and social networks, as well as more normative concepts such as gender equality, social equity, peace and justice and income and work.

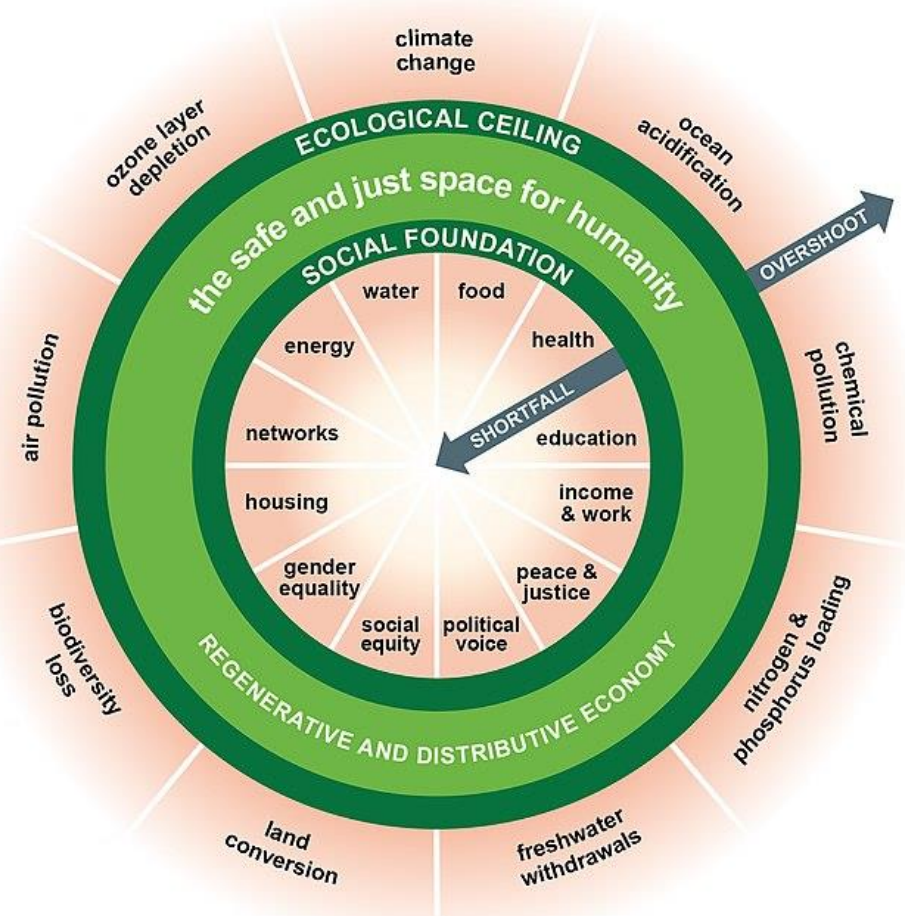

Figure 3. 'Ecological ceiling', 'social foundation' and the 'safe and just space for humanity'.

Source: Raworth (2017).

Following this approach, O’Neill et al., (2018) classified 150 countries according to their ecological ceilings and social foundation performance, given a number of selected indicators. The study showed the positive relationship between transgressing biophysical boundaries and achieving social thresholds. This supports a long tradition of works highlighting the close connection between economic development and environmental impacts (de Bruyn and van der Bergh, 1998; Stern, 2004; Wagner, 2008; Tapia-Granados J. A. and Carpintero, 2012; Krausmann et al., 2018). As a result, the socioeconomic consequences of the sustainability transition have become important, as there has historically been an explicit conflict between globally achieving social and environmental objectives. Thus, reconciling both planetary and social boundaries would be one of the main challenges of humanity.

\subsubsection{Sustainability transitions and Energy-Economy-Environment modelling}

Having recognized the key role of energy in tackling the climate crisis, as well as the importance of the biophysical boundaries on shaping the economy, the transition towards 
sustainability should not disregard these dimensions. Whereas it is straightforward to define transition as the process of changing from one situation, form, or state to another, sustainability has traditionally been a more elusive concept. For instance, the European Environment Agency identified almost 300 different interpretations of Sustainable Development (EEA, 1997). Therefore, 'Sustainability transitions' is necessarily a normative field, solution-oriented and multidisciplinary. Moreover, the unit of analysis considered as relevant is the determining factor in reviewing different sustainability transition approaches. This is a growing field of research (Markaard, Raven and Truffer, 2012) whose approaches are thoroughly reviewed in (Lachman, 2013) and can be summarised as follows:

1- The multi-level perspective (Geels, 2002, 2011): this approach focuses on the relationship between different agents and levels of interaction involving sustainability transitions. It defines three fundamental levels: i/ Landscape: the macro level, typically an exogenous framework conditioning the lower levels. It involves the culture, political institutions, international context, etc.; ii/ Regime: the socio-technical framework formed by the agents and social groups involved in the process, as well as the set of formal and informal rules that they follow, the current technological and technical status and the production and consumption conditions; iii/ Niche: the micro level, where innovation can spill-over up to the regime, therefore changing it, always limited by the landscape.

2- Strategic niches management (Kemp and Schot J. and Hoogma, 1998): new sustainable innovations require explicit action to break through the barriers towards being settled as part of the new regime, e.g., the lack of convenient infrastructure is a hurdle to the expansion of electric vehicles.

3- Transition management (Rotmans, 2011): this follows an evolutionary perspective and is focused on how institutions can shape transitions as they occur. Learning and good governance are considered as key variables in promoting a shift in the socio-technical regime.

4- Innovation systems (Jacobsson S. y Bergek, 2011): this approach analyses innovation systems to identify the promising elements and obstacles to technological development and thereby suggest specific policies.

5- Techno-economic paradigm (Freeman and C. Pérez, 1988): is a descriptive -as opposed to prescriptive- approach focused on the landscape (applying the multi-level perspective terminology) and based on the evolutionist and long-wave cycle (Kondrat'ev, 1984) economic theories. Macroeconomic cycles are activated by the emergence of disruptive novel technologies, allowing the other subsystems to co-evolve towards a new regime.

6- Socio-ecological approach (Fischer-Kowalski, 2011): a socio-ecological regime, as the fundamental unit of analysis of this approach, is "rooted in the energy system a society 
depends upon, that is the sources and dominant conversion technologies of energy". As a consequence, the basis of this perspective is the intertwining of the biophysical and socioeconomic systems in the context of complex systems. Therefore, sustainability transitions are a process whereby a socio-ecological regime which is crossing biophysical limits is moved within them.

Table 1 summarises the main characteristics of all these approaches to sustainability transitions. Although all the objects of study are present in this thesis, the socio-ecological approach provides a useful insight into energy and its interaction with the economy, i.e., the convenience of considering the nature of the problem of climate change.

Table 1. Sustainability transitions: summary of main approaches

\begin{tabular}{|c|c|c|c|}
\hline Sustainability & & & \\
\hline Transitions & Unit of analysis & Objective & Main Sources \\
\hline Approach & & & \\
\hline $\begin{array}{l}\text { Multi-level } \\
\text { Perspective }\end{array}$ & $\begin{array}{l}\text { Socio-Technical } \\
\text { regime. }\end{array}$ & $\begin{array}{l}\text { Interaction between } \\
\text { agents and levels aimed at } \\
\text { promoting the transition. }\end{array}$ & (Geels, 2002, 2011) \\
\hline $\begin{array}{l}\text { Niches } \\
\text { Management }\end{array}$ & Innovation niches. & $\begin{array}{l}\text { Identifying transition } \\
\text { hurdles to spill innovation } \\
\text { up to the regime level. }\end{array}$ & $\begin{array}{l}\text { (Kemp and Schot J. } \\
\text { and Hoogma, 1998) }\end{array}$ \\
\hline $\begin{array}{l}\text { Transitions } \\
\text { Management }\end{array}$ & Policy-making. & $\begin{array}{l}\text { Good governance aimed } \\
\text { at promoting the } \\
\text { transition. }\end{array}$ & (Rotmans, 2011) \\
\hline $\begin{array}{l}\text { Innovation } \\
\text { Systems }\end{array}$ & Innovation. & $\begin{array}{l}\text { Identifying promising } \\
\text { technological innovations } \\
\text { to promote them. }\end{array}$ & $\begin{array}{l}\text { (Jacobsson S. and } \\
\text { Bergek, 2011) }\end{array}$ \\
\hline $\begin{array}{l}\text { Techno- } \\
\text { economic } \\
\text { Paradigm }\end{array}$ & $\begin{array}{l}\text { Technological- } \\
\text { driven cycles } \\
\text { triggering } \\
\text { socioeconomic } \\
\text { system co-evolution. }\end{array}$ & $\begin{array}{l}\text { Not a normative } \\
\text { (prescriptive) approach. }\end{array}$ & $\begin{array}{l}\text { (Freeman and C. } \\
\text { Pérez, 1988) }\end{array}$ \\
\hline $\begin{array}{l}\text { Socio- } \\
\text { ecological } \\
\text { Approach }\end{array}$ & $\begin{array}{l}\text { Socio-ecological } \\
\text { regime. }\end{array}$ & $\begin{array}{l}\text { Transitioning towards a } \\
\text { socio-ecological regime } \\
\text { within the biophysical } \\
\text { limits. }\end{array}$ & $\begin{array}{l}\text { (Fischer-Kowalski, } \\
\text { 2011) }\end{array}$ \\
\hline
\end{tabular}

Own elaboration.

According to this approach, transitions are subject to uncertainty. Moreover, transitions are typically not gradual, but following different stages. Fischer-Kowalski (2011) describes, for instance, S-shaped processes that are highlighted (Rotmans, Kemp and van Asselt, 2001), but also lock-in situations or system collapse (Tainter, 1988) and tipping points in earth systems (Lenton 
et al., 2008). Therefore, gradual, smooth transitions are not common, uneven processes guided by disequilibrium and disturbances being more usual.

From this point of view, three different socio-ecological regimes can be identified historically: the hunter-gatherer, the agrarian and the industrial society (Haberl et al., 2011). The subsequent transitions from one regime to the following have invariably resulted in an intensification of human pressure on the environment. As shown in Table 2, the material and energy use per capita have always increased as a result of transitions. In particular, it is the use of non-renewable resources that has constantly increased, whereas the relative use of biomass is the only one which has been reduced. This reliance on the extraction of non-renewable resources could characterise the current economic system as an economy of acquisition (Carpintero, 2005; Naredo, 2010). Moreover, as shown by Krausmann et al. (2008), different socio-ecological regimes coexist simultaneously. While the developed countries have a socio-ecological profile consistent with the industrial society, most non-developed countries are closer to agrarian societies. According to Carpintero and Riechmann (2013), this implies at least three challenges for the transition to come: $i$ / it would be the first transition in human history towards a more sustainable regime; ii/ it would involve transitioning from a relatively vulnerable regime based on non-renewable resources and therefore subject to instability during the process; iii/ tensions might arise between regions with different socio-ecological regimes.

Table 2. Historical socioecological regimes.

\begin{tabular}{lcccc}
\hline & Unit & $\begin{array}{c}\text { Hunter- } \\
\text { gatherers }\end{array}$ & $\begin{array}{c}\text { Agrarian } \\
\text { society* }\end{array}$ & $\begin{array}{c}\text { Industrial } \\
\text { society** }\end{array}$ \\
\hline $\begin{array}{l}\text { Total energy use per } \\
\text { capita }\end{array}$ & $\mathrm{GJ} / \mathrm{cap} / \mathrm{yr}$ & $10-20$ & $40-70$ & $150-400$ \\
\hline $\begin{array}{l}\text { Use of materials per } \\
\text { capita }\end{array}$ & $\mathrm{t} / \mathrm{cap} / \mathrm{yr}$ & $0.5-1$ & $3-6$ & $15-25$ \\
\hline Population density & $\mathrm{Cap} / \mathrm{km} 2$ & $0.025-0.115$ & $<0.40$ & $<400$ \\
\hline Agricultural population & $\%$ & - & $>80 \%$ & $<10 \%$ \\
\hline $\begin{array}{l}\text { Total energy use per } \\
\text { unit area }\end{array}$ & $\mathrm{GJ} / \mathrm{ha} / \mathrm{yr}$ & $<0.01$ & $<30$ & $<600$ \\
\hline $\begin{array}{l}\text { Use of materials per } \\
\text { unit area }\end{array}$ & $\mathrm{t} / \mathrm{ha} / \mathrm{yr}$ & $<0.001$ & $<2$ & $<50$ \\
\hline $\begin{array}{l}\text { Biomass (share of } \\
\text { energy use) }\end{array}$ & $\%$ & $>99$ & $>95$ & $10-30$ \\
\hline
\end{tabular}

Source: Haberl et al. (2011).

* Typical values for an advanced European agrarian socio-metabolic regime (18th century). In agrarian societies based on labour-intensive horticultural production with low significance of livestock, population density may be significantly higher, while the per-capita use of materials and energy would be lower.

** Typical values for current fully industrialized economies. In countries with high population densities, per capita values of energy/materials use tend to be in the lower range, while values are high when measured per unit area. The reverse is true for countries with low population densities; in this case values per unit area can be very low. 
So, provided that the global economy could be ahead of the onset of a great and unprecedented transformation of the socio-ecological regime, the uncertainty associated to it is considerable. This justifies the necessity to analyse the possible transition pathways in order to shed some light on the potential outcomes that can be expected from the relevant decisions that humanity is facing. As a consequence, EEE models provide a relevant tool to analyse sustainability transitions to evaluate both their feasibility and implications. Moreover, Integrated Assessment Models (IAMs) are typically related to climate change analysis. A valid definition of an IAM could be any model with a multidisciplinary basis and different levels of regional and sectoral disaggregation, which is able to analyse the interactions between different dimensions of the reality and their environmental impacts. The development and improvement of IAMs is crucial to assessing climate change and how to mitigate it and adapt to its impacts. In fact, the prospects reported by the IPCC, mentioned in section 1.1.1., come from the systematic revision of a selected number of relevant IAMs. Table 3 shows a representative sample of IAMs, according to the classification attending to different features, made by Capellán-Pérez (2016):

i. Policy-evaluation (simulation) vs Optimization models (Toth, 2005; Scrieciu, Rezai and Mechler, 2013): these classify models according to what its driving force is. Whereas the latter are characterized by the optimization of one or more objective functions, the former does not and is focused on assessing the implications of one or more policies.

ii. Top-down vs Bottom-up models (Grubb, 1993; Hourcade et al., 2001): these describe the relevant level in models. Top-down models are able to analyse the system from a macroeconomic point of view, whereas Bottom-up models provide in-detail technological competition evaluation with a well-represented energy sector. Hybrid models combine both perspectives into an integrated approach.

iii. Highly-aggregated vs. higher-resolution -or disaggregated- models (Calvin et al., 2013): the former are closer to a monodisciplinary view, typically related to cost-benefit analysis and to climate change damage functions using future discount rates. Conversely, the latter provides a richer insight into reality, clearly representing different dimensions such as the energy sector, land, forestry, agriculture, etc.

iv. Level of integration among subsystems (Schneider, 1997): as the modelling techniques evolved, models became more complex and the different dimensions became increasingly interconnected, to better represent the real world. The lack of integration of the economic subsystem with the other model dimensions has remained a limitation of IAMs.

v. Deterministic vs. stochastic models (Capellán-Pérez, 2016): these models need to deal with the inherent uncertainties of both climate science and economics. Therefore, the parameters used can be grounded in the best guess according to the literature (deterministic), or they can 
include in-model probabilistic distributions (stochastic). In the case of deterministic models, an uncertainty and sensitivity analysis can be performed to check the model's validity.

vi. Standard vs. biophysical economics models: the biophysical economics approach (Odum, 1971) gives priority to material flows, and adjustments are more likely to be done by quantities instead of prices. Conversely, standard economics models consider material and energy flows as commodities, not as biophysical requirements to sustain the productive process.

vii. Equilibrium vs. disequilibrium models (Fiddaman, 2002; Scrieciu, Rezai and Mechler, 2013): IAMs have largely relied on partial or general equilibrium, especially the optimization ones. On the other hand, disequilibrium models are based on the view that markets do not necessarily clear.

viii. Non-complex vs complex systems models: Complex systems are made up of a number of interrelated components, whose relationships are typically based on non-linearity, emergence, feedback loops and they are also intrinsically dynamic and difficult to control (Ladyman, Lambert and Wiesner, 2013).

Table 3. Classification of Integrated Assessment Models

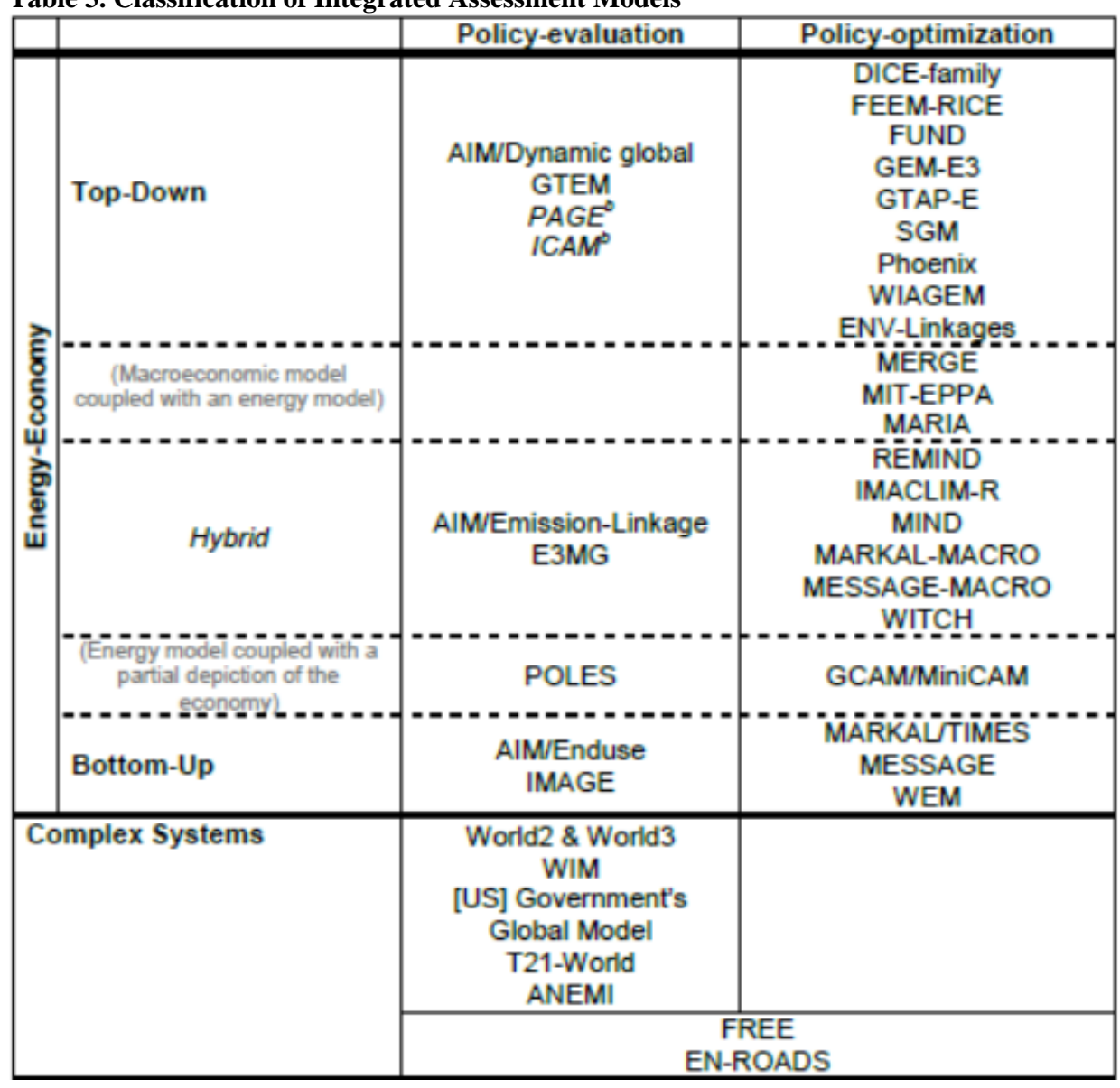

Own selection from Capellán-Pérez (2016). 
Beyond this useful classification, an emerging modelling field has stood out in recent years: ecological macroeconomics. According to Hardt and O'Neill (2017), as a novel perspective, as yet there is no agreement on a definition of what ecological macroeconomics is, but some common themes can be identified: i/ managing without growth (Peter A. Victor and Rosenbluth, 2007; Jackson, 2009); ii/ representing the dependence of the economy on the biosphere through new analytical methods and models (Fontana and Sawyer, 2016a); iii/ the combination of post-Keynesian (PKE) and ecological economics approaches (Rezai and Stagl, 2016; Taylor, Rezai and Foley, 2016). Several ecological macroeconomics literature reviews have been conducted (Pollitt et al., 2010; Scrieciu, Rezai and Mechler, 2013; Hardt and O'Neill, 2017), all of which found a lack of integration of the economy with the environment, especially concerning feedbacks. As Scrieciu, Rezai and Mechler (2013) put it:

"There is the need for a better analysis and study of these interrelationships, and particularly, the exploration of key feedbacks leading from drivers of demand for energy and land to mitigation and back to income and economic growth as drivers".

On the same line, Pollit et al. (2010) state that "one-way linkages are relatively straightforward, involving the outputs of one model being passed as the inputs to another, but obviously lack full feedbacks". And finally, Hard and O’Neill (2017) highlight the fact that ecological macroeconomics models have to deal with the challenge related "to the incorporation offeedback channels through which environmental changes caused by economic activities [...], can feed back to affect [the] economic performance", concluding that "such feedback channels are incorporated in very few models", citing an interview with Oliver Richters, which stresses "the need to develop economic models that can consistently model the interplay between supply constraints and demand-driven dynamics". Table 4 collects the models assessed in Hardt and O'Neill (2017), focusing on the feedbacks identified from the natural environment to the economy, which can come from waste (i), typically GHG, or resources (ii), as in Taylor, Rezai and Foley, (2016), Dafermos, Nikolaidi and Galanis (2017), Naqvi (2015), Cordier et al. (2017) and D’Alessandro, Luzzati and Morroni (2010). The more extended feedback comes from waste, typically GHG, to the economy, e.g., undermining labour/capital productivity (a), the profit share (b), propensity to invest/consume (c), or the labour force growth (d); also, an increase in capital depreciation (e), tax rates (f) or even investment in green capital (g). From the resources side, lower energy (h), materials (i), or other resources' (j) use/availability can reduce labour productivity (-P) or curtail production (-X). Moreover, feedbacks from society (employment) normally come from the unemployment rate via wages $(\mathrm{k})$, benefits $(\mathrm{l})$ or output reductions $(\mathrm{m})$. 
Table 4. Ecological Macroeconomics models and how they deal with feedbacks.

\begin{tabular}{|c|c|c|c|c|}
\hline $\begin{array}{l}\text { Model } \\
\text { IDs }\end{array}$ & Model Source & \multicolumn{3}{|c|}{$\begin{array}{l}\text { Type of Feedback \& } \\
\text { Model implementation }\end{array}$} \\
\hline & & Waste & Resources & Employment \\
\hline \multicolumn{5}{|c|}{ Post-Keynesian growth models } \\
\hline 1 & Fontana and Sawyer (2016) & & & \\
\hline 2 & Kemp-Benedict (2014a) & & & \\
\hline 3 & Rosenbaum (2015) & & & (k) \\
\hline 4 & Taylor, Rezai and Foley (2016) & $(\mathrm{a})(\mathrm{b})(\mathrm{e})$ & $(\mathrm{h}-\mathrm{P})$ & $(\mathrm{k})$ \\
\hline 5 & $\begin{array}{l}\text { Berg, Hartley and Richters } \\
\text { (2015) }\end{array}$ & & & \\
\hline 6 & $\begin{array}{l}\text { Campiglio, Godin and Kinsella } \\
\text { (2015) }\end{array}$ & & & \\
\hline 7 & Dafermos et al. (2017) & $(\mathrm{a})(\mathrm{c})(\mathrm{d})(\mathrm{e})(\mathrm{g})$ & $(\mathrm{h}-\mathrm{X}-\mathrm{P})(\mathrm{i}-\mathrm{X})$ & \\
\hline 8 & Godin (2012) & & & (1) \\
\hline 9 & Jackson and Victor (2015) & & & $(\mathrm{k})$ \\
\hline 10 & Jackson and Victor (2016) & & & \\
\hline 11 & Jackson et al. (2014) & & & \\
\hline 12 & Naqvi (2015) & $(\mathrm{e})(\mathrm{f})$ & & (l) \\
\hline 13 & Cambridge Econometrics (2014) & & & $(\mathrm{k})$ \\
\hline 14 & Sakai et al. (2018) & & (h-P) & (k) \\
\hline 15 & D’Alessandro et al. (2018) & & & (k) \\
\hline \multicolumn{5}{|c|}{ Other demand-driven growth models } \\
\hline 16 & Briens (2015) & & & (l) \\
\hline 17 & Cordier et al. (2015) & & (j) & \\
\hline 18 & Gran (unpublished) & & & (m) \\
\hline 19 & Victor and Rosenbluth (2007) & & & $(\mathrm{m})$ \\
\hline \multicolumn{5}{|c|}{ Supply-driven growth models } \\
\hline 20 & Bastin and Cassiers (2013) & & & \\
\hline 21 & $\begin{array}{l}\text { Bernardo and D'Alessandro } \\
\text { (2016) }\end{array}$ & & & $(\mathrm{k})(\mathrm{l})(\mathrm{m})$ \\
\hline 22 & $\begin{array}{l}\text { D'Alessandro, Luzzati and } \\
\text { Morroni (2010) }\end{array}$ & & $(\mathrm{h}-\mathrm{X})$ & \\
\hline \multicolumn{5}{|c|}{ Other models without growth } \\
\hline 23 & Kemp-Benedict (2014b) & & & \\
\hline 24 & Kronenberg (2010) & & & \\
\hline
\end{tabular}

Source: own re-elaboration from Hardt and O'Neill (2017)

As can be seen, feedbacks from society to the economy are more common than feedbacks from the environment. Only six of the studied ecological macroeconomics models include environment-economy feedbacks. Amongst these, despite the previously mentioned energyclimate relationship, only four include energy-economy feedbacks. A more general classification according to the methodological approach can be given by Figure 4 . The authors identify analytical models, mainly based on theoretical relationships that can be simulated to prove the system's features. Conversely, numerical models are based on a large number of equations and 
datasets in order to run computer-based simulations. They differentiate, among other things, between Monetary Input-Output, Physical Input-Output, System Dynamics and Stock-Flow Consistent models. Many models fall into the intersections between them, combining approaches; whereas others rely on a unique approach or even cannot be categorized as one of the mentioned approaches. These methodological approaches will be discussed in section 1.4.

\section{Analytical Models}
(1) Fontana \& Sawyer 2016
(3) Rosenbaum 2015
(22) D'Alessandro, Luzzati and Morroni. 2010
(2) Kemp-Benedict $2014 a$
(4) Taylor, Rezai and Foley 2016
(23) Kemp-Benedict $2014 \mathrm{~b}$

\section{Numerical Models}

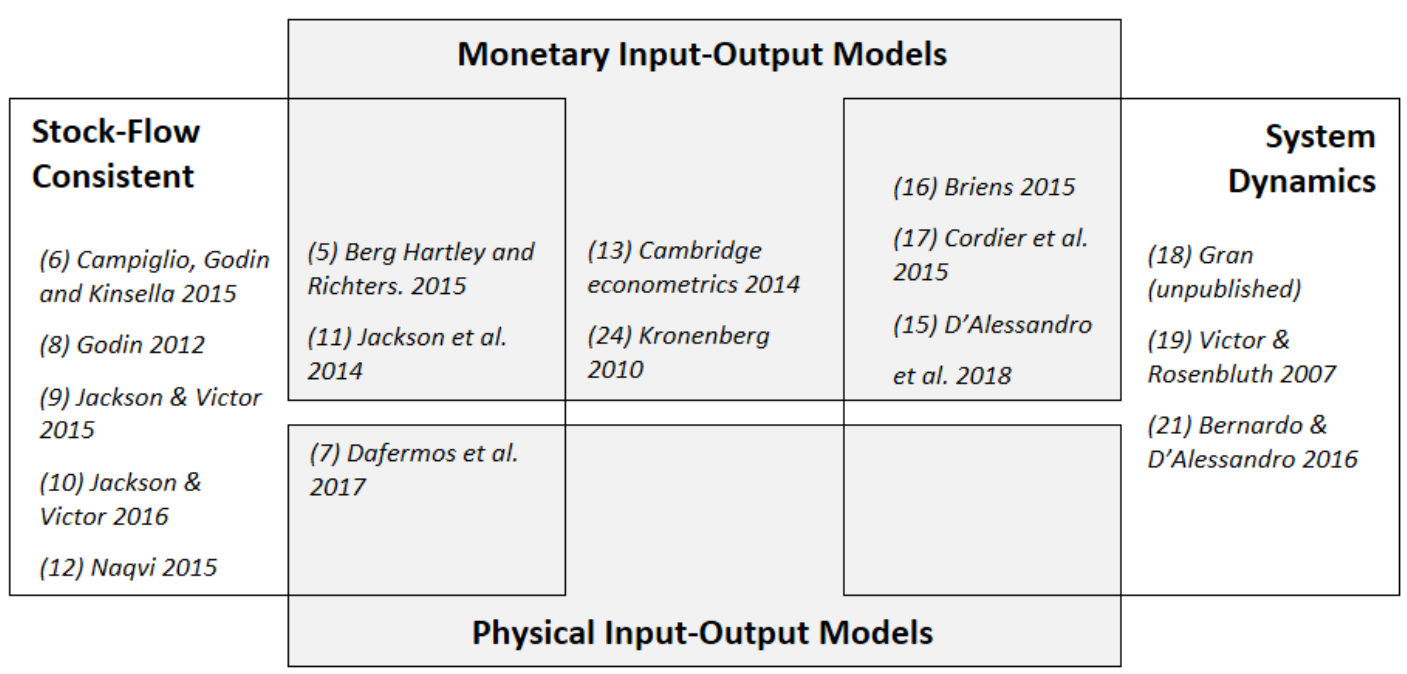

(14) Sakai et al. 2018

(20) Bastin and Cassiers 2013

Figure 4. Ecological Macroeconomics models. Source: Update and re-elaboration from Hardt and O'Neill (2018). 


\subsection{Objectives}

In the light of the abovementioned justification and motivation, as well as the revision of the state of the art, this doctoral thesis is aimed at disentangling the socioeconomic implications of a sustainability transition. Hence, the general research question that this thesis is committed to answering is the following:

- Is it feasible to successfully complete an energy transition towards sustainability in order to tackle climate change, while simultaneously achieving social goals?

In order to give a response to the main research question, three different objectives are set in the light of the abovementioned justification and motivation, as well as the revision of the state of the art:

\section{Objective 1: Systematic revision of worldwide sustainability transition plans}

The first objective aims to shed light on the real commitments of the nations' reporting to the UNFCCC. The Intended Nationally Determined Contributions submitted to the international body to meet the Paris Agreement are reviewed by answering these questions:

- What policies are the world nations committed to implementing in order to meet the $2^{\circ} \mathrm{C}$ environmental target?

- What are the potential socioeconomic implications of the analysed set of policies?

- How far do the national commitments go regarding NRER constraints?

- To what extent are emissions reduction targets compromised in the INDCs compatible with the main objective of the Paris Agreement?

- How do the transition plans deal with socioeconomic transformation, equality and the role of technology?

Objective 2: Integrated assessment of the environmental and socioeconomic effects of the energy transition within different scenarios under energy constraints and two geographical levels: World and Europe.

The second objective of this doctoral thesis is to evaluate the consequences of an energy transition towards sustainability. The research questions outlined below are addressed through the modelling of the energy-economy relationships, using the most adequate methodology for this purpose. In order to provide an original insight to the field, this model is rich in environmenteconomy feedbacks, so it can capture biophysical limits to growth. This would contribute to answering the following research questions: 
- How feasible is a rapid energy shift to renewable technologies compatible with high economic growth?

- What can be learned about the nature of economic growth and employment from an IAM perspective based on the Ecological Economics approach of the socioeconomic system's submission to biophysical boundaries?

- What socioeconomic transformations and policies would potentially favour meeting the Paris Agreement targets?

- What are the overall (macroeconomic, climatic, etc.) implications of a novel energy-economy nexus?

- What are the socioeconomic effects of a fast energy use reduction?

- What are the socioeconomic effects of different energy transition-related scenarios?

- Is it feasible to meet environmental targets on time without harming the social foundations of the socioeconomic system?

- What socioeconomic transformations and policies would potentially deliver environmental targets, along with sustainable social outcomes (i.e., staying within 'the safe and just space for humanity' in Raworth's terms)?

\section{Objective 3: Analyse the structural and sectorial impacts and contributions to}

\section{meeting environmental targets}

The third objective of this doctoral thesis is to test the implications of including a highly sectoral disaggregation in the models, as well as the sectoral impacts of the energy transition. This allows the following questions to be answered:

- To what extent are indirect (inter-industry) effects misrepresented in IAMs?

- How can a targeted industrial policy contribute to meeting environmental and socioeconomic goals?

- What are the environmental-economic implications of a more efficient economic structure during an energy transition?

- What sectors are more advisable to downscale and which ones need steering up? 


\subsection{Theoretical Framework}

\subsubsection{Ecological Economics.}

The origins of Ecological Economics can be traced back to the end of the $19^{\text {th }}$ and the early $20^{\text {th }}$ centuries. Scholars from different scientific fields are known as the pioneers of this theoretical approach, e.g., Sergei Podolinsky, Frederick Soddy or Patrick Geddes. They analysed the economic relationships with energy flows and looked at how the biophysical rules condition the productive process. The bridges built from nature to the economy led, during the $20^{\text {th }}$ century, to the consolidation of the field of Ecological Economics with such authors as Herman Daly, Robert Ayres, Kenneth Boulding or Nicholas Georgescu-Roegen.

Ecological Economics recognises the systemic interactions between the environment, society and the economy and the hierarchies between them. Accordingly, the biosphere would provide natural resources to produce goods and services, goods for direct consumption, capacity as a waste sink and basic life support. Whereas conventional economics considers the economy as the dominant system, leaving the biosphere as a mere supplier of commodities, Ecological Economics states that the economy is a closed sub-system of the environment -see Figure 5 (a)-. This distinction is far from being trivial. For instance, Martínez-Alier (1991) states that

...the economy must not be seen as a circular current or an exchange value spiral, that is, as a carousel or merry-go-round between producers and consumer that rounds and rounds, but as a one-way materials and energy entropic flow.

This vision directly confronts the circular flux of income depicted in conventional economics, where the environment is typically missing or is considered an externality. Conversely, Ecological Economics regards the economic process as linear, only capable of closing the circle via recycling. As shown in Figure 5 (b), the productive process requires a flow of inputs (domestic or imported, used and hidden, direct and indirect), such as fossil fuels, minerals or biomass. This produces a net addition to the material stock after the inputs are transformed into goods and services (throughput) and in the process producing an output, basically waste. That waste can be returned to the process by recycling it, but then another biophysical constraint arises: the second principle of thermodynamics or the law of entropy. 

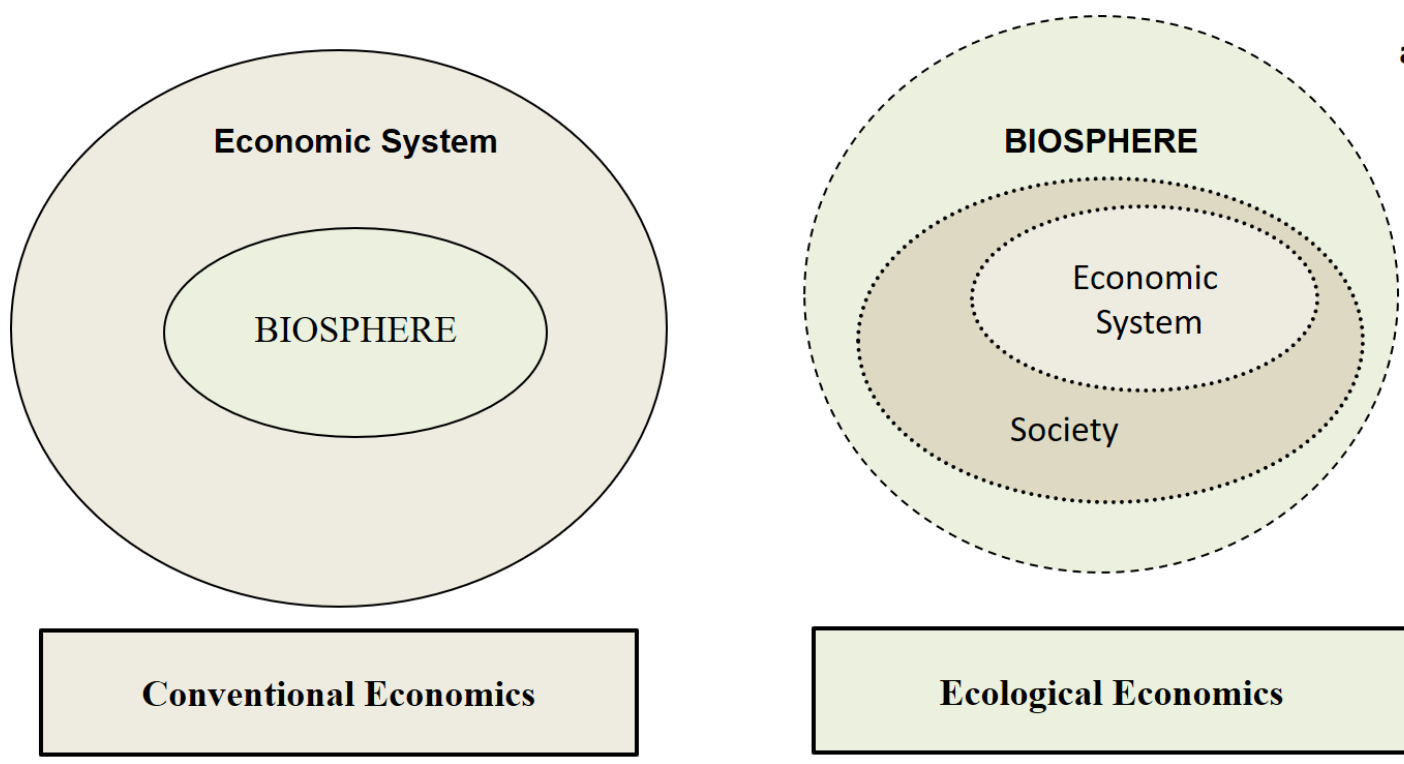

a)

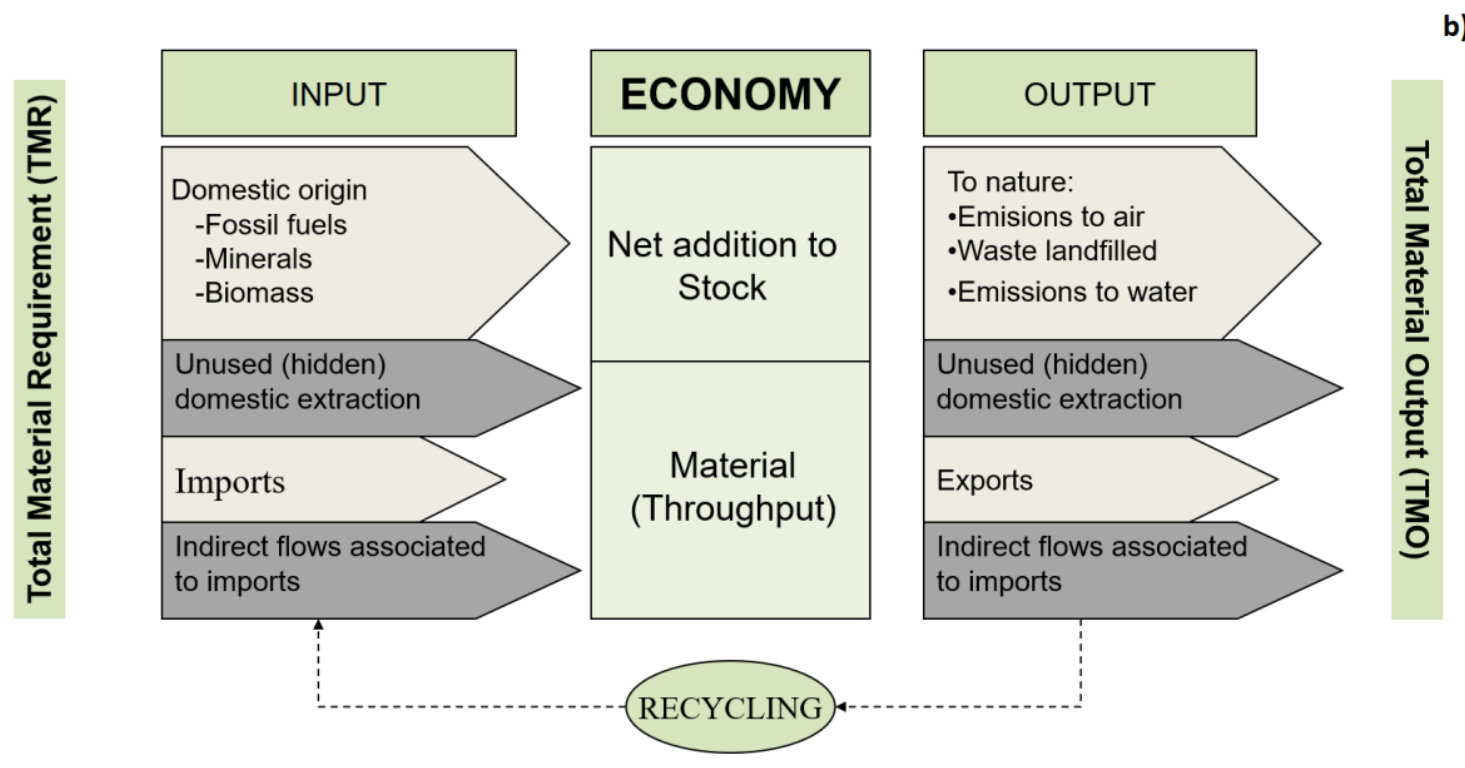

Figure 5. The Ecological Economics Framework.

Figure 5 (a). Systemic relationships according to the Conventional and Ecological Eeconomics framework. Source: Adapted from Carpintero (2019).

Figure 5 (b). The linear material flow of economic processes within the Ecological Economics approach. Source: Adapted from Eurostat (2001).

As Georgescu-Roegen studied in The law of entropy and the economic process (1971), the law of entropy implies that energy is always transformed from available to non-available or dissipated energy and never the other way round. If that were at all possible, says the Romanian author, we could burn the same coal piece as many times as desired. What this means is crucial for understanding the economic process: that full recycling is not possible and thus, that material use is subject to irreversibility. Moreover, the conventional assumption of perfect substitutability of productive factors (inputs of the typical production function) could be called into question. As 
a consequence, Ecological Economics looks at sustainability scarcity differently in comparison to Conventional Economics.

For Conventional Economics, sustainability consists in maintaining the total stock of (manufactured and natural) capital constant. In this sense, it would be a "weak" sustainability indicator, since the objective could be attained by compensating (in monetary terms) the capital depletion. Moreover, it is considered that the erosion of natural capital can be addressed by adding more manufactured capital -as it is the total which has to remain constant-. This is consistent with the perfect substitutability assumption mentioned above; also leading to the idea that total economic (monetary) output could be increased if labour and/or capital offset an eventual energy resources decline. On the contrary, Ecological Economics underpins "strong" sustainability indicators. Thus, as posed by Daly (1990), sustainability can be measured in three different stages -compatible with Figure 5(b)-:

- Extraction (input): the sustainable extraction would be different for NonRenewable and Renewable resources, the sustainable depletion rate -in order to find alternatives- being for the latter (e.g., oil) and the sustainable extraction rate for the former (e.g., biomass).

- Production (throughput): based on using the more sustainable technologies.

- Emission (output or waste): with a sustainable emissions rate, for instance, to avoid global warming.

As a consequence of these definitions, sustainability is a matter of scale for Ecological Economics, as suggested by the submission of the economic system to biophysical boundaries. This is also a sustainability view very similar to that followed by the socio-ecological approach in the sustainability transitions field.

All these propositions lead to the discussion of the notion of scarcity. Naredo (1987) explains that the way that economists have traditionally envisioned it has to do with different views of wealth. The Classical Political Economy established the boundaries of wealth on "consumable goods" that are "useful" and required "efforts to be produced". John Stuart Mill added that these useful objects must "possess exchangeable value". Even Marx focused on commodities, i.e., useful goods with an exchange value, to describe capitalism. Later, the neoclassicals contributed to this view with the famous definition of Economics, made by Robbins, as a science "which studies human behaviour as a relationship between ends and scarce means which have alternative uses". Thus, scarcity emerges as a relative concept based on a tautology: a good, or a resource, can only be scarce if it has an exchange value and it only has an exchange value -i.e., amounts to the wealth stock- if it is scarce. Conversely, Ecological Economics understands scarcity as an absolute, biophysically measured concept. Producing the economic 
throughput embodies an objective and quantifiable Total Material Requirement -see Figure 5(b)to be realized. Furthermore, the consumption of Non-Renewable Energy Resources (NRER) is not a reversible process -according to the law of entropy- and therefore, their scarcity would depend upon objective and measurable quantities instead of on any monetary exchange value.

Hence, in this thesis, an Ecological Economics approach is adopted, whereby the economic system is subject to social and biophysical constraints. From the biophysical side, the energy-economy nexus is explored, considering energy resources as a necessary biophysical requirement subject to irreversibility rather than a commodity easily substituted by other productive factors (labour and capital).

\subsubsection{Post-Keynesian Economics.}

After the publication of "The general theory of employment, interest and money", a body of economists claimed that the Keynes' theory was radical enough not to be a particular case within conventional economics, but an entirely different approach. However, other economists worked on reconciling The general theory with conventional economics, eventually leading to the Neoclassical Synthesis. Over the years, the former have been labelled as "Post-Keynesian" and the latter "New-Keynesian". Nevertheless, the Post-Keynesian framework and current developments are well aligned with Ecological Economics and Integrated Assessment Modelling. Although the Post-Keynesian economists came from several origins, all of them worked in the United-Kingdom, staying in Cambridge at some point. Joan Robinson, Hugh Townshend, Richard Kahn, Nicholas Kaldor (considered the pioneers), Piero Sraffa and Michal Kalecki are some of the most relevant Post-Keynesians (King, 2002; Pasinetti, 2007).

All the PKE theory builds on the idea that real, effective aggregate demand is the main driver of the economy, recognizing the possibility of supply-side constraints such as the availability of credit and labour force. Investment plays a key role in aggregate demand and is considered to be affected by 'animal spirits' i.e., expectations rather than the amount of savings, as conventional economics states. Income distribution, in turn, is of the utmost importance at determining the economy's expenditure, given that different propensities to spend are attributed to salary-earners and capital-owners. PKE rejects the neoclassical view of convergence towards equilibrium and full-employment. Instead, disequilibrium - even instability- and involuntary unemployment are at the core of the Post-Keynesian approach. Particularly, Kalecki's theory of employment -which is followed in this thesis- states that the level of employment is not determined by the match of labour demand and supply, under the coordination effects of labour prices, i.e., wages. Rather, wages are structurally and institutionally -e.g., by the sectoral distribution of the economy or by the collective negotiation- conditioned and the level of 
employment is determined by the aggregate demand of goods and services, i.e., in the real economy.

Among the main themes of PKE, a number of them are particularly compatible with Ecological Economics and useful for this thesis' objectives and approach: the principle of effective demand, production, disequilibrium, the role of institutions, path-dependency, historical time and irreversibility, fundamental uncertainty and income distribution (Lavoie, 2014). The review of the Ecological Macroeconomics models shown in Table 4, based on Hardt and O'Neill (2018), proves how suitable PKE is with the possibility of including waste, resources and social feedbacks. For instance, the reluctance of Ecological Economics to use prices as a measure of resources scarcity is well-known (Norgaard, 1990; Reynolds, 1999; Lawn, 2004; Jayasuriya, 2015; Henckens et al., 2016), and is better represented by absolute physical abundance. Consistently, PKE argues that the inertia and rigidities of productive processes, highly dependent on natural resources, lead to volume adjustments, this is due to quantity -and not prices- changes (Lavoie, 2014). Moreover, although arguable, Lavoie (2014) identifies the microeconomics of the Ecological Economics' pioneer Nicholas Georgescu-Roegen as a source of Post-Keynesian knowledge. Further, the same author points to Ecological Economics as one of the main current developments within PKE (Holt, Pressman and Spash, 2009; Kronenberg, 2010; Fontana and Sawyer, 2016b), although it is regarded as an extension (Cahen-Fourot and Lavoie, 2016). The challenge of this thesis would be to contribute to bridging Ecological Economics and PKE, not as a mere extension, but looking at a broader and real integration. 


\subsection{Methodological Framework}

The main novelty presented in this thesis, on top of the inclusion of energy-economy feedbacks, is its methodological approach. The combination of Input-Output Analysis (IOA) and System Dynamics (SD) is not very common in the IAM's literature. Moreover, the few models combining these methodologies, does not include any energy-economy feedback. The combination of IOA and SD allows their main strengths, highlighted below, to be taken advantage of. Therefore, both methodologies are combined in a single model which, according to the classification in section 1.1.2., is a simulation model with a hybrid approach (combining bottomup and top-down analysis), both well disaggregated and with a high level of integration between the different dimensions. It is deterministic (non-stochastic) and based on complex systems and biophysical and disequilibrium economics. MEDEAS is a geographically nested set of IAMs whereby the outcomes provided by the global level are determinant for the European level. But, above all, MEDEAS is built as a policy-evaluation (simulation) model, an approach identified by Scriecieu, Rezai and Mechler (2013) as a more realistic approach than optimisation ones, and also more aligned with heterodox economics approaches (see Figure 6).

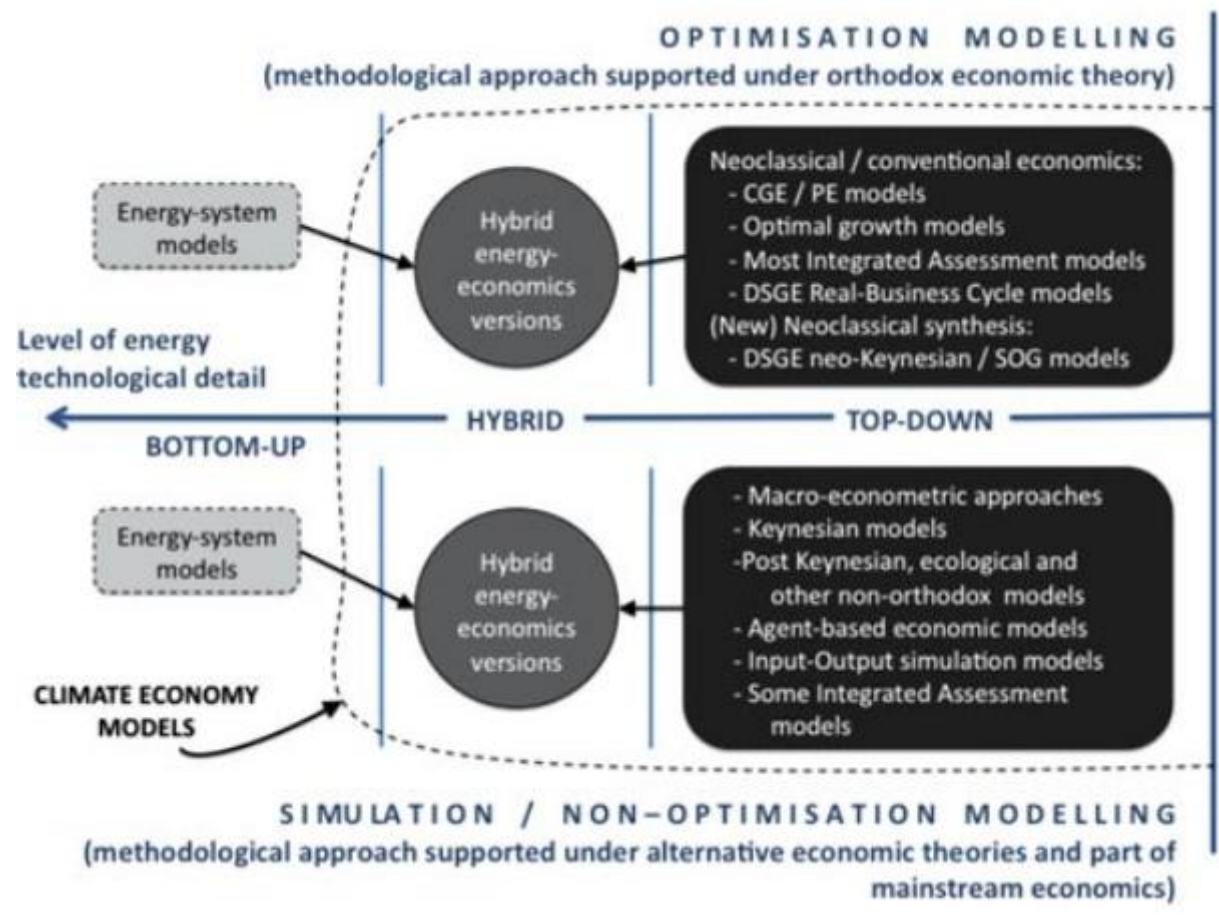

Figure 6. Optimisation and simulation IAMs and their interaction with economics.

Source: Scriecieu, Rezai and Mechler (2013).

The authors' literature review shows the main features of simulation models regarding important economics and epistemological options. First, optimisation models tend to be more theory-based with little empiric validation, while simulation ones are mostly grounded in an empirical approach (like SD) and include multiple validation tools. First, in these models, markets 
do not necessarily clear and the economic systems are under continuous perturbations, entailing greater uncertainty management. On the contrary, optimisation models rely on well-behaved markets with a quantification of uncertainty. They also allow for suboptimal utilization of resources, e.g., underemployment, unemployment, socially determined distribution (institutions matter). Technological change can be policy-induced rather than being driven by markets and prices. They are normally more prepared to support demand-driven economic growth, whereas in optimisation models, it is overwhelmingly the supply-side. In fact, the green transition is often seen as a cost in optimisation models; while, in demand-driven simulation models, it can be regarded as a stimulus to economic growth. Therefore, these models are more inclined to support 'Green Growth' narratives, something that is discussed in this thesis.

In order to fulfil this thesis' objectives, as well as to find an answer to all the research questions, the following methodology was developed:

\section{1- Review and evaluation of transition policies.}

COP21 was the Conference of Parties (UNFCCC) where the Paris Agreement was signed in 2015 . 186 countries, amounting to nearly $98 \%$ of global emissions, signed a commitment to avoid an increase of global temperatures well below $2^{\circ} \mathrm{C}$. With this purpose, all of them were required to send their own Intended Nationally Determined Contributions to clearly set what their policies would be and how they would finance them. A quantitative and systematic review has been done in order to understand what kind of transition policies are to be expected globally, as well as the investment required to deliver them. In addition, a qualitative analysis of the potential limits and inconsistencies between policies, objectives and regional disequilibrium is done. The objective -in relation to the thesis methodology- is twofold: i/ to obtain information about the policy targets and underlying narratives in order to define scenarios to input the model; ii/ to discuss the results obtained in the modelling in the light of the qualitative assessment of limits and inconsistencies. Further, beyond this thesis, the chapter would contribute to the literature by evaluating the capability of the INDCs to reach the Paris Agreement objectives, as well as quantifying the financial flows it would take to implement all the policy targets.

\section{2- Construction of an Ecological Macroeconomics model integrating system dynamics and Input-Output Analysis.}

In order to meet objectives 2 and 3 (see section 1.2), an Ecological Macroeconomics model has been built based on Input-Output Analysis (IOA) and System Dynamics (SD) and integrated into the IAM named MEDEAS (Capellán-Pérez et al., 2017). As shown in Figure 4 and Table 4 (section 1.1.2), to the best of our knowledge, there are no Ecological Macroeconomics models based on IOA and SD, with a Post-Keynesian background, which incorporate both 
environmental and societal feedbacks. Briens (2015) and Cordier et al. (2015) are both SD-IOA models, but classified by Hardt et al. as "other demand-driven growth models", the former entailing only societal feedbacks and the latter only resources feedbacks. Moreover, the resources feedback in Cordier et al. (2015) is unrelated to energy. On the other hand, D'Alessandro et al. (2018) is a model in which the energy transition is important, in the sense that it encompasses new investments, but the energy use does not produce feedbacks to the economy.

System Dynamics is a methodology that enables a wide understanding of complex systems behaviour. It is based on nonlinear relationships, a structure of stocks and flows, endogenous feedback loops and time delays. It was created by the MIT professor Forrester in the 1950s and was aimed at using computerised systems models to inform social policy. Later, he published World Dynamics (1971), where the World 3 model was described, eventually leading to the publication of The limits to growth (TLG). Despite the initial critiques to SD as an adequate modelling tool of economic systems -mainly targeted at the implications of TLG- it has gained endorsement over recent years. Radzicki (2009) and Radzicki and Tauheed (2009) argued that $\mathrm{SD}$ is a valuable methodology for economics modelling due to its aforementioned features. Although it has been used more frequently by heterodox economists (Victor and Rosenbluth, 2007; Briens, 2015; Bernardo and D'Alessandro, 2016; Cordier et al., 2017; D'Alessandro et al., 2018), it has also been used from a conventional economics point of view (Sterman et al., 2012; Režný and Bureš, 2018). Moreover, it is a very suitable framework for ecological economics, since nonlinearity is a characteristic of natural and complex systems, which in turn are rich in flows and stocks. In addition, it has the ability to capture irreversibility and tipping points through the saturation or depletion of these stocks. Also, the PKE assumption of path-dependency is covered through the same features and, particularly, by time delays. Moreover, as equilibrium is not a requirement of SD, disequilibrium economics can be easily modelled.

Input-Output Analysis is an analytical framework created by Wassiliy Leontief in the 1930s (1936, 1976). IOA works on the basis that every industry (sector) requires a fixed proportion of intermediate inputs to produce its output. These proportions can be quantified as a technical coefficients matrix (or A matrix) that would represent the underlying technology and structure of an economy. IOA is demand-driven, since it is a final demand-shock that triggers the productive process to satisfy this demand - which is largely compatible with PKE-. So, according to the economic structure defined by the A matrix, both the direct and indirect effects on production can be analysed. By disaggregating the economy and capturing the indirect effects, IOA is able to provide a more complete insight into the real carriers of economic growth. This framework is the so-called Leontief production function, which relies on complementarity, as opposed to the conventional aggregate production function that entails assuming perfect substitutability. The idea of complementarity fits well with the Ecological Economics approach, 
since it provides a more realistic insight into the role of technology and resources in the economy. Unfortunately, even though IOA was originally focused on material carriers, material flows accounting for databases are still not well developed -certainly not at a global level. Nevertheless, hybrid IOA enables an extension of the analysis by applying resources coefficients to the direct and indirect effects on the productive process (Leontief, 1970; Miller and Blair, 2009). Thus, the material inputs required to produce the economic throughput can be evaluated, providing meaningful insights into the economy's metabolism (Heun, Carbajales-Dale and Haney, 2015), especially if net energy is included in the modelling (Dale, Krumdieck and Bodger, 2012). This is of extreme importance for the current developments of Ecological Economics and for this thesis' objectives. By maintaining the principle of complementarity of IOA and estimating the direct and indirect energy carriers of the economic process, the model is able to assess the role of energy availability on economic growth.

\section{Note on sources, data and software}

Due to the nature of this thesis, access to sources of information, data and specialised software has been of the utmost importance. In the case of the evaluation of the national commitments to the Paris Agreement (INDCs), the UNFCCC clearly provides the documents submitted by the parties in the following link:

\section{https://www4.unfccc.int/sites/submissions/indc/Submission\%20Pages/submissions.aspx}

For the construction of the models, the WIOD database has been used. Despite the limitation of the time series available (1995-2011), it should be noted that: $\mathrm{i} / \mathrm{it}$ is a relatively long time series considering the lack of reliable, global, input-output databases; ii/ it is very suited for environment-economy analysis, since it provides energy satellite accounts; iii/ the database is publicly available for non-commercial use. Furthermore, for System Dynamics modelling, the software Venism version DLL version 7.3 has been used due to its acknowledgement as a powerful tool and its ease of access provided by the University of Valladolid. 


\subsection{Structure}

This thesis is formed by the Introduction, three chapters and the Conclusions. Every chapter is intended to fulfil different objectives (see section 1.2). Moreover, each chapter plays a fundamental role in the attainment of the overall objective of the thesis. Each chapter is necessary to develop the following chapters and addresses different objectives (see Figure 7). Chapter 1 addresses Objective 1 and provides the qualitative basis for the scenarios defined in Chapters 2 and 3. In turn, as MEDEAS is a geographically nested set of models, the outcomes produced by the World model (described in Chapter 2) are required inputs to the European model (described in Chapter 3). So Chapters 2 and 3 are aimed at addressing Objective 2 but, in addition, Chapter 3 is also able to provide a response to Objective 3.

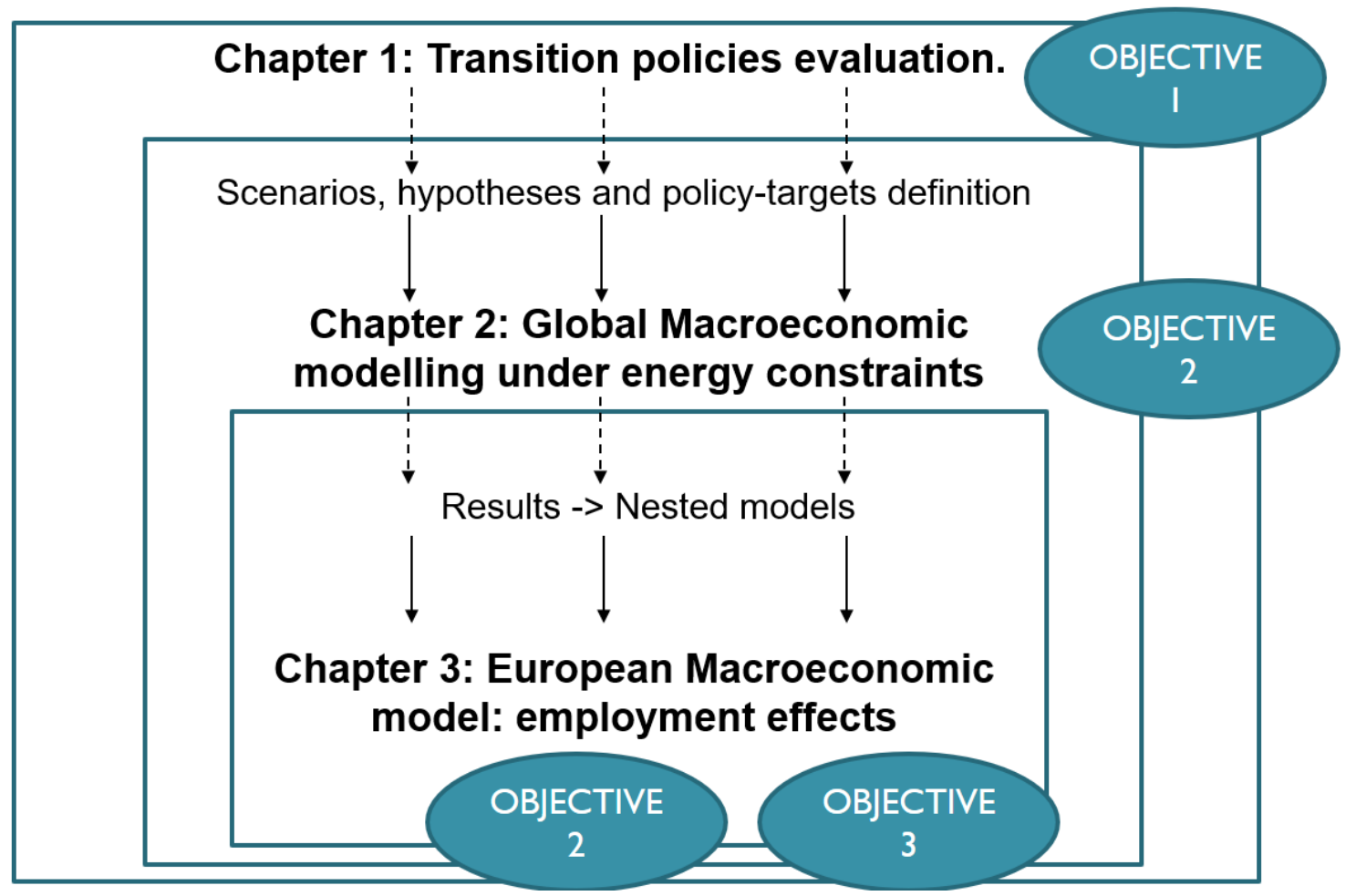

Figure 7. Thesis Framework

Therefore, the chapters' outline is the following:

Chapter 1: Less than $2^{\circ} \mathrm{C}$ ? An Economic-Environmental analysis of the Paris Agreement. In this chapter, 161 INDCs, representing 188 countries amounting to $98 \%$ of total global emissions, are evaluated. The different types of policies are classified by the sectors they are targeted to and quantified, and also attending to regional considerations. In addition, the financial requirements of the commitments are tracked and quantified, paying attention to the origin of the financial flows. Finally, their voluntary commitment to reducing GHG emissions is assessed. 


\section{Chapter 2: Macroeconomic modelling under energy constraints: Global low carbon}

transition scenarios. In this chapter, the construction of the global MEDEAS Economy module is described. The contribution of this new methodological approach is highlighted, especially regarding the strengths of combining IOA and SD for IAM. In this light, the sensitivity of the model to the inclusion of energy availability-economy feedbacks is evaluated. Furthermore, the importance of accounting for indirect energy and production carriers -not only direct- is measured. Finally, different sets of policy targets are combined in three scenarios to test different possible ecological and macroeconomic effects of the energy transition or their lack.

Chapter 3: A System Dynamics-Ecological Macroeconomics model: the energy transition in the EU. In this chapter, the construction of the European MEDEAS Economy module and Employment sub-module are described. The model is thereby used to apply the Energy Roadmap 2050 scenarios: a set of primary energy use (domestic and imported) reduction targets by different resources. Accordingly, the environmental and socioeconomic outcomes obtained in the defined scenarios are compared to those obtained by other European Commissionsupported modelling analyses. The contribution from Ecological Macroeconomics to the policyevaluation of energy transitions and to Post-Keynesian Economics is discussed in this chapter.

Finally, the conclusions section summarises the main findings of the research, providing responses to the research questions outlined in the objectives section (1.2). In addition, the theory and policy implication of this thesis are discussed, its limitations are noted and future research developments are presented. 


\section{Less than $2^{\circ} \mathrm{C}$ ? An economic-environmental evaluation of the Paris Agreement ${ }^{1}$}

\subsection{Introduction}

The consequences of climate change induced by human activity are a growing concern for the international community (IPCC, 2014; Melillo, Richmond and Yohe, 2014). Evident effects such as extreme meteorological phenomena, rising temperatures and rising sea levels show the rapid climatic adaptation of natural ecosystems. The rapid increase in these impacts and the fact that abrupt changes could arise leads to the conclusion that the cost of transferring the responsibility for putting it right to the coming generations becomes ever higher. In this sense, the IPCC (2014) has warned that if, by 2050, we have not managed to reduce the level of emissions with respect to 2010 by between $25 \%$ and $72 \%$, then maintaining the rise in world temperatures to below $2^{\circ} \mathrm{C}$ with respect to preindustrial levels will be "more improbable than probable". Besides the most visible consequences today, if the temperatures rose by more than $3^{\circ} \mathrm{C}-4^{\circ} \mathrm{C}$, humanity would face a scenario of massive extinction of species, entailing risks for human health and severe restrictions on access to food and water, so vital for survival (IPCC, 2014). Achieving this goal involves phasing out fossil fuels whereby around $82 \%$ of the current reserves of coal, $49 \%$ of natural gas reserves and $33 \%$ of the oil reserves should remain underground in order to avoid an increase in temperatures of more than $2^{\circ} \mathrm{C}$ (McGlade and Ekins, 2015).

Regarding these concerns, in December 2015, the $21^{\text {st }}$ Conference of Parties (COP21) was celebrated, made up of 188 countries, and whose most important result was the Paris Agreement (UNFCCC, 2016) and the collection of Intended Nationally Determined Contributions (INDCs) submitted by each of the participating countries. After de burial of the Kyoto Protocol, the current agreement is an unilateral vision in which the players establish their own voluntary objectives (Spash, 2016) through the INDCs. Although the agreement indicates that the main priority is to "hold the increase in the global average temperature to well below $2^{\circ} \mathrm{C}$ above preindustrial levels", during the COP21, the participants were sufficiently optimistic as to speak openly of $1.5^{\circ} \mathrm{C}$. Not only this, but in spite of the fact that they incorporated such equality criteria as the obligation of Developed Countries (DC) to a greater reduction in emissions and the

${ }^{1}$ This chapter has been published as: Nieto, J., Carpintero, Ó. and Miguel, L. J. (2018) 'Less than $2{ }^{\circ} \mathrm{C}$ ? An Economic-Environmental Evaluation of the Paris Agreement', Ecological Economics. doi: 10.1016/j.ecolecon.2017.10.007. 
channelling of financial resources to Least Developed Countries (LDC), the COP21 succeeded in involving some countries with medium incomes in these differentiated efforts (Viola, 2016).

In response to global concerns of these issues, a widening literature on sustainability transitions has emerged in recent years (Markaard, Raven and Truffer, 2012). Literature on climate summits mostly evaluates whether they comply with emissions limits or not (UNEP, 2010; den Elzen, Hof and Roelfsema, 2011; Höhne et al., 2012). Considering COP21 and the Paris Agreement (2015), main contributions are related to its impacts in energy technologies evolution (Peters, 2017; Lacal Arantegui and Jäger-Waldau, 2018) or evaluate possible transition pathways under its contexts in different regions (Gao, 2016; de Graaf, 2017; Liobikienè and Butkus, 2017). Some other works, conversely, points out difficulties to accomplish the COP21 objectives according to geopolitical and governance limits from a general perspective of the Paris Agreement (Spash, 2015; Viola, 2016). Moreover, an increasing number of governments, municipalities and NGOs are creating its own low carbon transitions plans according to their own criteria, or those established in the aforementioned climate summits. Thus, on the basis of Wiseman, Edwards and Luckins (2013), Nieto and Carpintero (2016) deal with a more in-depth analysis of 19 low-carbon transition plans from government sources and other dependent agencies, NGOs and research centres.

In this article, Paris Agreement is evaluated on the light of biophysical, technological and economic limits, throughout a systematic analysis of each of the 161 INDCs submitted by the 188 countries in COP21. Thus, the aim of this article is to put these INDCs under the same microscope that analysed some previous plans (Nieto and Carpintero, 2016), situating the focus on the socioeconomic impacts, international equality, technology, energy and emissions. This analysis will allow us to evaluate the feasibility of the Paris Agreement policies in complying with its own objectives through the national commitments (INDCs). In the same way, we will evaluate the main limitations of the imposed governance and finance framework. In order to achieve these aims, a systematic analysis of the policies, the emission reduction commitments and the funding needs for implanting INDCs has been carried out.

The article is structured as follows: Section 2.2 describes the methodological process used to give homogeneity to the data offered by the INDCs. Section 2.3 sets out the main results of the exhaustive analysis of these INDCs. Section 2.4 confronts the results extracted from INDCs with the biophysical restrictions and the literature. Finally, Section 2.5 summarizes the article's main conclusions. 


\subsection{Methodology}

The flexibility of the Paris Agreement has led to a lack of systematic presentation of the INDCs. Therefore, this paper proposes a methodology to homogenize data and categorize the information (for more detailed information, consult Appendix 1, as well as the repository of INDCs $)^{2}$. We have examined a total of 161 INDCs representing 188 countries that account for $97.8 \%$ of the world's emissions.

In order to achieve the aims of this article, we have paid special attention to the policies of mitigation as opposed to those of adaptation because of their economic (Buchner et al., 2015) and environmental importance. We have noted (as far as possible) the data concerning the objectives for reducing sectoral and global emissions, the policies for achieving the said objectives and their funding, with the greatest possible breakdown. We have also studied the proposed financial mechanisms and the nature of the agents who would lead the transition. We have grouped the different countries with respect to their level of income in accordance with the World Bank's (WB) classification, establishing a distinct group for the 12 most contaminating countries on the planet (Top 12) in 2014 (72.2\% of the total emissions) because of their relevance for climate policies.

With reference to emissions, the INDCs have both unconditional and conditional objectives. The former would be carried out exclusively with domestic resources, while the latter would be conditional on receiving outside assistance. In general, the INDCs presented some problems that made the analysis more difficult; such as the discrepancies between the year of reference and that of the time horizon. To resolve this issue, we have discarded those INDCs that do not have the year 2030 as their time horizon or the reference year outside the range 2005-2015. This reference year has been chosen because of two reasons. Firstly, EU used 2005 as one of the reference years (along with 1990 and 2030) in its Communication titled A roadmap for moving to a competitive low carbon economy in 2050. Secondly, most of the INDCs are within this time range, so it was reasonable to use it. Besides, a differential analysis has been carried out of the 12 most contaminating countries (Top12), for which we were able to establish a common reference year of 2005. On the other hand, the reduction objectives are presented in different ways:

i/ As a partial and/or sectoral objective: for instance, a proportion of renewable sources in the energy mix or objectives that are merely relative to one sector of the economy. These have not been considered in the calculation of emissions reductions.

ii/ In GHG emissions intensity (CO2eq/GDP). To calculate the net variation in emissions, we proceed as set out in Appendix 1.

${ }^{2}$ http://www4.unfccc.int/submissions/INDC/Submission\%20Pages/submissions.aspx 
iii/ As emissions reductions with respect to a base year. The only countries obliged to do so are those in Annex $\mathrm{I}^{3}$ and, with some exceptions, the only ones who do so in this way. No additional calculation is needed beyond establishing the base range and/or horizon year.

iv/ As emissions reductions with respect to a trend scenario (business as usual). This is the most common scenario used by all the countries not in Annex I, except Brazil ${ }^{4}$. To calculate the variation in absolute terms with respect to the base range, we proceed as detailed in Appendix 1.

Taking a conservative stance, we have considered that the trend and the real variation in emissions is the same for the Annex I countries, assuming that they will carry out all the promised policies and that they will, indeed, reach the appointed goals. In addition, we have calculated the weighted emissions with respect to each country's contribution to global emissions in 2013, the last year for which reliable, homogeneous data exist through the Emission Database for Global Atmospheric Research (EDGAR) of the European Commission.

On the other hand, the necessary funding for each plan has been broken down into mitigation, adaptation and other expenses. The INDCs provide figures in dollars (without specifying any basis) to be expended from 2020 to 2030. Financial effort is measured as the share of financial funding allocated by the INDC over GDP (2010 constant dollars at market prices). External funding and its proportion over total funding have been evaluated as well. Similarly, we have obtained the amount of funding required per unit percent of emissions reduction. This information has been obtained directly from the data facilitated by the INDCs. When not provided, it has been made the assumption that the share of external funding equals the proportion of conditional emissions reduction over total emissions reduction.

Finally, it has been summarized the main policies with respect to the different sectors of each country, as well as a summary table of the main policies to which each country is committed. The policies are broken down according to the Directives of the IPCC for the national inventories of greenhouse gases (1996). However, the breakdown of the energy sector has been used due to its strategic nature for some INDCs.

\subsection{Towards a new landscape: the INDCs in detail}

An exhaustive analysis of all the INDCs has been carried out with respect to four criteria: i/ the quality of the information provided; ii/ the proposed policies; iii/ the funding needed to carry

\footnotetext{
${ }^{3}$ Industrialized countries members of the OECD (Organisation for Economic Co-operation and Development) in 1992, plus countries with economies in transition (the EIT Parties), including the Russian Federation, the Baltic States, and several Central and Eastern European States.

${ }^{4}$ Unless explicitly mentioned alternatively, when a particular country is mentioned, the reference is its INDC, which can be consulted in the UNFCC repository, as explained in footnote 1.
} 
them out and, finally; iv/ the estimated reduction in emissions. The results are collected in the following sub-sections and a summary of the main results is shown in Table 12

\subsubsection{Quality of information}

The greatest difficulties involved in carrying out this research concerned the lack of homogeneity in the data. The INDCs come from different sources, the quantity and quality of the information is highly variable and even contains errors. The INDCs have been divided with respect to the quality of the general and funding information offered, according to the criteria of Table 5

Table 5. Information criteria

\begin{tabular}{|c|c|c|}
\hline & General information & Financial information \\
\hline Low Quality & $\begin{array}{l}\text { Low or none emissions } \\
\text { information and/or low or none } \\
\text { policies information. }\end{array}$ & No financial information. \\
\hline Medium Quality & $\begin{array}{l}\text { Sufficient emissions information } \\
\text { and/or sectoral disaggregated } \\
\text { policies information. }\end{array}$ & $\begin{array}{l}\text { Financial information in total } \\
\text { amounts. }\end{array}$ \\
\hline High Quality & $\begin{array}{l}\text { Good emissions information and } \\
\text { highly deep disaggregated } \\
\text { policies information. }\end{array}$ & $\begin{array}{l}\text { Financial information disaggregated } \\
\text { by area (mitigation/adaptation) } \\
\text { and/or by policies/sectors. }\end{array}$ \\
\hline
\end{tabular}

Source: Own compilation on the basis of the INDCs submitted to COP21.

According to what can be seen in

, the quality of the information follows a trajectory which is inversely proportional to the level of income of the country collecting the said information. Only $18.5 \%$ of the plans can be considered as offering general information of high quality, and only $12.7 \%$ as far as finance is concerned. In addition, only the plans from countries with medium-low and low incomes offer a higher than average quality in both categories.

These correspond mostly to small island states and African countries. For the former, climate change supposes the greatest possible threat (being submerged under the sea), while the latter see in the Paris Agreement an opportunity for sustainable development aided externally. The low quality of financial information provided by the OECD countries does not provide any data at all about the funding of their policies (two thirds of the plans have been classified as of "low quality"). The lack of any common standards or adequate auditing of the information received means that the objectives are difficult to compare or measure, which in turn makes any effective control over compliance almost impossible. 


\subsubsection{Mitigation policies: energy, industry, agriculture, waste and LULUCF}

The different policies under review in the INDCs respond to the following sectoral structure: i/ energy - electricity generation, transport and housing -; ii/ industrial processes; iii/ use of solvents and other products, iv/ agriculture, v/ change in land use and forestry (LULUCF) and, vi/ waste. Table 6 and 7 summarise the principal policies by sectors and each one is assigned a code to facilitate understanding and clarity in the other summary tables. Then, Table 9 collects all the policies pledged by each country in their INDCs, assigned to these codes.

This analysis is dealt with from the sectoral point of view by policies and, secondly, from the regional point of view by country and income group. In order to evaluate most common policies at world level, it has been calculated the number of countries choosing each policy over total countries. Then to address the regional analysis, the same process has been made in each income group region. Further information on the method is in Appendix 1.

\section{Analysis by sector and policy}

As can be seen in Table 8, the policies that stand out most of all are those aiming for an electric mix based on renewable energies (95.2\% of the INDCs). This policy is followed by transversal efficiency measures for all sectors and the increase in green cover through LULUCF. Some of these measures such as the electrification of the economy and decentralized electricity generation ( $23 \%$ and $31 \%$ respectively) take on even greater importance on a regional scale. With respect to the decentralization of energy, oil rich countries stand out; countries such as Nigeria, which aims to install off-grid photovoltaic panels, or Equatorial Guinea, with its "home energy" programme. In addition to those already mentioned, an important role will be played in the future of energy by natural gas and the combined cycle power stations, according to what can be seen from the INDCs.

As for the transport subsector, there is a great bid to foster public transport and efficiency policies for private vehicles (29.4\% and $27.0 \%$ of countries, respectively). The latter goal the countries hope to achieve through incentive-disincentive tax policies, in particular through the promotion of imports (important in the small island states), or the establishment of a carbon tax on inefficient vehicles. Although the commitment to biofuels is not at all generalized (18.3\% of the plans), it is important demographically and/or economically for some countries that are committed to it, such as Argentina, and especially India. Far less important is the promotion of the electric or hybrid vehicle (13.5\% of countries), although we find a relevant exception in India, which refers to its National Electric Mobility Mission Plan 2020 (NEMMP) detailing its action measures (Government of India, 2012). 
Table 6. Overview of main policies in INDCs.

\begin{tabular}{|c|c|c|c|c|}
\hline SECTOR & SUBSECTOR & POLICY & ACTION & CODE \\
\hline \multirow{17}{*}{ ENERGY } & \multirow{5}{*}{$\begin{array}{l}\text { ELECTRICITY } \\
\text { GENERATION }\end{array}$} & $\begin{array}{l}\text { Transition to renewable and cleaner } \\
\text { technologies. }\end{array}$ & Renewable deployment: solar, wind, hydro. & G1 \\
\hline & & Decentralization of energy generation. & Off and on-grid roof solar panels, solar thermal and small hydro. & G3 \\
\hline & & Rural electrification. & Substitute charcoal by electricity/Electrification & G4 \\
\hline & & Process efficiency. & $\begin{array}{l}\text { Best thermoelectric generation (coal and gas). } \\
\text { Reconstruction, construction or improvement of electricity grid. } \\
\text { Efficient technologies. }\end{array}$ & $\begin{array}{l}\text { G5 } \\
\text { G6 } \\
\text { G7 }\end{array}$ \\
\hline & & Reduction & Absolute reduction in energy consumption & G8 \\
\hline & \multirow{4}{*}{ RESIDENTIAL } & \multirow{4}{*}{ Consumption efficiency. } & $\begin{array}{l}\text { Enhanced technologies for heating and cooking (substitution of } \\
\text { charcoal). }\end{array}$ & $\mathrm{R} 1$ \\
\hline & & & Best lighting technologies. & $\mathrm{R} 2$ \\
\hline & & & Enhance buildings efficiency/solar thermal installation. & $\mathrm{R} 3$ \\
\hline & & & Social awareness. & $\mathrm{R} 4$ \\
\hline & \multirow{8}{*}{ TRANSPORT } & & Carbon tax (emissions). & $\mathrm{T} 3$ \\
\hline & & Fuels substitution. & Promotion and research on biofuels. & $\mathrm{T} 4$ \\
\hline & & & Promotion of electric and hybrid vehicle. & T5 \\
\hline & & \multirow{5}{*}{ Structural change. } & Mass public transport. & T6 \\
\hline & & & Intermodality and switch to an efficient transport system. & $\mathrm{T} 7$ \\
\hline & & & Spatial and urban planning. & $\mathrm{T} 8$ \\
\hline & & & Improvement of road system. & T9 \\
\hline & & & Non-motorized transport. & $\mathrm{T} 10$ \\
\hline
\end{tabular}

Source: Own compilation based on the INDCs reported to COP21. 
Table 7 (continuation of Table 6). Overview of main policies in INDCs.

\begin{tabular}{|c|c|c|c|}
\hline SECTOR & POLICY & ACTION & CODE \\
\hline \multirow{9}{*}{ INDUSTRY } & \multirow{3}{*}{ Process efficiency. } & Improve the overall efficiency of industry. & $\mathrm{I} 1$ \\
\hline & & Energy cogeneration. & $\mathrm{I} 2$ \\
\hline & & Measures oriented to industrial ecology. & $\mathrm{I} 3$ \\
\hline & Sectoral & Reduce emissions in cement industry. & I4 \\
\hline & \multirow{2}{*}{ Structural change. } & Modernization and switch to an enhanced value added industry. & I5 \\
\hline & & Tertiarisation (China). & I6 \\
\hline & Emissions & Carbon Capture and Storage/Use. & I7 \\
\hline & \multirow{2}{*}{ Extractive industry } & Reduce flaring and venting. & I8 \\
\hline & & Improvements in processes, efficiency and distribution. & I9 \\
\hline \multirow{3}{*}{ WASTE } & $\begin{array}{l}\text { Circular economy and } \\
\text { reduction }\end{array}$ & $\begin{array}{l}\text { Reduce, Reuse, Recycling. } \\
\text { Transform waste to energy. } \\
\text { Social awareness. }\end{array}$ & $\begin{array}{l}\text { W1 } \\
\text { W2 } \\
\text { W3 }\end{array}$ \\
\hline & Management & Improve landfill management, construct new ones and promotion of compost. & W4 \\
\hline & Sanitation & Sanitation improvement in residential sector. & W5 \\
\hline \multirow{3}{*}{ AGRICULTURE } & Structural change. & $\begin{array}{l}\text { Modernization and intensification of agriculture. } \\
\text { Climate Smart Agriculture (CSA). }\end{array}$ & $\begin{array}{l}\text { A1 } \\
\text { A2 } 2\end{array}$ \\
\hline & Sectoral & Reduce emissions of rice fields. & A3 \\
\hline & Others & $\begin{array}{l}\text { Control of fertilizers and pesticides. } \\
\text { Methane capture. }\end{array}$ & $\begin{array}{l}\text { A4 } \\
\text { A5 }\end{array}$ \\
\hline \multirow{2}{*}{ LULUCF } & \multirow{2}{*}{$\begin{array}{l}\text { Extend vegetation } \\
\text { cover }\end{array}$} & Avoid deforestation. & L1 \\
\hline & & Afforestation and reforestation. & L2 \\
\hline
\end{tabular}

Source: Own compilation based on the INDCs reported to COP21. 
In the industrial sector, what stand out are the measures to improve efficiency related with better technologies and the cogeneration of energy. In addition to reduction measures in sectors with especially high emissions, such as that of cement, structural measures are also envisaged, such as modernization and increasing the value added of industry and boosting the service sector of the economy (China). The use of carbon capture and storage (CCS) and carbon capture and utilization (CCU) (Saudi Arabia, Bosnia-Herzegovina, Malawi, Norway, Qatar, Saint Vincent and the Grenadines, Venezuela), as well as the use of clean technologies, are other measures aimed at reducing emissions. Furthermore, countries with an extractive industry do not provide for leaving their resources underground. They concern only an improvement in the extraction, processing and distribution processes, as well as a reduction in emissions due to gas flaring.

\section{Table 8. Top 15 Policies in the INCDs}

\begin{tabular}{|c|c|c|}
\hline Code & Policies & Proportion \\
\hline \hline G1 & Renewable deployment: solar, wind, hydro. & $95.2 \%$ \\
G7 & Efficient technologies. & $44.4 \%$ \\
L1 & Avoid deforestation & $43.7 \%$ \\
L2 & Afforestation and reforestation. & $41.3 \%$ \\
G3 & Off and on-grid roof solar panels, solar thermal and small hydro. & $31.0 \%$ \\
T6 & Mass public transport. & $29.4 \%$ \\
T1 & Encouraging acquisition of hybrid and efficient vehicles. & $27.0 \%$ \\
W4 & Improve landfill management, construct new ones and promotion of & \\
& compost. & $26.2 \%$ \\
G4 & Substitute charcoal by electricity/Electrification & $23.0 \%$ \\
W2 & Transform waste to energy. & $23.0 \%$ \\
G2 & Combined cycle power stations. Switch to natural gas. & $20.6 \%$ \\
R1 & Enhanced technologies for heating and cooking (substitution of & $20.6 \%$ \\
W1 & charcoal). & $19.8 \%$ \\
T4 & Reduce, Reuse, Recycle. & $18.3 \%$ \\
I1 & Promotion and research on biofuels. & $15.1 \%$ \\
\hline
\end{tabular}

Source: Own compilation on the basis of INDCs submitted to the COP21. Information provided by total parties with policies.

As for the waste sector, classic measures are considered, such as reduction (with a smaller presence), recycling and reuse, as well as what is usually called "recovery". They also consider the transformation of waste into energy through biogas or biomass, and the improvement of rubbish tips or their construction in countries that lack an adequate waste management $(26.2 \%$ of the INDCs). For its part, India, with an important public health problem related with the management of human waste in the cities, aims to promote an ambitious sewage network, beginning with the most basic aspect: the installation of lavatories in homes. In the agricultural sector, especially in low-income countries, the aims of "modernization" abound, although they do not specify how this should be done. Some countries, such as Afghanistan and Nigeria among 
others mention to apply for the so-called Climate Smart Agriculture (CSA), even though it is more an adaptation program instead of mitigation. On the other hand, measures are also planned to reduce methane emissions in the rice fields, to control the increased use of fertilizers and pesticides and, finally, to capture methane from the enteric fermentation of cattle and manure.

Finally, LULUCF sector is one of those that are becoming more important, particularly for those countries that already have a large surface area of forest. Of greatest importance in this sphere are: the fight against deforestation, the reforestation of deforested areas, and the afforestation of areas previously dedicated to other uses. Outstanding in this respect are such countries as Brazil (as a carbon sink), or others with such large populations as Bangladesh, and even those with such enormous economic and environmental importance as China.

\section{Regional analysis}

This sectoral policy view would be incomplete without a regional insight, which has a key relevance in the feasibility of accomplishing the Agreement. Figure 81 shows the deviation of each top 15 policy share by income group from the world average. It can be seen, for instance, that the electrification of the economy and its decentralized generation take on greater importance in the Less Developed Countries (LDCs). Charcoal is used abundantly in these countries as a source of primary energy for heating and cooking.

This is why low-income countries also stand out with respect to improvements in cooking and heating efficiency. In the same way, the lower middle-income countries are comparatively more committed to the reduction, recycling and reuse of waste than the rest, as well as to the fight against deforestation. The upper middle-income countries are committed above the average to promoting biofuels and decentralizing the generation of electricity. On the other hand, the highincome countries champion the improvement of their public transport systems and the efficiency of their industries. Finally, the countries of the OECD, in spite of the bias caused by the lack of data, seem to be more committed to natural gas and combined cycle power stations. In general terms, it can be seen that low income countries make above average use of the top 15 policies. 


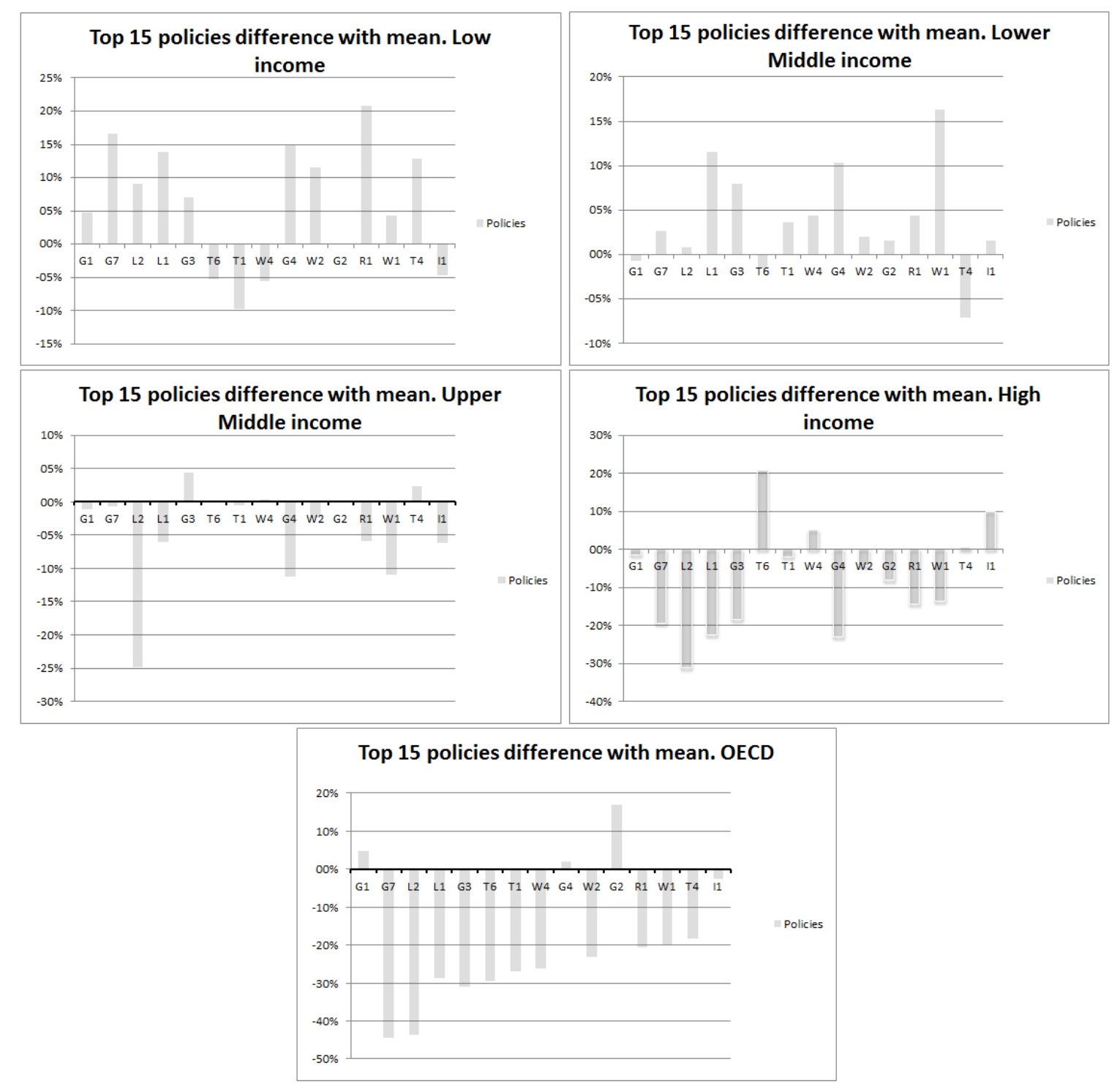

Figure 8. Top 15 policies. Differences of each policy with respect to the global mean by income groups. Source: Own elaboration on the basis of INDCs submitted to the COP21.

These tendencies are confirmed when we analyse the relative weight of each set of sectoral policies over the total number of countries. Figure 9 shows the deviation of sectoral relevance (measured as the number of countries taking policies from each sector, see Appendix 1) of each region from world average. Thus, LDCs have an above average impact on the policies concerning the generation of electricity, housing, waste management, agriculture and LULUCF; while DC do so in transport and the industrial sector. The importance of the abovementioned sectors, in the former case, follows an inverse relation to income, while in the second case, the relation is positive. This regional distribution of the policies will have important consequences for the efficacy of the Paris Agreement in reaching its goals. 


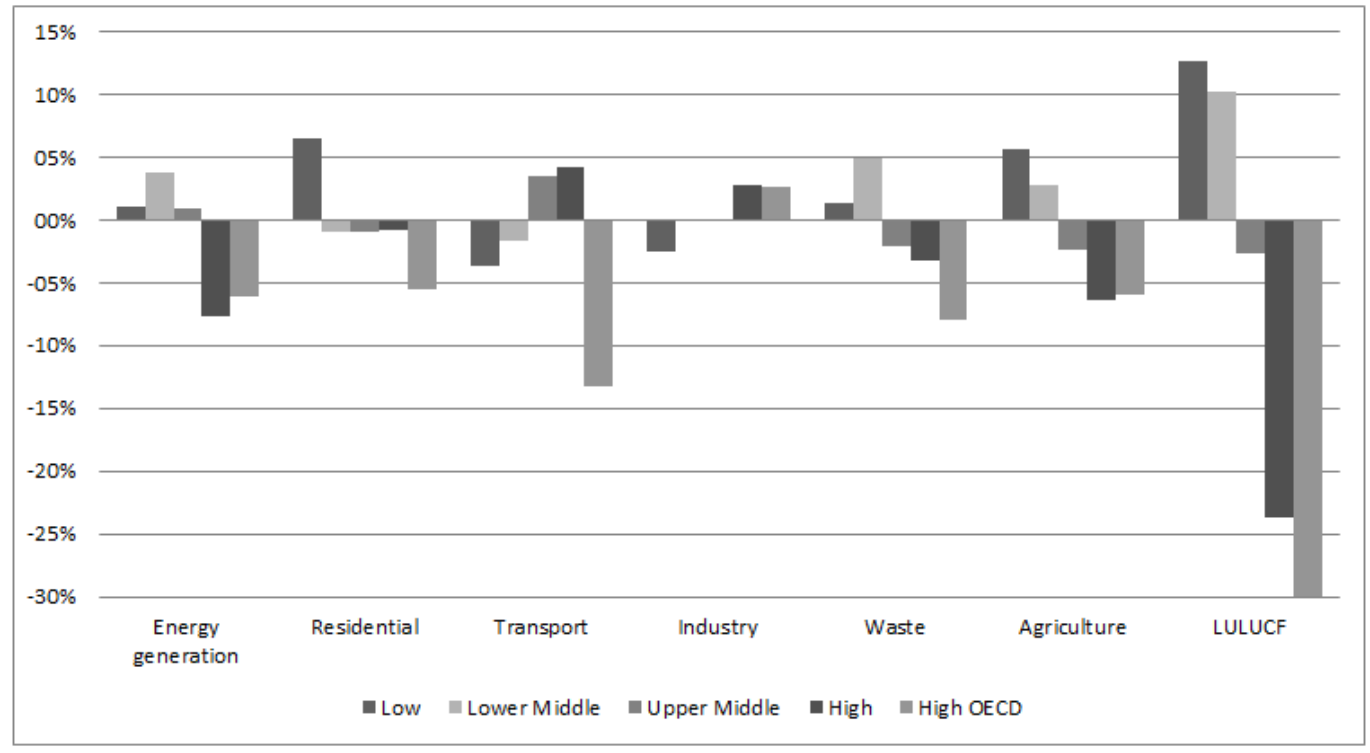

Figure 9. Sectoral relevance by income groups. Differences with respect to global sectoral mean.

Source: own elaboration on the basis of INDCs submitted to COP21. 


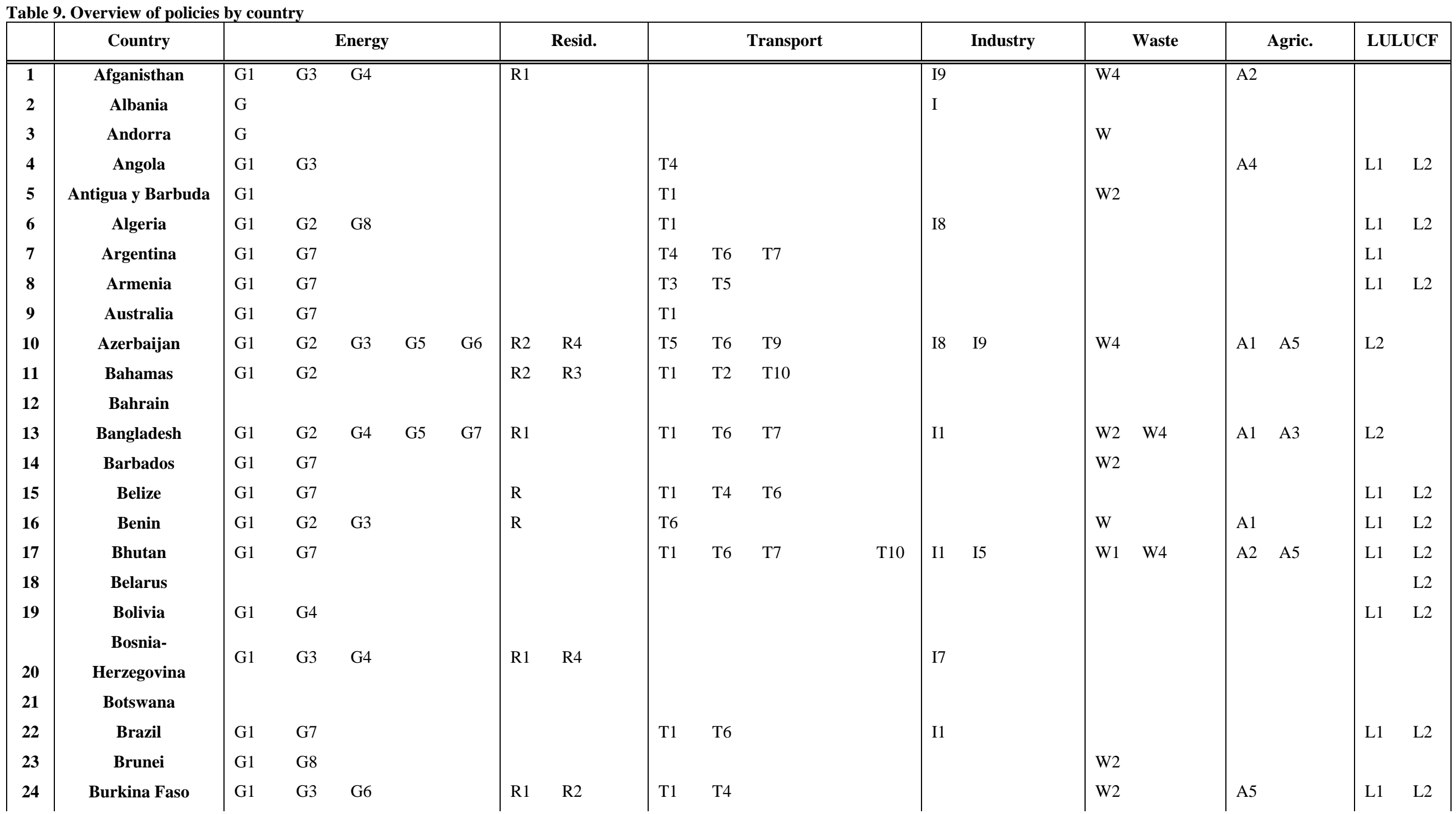




\begin{tabular}{|c|c|c|c|c|}
\hline 25 & Burundi & G1 & G3 & G7 \\
\hline 26 & Cabo Verde & G1 & G3 & G7 \\
\hline 27 & Cambodia & G1 & G3 & \\
\hline 28 & Cameroon & G1 & G7 & \\
\hline 29 & Canada & G1 & $\mathrm{G} 2$ & \\
\hline 30 & Chad & G1 & G5 & \\
\hline 31 & Chile & G1 & G4 & \\
\hline 32 & China & G1 & G2 & G5 \\
\hline 33 & Colombia & & & \\
\hline 34 & Comores & G1 & $\mathrm{G} 2$ & G6 \\
\hline 35 & Congo & G1 & G4 & \\
\hline 36 & Cook Islands & G1 & G6 & G7 \\
\hline 37 & Ivory Coast & G1 & G2 & G7 \\
\hline 38 & Costa Rica & G1 & G4 & G7 \\
\hline 39 & Cuba & G1 & G3 & \\
\hline 40 & Djibouti & G1 & G6 & \\
\hline 41 & Dominica & G1 & G3 & G7 \\
\hline 42 & Ecuador & G1 & $\mathrm{G} 2$ & \\
\hline 43 & Egypt & G1 & G7 & \\
\hline 44 & El Salvador & G1 & G7 & \\
\hline 45 & Eritrea & G1 & G4 & \\
\hline 46 & Ethiopia & G1 & & \\
\hline 47 & Fiji & G1 & G7 & \\
\hline 48 & Phillipines & & & \\
\hline 49 & Gabon & G1 & $\mathrm{G} 2$ & G7 \\
\hline 50 & Gambia & G1 & G6 & G7 \\
\hline 51 & Georgia & & & \\
\hline
\end{tabular}

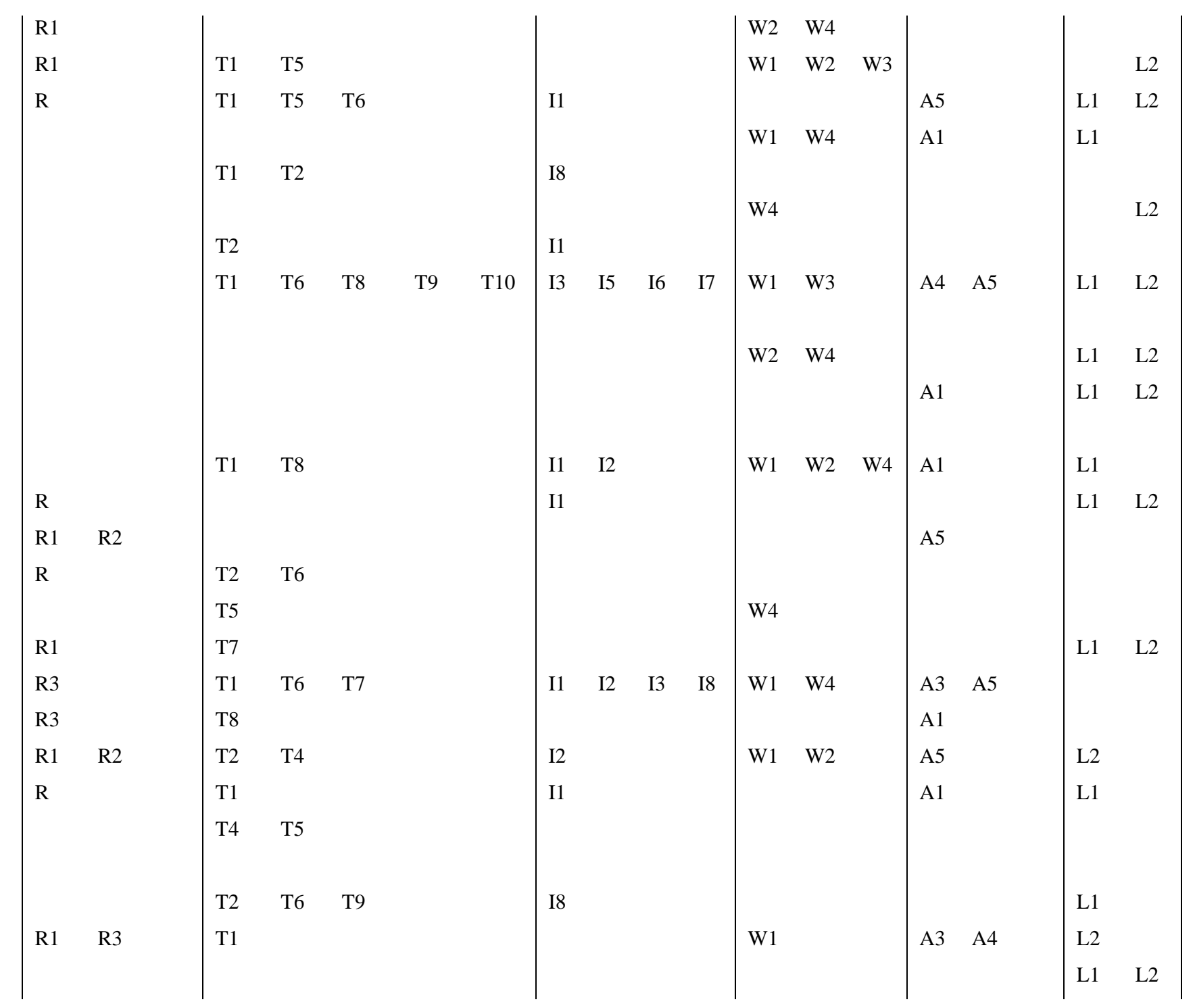




\begin{tabular}{|c|c|c|c|c|c|c|c|c|c|c|c|c|c|c|c|}
\hline 52 & Ghana & G1 & G7 & & & & $\mathrm{R} 1$ & $\mathrm{R} 2$ & & T6 & & & & & I1 \\
\hline 53 & Grenada & G1 & G7 & & & & & & & $\mathrm{T} 2$ & $\mathrm{~T} 3$ & $\mathrm{~T} 4$ & & & \\
\hline 54 & Guatemala & & & & & & & & & & & & & & \\
\hline 55 & Guinea & G1 & G4 & G7 & & & & & & & & & & & \\
\hline 56 & Guinea Bissau & G1 & & & & & & & & & & & & & \\
\hline 57 & Equatorial Guinea & G1 & & & & & & & & $\mathrm{T} 1$ & T6 & $\mathrm{T} 8$ & & & I1 \\
\hline 58 & Guyana & G1 & G3 & G7 & & & $\mathrm{R} 1$ & $\mathrm{R} 2$ & $\mathrm{R} 4$ & & & & & & $\mathrm{I} 2$ \\
\hline 59 & Haithi & & & & & & & & & & & & & & \\
\hline 60 & Iraq & & & & & & & & & & & & & & \\
\hline 61 & Honduras & & & & & & & & & & & & & & \\
\hline 62 & India & G1 & G3 & G4 & G5 & G6 & $\mathrm{R} 2$ & R3 & & $\mathrm{T} 1$ & $\mathrm{~T} 4$ & T5 & T6 & $\mathrm{T} 7$ & \\
\hline 63 & Indonesia & G1 & G7 & & & & & & & & & & & & \\
\hline 64 & Iran & & & & & & & & & & & & & & \\
\hline 65 & Iceland & G1 & G2 & & & & $\mathrm{R}$ & & & & & & & & I8 \\
\hline 66 & Marshall Islands & G1 & G3 & G7 & & & $\mathrm{R} 1$ & & & $\mathrm{~T} 1$ & $\mathrm{~T} 4$ & T5 & & & \\
\hline 67 & Israel & G1 & G2 & G7 & & & & & & T6 & & & & & \\
\hline 68 & Jamaica & G1 & G7 & & & & & & & $\mathrm{T} 1$ & $\mathrm{~T} 3$ & & & & \\
\hline 69 & Japan & G1 & G4 & & & & $\mathrm{R}$ & & & $\mathrm{T} 1$ & T5 & T6 & $\mathrm{T} 7$ & & I1 \\
\hline 70 & Jordan & G1 & G2 & G3 & G7 & & $\mathrm{R} 3$ & & & $\mathrm{~T} 1$ & T5 & T6 & $\mathrm{T} 7$ & & I2 \\
\hline 71 & Kazakhstan & G1 & G7 & & & & & & & & & & & & \\
\hline 72 & Kenya & G1 & G7 & & & & $\mathrm{R} 1$ & & & $\mathrm{~T} 1$ & & & & & \\
\hline 73 & Kiribati & G1 & G3 & & & & & & & $\mathrm{T} 4$ & & & & & \\
\hline 74 & Kuwait & & & & & & & & & & & & & & \\
\hline 75 & Kyrgizistan & & & & & & & & & & & & & & \\
\hline 76 & Lao & G1 & G4 & & & & & & & $\mathrm{T} 4$ & T6 & T9 & & & \\
\hline 77 & Lesotho & G1 & G4 & G6 & & & $\mathrm{R} 1$ & $\mathrm{R} 2$ & & $\mathrm{~T} 1$ & T6 & & & & I1 \\
\hline 78 & Lebanon & G1 & G7 & & & & & & & & & & & & \\
\hline
\end{tabular}

\begin{tabular}{|c|c|c|c|c|}
\hline W1 & & & L1 & \\
\hline W2 & W4 & & $\mathrm{L} 1$ & L2 \\
\hline & & & L1 & L2 \\
\hline & & & $\mathrm{L} 1$ & L2 \\
\hline W1 & & A2 & $\mathrm{L} 1$ & L2 \\
\hline & & A5 & $\mathrm{L} 1$ & L2 \\
\hline W1 & W2 W5 & & & $\mathrm{L} 2$ \\
\hline W1 & W4 & A1 & $\mathrm{L} 1$ & L2 \\
\hline W4 & & & & \\
\hline W1 & W4 & A4 & $\mathrm{L} 1$ & $\mathrm{~L} 2$ \\
\hline W4 & & & L2 & \\
\hline W4 & & & L2 & \\
\hline W4 & & A2 & L2 & \\
\hline & & & $\mathrm{L} 1$ & L2 \\
\hline W1 & W4 & & L1 & L2 \\
\hline
\end{tabular}




\begin{tabular}{|c|c|c|c|c|c|}
\hline 79 & Liberia & G1 & G4 & G7 & \\
\hline 80 & Liechtenstein & & & & \\
\hline 81 & Macedonia & & & & \\
\hline 82 & Madagascar & G1 & G4 & G7 & \\
\hline 83 & Malaysia & & & & \\
\hline 84 & Malawi & G1 & G3 & & \\
\hline 85 & Maldives & & & & \\
\hline 86 & Mali & G1 & G4 & & \\
\hline 87 & Morocco & G1 & G2 & G7 & \\
\hline 88 & Mauritius & G1 & $\mathrm{G} 2$ & G4 & \\
\hline 89 & Mauritania & G1 & G4 & G7 & \\
\hline 90 & Mexico & & & & \\
\hline 91 & Micronesia & & & & \\
\hline 92 & Moldova & & & & \\
\hline 93 & Monaco & & & & \\
\hline 94 & Mongolia & G1 & G5 & G6 & \\
\hline 95 & Montenegro & & & & \\
\hline 96 & Mozambique & G1 & $\mathrm{G} 2$ & & \\
\hline 97 & Myanmar & G1 & G3 & G4 & G7 \\
\hline 98 & Namibia & G1 & & & \\
\hline 99 & Nauru & & & & \\
\hline 100 & Nepal & G1 & & & \\
\hline 101 & Niger & G1 & G2 & G4 & \\
\hline 102 & Nigeria & G1 & G2 & G3 & G7 \\
\hline 103 & Niue & G1 & G7 & & \\
\hline 104 & Norway & G1 & & & \\
\hline 105 & New Zealand & & & & \\
\hline
\end{tabular}

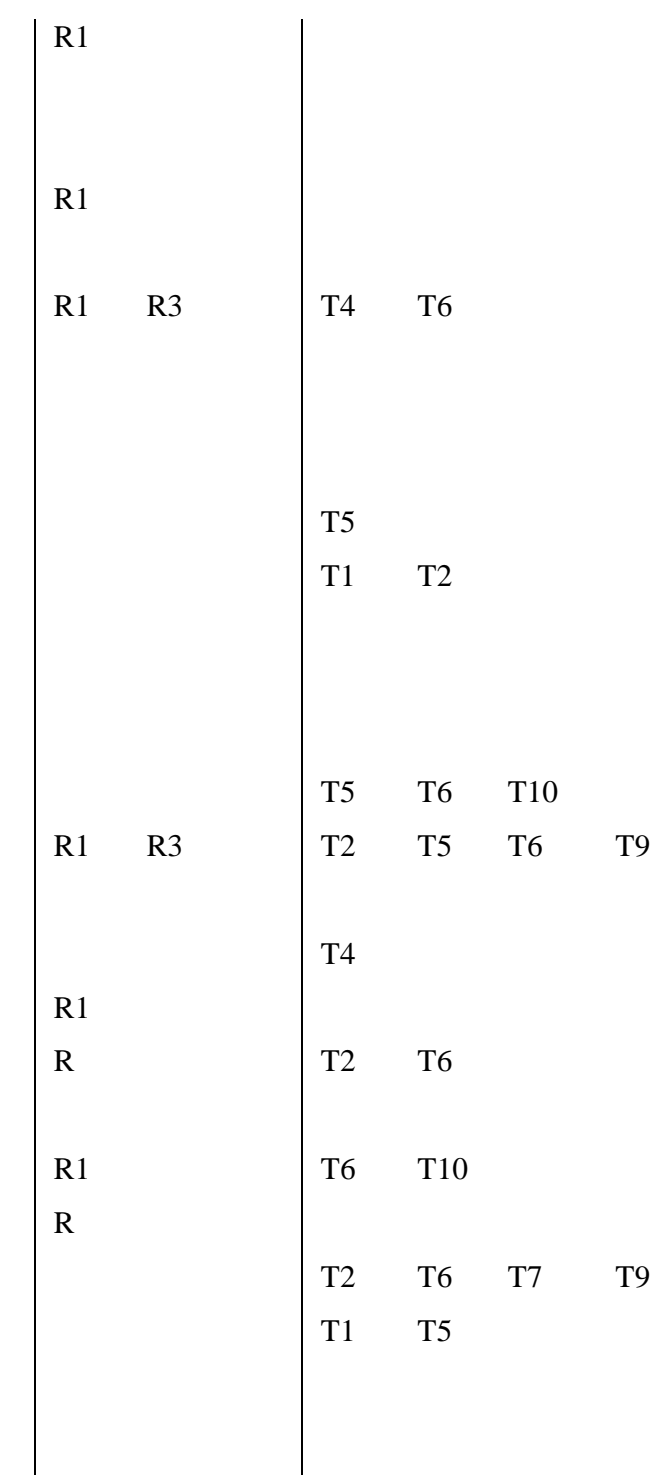

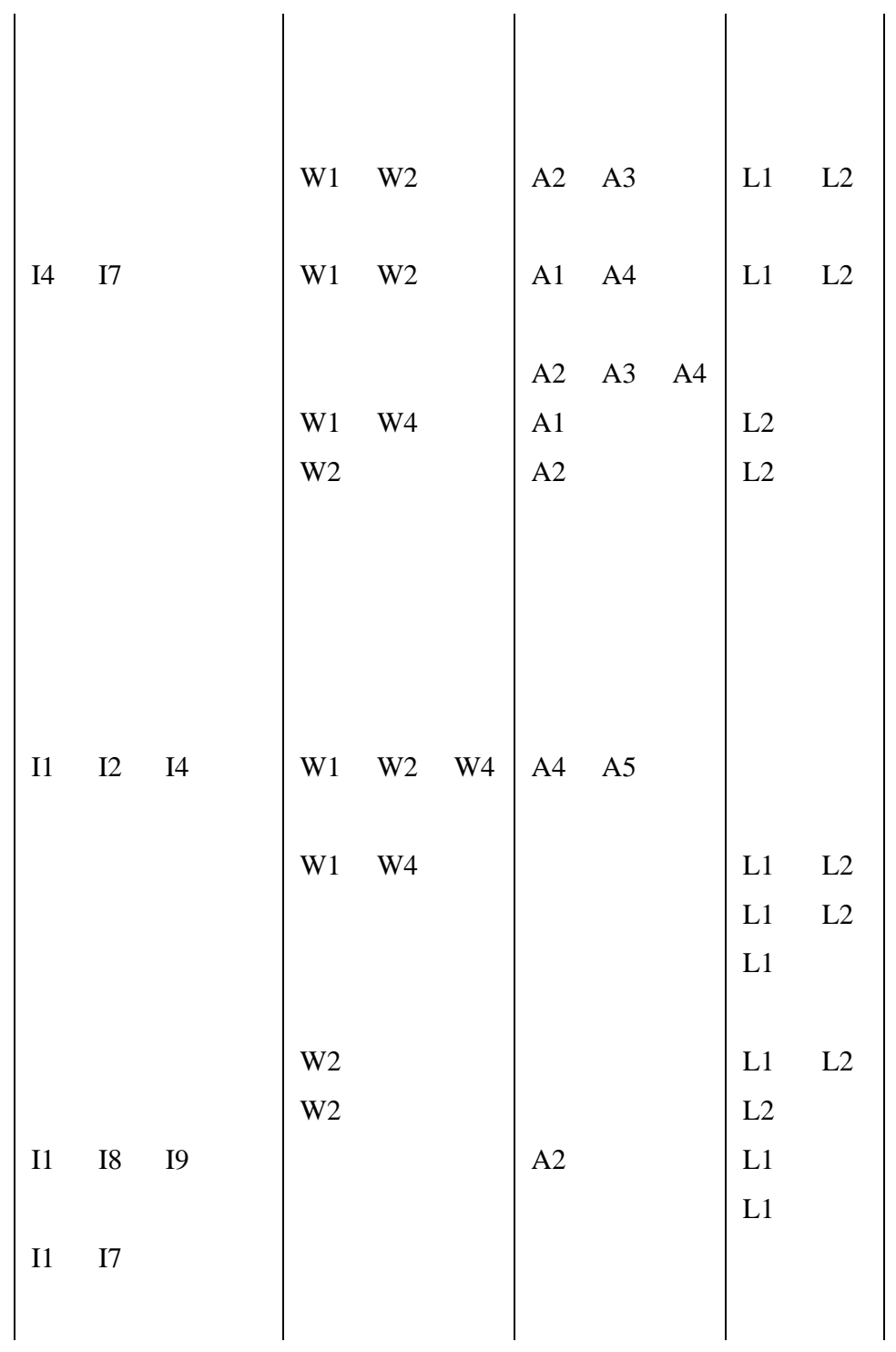




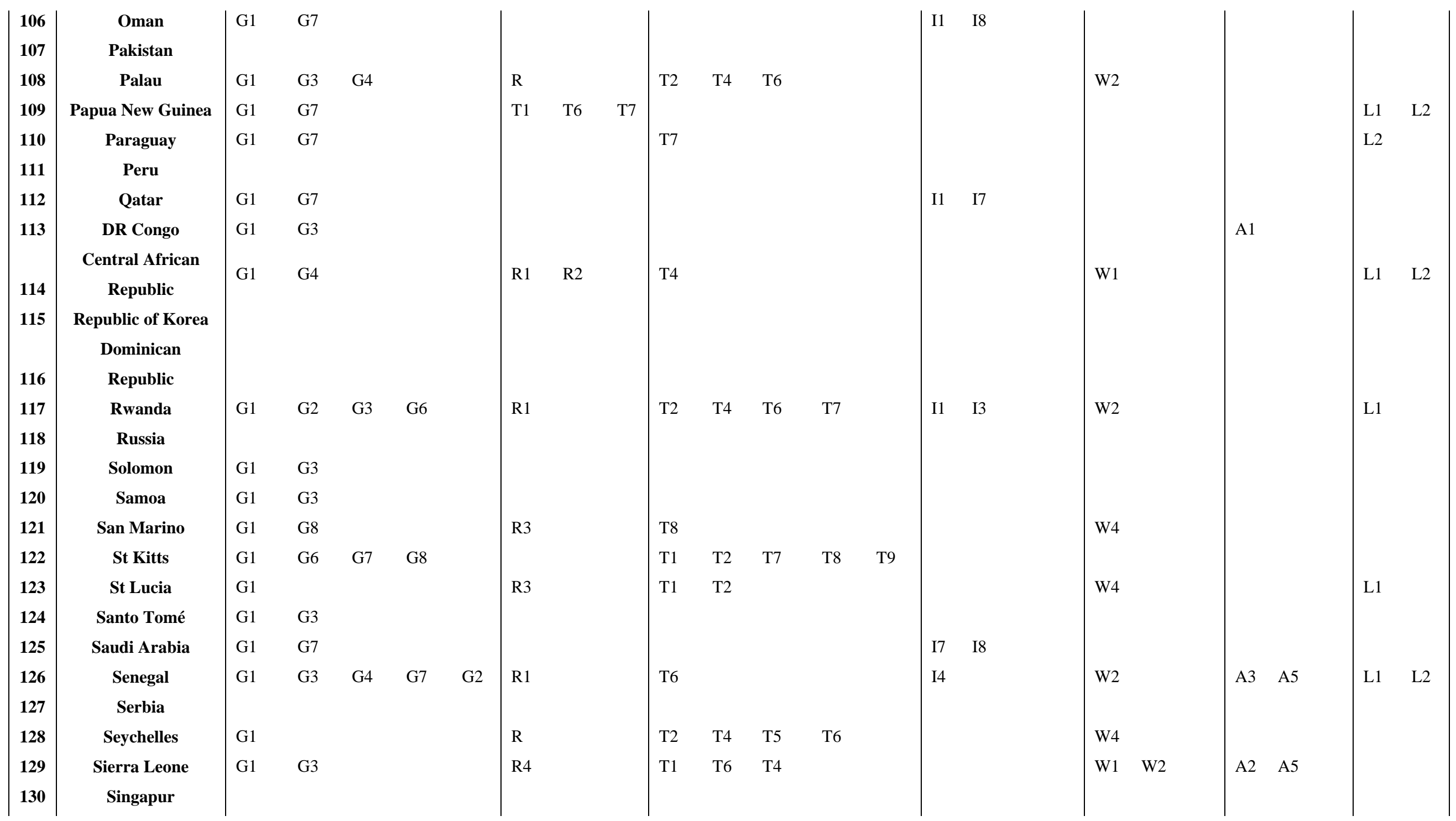




\begin{tabular}{|c|c|c|c|c|c|}
\hline 131 & Somalia & G1 & & & \\
\hline 132 & Sri Lanka & & & & \\
\hline 133 & $\begin{array}{l}\text { St Vincent and the } \\
\text { Grenadines }\end{array}$ & G1 & G3 & G7 & \\
\hline 134 & South Africa & G1 & & & \\
\hline 135 & Sudan & G1 & G2 & G3 & G7 \\
\hline 136 & South Sudan & G1 & G7 & & \\
\hline 137 & Switzerland & & & & \\
\hline 138 & Surinam & G1 & G3 & & \\
\hline 139 & Swazilandia & & & & \\
\hline 140 & Thailand & G1 & G6 & G7 & \\
\hline 141 & Tajikistan & G1 & G6 & & \\
\hline 142 & Tanzania & G1 & G2 & G4 & G6 \\
\hline 143 & Togo & G1 & & & \\
\hline 144 & Tonga & G1 & G3 & G6 & \\
\hline & Trinidad and & & & & \\
\hline 145 & Tobago & & & & \\
\hline 146 & Tunez & G1 & & & \\
\hline 147 & Turkmenistan & & & & \\
\hline 148 & Turkey & G1 & G3 & G6 & \\
\hline 149 & Tuvalu & G1 & G3 & G7 & \\
\hline 150 & UAE & G1 & G2 & & \\
\hline 151 & Ukraine & & & & \\
\hline 152 & EU28 & & & & \\
\hline 153 & Uganda & G1 & G3 & G4 & \\
\hline 154 & Uruguay & G1 & & & \\
\hline 155 & USA & G1 & & & \\
\hline
\end{tabular}
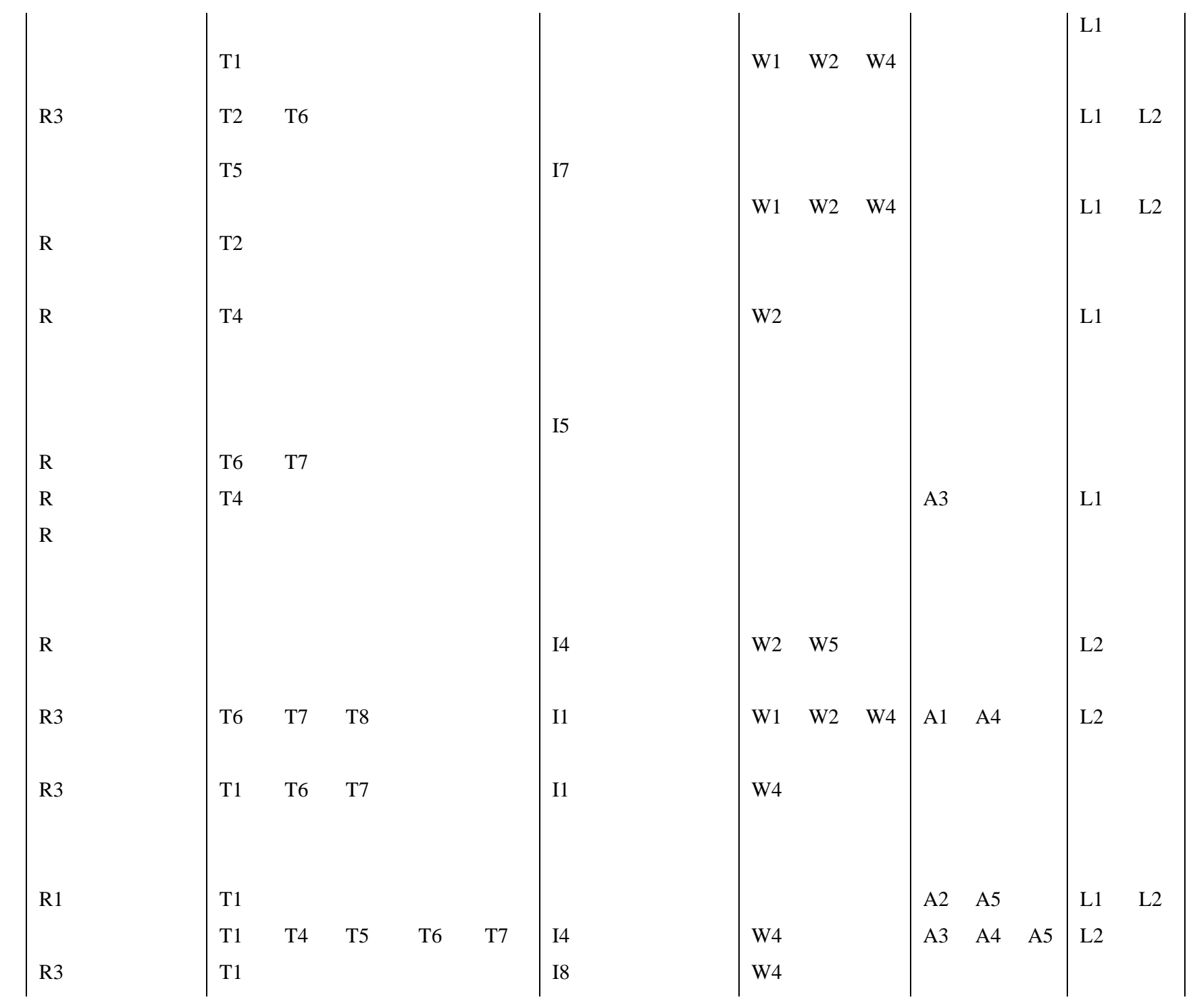


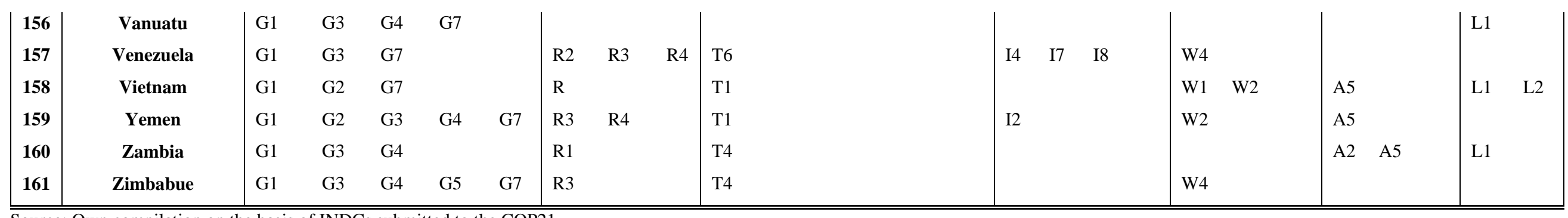

Source: Own compilation on the basis of INDCs submitted to the COP21. 


\subsubsection{Finance, equity and leadership of the transition}

Means of implementation are needed to set these policies in motion. Article 9.1 of the Paris Agreement establishes that DCs (Annex I countries, i.e. OECD) should provide LDCs with financial resources. In addition, there should be reports every two years on the resources mobilized. In this sense, the great majority of the INDCs of the LDCs incorporate a series of unconditional objectives, assumed by the country itself, and other objectives conditioned by the reception of external support. Besides financial resources, other external support contemplated in the Agreement includes capacity building and technology transfer.

All the figures set out in this section must be considered with caution, due to the lack of homogeneity and clarity of the INDCs. Thus, the proportions destined to mitigation policies (83.2\%), as opposed to those of adaptation, are often biased due to the high figures given by India (2500MM\$), Iran (927.5MM\$) and South Africa (898.79MM\$) that account for $79.8 \%$ of the total funding. The group of countries that make the greatest effort in terms of finance with respect to their GDP are the low-income countries, due both to their reduced level of GDP and the great quantity of external finance they have to account for. Specifically, $87.1 \%$ of all the financing required by the INDCs over the low-income countries which has been evaluated corresponds to external resources. The choice, in Table 10, of the last indicator instead of the first is due to the fact that it is excessively biased because of the lack of data. It can be observed that the majority of countries requiring external financing do so in a relatively high proportion. This is such that a conservative estimate (only including the external financing explicitly mentioned) shows that almost half $(41.4 \%)$ of the funding needed to completely implement the INDCs depends on international cooperation. Of course, this is a challenge in the design of climate funding which we shall deal with below.

In order to channel the public and private resources that finance the mitigation and adaptation policies from DCs to LDCs, the UNFCCC has developed a complex system of climate funding (Buchner et al., 2015; Román, 2013). The ones most cited by the INDCs are the Green Climate Fund (GCF), the Green Environment Facility (GEF) and the Clean Development Mechanism (CDM) for compensation. The CDM should be a zero sum game (Erickson et al., 2014) in which investment in mitigation projects in LDCs generates 'Certified Emission Reductions' (CER) that can be used to increase emissions by the same amount that the investment reduced them, or alternatively can be sold on the carbon markets. In total, 42 countries want to gain access or have already gained access and want to continue with the CDM, not counting those who have expressed a desire to use unspecified market mechanisms. 
Table 10. Financial allocation by income group (billions US\$). Totals and effort related to GDP.

\begin{tabular}{|c|c|c|c|c|c|c|c|c|}
\hline & $\begin{array}{l}\text { Mitigation } \\
\text { (bs US\$) }\end{array}$ & $\begin{array}{c}\text { Share } \\
\text { on } \\
\text { total } \\
(\%)\end{array}$ & $\begin{array}{c}\text { Adaptation } \\
\text { (bs US \$) }\end{array}$ & $\begin{array}{c}\text { Share } \\
\text { on } \\
\text { total } \\
(\%)\end{array}$ & $\begin{array}{c}\text { Other } \\
\text { (bs } \\
\text { US\$) }\end{array}$ & $\begin{array}{c}\text { Total } \\
(\mathbf{b s} \\
\text { US\$)* }\end{array}$ & $\begin{array}{l}\text { GDP } \\
(\%)\end{array}$ & $\begin{array}{c}\text { External } \\
\text { support } \\
(\%) * *\end{array}$ \\
\hline Low & 387.0 & 61.8 & 156.4 & 25.0 & 82.5 & 625.8 & 204.6 & 87.1 \\
\hline $\begin{array}{l}\text { Lower } \\
\text { Middle }\end{array}$ & 1016.3 & 35.9 & 323.3 & 11.4 & 1492.3 & 2831.8 & 99.1 & 73.2 \\
\hline $\begin{array}{l}\text { Upper } \\
\text { Middle }\end{array}$ & 1793.3 & 91.5 & 167.4 & 8.5 & 0.0 & 1960.7 & 69.4 & 92.7 \\
\hline High & 6.2 & 78.6 & 1.5 & 19.4 & 0.2 & 7.9 & 22.7 & 77.8 \\
\hline $\begin{array}{c}\text { High } \\
\text { OECD }\end{array}$ & ND & ND & ND & ND & ND & ND & ND & ND \\
\hline $\begin{array}{c}\text { Top } 12 \\
\text { polluters }\end{array}$ & 846.5 & 33.6 & 222.8 & 8.8 & 1452.3 & 2521.6 & 89.2 & - \\
\hline TOTAL & 3202.7 & 83.2 & 648.5 & 16.8 & 1574.9 & 5426.2 & 7.3 & 41.4 \\
\hline
\end{tabular}

Source: Own compilation on the basis of INDCs submitted to COP21. GDP (constant 2005 US\$). * The totals in bs

US\$ are not always the sum of Mitigation+Adaptation+Other because some INDCs offer totals with differences whose origin is not explained. ** The percentage represents the proportion of external resources required by those INDCs that do offer data. However, the total percentage is the total amount of external resources required by all the plans over the total financing of the all the INDCs, including those that have no breakdowns.

The funding sources proposed by countries say a lot about the agents who will guide the practical set up of the INDCs. Depending on whether the conditional part of the external support for LDCs is larger or smaller, the transition will be influenced by the criteria established by international institutions or by particular interests of countries with which they reach bilateral agreements. In addition, naturally, the degree of importance given to the public or private sector will have consequences in the transition's directive criteria, its effectiveness, and the coordination between policies and how fast the changes are implemented.

Based on the finance sections of INDCs, it can be seen that in low-income countries, more importance is given to external support (in particular the GCF), donations, carbon markets and the CDM. The weakness of these States means that, in addition, the private sector plays an important role. Those outstanding for their confidence in the private sector are Burkina Faso, Liberia and Sierra Leone. For its heterogeneity of agents, Uganda is also worthy of note, with a transition led by the public sector, but with the participation of the local communities, publicprivate partnerships (PPP) and the international community.

In the medium-low income countries, public participation and multilateral finance institutions have greater weight. The external support continues to be the principal driving force of the transition, although bilateral agreements are gaining weight, while the participation in such control mechanisms as CDMs are falling slightly (this is a constant as income rises). While Indonesia mainly has confidence in the private sector, Bolivia does so in the public sector and 
demands that the external support should be totally non-returnable. As the countries' level of income rises, the financial autonomy to put the transition into practice also rises.

In the medium-high income countries, Colombia mainly has confidence in the private sector and tries to involve the university system in the transition; while Cuba, on the other hand, continues to have confidence in a transition through the public sector, with such measures as the distribution of clean technologies for the residential sector (lighting and cooking). China, however, deploys some very diverse means led by the State, such as the PPP, favourable taxation, public contracts, green credit and financial guidance through the public bank, disaster insurance, etc. As we analyse the INDCs of the countries with higher incomes, the information becomes scarcer, but it continues with the dynamic of increasing the internal autonomy and government leadership.

\subsubsection{Reducing emissions?}

Since one of the objectives of this article is the evaluation of the efficacy of the INDCs to comply with the Paris Agreement, the calculation of the variation in absolute emissions for each one is fundamental. The said calculations have had to be done because of the disparity in the forms of presentation of the contributions and have been carried out according to what is set out in the section 2.2. and Appendix 1Appendix 1. Methodological appendix for INDCs revision whereas Table 12 shows these results. As explained in section 2.2, there has been needed to estimate emissions reductions from the INDC's data for those not giving the information as a reduction from a base year. Taking the simple arithmetic means, and if the mitigation policies (BAU) are not carried out, then each country would double (an increase of 95.7\%) their emissions of GHGs in 2030 as compared to their defined level between 2005-2015. In order to get a better adjusted calculation, if we take the weighted mean as each country's contribution to world emissions (in 2014), the result would be an increase in world emissions of $31.5 \%$. This result can basically be explained by the top 12 polluters, which will be analysed separately below.

The setting in which mitigation policies are carried out is not much rosier. In the best of cases (conditional on the reception of external support from countries not included in Annex I), each country would emit an average of $37.8 \%$ more than in the years $2005-2015$. When this is weighted, the figure would be a $19.3 \%$ increase due to the contribution of some Top 12 polluters, as we discussed in the next subsection. In the least optimistic case, in which none of the conditional policies are put into practice, each country would modify their emissions on average with respect to the base interval by $75.0 \%$. If this is weighted, emissions would increase on a global level around $25.8 \%$. 
Although the INDCs always talk about reductions, they are seen in GHG emissions intensity (CO2eq/GDP) or over a BAU setting. Predicting the countries where the GDP will grow much more than their emissions and the BAU settings being on the increase, the final result is that of a net increase in GHG emissions, which cancels out the reductions in the Annex I countries and Brazil. India, for instance, aims to more than quadruple their emissions, China aims to increase by $39.8 \%$, while other countries such as Burundi, Papua New Guinea, Liberia, Bangladesh or Congo oscillate around a growth factor of between 3 and 4 . The trend scenarios of Congo and Burundi stand out especially, as they plan to multiply their emissions by more than 6 and 5 times, respectively.

In effect, Figure 10 reflects a decreasing tendency in mean emissions as income rises. However, the weighted mean shows an initially upward trajectory, which then decreases as the income level increases. This is so because the low-income countries currently represent a very small fraction of the emissions, while India (lower middle) would explain the highest point. On the other hand, the upper middle countries see China's increase compensated for by the absolute reduction in emissions proposed by Brazil. As can be seen, the OECD countries (all of those in Annex I) are the only ones that plan to make an absolute reduction in emissions.

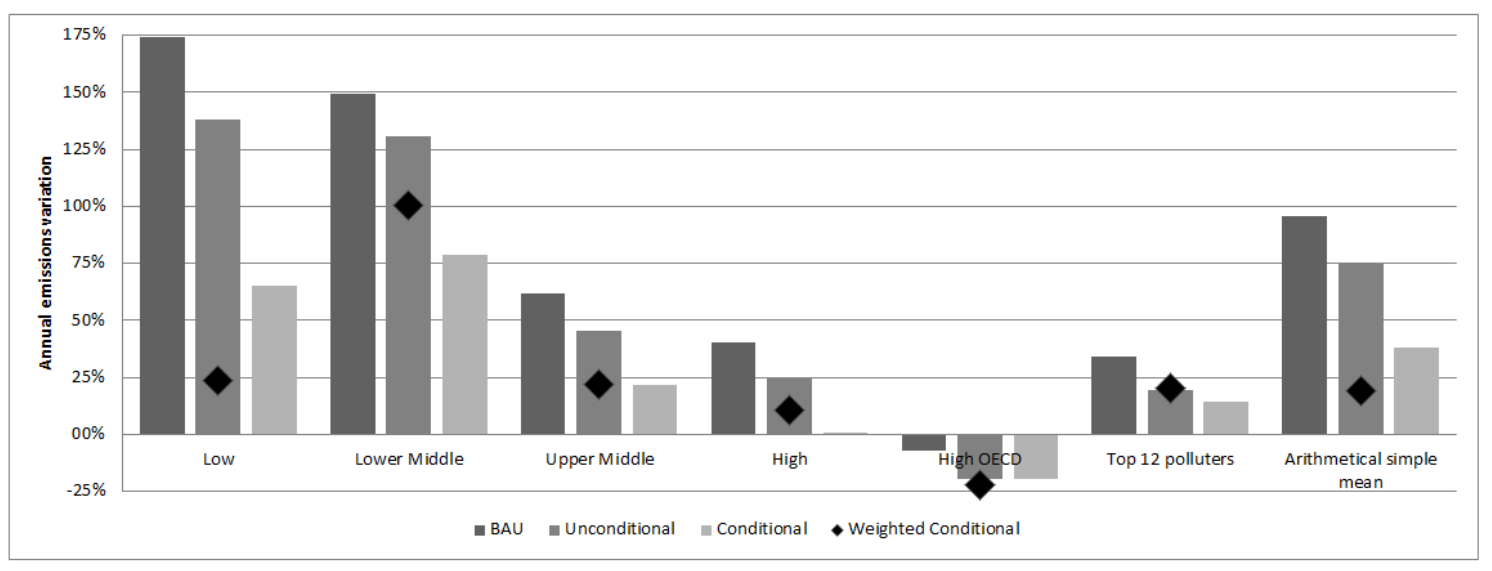

Figure 10. Emissions variations by income level and different scenarios from baseline 2005-2015 to 2030 Source: Own elaboration on the basis of the INDCs submitted to COP21.

Finally, as can be seen in Table 12, the countries that use their resources less efficiently (measured in dollars by percent unit of absolute reduction or over the BAU scenario) are LDCs ${ }^{5}$. This is due to two reasons. The first one is because they are the countries that plan to depend on greater external funding. The second one is because their mitigation policies would be more than compensated for by economic growth.

\footnotetext{
${ }^{5}$ The high index shown by the upper middle countries is due to the high inefficiency in reducing emissions of the funding used by Iran (77.3MM\$ per percent unit of reduction over the BAU scenario).
} 


\subsubsection{The Top 12 polluters pathway}

Top 12 polluters encompasses $60 \%$ of world population and $72.2 \%$ of GHG emissions. Policies and objectives established by this group will affect 6 out of 10 world inhabitants (and probably increasing as population in China, India and others do not stop rising). Regarding the information provided by Top 12 polluters can be seen (Table 11) that policies information varies amongst them, but financial information is of low quality in general. In the first place of policies these countries choose a transition towards a renewable electricity mix. In the second place in most used policies by, Top 12 polluters are the improvement in the efficiency of private vehicles $(77 \%)$.

As a result of the Top 12 policies and emissions reduction objectives, the whole Paris Agreement expected outcomes vary. In fact, when the average emissions reduction objectives are weighted by the countries contribution to GHG world emissions, the result is lower. This is because the increases in China and India (39.8\% and 232.78\%) respectively) are offset by the reduction compulsorily proposed by Annex I countries plus Brazil. Nevertheless, if just China and India are taken apart, Paris Agreement expected outcomes would be rather different. For instance, without their contribution, the emissions would decrease by $4.0 \%$ in the Conditional scenario, while they would slightly rise by $2.5 \%$ unconditionally. In other words, given the past behaviour of DCs economies, the incorporation of China and India to their consumption and production patterns would be the main reason why the Paris Agreement objectives are so difficult to achieve. Paradoxically, without the economic contribution of India (as China does not provide finance information) the allocation of resources destined to mitigation would be almost halved in terms of world GDP, dropping to $3.9 \%$.

Table 11. Overview of Top 12 polluter. Information, emissions and financial resources.

\begin{tabular}{|c|c|c|c|c|c|}
\hline & \multicolumn{3}{|c|}{$\begin{array}{c}\text { Absolute emissions variation } \\
\text { respect } 2005(\%)\end{array}$} & \multirow[t]{2}{*}{ Main policies* } & \multirow[t]{2}{*}{$\begin{array}{c}\text { Share of } \\
\text { total } \\
\text { emissions }\end{array}$} \\
\hline & $\mathbf{B A U}$ & Unc & Cond & & \\
\hline China & - & $39.8 \%$ & - & $\begin{array}{l}\text { G1, G2, G5, T1, T6, T8, T10, I3, I5, I6, } \\
\text { I7, W1, W3, A4, A5, L1, L2 }\end{array}$ & $23.9 \%$ \\
\hline U.S.A. & - & $-28.0 \%$ & - & G1, R3, T1, I8, W4 & $12.1 \%$ \\
\hline EU-28 & - & $-34.8 \%$ & - & No information. & $9.0 \%$ \\
\hline India & - & $232.8 \%$ & - & $\begin{array}{l}\text { G1, G3, G5, G6, R2, R3, T1, T4, T5, T6, } \\
\text { T7, W1, W2, W5, L2 }\end{array}$ & $5.7 \%$ \\
\hline Brazil & - & $-43.0 \%$ & - & $\mathrm{G} 1, \mathrm{G} 7, \mathrm{~T} 1, \mathrm{~T} 6, \mathrm{I} 1, \mathrm{~L} 1, \mathrm{~L} 2$ & $5.7 \%$ \\
\hline $\begin{array}{l}\text { Russian } \\
\text { Fed. }\end{array}$ & - & $10.3 \%$ & - & No information. & $5.3 \%$ \\
\hline Japan & - & $-22.7 \%$ & - & $\begin{array}{l}\text { G1, G4, R, T1, T5, T6, T7, I1, I2, W1, } \\
\text { W4, A4, L1, L2 }\end{array}$ & $2.8 \%$ \\
\hline Canada & $35.0 \%$ & $-30.0 \%$ & & No information. & $2.0 \%$ \\
\hline Congo, DR & $74.0 \%$ & $74.0 \%$ & $44.4 \%$ & $\mathrm{G} 1, \mathrm{G} 3, \mathrm{~A} 1$ & $1.5 \%$ \\
\hline Indonesia & $123.7 \%$ & $65.6 \%$ & $32.0 \%$ & $\mathrm{G} 1, \mathrm{G} 7, \mathrm{~W} 1, \mathrm{~W} 4, \mathrm{~A} 1, \mathrm{~L} 1, \mathrm{~L} 2$ & $1.5 \%$ \\
\hline
\end{tabular}




\begin{tabular}{cccclc}
$\begin{array}{c}\text { Australia } \\
\text { Korean } \\
\text { Rep. }\end{array}$ & $-51.9 \%$ & $-28.0 \%$ & - & G1, G7, T1 & $1.5 \%$ \\
\hline Total & $\mathbf{7 1 . 2 \%}$ & $\mathbf{2 6 . 3 \%}$ & $\mathbf{1 0 . 5 \%}$ & & $1.3 \%$ \\
Weighted & $\mathbf{2 4 . 5 \%}$ & $\mathbf{2 0 . 5 \%}$ & $\mathbf{1 9 . 2 \%}$ & $\mathbf{7 2 . 2 \%}$ \\
\hline \hline
\end{tabular}

Source: Own elaboration on the basis of the INDCs analysed (INDCs,2016).

*According to the code stated in Table 6.

\subsection{Economic and environmental features of INDCs}

In order to globally evaluate the INDCs, we follow the definition of Fischer-Kowalski (2011) of a socio-metabolic transition towards sustainability as that in which society does not pass the limits imposed by the biophysical system upon which it depends. To do this, it is not enough to analyse the sufficiency or insufficiency of the reduction in GHG emissions to the atmosphere. It is also necessary to evaluate the energy and material sustainability of the suggested policies to promote a socio-economic structure. Sections 2.4.1, 2.4.2, 2.4.3 and 2.4.4 contrast policies collected in the INDCs (see section 2.3.2) with the literature. Supported in this literature, we discuss the feasibility of INDCs proposed policies and its capability to jointly achieve the $2^{\circ} \mathrm{C}$ objective. Sections 2.4.5 and 2.4.6 follow up the same rationale but referring to finance (see section 2.3.3) and emissions reduction (see section 2.3.4) respectively instead of policies. The variables through which the INDCs are classified are as follows: i/ socio-economic impact of the transition; ii/ focus on energy management; iii/ substitution of non-renewable sources; iv/ the role of technology; v/ equality of the transition; vi/ degree of compliance with emission reductions.

\subsubsection{Socio-economic impact}

Although the Director of Strategies of the UNFCCC has admitted that the fight against climate change requires a "fundamental transformation in the way we use and produce energy" (Thorgeirsson, 2015), there is a generalized belief that this is consistent with maintaining the current socio-economic system (Spash, 2016).

Although numerous INDCs, such as China, appeal to economic growth and the modernization of their productive structure as a mitigation strategy, there is abundant empirical evidence of the string correlation between growth and environmental impact (de Bruyn and van der Bergh, 1998; Stern, 2004; Carpintero, 2005; Wagner, 2008; Tapia Granados, Ionides and Carpintero, 2012; Tapia-Granados J. A. and Carpintero, 2012). Far from there being a process of dematerialization associated with economic growth (Shafik, 1994) ${ }^{6}$, what has been observed is a process of environmental load displacement (Muradian, O'Connor and Martinez-Alier, 2002;

6 As established by the Environmental Kuznets Curve. 
Cole, 2004; Peng, Zhang and Sun, 2016). The transfer of "dirty" production to poor regions has been facilitated by productive specialization, commerce and international finance (Batra, Beladi and Frasca, 1998; Andersson and Lindroth, 2001; Steen-Olsen et al., 2012; Muñoz, Strohmaier and Roca, 2011). In addition, we know that both technological industry (Pellow and Park, 2002) and, in general, industrial modernization and the switch to a tertiary economy (Carpintero, 2003) are great consumers of both energy and materials.

On the other hand, numerous INDCs, of note among them being Bangladesh, Cameroon, Turkey or Morocco, express their interest in modernizing their agricultural systems, although they do not explain how this might mitigate the emissions of GHG. However, history tells us that agricultural modernization turns into a process of subordination to industry, making the former dependent on the latter and closely linked to oil products ${ }^{7}$. Thus, agriculture modernization would only result in an increase in both direct and indirect emissions. The indirect emissions are not usually assigned to agriculture, which are normally reduced to methane from livestock and the directly emitted waste. This way, the contribution of modern agriculture to climate change is often undervalued.

For all the above reasons, the link between economic growth and wellbeing, and also between growth and environmental sustainability, is weakening, as an abundant literature on ecological economics has long been stressing (Víctor, 2015; Jackson, 2011). Measures from industrial ecology approach, followed by Rwanda among others, would contribute in a more effective way to reduce environmental impacts (Ivner and Broberg, 2015; Wen and Meng, 2015; Yu, Han and Cui, 2015; Côte and Liu, 2016). Given the environmental costs of modern agriculture, it would be much more interesting to transit towards agroecology, with a similar performance for modern agriculture but with less dependence on petroleum and environmental impacts (Gliessman, 2015; Altieri, 1995; Pretty, Morison and Hine, 2003; Badgley et al., 2007; Seufert, Ramankutty and Foley, 2012). This model would be based on a proximity system of agricultural foodstuffs that would reduce the need for transport as well as a less meat intensive diet. Bhutan, for instance, advocates encouraging organic farming. China, on the other hand, advocates measures aimed at encouraging an agricultural system that adequately closes the ecological cycles, as well as reaching "zero growth" in pesticides and herbicides (intensive in petroleum use).

7 Related with its use in making pesticides and herbicides, fuel for machines and that associated with the transport needed to carry the food from where it is produced to where it is consumed (a distance that this process increases). 


\subsubsection{Demand side management policies}

With the exception of a few countries, such as Algeria, Barbados, Bhutan or Costa Rica, the majority of the INDCs assume there will be a growing demand for energy, i.e., energy demand is considered as an exogenous variable. Instead of proposing ways to reduce energy demand, beyond the general compromise with efficiency gains, the INDCs focus on changing the energy mix. However, this view would seem to ignore the energy resources we have counted on in the past and which can be counted on in the future. The development and growth of industrial society cannot be understood without the concurrence of fossil fuels and their enormous energy potential (Hall 2011; Fouquet 2016). There are, therefore, at least two factors that seriously compromise this basic assumption of the great majority of INDCs and government sources studied.

First of all, the arrival of the conventional peak oil (M K Hubbert, 1956; ASPO, 2008; IEA, 2010) has opened the door for non-conventional oil with a much lower energy performance $\left(\right.$ EROEI $\left.^{8}\right)$ (Charles A. S. Hall and Klitgaard, 2012), which are also more expensive and contaminating to extract (Heinberg, 2014). This, together with the foreseeable arrival of extraction peaks in other vitally important energy sources (Heinberg, 2007), leads us to anticipate risks for the future energy supply. Moreover, the International Energy Agency (IEA, 2016) recognized that it is not assured that investments in new oil explorations will be enough to meet demand due to high decline in output from existing fields. Secondly, if the transitions towards low-carbon economies of the INDCs are to be taken seriously, leaving a high proportion of fossil fuels underground should be mandatory (McGlade and Ekings, 2015). The substitution of the energy they provide (to say nothing of whether such provision will get larger or not) by other sources free from GHGs would seem to be complicated, if not accompanied by a reduction in energy consumption, as we shall see below.

The main hurdle to follow this path is that it implies changing consumption and production patterns by means of demand side management policies (Creutzig et al., 2016), especially in DCs and emergent countries. Nevertheless, these policies applied to agriculture, transport, buildings and other sectors show interesting results for climate change mitigation. For instance, households' food consumption has high impacts on energy consumption and direct and indirect emissions (Di Donato, Lomas and Carpintero, 2015). Therefore, changes in diets would be able to reduce by 35\% GHG emissions (Stehfest et al., 2009), but it would require a huge conversion in agro-alimentary sector. In addition, reduction of transport needs would require reorganizing the cities design once all of their infrastructures are yet installed. Finally, this reduction

${ }^{8}$ Energy returned on energy invested (EROEI) is the mean energy performance as the relation between the amount of energy obtained by each unit of energy invested in a process. 
in transport needs could need shorter commercialization channels and reducing the volume of international trade.

\subsubsection{Substitution of non-renewable energies}

On applying a management approach to the energy supply, the INDCs only consider a substitution of the current energy mix by another one with a greater renewable and/or nuclear proportion. Nevertheless, the ability to substitute one technology for another is far from being perfect.

The support or maintenance of nuclear energy is subject to limitations as far as resources goes, and this should be taken into account. If the forecast of the IEA turns out to be true, the extraction peak of uranium may well be reached in the next few decades (Zittel and Schindler, 2006). On the other hand, the substitution by biomass (in particular biofuels) is also subject to strong limitations (Patzek, 2004; Pimentel, Patzek and Cecil, 2007; de Castro et al., 2014). Due to the strong dependence of modern agriculture on fossil fuels, agrofuels present a very poor EROEI (de Castro et al., 2014). Furthermore, their cultivation enters into competition with land dedicated to food production, upon which it would exercise such pressure as to possibly result in price rises.

In addition, the electrification of the economy, even if it could be done totally through renewable sources, would not be simple at all. In this sense, there are sound arguments to sustain that renewable sources do not have sufficient capacity to replace the energy potential of fossil fuels (Hoogwijk, 2004; de Castro et al., 2011; Capellán-Pérez et al., 2014, 2015; Moriarty and Honnery, 2016). There are also rigidities in the substitution of sources due to the different uses they have. For instance, the fuel used in planes, transport and heavy industry cannot simply be substituted by electric energy. In spite of some meritorious efforts in this sense, it would seem clear that it is very difficult to consider a simple technological exchange in the energy mix if it is not accompanied by a reduction in energy consumption.

Finally, it is worth to mention that in absence of a clear policy of leaving fossil fuels underground (McGlade and Ekins, 2015), the international community could face the green paradox. As the market penetration of non-fossil sources increases, their demand would fall, leading to decrease of prices. If there is no political decision to leave fossil fuels underground, their consumption will probably be rebooted via prices incentives. So, if these circumstances are to be avoided, changing the energy mix through is not enough to address decarbonisation. 


\subsubsection{The role of technology}

The transition towards a hypocarbon model is already possible today, but it would involve a great socio-economic transformation, as stated before. Therefore, technological solutions are proposed, prominently, those referred to efficiency. These policies are the ones that have captured the most funding in recent years ${ }^{9}$ (Buchner et al., 2015) and are the preferred policies of the INDCs. Although they are destined to reducing energy consumption, the rebound effect (Carpintero, 2003; Blake, 2005; Polimeni et al., 2015) may paradoxically cause the opposite effect, since the most efficient technology reduces the price and increases consumption beyond the initial reduction.

A reflection of this point of view would be carbon capture and storage (CCS) or afforestation, which would allow the economy system to keep emitting GHGs into the atmosphere. For instance, Saudi Arabia, one of the main world oil producers, focus on capturing $\mathrm{CO}_{2}$ from their fields rather than leaving the fossil fuel underground and diversify its economy. The first of them has shown it can face up to obstacles that are difficult to overcome in order to be economically viable (Raveendran, 2013; Leung, Caramanna and Maroto-Valer, 2014). On the other hand, afforestation is another of the most widely used measures among the INDCs, especially in LDCs. However, as the forestry land competes with agriculture land, a strong increase in forested areas could push up the prices of prime materials for food and biofuels. In the best of cases, the afforestation of the most ambitious countries could offset deforestation to other countries in order to meet the farmland global requirements (Nilsson and Schopfhauser, 1995; Alig et al., 1997; Murray, McCarl and Lee, 2004; Ewers and Rodrigues, 2008; González-Eguino et al., 2017). It is, therefore, a policy that could be incompatible with the current agro-alimentary model and the promotion of biofuels, or maybe subject to filtrations that would convert afforestation into a neutral climate policy.

Although it is a critical sector (Capellán-Pérez et al., 2014), the transition towards sustainable transport is of secondary importance in the INDCs and there are serious difficulties when attempting to carry it out. As mentioned above, it would be extremely difficult to supply a growing fleet of private vehicles by substituting fossil fuels for electricity or biofuels. In addition, their deployment would enter into conflict with the availability of such materials as lithium (Ortego, Valero and Valero, 2016) and require strong institutional support for the creation of niches in the market and infrastructures. This means that the process could take decades to complete (Kemp and Schot J. y Hoogma, 1998; Fouquet, 2016). In any case, transport

\footnotetext{
${ }^{9}$ In its less conservative range (HSBC, 2014).
} 
electrification is not even a very demanded policy in INDCs, as just $13.5 \%$ chooses it. Rather, hybrid and more efficient vehicles is the most demanded transport policy amongst the INDCs.

\subsubsection{Transition equity}

Emergent medium income countries, such as China or India, interpret equity in the transition as an excuse to maintain the growth of their emissions. The return to individual, voluntary contributions agreed on in the Paris Agreement has only further contributed to sustaining this point of view. However, the obligatory nature of the transfer of resources from the DCs to the LDCs has led to the consideration of the INDCs of the DCs as adequate in terms of equity on an individual level. Nevertheless, the global view indicates a different reality, since the lack of a globally integrated agreement makes it ineffective. The measures that delve into the need to redistribute the effort are reduced to the international climate funding institutions that work through individual projects and to bilateral agreements between DCs and the rest.

The commitment achieved in the Copenhagen Agreement (renewed in Paris) to mobilize 100MM \$ annually from DCs to LDCs has not only not been kept until now, but falls far short of the needs detected in the INDCs by the LDCs. The total external support distributed between 2020 and 2030 results in the need of $160 \mathrm{MM} \$$ annually. Conversely, achieving a low-carbon energy sector will require an average of 1.2 trillion \$ in additional investments every year until 2050 (IEA 2014). However, the INDCs just compromise 286.45MM \$ annually from the total accredited investment. The comparison highlights the fact that, in the best of cases, the financial information of the INDCs is extremely deficient and that, if taken as an approximation, the Paris Agreement would be inefficient in achieving its means of implementation.

According to the Landscape of Climate Change (Buchner, 2015), the climate and development institutions only provided $26 \%$ of the funding, of which half was national, so only $13 \%$ came from bilateral and multilateral institutions. Furthermore, $74 \%$ of all climate investment (both public and private) remained in the country of origin, reaching $94 \%$ in the case of private funding. This shows that private funding tends not to have an important role in the equity of the transit. Similarly, by its very nature, and in the absence of adequate incentives, private funding is subject to the rhythms and needs of the enterprises, which has proven to be ineffective in the fight against climate change (Atteridge, 2011). However, the weight of private funding in climate policies has been constantly increasing, from 56\% of the total in 2011 to $62 \%$ in 2015 (Buchner, B., Falconer, A., Hervé-Mignucci, M., Trabacchi, C., and Brinkman, M., 2011; Buchner et al., 2015). In the light of all this, it would not seem to be a good trend for promoting equity, efficiency and multilateralism. 
The most important incentives instrument in climate funding is the Clean Development Mechanism (CDM), which is widely incorporated into the INDCs. The CDM, as described previously, which is theoretically neutral in so far as emissions reductions is concerned, could be contributing to their increase. This would be because of problems in determining additionally or the incorrect limitation in the number of years projects can last (Erickson, Lazarus and SpaldingFecher, 2014). Funding through projects is, indeed, one of the main lagoons in a global climate policy, since the climate finance institutions (GCF, GEF, etc.) finance projects and do not obey an equitable global transit strategy that can effectively reduce emissions.

\subsubsection{Compliance with the objectives of emissions reductions}

As the Non-Annex 1 countries are allowed to present their mitigation objectives on a trend scenario, the Paris Agreement ends up causing substantial increases, on a global scale, of GHG emissions. In addition, these figures are obtained on the basis of several conservative suppositions. Thus, it is considered that the reductions of the Annex I countries will be complied with and are also accounted for as BAU scenarios. In those INDCs that offer a reduction interval, they have opted for the upper bound; while, in the "Conditional" scenario, they assume that all the external funding is received. These increases in annual emissions, much higher than the planet's impact absorption capacity, would go against the principal objective of the Paris Agreement: not surpassing the $2^{\circ} \mathrm{C}$ above preindustrial levels.

Supposing that the proportion each country contributes to world emissions does not vary too much, if we take the weighted mean in each scenario, while maintaining the level reached between 2030 and 2050 constant, then the world temperature would increase by at least $3^{\circ} \mathrm{C}$ (IPCC, 2014). Even the IEA (2016) assumes increasing emissions in all their scenarios. Should annual emissions continue to increase in the same proportion, a rise of $4^{\circ} \mathrm{C}$ would be practically guaranteed. This increase would endanger humanity's essential food production and would irreversibly worsen the problems related to extreme meteorological phenomena (IPCC, 2014). Thus, we will probably see a transfer of resources from mitigation and the regular economic activities to the defensive efforts of adaptation. 
Table 12. Overview of main results (excluding policies).

\begin{tabular}{|c|c|c|c|c|c|c|c|c|c|c|c|c|}
\hline \multirow[b]{2}{*}{ Income level } & \multicolumn{2}{|c|}{$\begin{array}{c}\text { General } \\
\text { information } \\
\text { quality }\end{array}$} & \multicolumn{2}{|c|}{$\begin{array}{c}\text { Financial } \\
\text { information } \\
\text { quality }\end{array}$} & \multirow[t]{2}{*}{$\begin{array}{c}\text { Finance } \\
\text { (bs \$) }\end{array}$} & \multirow{2}{*}{$\begin{array}{c}\text { Financial } \\
\text { effort ( } \% \\
\text { over } \\
\text { GDP) } \\
\text { FINANCE }\end{array}$} & \multirow[t]{2}{*}{$\begin{array}{c}\text { External } \\
\text { financial } \\
\text { support } \\
(\%)^{*}\end{array}$} & $\mathbf{B a U}$ & \multirow[t]{2}{*}{$\begin{array}{c}\text { Conditional } \\
\text { variation } \\
\text { (respect } \\
\text { 2005-2015) }\end{array}$} & \multirow[t]{2}{*}{$\begin{array}{l}\text { Unconditional } \\
\text { Variation } \\
\text { (respect 2005- } \\
\text { 2015) }\end{array}$} & \multirow[t]{2}{*}{$\begin{array}{c}\text { Financial } \\
\text { effectiveness } \\
\text { (\$/Absolute } \\
\text { reduction) }\end{array}$} & \multirow[t]{2}{*}{$\begin{array}{c}\text { Emissions } \\
\text { share** }\end{array}$} \\
\hline & High & Low & High & Low & & & & & & & & \\
\hline Low & $30.0 \%$ & $6.7 \%$ & $26.7 \%$ & $16.7 \%$ & 625.8 & $204.6 \%$ & $87.1 \%$ & $174.3 \%$ & $65.2 \%$ & $137.9 \%$ & 15.9 & $5.2 \%$ \\
\hline Lower Middle & $22.2 \%$ & $22.2 \%$ & $20.0 \%$ & $53.3 \%$ & 2831.8 & $99.1 \%$ & $73.2 \%$ & $149.2 \%$ & $78.7 \%$ & $130.5 \%$ & 1.2 & $16.5 \%$ \\
\hline Upper Middle & $14.9 \%$ & $34.0 \%$ & $4.3 \%$ & $61.7 \%$ & 1960.7 & $69.4 \%$ & $92.7 \%$ & $61.7 \%$ & $21.8 \%$ & $45.4 \%$ & 0.7 & $37.9 \%$ \\
\hline High & $9.1 \%$ & $45.5 \%$ & $4.5 \%$ & $77.3 \%$ & 7.9 & $22.7 \%$ & $77.8 \%$ & $40.0 \%$ & $0.2 \%$ & $24.2 \%$ & 0.1 & $8.8 \%$ \\
\hline High OECD & $8.3 \%$ & $66.7 \%$ & n.d. & $100.0 \%$ & ND & ND & ND & $-7.0 \%$ & $-19.6 \%$ & $-19.6 \%$ & ND & $29.4 \%$ \\
\hline Top $12 * * *$ & $16.7 \%$ & $41.7 \%$ & $0.0 \%$ & $83.3 \%$ & 2521.6 & $89.2 \%$ & - & $34.2 \%$ & $14.0 \%$ & $19.3 \%$ & ND & $72.2 \%$ \\
\hline $\begin{array}{l}\text { Global simple } \\
\text { arithmetic mean } \\
\text { and totals }\end{array}$ & $18.5 \%$ & $29.9 \%$ & $12.7 \%$ & $31.2 \%$ & 5426.2 & $7.3 \%$ & $41.4 \%$ & $95.7 \%$ & $37.8 \%$ & $75.0 \%$ & 6.8 & $97.8 \%$ \\
\hline Weighted mean & & & & & & & & $31.5 \%$ & $19.3 \%$ & $25.8 \%$ & & \\
\hline
\end{tabular}

Own elaboration.

* The percentage represents the proportion of external resources required by those INDCs that do offer data. However, the total percentage is the total amount of external resources required by all the plans over the total financing of the all the INDCs, including those that have no breakdowns

** Share of global emissions (2012) according to EDGAR. The sum of all country groups does not account for 100\% because of discarded INDCs and non-participant countries in COP.

*** Top 12 polluter emissions variation are for base year 2005. 


\subsection{Conclusions}

The Paris Agreement sets up a landscape in which the interventions of the agents that bring about the transition will be carried out. In spite of the heterogeneity in the documentation of the INDCs, this paper proposes a classification of the characteristics of the commitments of each country. This classification and its results (summarised in Table 12) allows analysing the different patterns of national proposals and the real effectiveness of the proposed measures.

Policies show certain patterns at global level (renewable electricity mix, efficiency, afforestation, etc.), but regional distribution matters too. The non-integrated, individual, voluntary approach of the Paris Agreement, under a free trade and capital flows framework, could lead policies in one region to be offset by the dynamic response in other regions. Responsibility of climate change falls on Developed Countries (DCs) and their consumption and production patterns. However, the incorporation of China and India to these patterns, sometimes in order to satisfy DCs demand through environmental load displacement, hinders the accomplishment of Paris Agreement even more. As long as the socioeconomic system remains unchanged, the objective of the Paris Agreement would have to face numerous challenges like these.

Another difficulty facing the full compliance of the INDCs is the voluntary nature of their commitment and the non-existence of any control, monitoring and penalization system. In addition, the low quality and scarce clarity of information provided concerning these individual commitments (only $18.5 \%$ provide good information on policies and emissions and $12.7 \%$ on finance) contributes to worsening difficulties for any kind of follow-up. What is more, the "Conditional" compliance of the INDCs is subject to the receipt, on the part of LDCs, of external funding that represents $41.4 \%$ of the total funding. Not only this, but the channelling of this funding (external and internal) through a model based on individual projects, carbon markets (through the $\mathrm{CDM}$ ) and their growing dependence on private initiative, make for an uncertain future panorama. Ultimately, after burying the Kyoto Protocol and the questionable results from the Copenhagen Agreement (2009), the renunciation of an integrated, global model in the Paris Agreement seems to lead to expected results that will be weak. In addition, geographical, institutional and biophysical constraints matter, dynamically adjusting the consequences of policies submitted. Further climate agreements should take this into consideration in order to achieve effective results.

Thus, from the detailed review of the INDCs, it can be concluded that, in the best of cases, annual world emissions would increase by around $19.3 \%$ in 2030 with respect to the base interval (2005-2015). Even so, this supposes a reduction in comparison with the $31.5 \%$ increase projected by the BAU scenario in which no measures are taken. Should this level remain constant between 
2030 and 2050, the world temperature would increase by at least $3^{\circ} \mathrm{C}$ (IPCC, 2014). Should annual emissions continue to increase in the same proportion, an increase of $4^{\circ} \mathrm{C}$ would practically be assured. Adaptation of natural and economic systems to climate change will thus have to be addressed in the near future. 


\section{Macroeconomic modelling under energy constraints: Global low carbon transition scenarios ${ }^{10}$.}

\subsection{Introduction}

Climate change is rapidly moving from being a potential, abstract threat to becoming a harmful reality. As a result, transitions towards sustainability, or low-carbon transitions, have emerged with a broadening body of literature (Markaard, Raven and Truffer, 2012). We define a low-carbon transition as the process aimed at a shift in the energy resources ant technologies that a society relies upon in order to achieve a state where zero or low carbon emissions are required to sustain the socioeconomic system (i.e. a low-carbon economy). Moreover, the international community is attempting to cope with climate change through different Conferences of Parties (COPs). The most relevant conference in recent years was COP21, where the Paris Agreement was signed. This agreement established as its main objective to "hold the increase in the global average temperature to well below $2^{\circ} \mathrm{C}$ above pre-industrial levels". Despite the Intergovernmental Panel on Climate Change (IPCC) stating that, in order to avoid surpassing the $2^{\circ} \mathrm{C}$ threshold, carbon emissions would have to be reduced between $41 \%$ and $72 \%$ by 2050 with respect to 2010 (IPCC, 2014), the Paris Agreement commitments deliver net increases, until at least (Rogelj et al., 2016; Raftery et al., 2017; Nieto, Carpintero and Miguel, 2018). Given the close relationship between emissions and energy consumption, any assessment of the economy's capacity to meet climate goals requires strong Energy-Economy-Environment (EEE) models, within the broader definition of Integrated Assessment Models (IAMs). Nevertheless, the concept of limits is rarely considered by either policy-makers or academic IAMs. Furthermore, ecological economics states that there are biophysical boundaries that the economy cannot exceed (Daly, 1968; Costanza, 1989, 1991; Farley and Daly, 2003). The analysis of Integrated Assessment Models (IAMs) is often split into two different approaches concerning the common features of how they characterize the economy, namely: optimization and simulation models (Scrieciu, Rezai and Mechler, 2013).

On the one hand, optimization models tend to use neoclassical production functions standard Constant Elasticity of Substitution (CES) functions- that assume perfect substitutability of productive factors, that markets clear and that a general equilibrium is reached. Optimization models assume well-behaved markets, coordinated via prices, and being the main driver of

${ }^{10}$ This chapter has been accepted for publication in Energy Policy on $1^{\text {st }}$ of November 2019, as Nieto, J., Carpintero, Ó., Miguel, L. J., de Blas, I. 'Macroeconomic modelling under energy constraints: Global low carbon transition scenarios’, Energy Policy. In press. doi: 10.1016/j.enpol.2019.111090. 
technological change and the focus of macroeconomic policies (e.g. carbon prices). Due to the usual convergence to markets equilibrium in these models, computable general equilibrium (CGE) models are the most representative amongst optimization model. Although they sometimes allow for multiple inferior equilibriums, their optimal growth (Sterman et al., 2012) path enforcing convergence towards full employment lead to superior equilibriums. However, despite their common use, these models have been widely criticised for not being grounded in the complex and dynamic reality.

On the other hand, simulation models rely on a different approach. The main contribution of simulation models is that they describe EEE relationships in a way that allow the propagation of disturbances into the system to be examined and the outcomes of the different policies to be evaluated. Simulation models do not optimize i.e. do not follow an optimum path, implying that markets do not necessarily clear, i.e. are in equilibrium. They conduct observation-based economic interactions modelling and provide more freedom to assess different phenomena (Scrieciu, Rezai and Mechler, 2013). Simulation models are often policy evaluation models and are not prescriptive as optimization ones are. Policies are not only market-driven, so institutions play an important role in policies definition. They pay special attention to income distribution and demand-led growth (as opposed as supply-driven in optimization models). Demand-led models are commonly sustained in Keynesian or post-Keynesian economics assuming disequilibrium, meaning non-clearing markets, demand-led growth although subject to certain supply constraints (Lavoie, 2014; Taylor, Rezai and Foley, 2016). As simulation fits better with dynamic modelling and disequilibrium economics, a number of models have been grounded on these approaches. Some examples are the non-equilibrium E3MG model (Pollit, 2014), ICAM (Dowlatabadi, 1998), GTEM (Kemfert, 2005), AIM (Kainuma, 2003; Morita et al., 2003; Masui et al., 2006) and IMAGE (Alcamo, Leemans and Kreileman, 1998; Bouwman, Kram and Goldewijk, 2006; Stehfest et al., 2014).

Nevertheless, a common weakness in both simulation and optimization models comes from the lack of integration between the economy and the biophysical system. In principle, the energy-economy nexus is not well developed, assuming a simple linear positive relationship between them. In a nutshell, exogenous economic growth boosts energy demand, which is in turn supplied by a changing energy mix. At best, this linear relationship is nuanced by energy efficiency gains, but its positive slope normally remains unchanged. Consequently, policy-makers are usually advised to focus on a mere technological transition towards a renewable energy mix, regardless of energy demand. Moreover, to our knowledge, most conventional models assume high degree of energy substitutability between energy technologies and resources, implicitly leaving energy availability unattended. This, together with the weak integration between the economy and the environment, lead these models to produce stable, gradual transitions pathways. 
In addition, the economy is usually pictured as a monolithic energy-consuming machine, ignoring its complex sectoral structure and highly disaggregated decision-making. Although it is well known that energy resources are the key factor in low-carbon transitions, plans and international agreements do not usually take into consideration the aforementioned biophysical limits; something which could challenge their feasibility (McGlade and Ekins, 2015; Moriarty and Honnery, 2016; Spash, 2016; Nieto, Carpintero and Miguel, 2018). Therefore, in this paper, we argue that IAMs might be undervaluing the supply constraints of energy resources and the importance of the economic structure in low-carbon transitions.

To check this hypothesis, we have developed a model capable of overcoming these limitations. This model is the economy module of a broader system dynamics model named MEDEAS (Capellán-Pérez et al., 2017). The feedback-rich structure of system dynamics (SD) allows the model to consider energy limits. The best known contribution to simulation models was the pioneering World3 system dynamics (SD) model of Limits to Growth (Meadows et al.,, 1974; Meadows and Randers, 2013). Moreover, the economy module described in this article captures the economic structure through Input-Output analysis (IOA). Despite the existence of dynamic IO models, IOA has been criticised for assuming a fixed underlying technology, represented by the technical coefficients matrix. As the MEDEAS approach is grounded in SD and its scenario-based perspective, it can be adapted to a dynamic view. In addition, theoretical and policy-making implications for economic growth, energy availability and low-carbon transitions are also discussed. The article is structured as follows: section 3.2 sets up the theoretical framework of the methodology used; section 3.3 describes the functioning of the economic model developed; then, in section 3.4, the most relevant results are set out, according to the Business as usual, Green-growth and Post-growth scenarios; finally, section 3.5 summarises the main concluding remarks of the study.

\subsection{Theoretical framework: limits, economic structure and system dynamics}

The literature on sustainability transitions has been receiving increased interest from both scholars and policy makers consistent with the onset of the most visible impacts due to climate change (Markaard, Raven and Truffer, 2012). This body of literature, has been typically focused on sociotechnical change, innovation, agents' interrelations at different levels and increasingly on the metabolic structure of societies (Geels, 2002, 2011; Fischer-Kowalski and Haberl, 2007; Haberl et al., 2011). Sustainability transitions, as understood by the socio-metabolic approach, are characterised by the transformation of the current energy regime to a different one which does not surpass biophysical boundaries (M Fischer-Kowalski, 2011). In other words, as stated by Raworth (2018), there is an environmental ceiling which the economy cannot breach, as well as a social floor. Between these boundaries, environmental and social sustainability should meet. 
These approaches connect with the tradition of ecological economics. Interaction between the economy and the environment, as understood by ecological economics, points out the subordination of the former to the limits imposed by the latter (Daly, 1968; Costanza, 1989, 1991; Farley and Daly, 2003). Concretely, as stated by Georgescu-Roegen(1971), according to the first and second principles of thermodynamics, the economy would be subject to irreversibility. This means that the entropic nature of the economic process degrades the amount and quality of energy resources and thus that economic growth, or even the steady-state, are limited by energy availability. Consequently, economic models should consider these limits to achieve a better understanding of the economic process (Georgescu-Roegen, 1975).

As stated before, system dynamics (SD) proves to be an adequate methodology for capturing these relationships, but it is also a relevant tool for economic analysis (Radzicki and Tauheed, 2009). Although it has typically been used by heterodox economists (Radzicki, 2009), it has recently even been extended to neoclassical models (Režný and Bureš, 2018). However, due to its features and functionalities, not assuming an a priori equilibrium, this technique has been much more attractive to the heterodox economists than to the neoclassical economists (Peter A Victor and Rosenbluth, 2007; Briens, 2015; Bernardo and D'Alessandro, 2016; Cordier et al., 2017). System dynamics was originated in control engineering and automation to determine a structure with different, interrelated input and output flows to fill or drain (respectively) different stocks. Two variables connected by a causal link, can change in the same direction (positive relationship) or in opposite directions (negative relationship). In a positive -or reinforcingfeedback loop, the growth of the first variable causes the growth of the second variable, but also the growth of the second variable causes the growth of the first variable. In a traditional predatorprey model with a lack of predators, a positive feedback loop emerges as the prey's population growth lead to an increase in births, in a self-reinforcing process. This would turn the system unstable unless a limiting factor is applied, creating a negative feedback loop, e.g. the introduction of more predators in the ecosystem. Therefore, the main advantage of SD is its capability to include feedbacks, which allows non-linear relationships between variables, better capturing realworld systems. Figure 11 shows a general simplification of the stock-flow feedback structure of SD. 


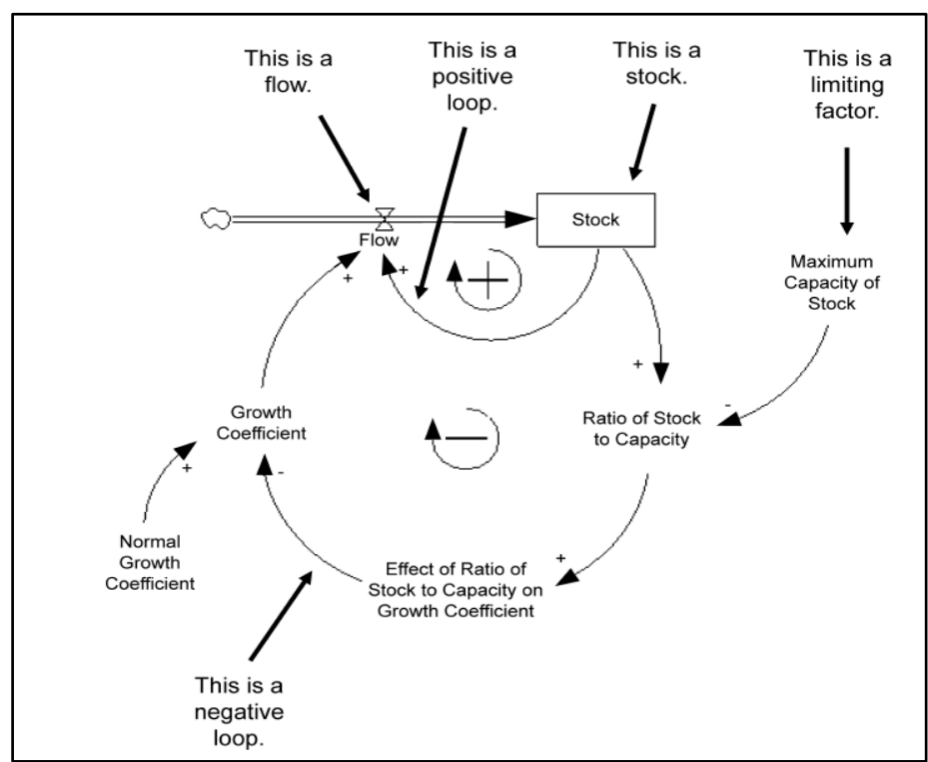

Figure 11. General overview of system dynamics structure based on stocks, flows and feedbacks. Source: Radzicky (2009).

The traditional (and widely spread among IAMs) energy-economy nexus, pictures a simple, one-way relationship whereby GDP growth leads to energy use mediated by energy intensity (Stern, 2011; Charles A S Hall and Klitgaard, 2012; Foxon, 2017). Accordingly, the greater economic growth desired, the more energy is required to satisfy it (linear, positive relationship). However, if energy limits are to be considered, a better representation would be that of Figure 12. GDP growth takes energy demand, which could be lowered by improving energy efficiency. In turn, primary energy reserves must be extracted and transformed into the final energy supply in order to meet this demand. As long as the energy needed to keep the GDP growing at a certain rate is satisfied by the energy supply, the relationship would still be positive. On the contrary, a restrained availability would force GDP growth down from its initial requirements. Therefore, a negative loop would have been established in the energy-economy nexus. In order to avoid such a situation, either an increase in primary energy production (extracting non-renewable energy resources (NRER) or installing new renewable energy source (RER) infrastructures) or a reduction in energy requirements (via efficiency gains or reducing GDP growth), or a combination of both, would be required. The first procedure alone would have to face NRER depletion and growing greenhouse gas emissions, as well as increasingly growth rates for the installation of RER infrastructures. The second procedure's main challenge would be to achieve net reductions in energy requirements, in such a way that GDP growth would not offset efficiency gains; otherwise, GDP would decline progressively, causing socioeconomic adversity as welfare relies on GDP. Thus, the economic process would be tied to energy constraints within a negative loop, leading to a non-linear relationship. Hence, Figure 12 shows the simplified theoretical SD structure of such an energy-economy feedback, whose concrete structure in our model is carefully explained in section 3.3. This forms the cornerstone of the 
MEDEAS-World model (Capellán-Pérez et al., 2017) and is, in particular, the economy module's main contribution.

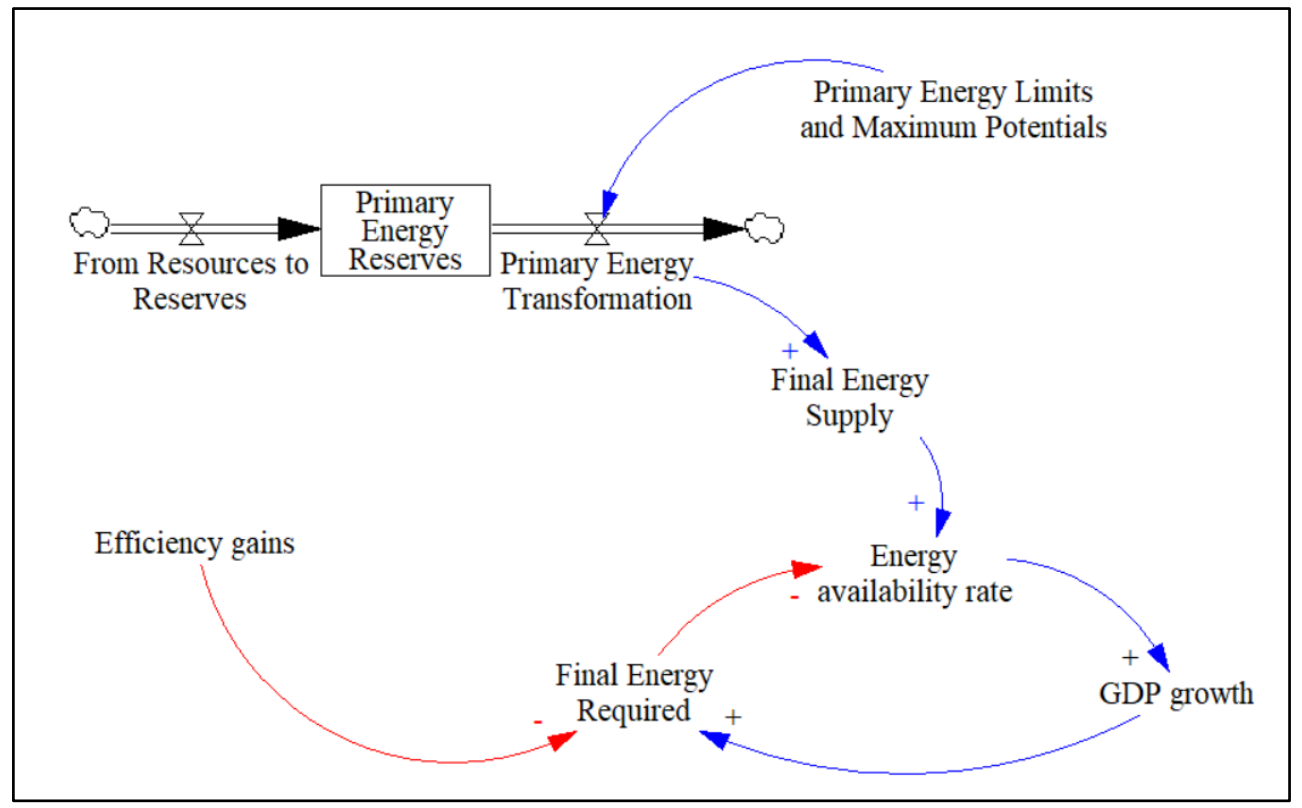

Figure 12. Negative feedback loop between GDP growth and energy availability.

Source: own elaboration.

The relevance of SD for capturing these kinds of relationship is highlighted by the remarkable success of Limits to Growth (Meadows, 1972), in estimating the fundamental tendencies of its key variables (Bardi, 2011; Meadows and Randers, 2013). Hence, the main advantage of system dynamics modelling consists of its capability to capture the complexity of systems, path-dependency across time and feedbacks (Uehara, Nagase and Wakeland, 2013; Capellán-Pérez, 2016). Nevertheless, correctly specifying the energy-economy nexus is of the utmost importance in order to improve the significance of the outcomes (Capellán-Pérez et al., 2015; Palmer, 2018). Despite this, there is still discussion on whether the sustainability transition would trigger a new era of 'green-growth' (Bowen and Hepburn, 2012; Kander and Stern, 2014; Csereklyei and Stern, 2015) or, conversely, would require a 'post-growth' approach involving degrowth or a steady-state economy (Daly, 1973; Kerschner, 2010; Jackson, 2011; Dietz and O’Neill, 2013; D'Alisa, Kallis and Federico, 2014; Lange, 2018).

Should the energy-economy linkage not be considered in the model, the economy would implicitly not be represented as subject to biophysical constraints. At best, the model's results could only be restrained to show a growing gap between energy demand and supply, suggesting instability for the economic system (Capellán-Pérez et al., 2015). Whereas mainstream economic theories argue that disequilibrium will be corrected via prices; quantities adjustment, put forward by the Keynesian tradition, is a more convenient approach given the biophysical nature of the MEDEAS model. Nevertheless, prices are still implicit in the model, embedded in the deflated 
monetary values (see section 3.3.1.3). Although scholars are increasingly coping with energy limits, only slight absolute or relative decreases in economic output are being reported (Kiuila, 2018; Režný and Bureš, 2018). Furthermore, these models and others might be overestimating the economy's capacity to keep growing under energy constraints. Arguably, their economic production supply approach, basically relying on capital and labour stock, might result in the partial irrelevance of energy constraints, as long as the growth in production factors offsets the effects of a scarcity of resources.

Recently, ecological macroeconomic models have gone one step further, introducing inequality, work patterns, economic structure and even a post-growth approach (Rezai and Stagl, 2016; Hardt and O'Neill, 2017). Supply limits are widely included, but often related to the effects of capital and labour supply on investment and employment, respectively. Environmental constraints generally appear as natural capital depletion (Bernardo and D'Alessandro, 2014; Fontana and Sawyer, 2016a). Other research, such as that of Taylor, Rezai and Foley(2016), establishes that climate change would undermine investment and thus, economic growth. Nevertheless, it concludes that mitigation policies can stabilise climate with a cost not higher than $1 \%$ of global GDP. Finally, models using Input-Output analysis (IOA) allow the relevance of economic structure in EEE interactions to be captured (James, Jansen and Opschoor, 1978; De Haan, 2001).

A combination of system dynamics and IOA provides significant results, as in Briens (2015), where an Input-Output-based system dynamics model is used to impose a degrowth scenario through different policies. IOA offers two main advantages against other methodologies. First, considering complementarity instead of perfect substitution better reflects the real performance of the productive process (Georgescu-Roegen, 1971; Stern, 1997; Farley and Daly, 2003; D’Alessandro, Luzzati and Morroni, 2010). Second, capturing both direct and indirect effects of a variation in final demand on sectoral production delivers more accurate monetary outcomes, as well as the energy carriers of production (Leontief, 1970; Miller and Blair, 2009). Despite the undeniable relevance of economic structure, models often forecast huge economic and technological transformations, maintaining it unaltered. For instance, we can expect different results from the current economic structure than those obtained after a transition where fossil fuel refineries are no longer as important as they are nowadays. For this reason, technical coefficients vary along time according to scenarios (see Appendix 2.B). 


\subsection{Modelling a feasible world economy. Methodology}

MEDEAS-World is a global model in which the world is considered as one region within the IO framework, i.e. trade flows are disregarded. This global region is the result of the aggregation of 39 countries and a Rest of the World region (see section 3.3.1.3.). It is a simulation model, based on system dynamics (SD), built on different modules that are shown in Figure 13 (Capellán-Pérez et al., 2017). The validation of the models has been carried out following several of the usual validation procedures of models in system dynamics (Barlas, 1996; Sterman, 2000). Following them, "structure validity", "extreme-condition", "behaviour-sensitivity", "boundaryadequacy", "dimensional consistency" and "behaviour-reproduction" tests have been carried out. Sensitivity analysis has also been applied to the variables subject to more uncertainty of the model. The historical data, although the available series are short, has been used for a first validation. Subsequently, the models have been subjected to a robustness test. Sensitivity analysis have been made and results compared with other models.

Considering that the purpose of this paper is to evaluate the economy module, only relevant connections with it are described. Concisely, economic output requires a certain level of energy demand and this is compared with energy supply availability. So, the energy and the economy module are two-way integrated through energy demand and energy availability. Final energy demand is the main result of the combination of the economy and energy module's operations and the most relevant link with the rest of the model. The economy module's outputs are: energy demand, direct and indirect (the land use required) $\mathrm{CO}_{2}$ emissions, materials demand (through the demand of new energy infrastructures) and other social and environmental impacts.

The main feedbacks to the economy module from the rest of the model, apart from exogenous variations described later, are delivered by the climate change impacts (CC damage function), (EROEI) and the energy supply availability. Figure 16 shows the simplified influences diagram of the economy module, illustrating the main relationship between the variables. For the sake of simplicity, in this paper, only energy-related feedbacks are activated. Thus, there is no influence of the climate change damage function in our results. The MEDEAS-World model considers 35 different industries (see Appendix 2.A.), as the main source for IOA is the World Input-Output Database (WIOD) (Dietzenbacher et al., 2013). The WIOD was selected because of its public data, its environmental accounts (Genty, 2012), especially regarding energy, and its socio-economic accounts (Timmer et al., 2015). Despite the significant sectoral disaggregation, energy-related sectors do not differentiate between energy types. For instance, sector 2 (Quarry and Minery) include indistinctly non-energy and energy-related materials; sector 8 (Coke oven, Refined petroleum and Nuclear fuel) as well as sector 17 (Electricity, Gas and Water supply) include several final energy use types. All sectors have been taken as energy-demanding including 
the energy-related ones and therefore, energy supply is estimated in the energy module according to the final energy requirements of all sectors. All the same can be applied to materials.

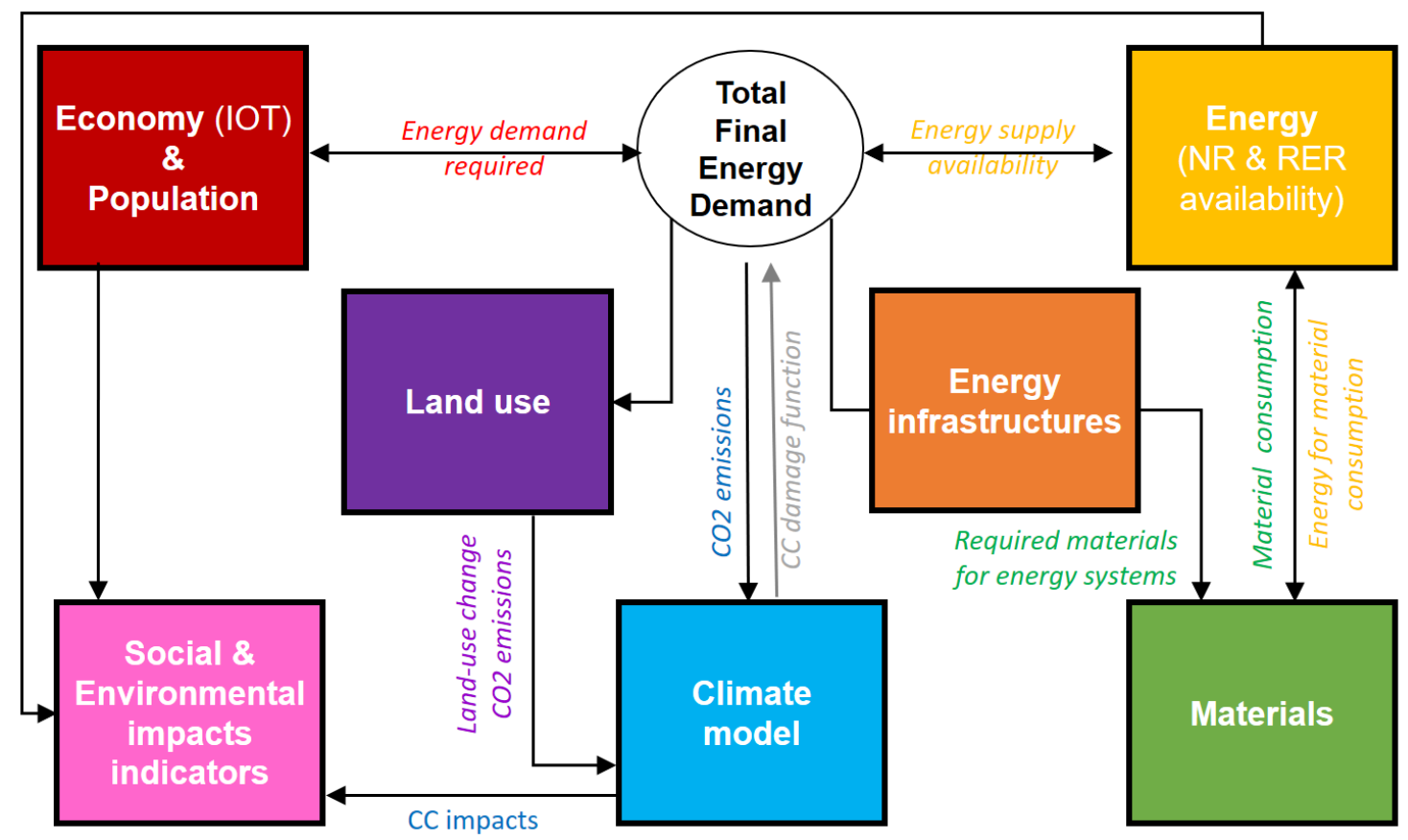

Figure 13- MEDEAS-World model schematic overview. Source: (Capellán-Pérez et al., 2017)

Before going into the economy module's particulars, it is worth giving an overall view of how the whole MEDEAS world model functions. The different module functionalities are the following (see in brackets the corresponding section in Capellán-Perez et al. (2017) where further information can be found):

3.1. Economy (IOT) \& Population (Economy module): through hybrid (i.e. combining monetary and physical units, see sections 3.3.1.3 and 3.3.1.4) Input-Output Analysis, the final energy demand by industries and the final end-use energy carriers are estimated. Subsequently, it will be referred as final energy demand and supply when not mentioning different end-use energy carriers [section 2.2 in Capellán-Perez et al. (2017)]

3.2. Energy (NR \& RER availability) (Energy module): this includes the renewable (RER) and non-renewable energy (NRER) resource potentials and availability, taking into account biophysical and temporal constraints. In total, 5 final end-use energy carriers are considered (electricity, heat, solids, gases and liquids) and a diversity of energy technologies are modelled. The energy module provides the net final energy supply which, in turn, constrains the final energy use by the economy. This energy-economy feedback is not often taken into consideration in the literature, which could lead models to unfeasible results. [section 2.3 in Capellán-Perez et al. (2017)] 
3.3. Energy infrastructures module: this estimates the infrastructure deployment of power plants to generate electricity and heat. [section 2.3 in Capellán-Pérez et al. (2017)]

3.4. Materials module: materials required by the economy, and especially for the construction of energy infrastructures, are tracked by MEDEAS. [section 2.4 in Capellán-Pérez et al. (2017)]

3.5. Climate module: this projects the GHG emissions of the system, which could also be fed back through a damage function. However, as mentioned above, this feedback has been deactivated for the purpose of this work and is shown in grey in Figure 13. [section 2.5 in Capellán-Pérez et al. (2017)]

3.6. Land use module: land-use requirements of the RER are accounted in the land-use module. [section 2.6 in Capellán-Pérez et al. (2017)]

3.7. Social and environmental impacts indicators: this module collects the main outcomes regarding impacts in these two areas. [section 2.7 in Capellán-Pérez et al. (2017)]

\subsubsection{The economy module}

The MEDEAS-World economy module's general structure could be summarised in a sequential way as shown in Figure 14; whereas a more detailed, simplified influence diagram can be seen in Figure 16. Likewise, Appendix 2.D shows the system dynamics structure of the model in several views, as depicted in the software employed. The economy module is sectorally disaggregated by 35 industries (see Appendix 2.A.), is demand-driven and subject to energy feedbacks. Basically, exogenous final demand growth is imposed by scenarios regarding population and GDP per capita growth. Then, along with income share scenarios, the adequate inputs are delivered to feed the sectoral final demand function, which distributes this growth amongst industries. Once the variation of the sectoral final demand is known, Input-Output Analysis (IOA) obtains the output required by each industry to satisfy it. As energy is needed to produce economic output, energy coefficients (namely, sectoral final energy intensities) permit the model to obtain the final energy required (by energy source) to produce the sectoral output. Both final energy intensities and economic structure, represented by the A matrix (see section 3.3.1.3), evolve during the simulation period according to their historical trends and scenario assumptions. Depending on the final energy of each type needed for the economy to grow at a predetermined rate, the energy module (influenced by the others) computes ways to deliver. Primary energy must be extracted and transformed, new infrastructures might have to be deployed, and materials must be extracted and processed to fulfil this commitment. Therefore, taking into account NRER depletion curves, EROEI, RER potential and growing installed capacity, the energy module delivers the final energy availability. After that, final energy demand and final energy supply are compared, providing the model with the feasible production and, in 
turn, feasible final demand, by inversely applying IOA. Therefore, although energy and economic demand begin the simulation as being completely exogenous, they become endogenous as soon as energy scarcity appears.

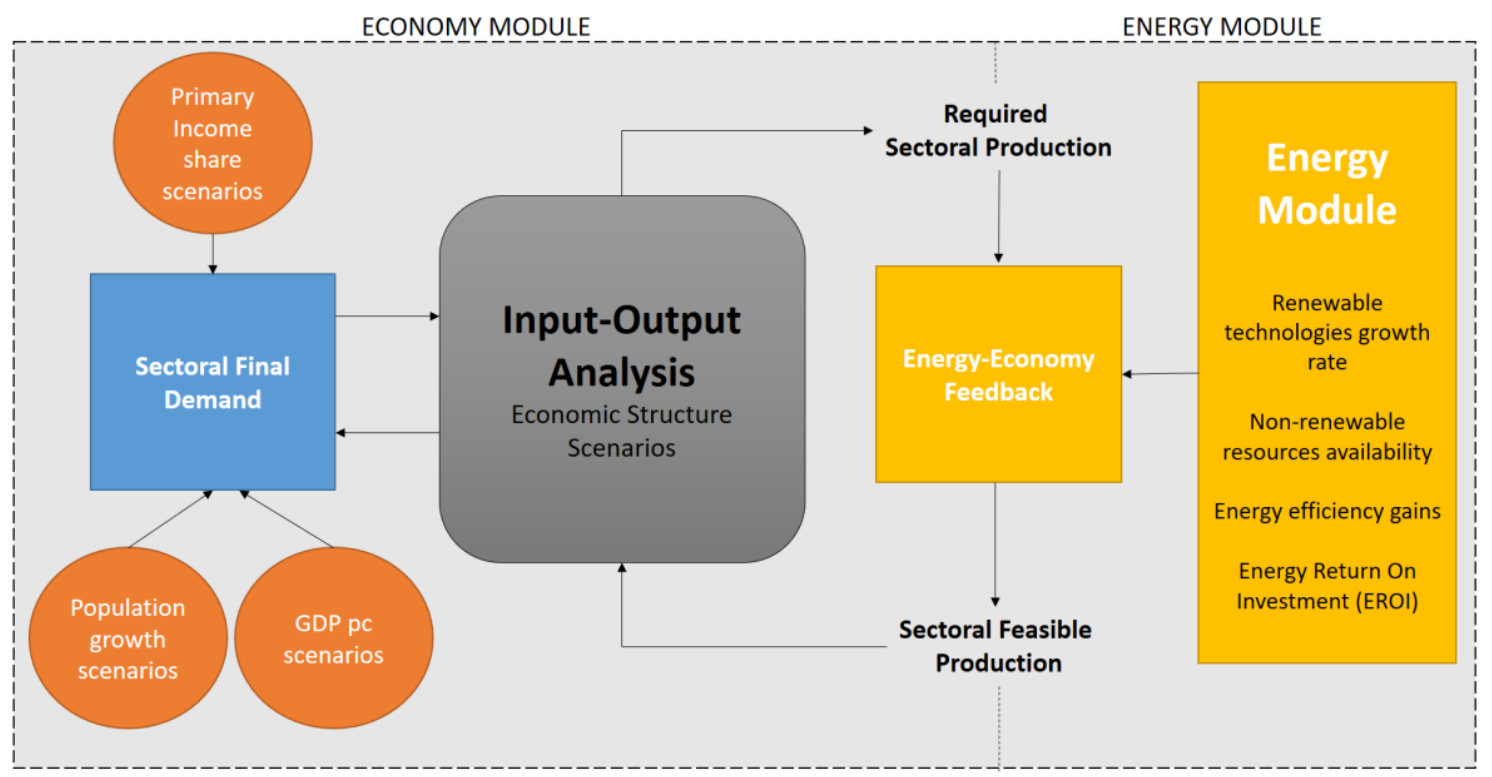

Figure 14. Economy module structure and main energy inputs. Source: own elaboration.

\subsubsection{Primary Income}

As mentioned before, the economy module is demand-driven. An exogenous final demand variation via Gross Domestic Product per capita (GDPpc) is forced into the system regarding past trends and scenario storylines. Given that population growth is also determined exogenously, total expected GDP growth is easily calculated by multiplying GDPpc and population. Labour and capital compensation (wages and gross profits respectively), i.e. primary income, is estimated by the model because it is the main input to final demand functions -in households' consumption and gross fixed capital formation-, as described in section 3.3.1.2. For this reason, primary income share (the proportion represented by each primary income category over GDP) scenarios have been established according to their characteristics (see section 3.4). Then, labour and capital compensation is obtained by multiplying GDP by these exogenous income shares. Let $l a b$ and cap be labour and capital compensation respectively. Then, $\alpha_{\text {lab }}=$ $\frac{\mathrm{lab}}{\mathrm{GDP}}$ and $\alpha_{\mathrm{cap}}=\frac{\mathrm{cap}}{\mathrm{GDP}}$ stand for each primary income share. They gradually evolve from their initial observed value until they reach each scenario target value. Therefore, by multiplying GDP by $\alpha_{\text {lab }}$ and $\alpha_{\text {cap }}$, we obtain the primary income lab and cap. Hereafter, primary income distribution -that will be noted indistinctly as income distribution- operates as an input for sectoral final demand functions. 


\subsubsection{Final demand}

After the previously explained economy-wide variation in final demand is estimated, final demand is distributed among industries. For this purpose, a sectoral final demand function has been estimated by institutional sectors running panel data regressions, taking income as the main explanatory variable. All regressions are corrected for autocorrelation, heterokedasticity and contemporary correlation depending on the case, while Eq. 1 defines the components of the sectoral final demand function:

$$
\mathrm{fd}=\mathrm{c}+\mathrm{gfcf}+\mathrm{ge}+\text { invent }
$$

Eq. 1

Where fd is the $35 \times 1$ vector of final demand formed by its vector components such as $\mathrm{c}$, thehouseholds and non-profit organisations serving household consumption, gf cf is gross fixed capital formation, ge is government expenditure and invent is changes in inventories and valuables. Following the conditions imposed by the database used, gfcf measures the investments made by each institutional sector in durable products produced by industry ' $i$ '. For this reason, considering that almost half of investments are concentrated in the construction sector and the significant weight of households in construction investment, gfcf_18 (i.e. gross fixed capital formation in the construction sector, number 18 in Appendix 2.A) has been modelled separately due to its particularities (a high proportion of households' investment). Likewise, ge is relatively autonomous or, at best, inversely linked to the economic cycle. Even in this case, nothing can ensure that ge will perform in this way, as it basically depends on policy choices. Because of this, ge by industries is exogenously considered the proportion of each industry's final demand -e.g. $66 \%$ in Education or $4.5 \%$ in Inland transport- of the last available historical observation. The same approach has been followed to include invent because of its residual weight in total final demand. Eq. 2-Eq. 4 collect the main structure of each sectoral final demand disregarding vector notation.

$$
\begin{aligned}
& \ln (c)=\beta_{0}+\beta_{1 i} \operatorname{Sec}_{i}+\beta_{2} \ln (\operatorname{Lab}) \quad \mathrm{i} \in\{1, \ldots, 35\} \quad \text { Eq. } 2 \\
& \ln (\boldsymbol{g} \boldsymbol{f} \boldsymbol{c f})=\boldsymbol{\beta}_{\mathbf{0}}+\boldsymbol{\beta}_{1 i} \boldsymbol{S e c}_{\boldsymbol{i}}+\boldsymbol{\beta}_{\mathbf{2}} \ln (\boldsymbol{C a p}) \mathrm{i} \in\{1, \ldots, 17 \cap 19, \ldots, 35\} \quad \text { Eq. } 3 \\
& \ln \left(g f c f_{-} 18\right)=\beta_{0}+\beta_{1} \ln (L a b)+\beta_{2} \ln (\text { Cap }) . \quad \text { Eq. } 4
\end{aligned}
$$

where $\beta_{0}$ is the intercept of each function, $\beta_{1 i}$ is the sectoral intercept that captures the structural effects of sectoral distribution in panel data regressions, $\operatorname{Sec}_{i}$ is a dichotomous variable with value 1 when forecasting the actual sector and 0 otherwise. Lab stands for labour compensation (wages) and Cap for capital compensation (gross profits), while $\beta_{2}$ stands for the coefficients multiplying the explanatory variables. Subscript i indicates the different industries. Although the literature usually takes interest rates as an explanatory variable, there are difficulties 
to estimate a global interest rate, which leads us not to include it in our world model. The literature also suggests that the effects of real interest rates differ radically between regions (Hein and Ochsen, 2003); are not clear (Lavoie, 1995, 2014); or are even non-significant (Stockhammer, Onaran and Ederer, 2009). All the institutional sectors' final demand rely on income: con wages, $g f f$ on gross profits and $g f c f_{\_} 18$ on both primary income components, given the abovementioned particularities. Therefore, sectoral final demand is a function of economic structure and income.

\subsubsection{Input-Output Analysis}

Once the first economy-wide variation in final demand is distributed among the 35 industries, Input-Output Analysis allows the production required to satisfy each industry's demand (Miller and Blair, 2009) to be calculated. The WIOD database includes 41countries (including OECD countries, other major economies and a Rest of the World region) containing the whole world economy. Nonetheless, because MEDEAS takes the world as one economy with no international trade, all countries have been collapsed into just one. Furthermore, original IOT series in previous year prices have been translated into a World IOT in chained, linked volumes with a mobile base year.

Figure 15 indicates that intermediate consumption are the trade flows between sectors that simultaneously behave as sellers (subscript ' $i$ ' in rows) and purchasers (subscript ' $j$ ' in columns) $\left(z_{i j}\right)$. This delivers a squared matrix with 35 different industries (see Appendix 2.A). Total Gross Value Added (GVA) equals total Final Demand (fd), and therefore total GDP. Production can be measured demand-side as the sales of sector ' $i$ ' plus the final demand of products and services from sector ' $\mathrm{i}$ ' or supply-side as the sum of total intermediate products purchases of sector ' $\mathrm{j}$ ' from the rest of sectors ' $\mathrm{i}$ ' plus the GVA (lab and cap) generated in this sector ' $\mathrm{j}$ '. This supply-side view is crucial to understand the structural relationships between industries, i.e., the amount of inputs from each industry needed by others to produce 1 unit of product. 


\begin{tabular}{|c|c|c|c|c|c|c|}
\hline \multicolumn{3}{|c|}{ Intermediate Demand } & \multicolumn{3}{|c|}{ Final Demand } & \\
\hline$z_{1,1}$ & $Z_{1}, \ldots$ & $z_{1, n}$ & $f d_{1,1}$ & $f d_{1, . .}$ & $f d_{1, n}$ & $x_{1}$ \\
\hline$Z_{\ldots, 1}$ & $Z_{\ldots, \ldots}$ & $Z_{\ldots, n}$ & $f d_{\ldots, 1}$ & $f d_{\ldots, .}$ & $f d_{\ldots, n}$ & $x_{\ldots}$ \\
\hline$z_{n, 1}$ & $z_{n, \ldots}$ & $z_{n, n}$ & $f d_{n, 1}$ & $f d_{n, \ldots}$ & $f d_{i, n}$ & $x_{n}$ \\
\hline$G V A_{1}$ & $G V A_{\ldots}$ & $G V A_{n}$ & & & & \\
\hline$x_{1}$ & $x_{\ldots}$ & $x_{n}$ & & & & \\
\hline
\end{tabular}

\begin{tabular}{|c|c|c|}
\hline $\begin{array}{l}\text { Intermediate } \\
\text { Demand }\end{array}$ & $\begin{array}{l}\text { Final } \\
\text { Demand }\end{array}$ & \\
\hline$z_{i, j}$ & $f d_{i}$ & $x_{i}$ \\
\hline$G V A_{j}$ & & \\
\hline$x_{j}$ & & \\
\hline
\end{tabular}

Figure 15. From interregional Input-Output tables (IOT) to a World IOT. Source: own elaboration

Regional disaggregation. $z_{1, n}$ : intermediate consumption from region 1 to region $\mathrm{n} ; f d_{1, n}$ : final demand of products and services from region 1 made by region $\mathrm{n} ; x_{n}$ : production in region $\mathrm{n} ; G V A_{n}$ : gross value added in region $\mathrm{n}$. Sectoral disaggregation: represented in the One Region IOT. $z_{i, j}$ refers the sales from sector ' $\mathrm{i}$ ' (rows) purchased by sector ' $\mathrm{j}$ ' (columns). Gross Value Added is measured by columns ' $\mathrm{j}$ ' and $x_{i}=x_{j}$ representing that all the production responds to demand requirements (demand not satisfied is measured as Changes in inventories).

Thus, technical coefficients measure the fixed complementary relationship between inputs and outputs according to Eq. 5:

$$
a_{i j}=\frac{z_{i j}}{x_{j}} \quad \quad \mathrm{i}, \mathrm{j} \in\{1, \ldots, 35\}
$$

Eq. 5

where $a_{i j}$ is the technical coefficient of sector i over sector $\mathbf{j}$. Let us denote $\mathbf{A}$ as the squared technical coefficients matrix including all $a_{i j}$ and $\mathbf{Z}$ the squared matrix of intermediate consumption including all $z_{i j}$. Finally $\hat{\mathbf{x}}$ is the diagonal matrix of sectoral production. Hence, in matrix notation, $\mathbf{A}=\left[a_{i j}\right]=\mathbf{Z} \hat{\mathbf{x}}^{-1}$ and thus $\mathbf{Z}=\mathbf{A} \hat{\mathbf{x}}$. As said before, from a demand point of view, production is the sum of intermediate consumption and final demand. In matrix notation $\mathrm{x}=Z+$ $f d$ being ' $\mathrm{x}$ ' the column vector of sectoral production and ' $\mathrm{fd}$ ' the final demand vector, therefore.

$$
\begin{aligned}
& \mathbf{x}==(\mathbf{I}-\mathbf{A})^{-1} \cdot \boldsymbol{f d} \\
& \mathbf{x}=\mathbf{L} \cdot \mathbf{f d}
\end{aligned}
$$

Eq. 8

where $(\mathbf{I}-\mathbf{A})^{-1}=\mathbf{L}=\left[l_{\mathrm{ij}}\right]$ is the so-called Leontief inverse, reflecting the elasticity of production ( $\mathbf{x})$ to changes in final demand (fd). In other words, it measures how production reacts to satisfy a variation in final demand, so sectoral production is obtained through IOA in MEDEAS. Considering that static technical coefficients would not be a reasonable assumption 
for such a long simulation period encompassing structural change, the A Matrix evolves according to tendencies and scenarios. The evolution of the A matrix is set to begin by 2020 and to finish as soon as either the consistency condition is met $^{11}$, or the simulation period reaches 2050 . Table 13 shows each scenario assumption and Appendix 2.B shows the different target matrices towards which the original A matrix evolves.

\subsubsection{Energy-Economy Feedback}

Most EEE models take economic growth as given within a certain exogenous growth rate, which also drives energy demand. Therefore, economic and energy demand show a positive slope, occasionally nuanced by efficiency gains in the case of energy (a kind of relative decoupling between them). In addition, energy demand is always met by energy supply and the only problem to be solved is the energy mix which defines the said supply. In the MEDEAS world model, the economy receives a feedback from the energy system so, if the energy supply is not enough to meet the demand, economic output must be reduced. It is important to recall that, although energy stock (reserves for NRER and energy potentials for RER) naturally determines its feasible amount, it is the energy supply flow and not the stock which has to match the final energy demand flow for each period. This means that the extraction, processing and distribution for NRER and infrastructure deployment, as well as the generation and distribution for RER, are the activities that deliver the final energy supply flow. This means that energy scarcity can surge, even if energy reserves and potentials are still available to transform into final energy (see Figure 18). Because this flow is determined by the energy infrastructures deployed in past periods, the system's capability to fully satisfy the economy's demand is path-dependent.

In the previous section, how the production required to satisfy demand by sectors was calculated. After that the hybrid Input-Output analysis with energy intensities (e) as the energy coefficients is conducted. Being $\widehat{\mathbf{f e d}}^{k j}=\left[\mathbf{f e d}_{\mathbf{k j}}\right]$ the $35 \times 35$ diagonal matrix of final energy demand by 5 final end-use energy carriers ' $k$ ' and 35 sectors ' $\mathrm{j}$ ', the $175 \times 175$ diagonal matrix of total final energy demand ( $\widehat{\text { ed }})$ is

$$
\widehat{\mathbf{f e d}}=\left[\begin{array}{ccc}
\widehat{\mathbf{f e d}}^{11} & \mathbf{0} & \mathbf{0} \\
\mathbf{0} & \ddots & \mathbf{0} \\
\mathbf{0} & \mathbf{0} & \widehat{\mathbf{f e d}}^{\mathrm{kj}}
\end{array}\right] ; \mathrm{k} \in\{1, \ldots, 5\} ; \mathrm{j} \in\{1, \ldots, 35\}
$$

${ }^{11}$ According to Input-Output Table accounting balances, the column sum of technical coefficients $(\mu)$ must be lower than 1 , where $(1-\mu)$ is the share of value added in sectoral production. Given that certain sectoral structural coherence must be maintained, each sector's technical coefficients stop evolving as soon as $(1-\mu)$ becomes one third of its original value. 
The same structure could be applied to energy intensities, so we have the $\hat{\mathbf{e}}^{\mathbf{k j}}$ diagonal matrix of diagonal matrices of each sectoral final end-use energy carrier. Then, $\hat{\mathbf{x}}^{-1}$ is the diagonal matrix of sectoral production, according to Eqs. 9-10:

$$
\begin{aligned}
& \widehat{\mathbf{e}}^{\mathbf{k j}}=\widehat{\mathbf{f e d}}^{\mathbf{k j}} \cdot \hat{\mathbf{x}}^{-1}=\left(\begin{array}{ccc}
\frac{f e d_{11}}{x_{1}} & 0 & 0 \\
0 & \ddots & 0 \\
0 & 0 & \frac{f e d_{k j}}{x_{j}}
\end{array}\right)=\left(\begin{array}{ccc}
e_{11} & 0 & 0 \\
0 & \ddots & 0 \\
0 & 0 & e_{k j}
\end{array}\right) \quad \text { Eq.9 } \\
& f \mathbf{e d}^{\mathrm{kj}}=\hat{\mathbf{e}}^{\mathrm{kj}} \cdot \mathbf{x}+\overline{\mathrm{hh}}^{\mathrm{kj}} \cdot \mathbf{c}=\hat{\mathbf{e}}^{\mathrm{kj}} \cdot \mathbf{L} \cdot \mathbf{f d}+{\overline{h h_{-}}}^{\mathrm{kj}} \cdot \mathbf{c}
\end{aligned}
$$

Thus, the module uses an identity (Eq. 9) to estimate the final energy demand by sector $\mathrm{j}$ and source $\mathrm{k}\left(\mathbf{f e d}^{\mathbf{k j}}\right)$. The final energy demand would be the result (Eq.10) of multiplying sectoral energy intensities $\left(\hat{\mathbf{e}}^{\mathbf{k j}}\right)$ by production $(\mathbf{x}=\mathbf{L} \cdot \mathbf{f d})$ plus the $35 \times 35$ households energy intensities by resource and sector diagonal matrix ( $\widehat{\mathbf{h h}}_{\mathbf{e}} \mathbf{e}^{\mathbf{k j}}$ ) multiplied by households' consumption (c). Appendix 2.C describes how to estimate separately the direct and indirect effects of the final energy demand, which do not correspond to the two different components in Eq.10. Then, the model checks whether the total energy demand by resource $\left(\mathbf{t f e d}=\left[\operatorname{tfed}_{k}\right]=\sum_{\mathbf{j}=1}^{35} f e d_{k j}\right)$ is higher or lower than the final energy supply by end-use carrier (tfes $=\left[t f e s_{k}\right]$ ). Consequently, Eq. 11 shows how feasible energy demand $\left(\mathbf{f}_{-} \mathbf{f} \mathbf{e d}^{\mathbf{k j}}\right)$ is calculated:

$$
\mathbf{f}_{-} \mathbf{f e d}^{\mathbf{k j}}=\mathbf{f e d}^{\mathbf{k j}} \cdot \varepsilon ; \quad \varepsilon=\operatorname{Min}\left(1, \frac{\mathrm{tfes}}{\mathrm{tfed}}\right) . \quad 0<\varepsilon>1
$$

with $\varepsilon$ as a shortage coefficient valued as being 1 when tfes $\geq \mathrm{tfed}$, and thus no energy constraints, and the quotient between them otherwise. As there is no assumption of perfect substitutability in either economic or energy inputs, the type of energy which is lacking in a higher proportion (i.e., the minimum quotient in Eq.11) determines the shortage coefficient. Moreover, for the sake of simplicity, it has been considered that economic output decreases proportionally amongst industries in the case that shortages appear. Thus, feasible sectoral energy demand imposes a new sectoral feasible output which, by taking it instead of the required output, and rearranging Eq. 10, we have:

$$
f_{-} \mathrm{x}=\mathrm{e}^{-1} \cdot \mathrm{f}_{-} \mathrm{fed} \mathrm{dj}^{\mathrm{k}}
$$

Finally, introducing Eq. 11 into Eq. 12:

$$
f_{-} x=e^{-1} \cdot f e d^{k j} \cdot \operatorname{Min}\left(1, \frac{t f e s}{t f e d}\right)
$$

Therefore, economic output is a function of energy intensity (negative effect), energy demand and energy supply when $\mathbf{t f e s}<\mathbf{t f e d}$. Moreover, considering that energy demand stands 
for Eq. 10, the economic output would also, indirectly, be a function of economic structure and final demand. Lastly, conducting an inverse IOA, final demand satisfied by feasible output is obtained-solving Eq. 7 for $\mathbf{f d}$ instead of $\mathbf{x}$ - delivering the feasible final demand.

Energy constraints do not have to be seen as a literal shortage, such as, for instance, gasoline running out in petrol stations. Conversely, as long as it takes energy to produce economic output, it should be seen as limiting the economy's maximum potential. Considering this outcome, as total final demand equals total GDP in the world economy, income in the subsequent years is obtained by multiplying this figure by labour and capital shares. Hence, income becomes endogenous as soon as energy scarcity appears. This approach raises the question of economic growth feasibility under biophysical (energy) constraints. Regarding the importance of energy supply to determine economic output, a brief overview of the energy module is provided below. In order to evaluate how sensitive the results are to this energy-economy feedback, it can be deactivated by disregarding geological limits.

\subsubsection{Energy Module}

Energy availability is the main output of the Energy module; it is the core, most developed and complex module in MEDEAS. In order to fully understand its internal rationale and concrete mechanisms, it would be advisable to see the model's technical report (Capellán-Pérez et al., 2017), where it is thoroughly described in section 2.3. Nonetheless, for the sake of simplicity, the essentials for understanding its relationships with the Economy module are briefly noted. Basically, the Economy module demands a certain volume of each final end-use energy carrier from the energy system, which in turn delivers the energy available to satisfy it. The main processes which take place in the Energy module refer to the installed capacity of renewable energy, the availability of non-renewable energy resources, the energy efficiency gains and the EROEI. Basically, RER installed capacity and NRE availability are estimated according to different scenarios based on literature, and regarding different technologies and primary resources, respectively. The literature used for this purpose is shown in Table 13 in section 3.4. The maximum extraction curves impose a limit to yearly NRER extraction, which endogenously evolve in a path-dependent way since they are bounded to the extraction in precedent years and therefore, to final energy demand. Moreover, given the high uncertainty involving the extraction curves, the 'Middle' and 'Best Guess' options have been selected in order to avoid extreme, unrealistic outcomes. In fact, the results shown in this article compare the situation regarding and disregarding energy limits. More information and a thorough literature review on depletion curves can be found in section 2.3.3 in Capellán-Pérez et al. (2017). The selection of renewable energies starts from the historical evolution data and establishes the maximum values of annual growth. These values can be modified by the user of the model. Demand drives the development of new 
infrastructures (power plants). The distribution of the power plants among the different options is currently chosen based on the EROEI, and taking into account other restrictions. The choice of EROEI as a criterion is based on the need to optimize the total consumption of energy in a scenario of limited energy resources. Section 2.4.5. in Capellán-Pérez et al. (2017) provides more insights on this. Also, de Castro et al. (2019) discusses further on that, as well as on the role of EROEI in MEDEAS model. Moreover, given the inertia and rigidities in the productive processes highly dependent on natural resources, adjustments are typically produced with quantity changes (instead of prices, i.e. costs), as post-Keynesian approaches have highlighted (Lavoie, 2014). Sectoral final energy intensities have been estimated for each scenario as well, with particular regard to the transport sectors. Finally, as long as the system transits to a different energy mix, the higher (lesser) EROEI provided by the actual technologies and resources, the lesser (higher) installed capacity will be required to satisfy the same amount of energy demand (i.e., if EROEI declines, an additional $1 \%$ of energy demand would take more than an additional $1 \%$ of energy capacity installed). 


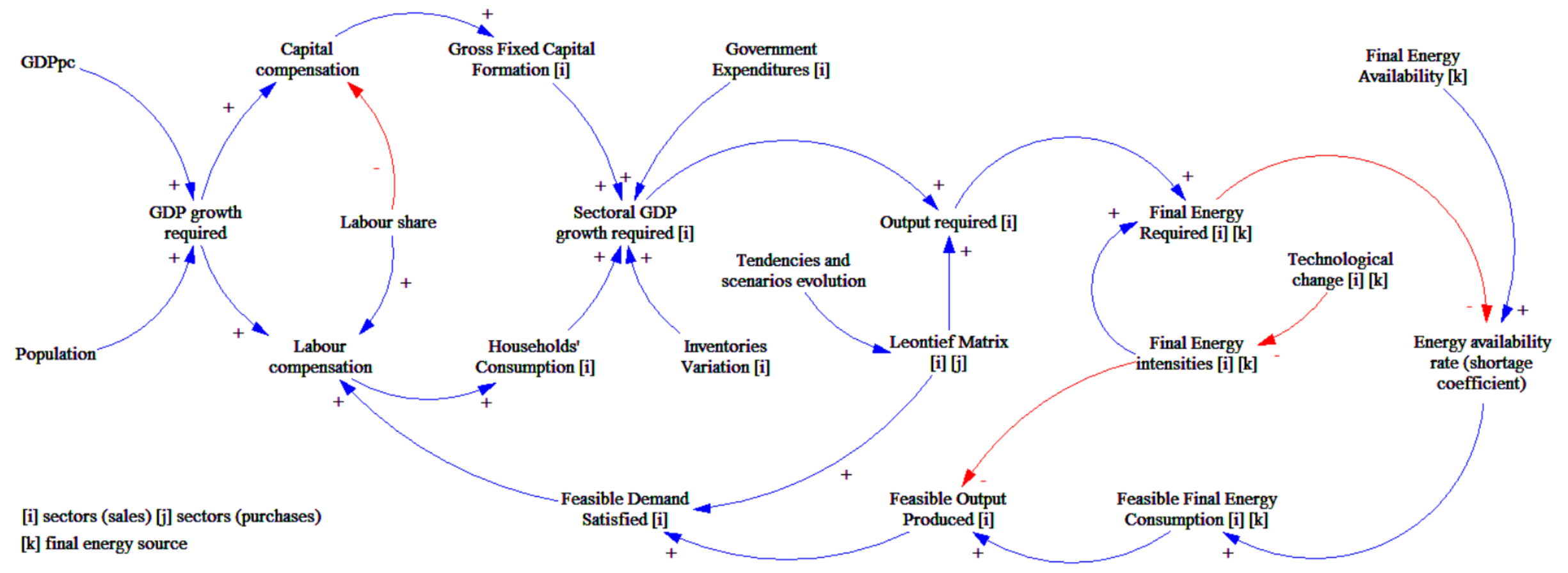

Figure 16. Simplified influence diagram of the Economy module.

Source: own elaboration. Red arrows imply negative relationship between variables; Blue arrows, a positive relationship. 


\subsection{Low-carbon economies coping with the limits. Results.}

The transition towards low-carbon economies needs the implementation of policies, time to fully deploy them, and an economic system to support them. The combination of these elements shapes different scenarios for the most likely future landscape. The most relevant results from scenarios, in terms of climate and economic policy, can be represented by emissions and GDP growth (see section 3.4.1), as described below. Furthermore, economic structural change is evaluated in section 3.4.2.

In this article, we have considered three different scenarios, following specific storylines and the extended simulation period until 2050. The Business as Usual (BAU) scenario basically provides the model with inputs based on current trends and no further policies to meet climate goals.

Conversely, the Green Growth (GG) scenario storyline states the deployment of a technology-based set of policies aimed at achieving the climate goals (i.e., the $2^{\circ} \mathrm{C}$ Paris Agreement objective) boosted by economic growth (Bowen and Hepburn, 2012; Kander and Stern, 2014; Csereklyei and Stern, 2015). According to the key assumptions in the different 'scenarios families' given by van Vuuren et al. (2012), this scenario would be consistent with the SSP1 narrative. This implies relatively low population growth rates, high economic expectation (Expected GDPpc growth), high increase in energy efficiency and transition policies towards a renewable energy mix. Higher GDPpc growth rates are grounded on high development expectations for the Low and Medium Income countries and medium expectations for the High Income Countries. Since the Paris Agreement can be described as following a green growth approach (Nieto et al., 2018; Spash, 2016), its policies could be considered the foundation of this scenario. These policies can be summarised as a common objective to electrify the economy, being complemented by a general switch to RER in the electricity energy mix, although including nuclear energy. In addition, policies are aimed at fostering bioenergy and energy efficiency gains, especially in the transport sector. Finally, the general spirit of the policies aims to achieve all these goals with a so-called 'inclusive economic growth'. According to this, inequality would increase across and within countries, so income distribution in this scenarios tends to increase the labour share. The more or less explicit objective is to undertake a modernisation process widely based on the path previously followed by developed countries, but including a technology-based transition to RER. Because of this, the A matrix, as a representation of the underlying technological structure, smoothly evolves towards Denmark's figures, as a developed European country highly committed to sustainability. 
Lastly, we propose a third Post-Growth (PG) scenario. There is no explicit consensus on what a Post-Growth scenario means on the literature, but a well-known set of policies can be identified in ecological macroeconomics models (Hardt and O’Neil, 2018) as well as some assumptions that can be linked to a 'Regional Sustainable Development' narrative (van Vuuren et al., 2012). Because GDP growth is ruled out as the most important policy objective, economic growth slowly declines whereas other policy objectives are being pursued. This way, medium population growth along with the possibility of rapid technological change and proactive environmental protection, as well as a reduction of income inequality are applied to this scenario. Therefore, we implement a planned degrowth in the GDPpc targets, and income distribution leans towards labour compensation more than in GG. Likewise, the economic structure (represented by the A Matrix) changes favouring (penalising) the less (most) energy intensive sectors (see Appendix 2.B and section 3.4.2).

This approach is based on the procedures used by Leontief and Duchin (1986), whereby expected reductions or increases in relative demand for sectoral productive processes are represented by changing A matrix rows (i.e., sales proportion over each sector's output). Regarding energy, the figures are comparable to those in the GG scenario, but with reduced bioenergy growth to reduce competition pressures with other land uses and the phasing-out of nuclear energy in order to reduce as much as possible the NRER requirements. Assumptions regarding RER energy potentials and NRER depletion curves have been made for all the scenarios. The most relevant exogenous inputs regarding these scenarios are summarised in Table 13 The main results, according to these scenarios, are shown thereafter.

Table 13. Overview of the most relevant scenario inputs.

\begin{tabular}{|c|c|c|c|c|}
\hline Variable & $\begin{array}{l}\text { Business } \\
\text { as Usual }\end{array}$ & $\begin{array}{l}\text { Green } \\
\text { Growth }\end{array}$ & $\begin{array}{l}\text { Post- } \\
\text { Growth }\end{array}$ & All Scenarios \\
\hline \multicolumn{5}{|l|}{ SOCIOECONOMIC } \\
\hline GDP pc growth * & $1.42 \%$ & $2.55 \%$ & $-0.67 \%$ & \\
\hline Population growth * & $0.72 \%$ & $0.61 \%$ & $0.76 \%$ & \\
\hline $\begin{array}{lll}\text { Target } & \text { labour } & \text { share } \\
(2050) & & \end{array}$ & $52 \%$ & $60 \%$ & $65 \%$ & \\
\hline Target A matrix (2050) ** & $\begin{array}{l}\text { Historical } \\
\text { evolution }\end{array}$ & $\begin{array}{l}2009 \\
\text { Denmark } \\
\text { IOT }\end{array}$ & $\begin{array}{l}\text { Non } \\
\text { energy- } \\
\text { intensive }\end{array}$ & \\
\hline $\begin{array}{ll}\text { Phase-out oil for } \\
\text { electricity and heat? }\end{array}$ & No & Yes & Yes & \\
\hline $\begin{array}{l}\text { Energy efficiency gains } \\
\text { (max. yearly growth) }\end{array}$ & $1 \%$ & $1.5 \%$ & $1.5 \%$ & \\
\hline $\begin{array}{l}\text { Afforestation } \\
\text { programme? }\end{array}$ & No & Yes & Yes & \\
\hline Nuclear installed capacity & Constant & Growth & Phase-out & \\
\hline
\end{tabular}




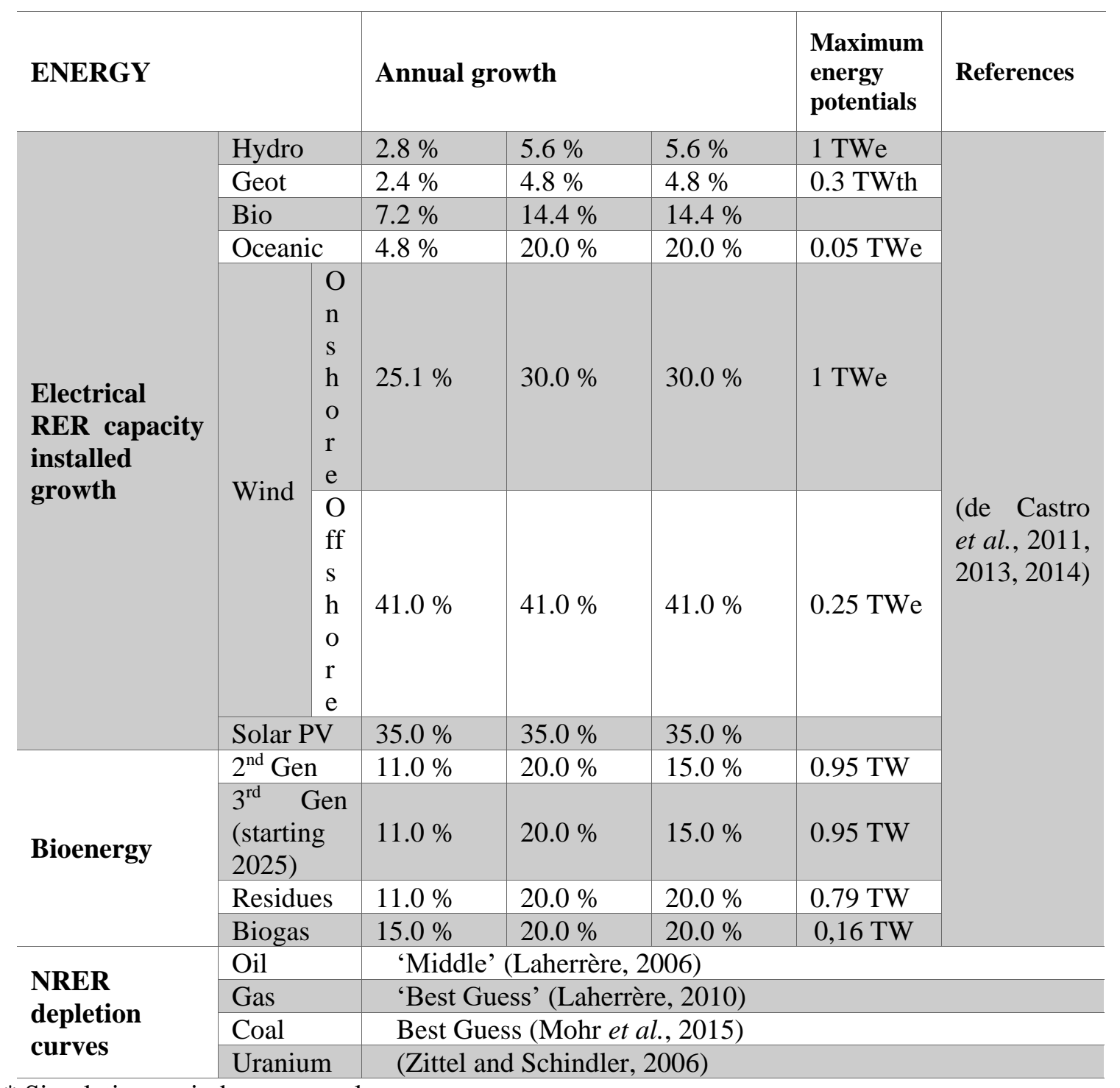

* Simulation period average value.

** See Appendix 2.B. Target matrices

Source: own elaboration.

Although the scenario design is partially based on qualitative assumptions from the literature (O'Neill et al., 2017; Riahi et al., 2017), the BAU can be summarised as a projection of current trends and Post-growth as a scenario not often considered in the literature; while Green Growth is the most akin to its homologous version in the literature (i.e., SSP2 from IPCC).

\subsubsection{Emissions and GDP growth under energy constraints}

The variation in emissions has been estimated up to 2030 and 2050, as the former is the reference year for the Paris Agreement and the latter is the reference year for the IPCC reports. The base year is the average emissions from 2005-2015, since the Paris Agreement commitments (more than 160 INDCs) vary their base year within the mentioned range. Moreover, in order to evaluate the relevance of including energy limits, results have been assessed both considering (labelled as 'Limits' in graphs) and disregarding energy limits (labelled as 'No limits'). The 
difference between both assumptions is operated by activating or deactivating geological limits. Figure 17 shows emission outcomes by scenarios. Firstly, it does not matter whether we assume energy limits or not in the no policies scenario (BAU), as it dramatically fails to achieve climate goals. In this respect, the green growth scenario (GG) outcomes are substantially different if we activate the energy-economy feedback, i.e. geological limits are enabled, at least by 2050 . Should the economy be able to take as much energy as needed regardless of its availability, emissions would even change their sign as compared to the same scenario when the energy-economy feedback is considered. There are no evident differences by $2030(\approx+14 \%)$, as no significant energy shortages appear until afterwards that date.

However, by 2050, if the economy finds no obstacles in its consumption of as much energy as required to grow at a certain rate, emissions would rise by 51\%. As stated in Eq.10, energy demand depends upon GDP growth, energy intensities (both sectoral and household) and economic structure (represented by the Leontief matrix). Whereas energy intensities and the economic structure are increasingly efficient ${ }^{12}$ reducing the restraining effect of energy the higher GDP growth (see Table 13) expands final energy demand, eventually offsetting the efficiency gains and leading to energy scarcity as well. As a consequence, GDP growth is also hampered, although later than in BAU (Figure 18). On account of this rebound effect in the GG scenario, the energy system needs to draw on NRER for a longer period, even considering the high rate at which RER infrastructures are deployed (see Table 13). Conversely, as soon as energy limits are taken into account, results vary substantially. As can be seen in Figure 17, emissions fall by around $16 \%$, although still far from meeting IPCC goals to avoid a $2^{\circ} \mathrm{C}$ increase ( $-41 \%$ to $\left.-72 \%\right)$. Contrary to the previous case, the final energy demand is not always satisfied, resulting in lower energy consumption and hence lower emissions. In addition to NRER exhaustion, as RER infrastructures gain momentum in the energy mix, the system's EROEI declines. Subsequently, a higher installed capacity for the same energy demand is required. To sum up, a relatively high GDP growth forces energy demand up, offsetting efficiency gains and a more efficient economic structure. Because the final energy supply flow is not able to meet the final energy demand, energy consumption is lower, leading to better climate outcomes. In other words, emissions are reduced at the cost of depleting energy resources.

\footnotetext{
${ }^{12}$ Producing the same amount of economic output allows a higher value added (GDP) to be obtained or, conversely: in order to obtain the same GDP, less production is required. See Appendix 2.B. Target matrices for the World model. (Target matrices).
} 


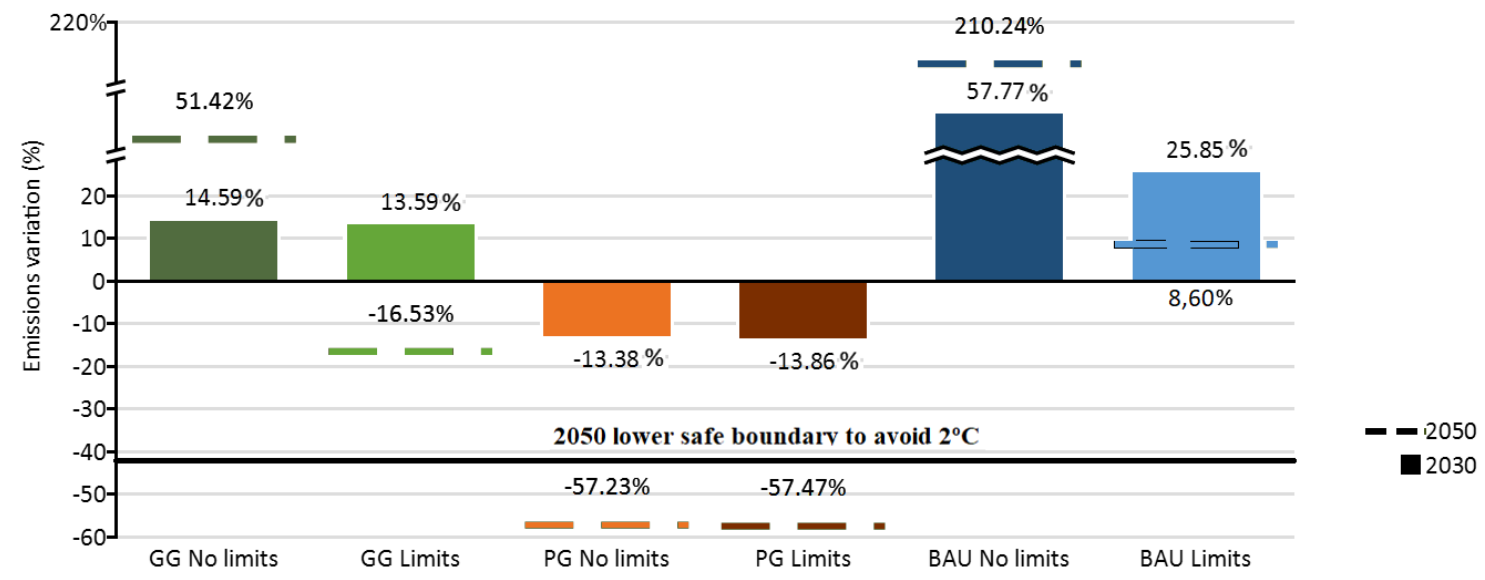

Figure 17. Emissions change by scenarios. From 2005-2015 mean to 2030 and 2050.

GG: Green Growth scenario; PG: Post-Growth scenario; BAU: Business as Usual scenario. Source: Own elaboration on the basis of MEDEAS World results.

Alternatively, the post-growth (PG) scenario remains entirely below the $2^{\circ} \mathrm{C}$ threshold in both cases $(\approx-57 \%)$. As verified by the GG scenario, a huge drop in energy intensities and a more efficient economic structure is not enough to downsize final energy demand. To overcome this hurdle, the PG scenario drops energy intensities just the same, but estimates a different, more efficient A matrix and a declining GDP growth (see Table 13 and Appendix 2.B for target matrices). To summarise, different outcomes amongst scenarios, especially between the GG and PG scenarios and the no policy scenario (BAU), are widely explained by the RER increase in the energy mix and the phasing-out of petroleum for heat and electricity. However, differences between GG and PG are mostly socioeconomic, reflected by different economic growth efforts, sectoral economic structures and functional income distribution.

Figure 18 shows the different outcomes for GDP growth regarding the figures in Table 13. The darker lines show exogenous GDP growth scenarios, i.e., disregarding the energyeconomy feedback ('No Limits') and the lighter ones the results once the energy-economy feedback is activated ('Limits'). MEDEAS follows a metabolic approach whereby biophysical requirements are needed for throughput. Therefore, if higher energy supply is required for the expected GDP growth rate, then the economy will be able to grow lower than expected. As a consequence, in the absence of any further energy transition policies (BAU), the economy might stagnate within the next decade and start a sustained downsizing afterwards. As there is no phasing-out of oil for heat and electricity, the liquid energy potential could fail to meet the economic system's demand even at an early stage, leading to the collapse of economic output. Since there are no policies aimed at actively improving energy efficiency or changing the energy mix, economic growth is not able to recover during the simulation, as it faces subsequent resources scarcities -specially solids (coal)- after the initial liquids shortage. 


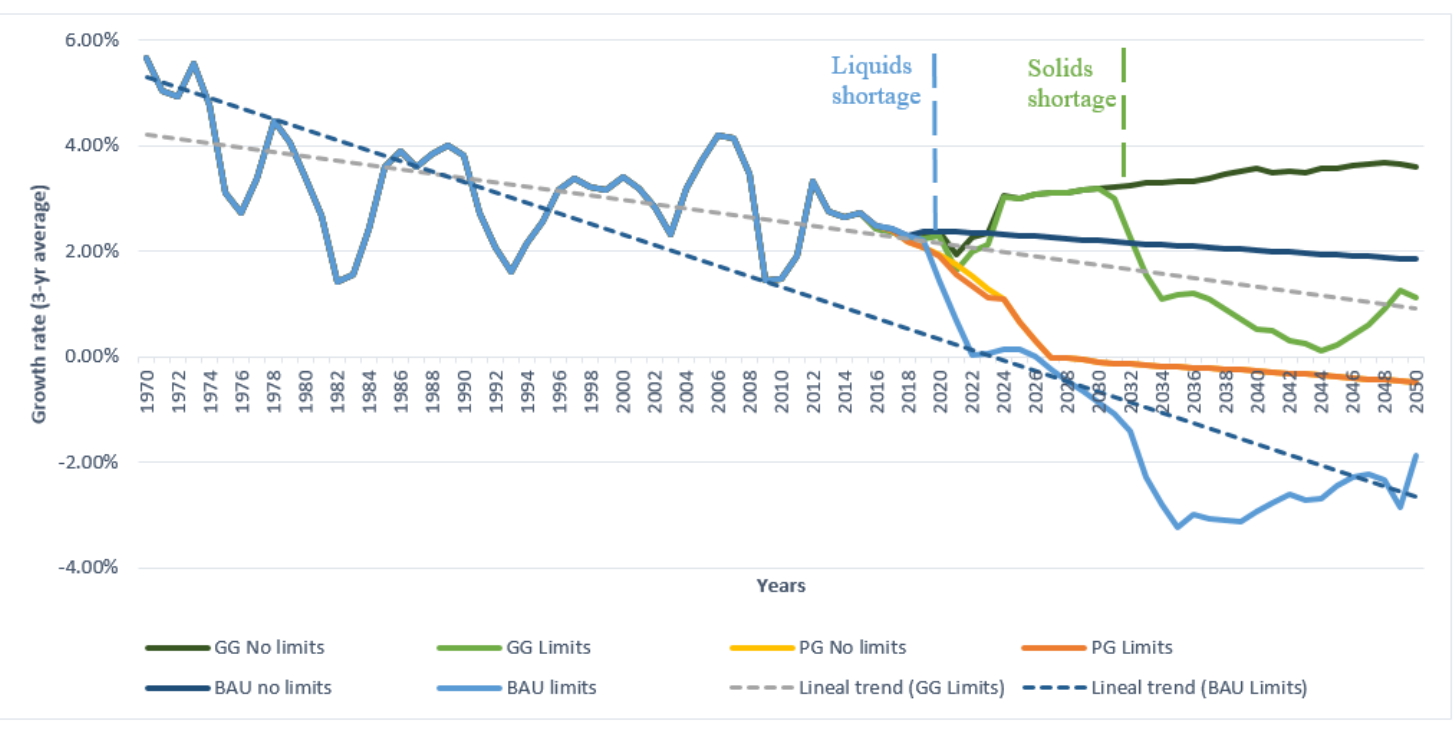

Figure 18. GDP growth scenarios (3-yr mobile average).

Source: own elaboration on the basis of MEDEAS World results.

Furthermore, should the Paris Agreement policies be undertaken (GG scenario) within the next decades, economic growth would be compatible with a rapid energy transition, at least until the mid-2030s. There is a solids shortage which hinders economic growth from maintaining its trend, although still not enough to stop increasing output. In other words, the economic activity will demand such an amount of final energy provided by liquids that the energy system will not be able to deliver. Thus, if the total output cannot be produced, the final demand is not fully satisfied, undermining GDP growth. By the end of the simulation period, GDP growth seems to be recovering. What this means is that once energy scarcity begins to determine the potential economic output, the constraint can be more or less severe regarding the shortage coefficient. Nevertheless, both BAU and GG trends lead, at the very least, to a slow-growth regime in the next few decades to come.

What MEDEAS captures is not a sudden or dramatic energy crisis such as the 70's oil crisis, driven by geopolitical and institutional reasons. Rather, a lack of energy supply is posing a decline in the economy's capacity to increase throughput that might hinder economic growth and drive the global economy to stagnation. In the low-carbon transition, time matters and this is captured by MEDEAS. It takes energy to deploy the renewable energy infrastructures and at the earlier stage this will need to be carried out with a high proportion of NRER in what has been called the 'energy trap' (Sers and Victor, 2018) or, put it in other words, the 'Sower's way' referred to net energy availability (Sgouridis, Csala and Bardi, 2016). Certainly, the geographic coexistence of different metabolic regimes could strengthen this tendency. In fact, not by chance the Paris Agreement only imposes a carbon reduction to the High Income countries and allows huge carbon increases in the lower income countries. The use of NRER will potentially remain 
an important share of the energy mix in the years to come, especially in Middle Income countries. Given the increasing cost (both in energy and economic terms) of their extraction due to the reduction in the accessibility of the better resources, the development process of the so-called 'emergent countries' could be hampered and might potentially lead to geostrategic conflicts.

In this context of a slowing GDP growth, a trend that can even be noticed by just taking the historical data, the PG scenario implies an adaptive approach which attains climate goals. The downsizing of economic growth is conducted in a steady way, with neither considerable fluctuations, nor abrupt collapses, whereas income distribution is improved. Essentially, whilst GG scenarios have to face involuntary economic downsizing and energy source depletion just to achieve an insufficient emissions reduction, the PG scenario widely meets climate goals without facing the huge cost of non-planned, disruptive, plummeting economic output. Moreover, an economic system which pushes NRER reserves down less allows the whole system to retain a larger amount of these resources underground. In this context, policies aimed at maintaining welfare, or increasing it in the case of developing countries, would be of the utmost important if the energy transition is to be completed on a fair and equal basis. For this purpose, it is fundamental a decoupling between welfare and economic growth. A new set of Post-Growth policies could be useful to achieve socioeconomic goals along with the climate targets. We explore further on that in section 3.5.

As long as energy feedbacks are not included in models, their outcomes might be flawed, suggesting that economic output could be increased without limits. Standard production functions, even if considering energy (or, more generally, natural resources) as a production factor, could at best capture relative reductions on its positive slope. On the one hand, the assumption of perfect substitutability of production factors allows conventional models to counterbalance energy constraints by adding more of the other inputs (namely, capital and labour). On the other hand, by considering natural resources (natural capital) as one more input, their depletion (depreciation) can theoretically be corrected by new investment, omitting the irreversibility of environmental impacts. System dynamics and its stock and flow, feedback-rich structure allow the model to capture energy boundaries that the economy cannot surpass. Once energy constraints are integrated into the model, the results show that climate goals could only be met by keeping economic growth as a policy objective at a high socioeconomic cost (output collapse) and the depletion of NRER. What this suggests is a growth-mitigation paradox, where the only reason why climate goals are barely met in the GG scenario is because an economic collapse occurs during the simulation period. What this result might suggest is that most EnergyEconomy-Environment models could be inaccurately specifying energy-economy interactions. 
Nonetheless, when scarcity becomes significant ( $\varepsilon \cong 0.98$ or lower), the liquids scarcity stands out above the other resources. The NRER extraction rate is no longer high enough to meet the economic growth rates the world is used to, or those that the so-called non-developed countries would require to follow the development pathways previously undertaken by rich countries. What is more, high economic growth might not even be a feasible option for the future, regardless of whether the energy transition is completed or not. Furthermore, as long as climate impacts are disregarded in this analysis, the GDP outcomes could be expected to be worsened in the scenarios with higher GHG emissions.

\subsubsection{Structural change and the uncertain pathways towards sustainability}

The economic structure is a key issue in sustainability transitions. The economic system consists of several sub-economies, each of them with their own interrelated rationales. Here, the economy has been divided into 35 different industries (see Appendix 2.A), according to WIOD (Dietzenbacher et al., 2013). As stated in section 3.3.1.2, the total final demand provided by scenarios unfolds disparately amongst the 35 sectors. What is more, whether this demand is made by household consumption or by gross fixed capital formation (investments) depends on income distribution (see section 3.3.1.1).

As described in Eq. 10, energy demand depends on the economic structure $(L)$, energy intensities ( $\left.\hat{\mathrm{e}}_{k}\right)$ and final demand $(D)$. Thus, the column sum of the result of pre-multiplying $\hat{\mathrm{e}}_{k}$ by $L$ yields the energy multipliers shown in Table 14 for 2009. These multipliers can be interpreted as the sectoral energy sensitivity to final demand (GDP) growth by final end-use energy carrier. For instance, it takes 1.260 EJ of electricity to satisfy 1 trillion USD of additional final demand for sector 1 (see Table 14) products. Thus, having a less energy-intensive economy, measured as the energy consumption required to satisfy the same GDP, relies on energy intensity and economic structure. Hence, a less energy-intensive economy could be achieved through reductions in energy intensity (efficiency gains), a less input-consuming productive process (downsizing the overall values of $a_{i j}$ in the A Matrix) or, conversely, an increase in one of them not high enough to offset the reduction in the other. 
Table 14. Energy sensitivity to final demand growth by resources (EJ/trillion USD).

\begin{tabular}{|c|c|c|c|c|c|}
\hline Sector & Electricity & Gas & Heat & Liquids & Solids \\
\hline $\mathbf{1}$ & 1.260 & 0.802 & 0.173 & 3.996 & 0.757 \\
\hline $\mathbf{2}$ & 1.907 & 5.580 & 0.308 & 2.179 & 1.737 \\
\hline $\mathbf{3}$ & 1.430 & 1.147 & 0.293 & 2.917 & 1.925 \\
\hline $\mathbf{4}$ & 2.135 & 1.317 & 0.525 & 2.601 & 1.647 \\
\hline $\mathbf{5}$ & 1.482 & 1.049 & 0.335 & 2.603 & 1.355 \\
\hline $\mathbf{6}$ & 1.909 & 1.208 & 0.423 & 2.985 & 2.786 \\
\hline $\mathbf{7}$ & 2.218 & 1.365 & 0.515 & 2.045 & 2.911 \\
\hline $\mathbf{8}$ & 2.071 & 5.170 & 1.017 & 10.005 & 1.788 \\
\hline $\mathbf{9}$ & 2.858 & 2.997 & 1.055 & 3.353 & 2.168 \\
\hline $\mathbf{1 0}$ & 3.446 & 2.539 & 0.670 & 3.913 & 3.972 \\
\hline $\mathbf{1 1}$ & 3.414 & 3.362 & 0.362 & 4.062 & 10.724 \\
\hline $\mathbf{1 2}$ & 4.259 & 2.972 & 0.504 & 2.341 & 5.081 \\
\hline $\mathbf{1 3}$ & 1.858 & 1.276 & 0.267 & 1.822 & 1.798 \\
\hline $\mathbf{1 4}$ & 1.467 & 0.997 & 0.209 & 1.618 & 1.295 \\
\hline $\mathbf{1 5}$ & 1.731 & 1.195 & 0.276 & 1.830 & 1.584 \\
\hline $\mathbf{1 6}$ & 2.047 & 1.674 & 0.418 & 3.258 & 2.403 \\
\hline $\mathbf{1 7}$ & 3.958 & 4.320 & 0.394 & 1.841 & 3.451 \\
\hline $\mathbf{1 8}$ & 1.437 & 1.288 & 0.204 & 2.503 & 2.138 \\
\hline $\mathbf{1 9}$ & 0.904 & 0.597 & 0.127 & 1.477 & 0.553 \\
\hline $\mathbf{2 0}$ & 0.507 & 0.346 & 0.094 & 1.352 & 0.273 \\
\hline $\mathbf{2 1}$ & 0.797 & 0.463 & 0.089 & 1.645 & 0.280 \\
\hline $\mathbf{2 2}$ & 1.469 & 0.963 & 0.163 & 2.241 & 1.052 \\
\hline $\mathbf{2 3}$ & 1.070 & 2.384 & 0.139 & 7.855 & 0.609 \\
\hline $\mathbf{2 4}$ & 0.636 & 0.800 & 0.163 & 30.073 & 0.512 \\
\hline $\mathbf{2 5}$ & 0.715 & 0.914 & 0.182 & 28.052 & 0.566 \\
\hline $\mathbf{2 6}$ & 1.069 & 0.838 & 0.216 & 4.772 & 0.585 \\
\hline $\mathbf{2 7}$ & 0.638 & 0.514 & 0.082 & 1.193 & 0.305 \\
\hline $\mathbf{2 8}$ & 0.437 & 0.270 & 0.060 & 0.862 & 0.209 \\
\hline $\mathbf{2 9}$ & 0.500 & 0.264 & 0.082 & 0.503 & 0.220 \\
\hline $\mathbf{3 0}$ & 0.604 & 0.435 & 0.088 & 1.368 & 0.358 \\
\hline $\mathbf{3 1}$ & 1.005 & 1.230 & 0.126 & 1.773 & 0.503 \\
\hline $\mathbf{3 2}$ & 1.107 & 0.538 & 0.128 & 1.519 & 0.444 \\
\hline $\mathbf{3 3}$ & 0.942 & 0.645 & 0.162 & 1.625 & 0.525 \\
\hline $\mathbf{3 4}$ & 0.994 & 0.660 & 0.170 & 1.967 & 0.534 \\
\hline $\mathbf{3 5}$ & 0.171 & 0.374 & 0.027 & 0.279 & 0.146 \\
\hline $\mathbf{5 0}$ & & & & \\
\hline
\end{tabular}

Source: Own elaboration on the basis of WIOD and IEA.

Table 14 provides useful information for policy-makers for selecting the appropriate sectors to undertake different policies. Despite industrial policy, i.e. the administration's encouragement of key sectors to the detriment of others, has been ruled out during the last decades, it emerges as a useful tool to achieve climate goals. Thus, industrial policy could focus on reducing the weight in the economy of the most energy-intensive sectors or increasing the less energy-intensive sectors as in the PG scenario (see Appendix 2.B) In addition, it can be used to 
identify the most sensitive energy source to satisfy economic demand. For instance, energy carriers from liquids to increase GDP are the highest, especially in the transport sectors (23-25), fossil fuel refineries (8) and even the primary sector (1). These facts explain why liquid limits are the first to be significantly found and why it causes the deeper output impact when it occurs, when compared with other final end-use energy carriers such as solids.

By definition, the BAU scenario's assumptions make it considerably energy-demanding. Firstly, since energy transition policies are not as important as they are in the other scenarios, energy intensities decline slower. Secondly, if the technical coefficients (A matrix) were to evolve following the historical projection, the world might move towards a more inefficient economic system. As mentioned in section 3.3.1.3, the more intermediate products purchases required to produce each industry's output, the smaller the share remaining for the gross value added (wages and profits as it is measured at factor costs). Therefore, to avoid unrealistic outcomes, the A matrix in the BAU scenario is not allowed to decrease the value added beyond one third of its initial share by sector (see Appendix 2.B). Conversely, the Green Growth scenario experiences a higher energy intensity drop and the economy moves towards a more efficient structure. As the A matrix comes closer to Denmark's structure, obtaining the same GDP growth requires less production in each period. Nevertheless, a rebound effect appears due to the increased capacity of the economy to boost final demand. As a result, the efficiency gains are partially offset and total energy requirements increase by approximately $10 \%$ in 2030, although it manages to decrease the mentioned requirements by $13 \%$ in 2050 (see Figure 19). Lastly, the Post-Growth scenario simulates an industrial policy focused on favouring less energy-intensive sectors such as, 'Education', 'Health and Social Work' or 'Other Community, Social and Personal Services', while disfavouring others like 'Coke, Refined Petroleum and Nuclear fuel', 'Air transport' or 'Chemicals and Chemical products'. This approach (Leontief and Duchin, 1986) allows the model to explore an energy-focused industrial transformation. As a result, along with a steady decline in GDP growth, the PG scenario decreases its total energy needs by $17 \%$ in 2030 and $44 \%$ in 2050 , according to the total effects shown in Figure 19.

Besides, Input-Output Analysis allows us to accurately differentiate between direct effects (those triggered by the variation in demand itself) and indirect effects (those activated by the spill-over to deliver intermediate inputs across industries) by energy resources (see Appendix 2.C). Figure 19 shows the total contribution of both direct and indirect effects to energy growth, which always sum 100\%, as well as the total final energy demand variation by 2030 and 2050 (total effects, in dotted lines). The results shown in Figure 19 are only valid for simulations accounting with energy limits, so the energy use reported here is linked to the energy emissions and GDP growth shown in Figure 17 and Figure 18 labelled as 'Limits'. The bars with a positive value -looking rightwards- indicate that the effect (direct or indirect) contributed to the total 
energy use change by 2050 with the same sign, and the other way around. For instance, in the GG scenario, the solids' use is $12 \%$ lower in 2050 . The indirect effects, i.e. the contribution of the intermediate products' trade flows between industries highly contributed to this reduction (partly due to the A matrix change and partly by the industries' energy efficiency gains). Conversely, the direct effects triggered by an increased final demand weakened the energy use reduction capacity of the indirect effects, so the total final decrease in solids' use is lower. As an overall result, the significant importance of the contribution of indirect effects to the total energy demand variation, even pushing in the opposite direction to direct effects, underlines the relevance of integrating Input-Output Analysis into IAMs. This can be clearly seen in the PG scenario, where in spite of the direct contribution to reduce energy demand via a decline in GDP growth, indirect effects strongly oversize them. The shift in the intermediate structure of the economy accounts $57 \%$ of the responsibility in solids' use reduction (-50\%), 53\% in heat (-58\%) and $42 \%$ in liquids $(-67 \%)$. Moreover, the indirect effects are able to reduce electricity use despite the pressure to be increased by direct effects -bar looking leftwards while total effects being negative- in the context of a strong electrification process. The same can be applied to gases, considered a 'bridge' resource in the energy transition. As a consequence, we can conclude that without an important economic structure transformation, climate goals could hardly be met since GHG emissions are strongly linked to energy use (see Figure 17). The total effects show that the total energy demand is still increasing with the BAU $(+12 \%)$ and GG scenarios $(+10 \%)$ by 2030 ; whereas the PG is already declining (-17\%). This explains the inability of any scenario other than PG to reduce emissions before 2030 (Figure 17).

The energy demand decline in the BAU scenario (2050) is mostly due to direct effects: the reduction in final demand imposed by energy scarcity would be the main driver of the energy demand downsizing. Nevertheless, for electricity demand, indirect and direct effects contribute to the energy demand variation in different ways resulting in an overall increase. The electricity use is increased by 2050 (8\%) basically due to the energy mix tendency to electrify and the more inefficient economic structure. As a consequence, electricity use increases despite the economic downturn which leads GDP (direct effects) to decrease. The relatively lower reduction in the liquids use and the lack of an intense shift in the electricity mix to renewables explain why GHG emissions (Figure 17) increase even though the economic system is in recession. The more inefficient A matrix structure leads the indirect effects to increase electricity demand, whereas energy intensities drop, bringing about an overall decline thanks to the direct effects. The contribution to the decline in energy demand in the GG scenario is also evident, with even a reduction in the energy demand in those resources that actually increased (electricity and gases). As mentioned before, the indirect effects were the main driver of the decline in energy demand in 
the post-growth scenario, highlighting the relevance of industrial policy along with energy efficiency gains.

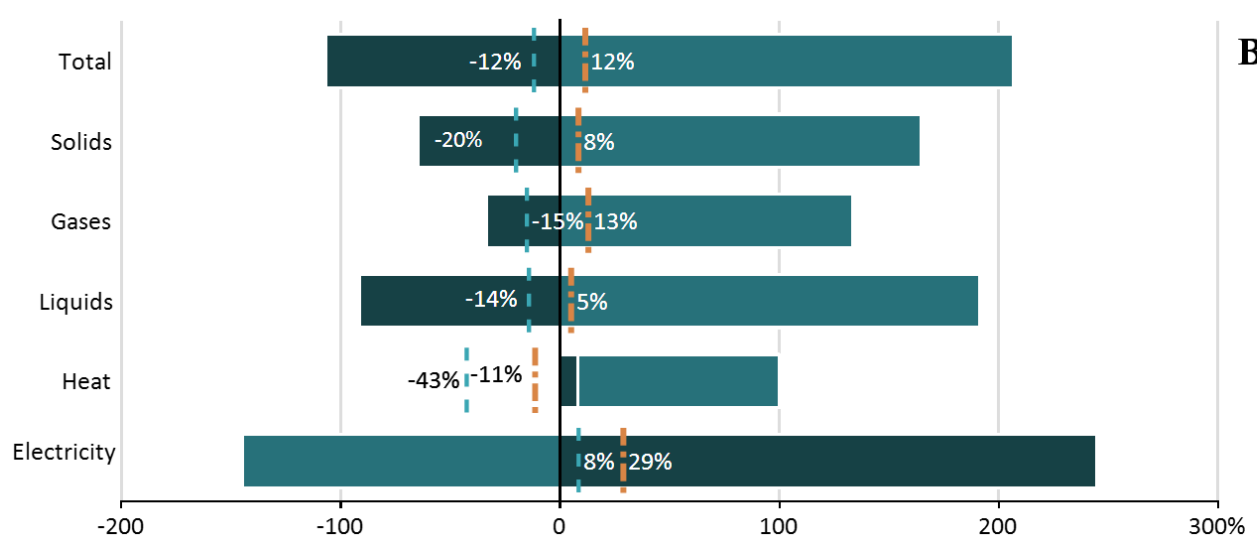

\section{BAU scenario}

Indirect Effects Contribution 2050

Direct Effects

Contribution 2050

- Total Effects 2030

-. - Total Effects 2050

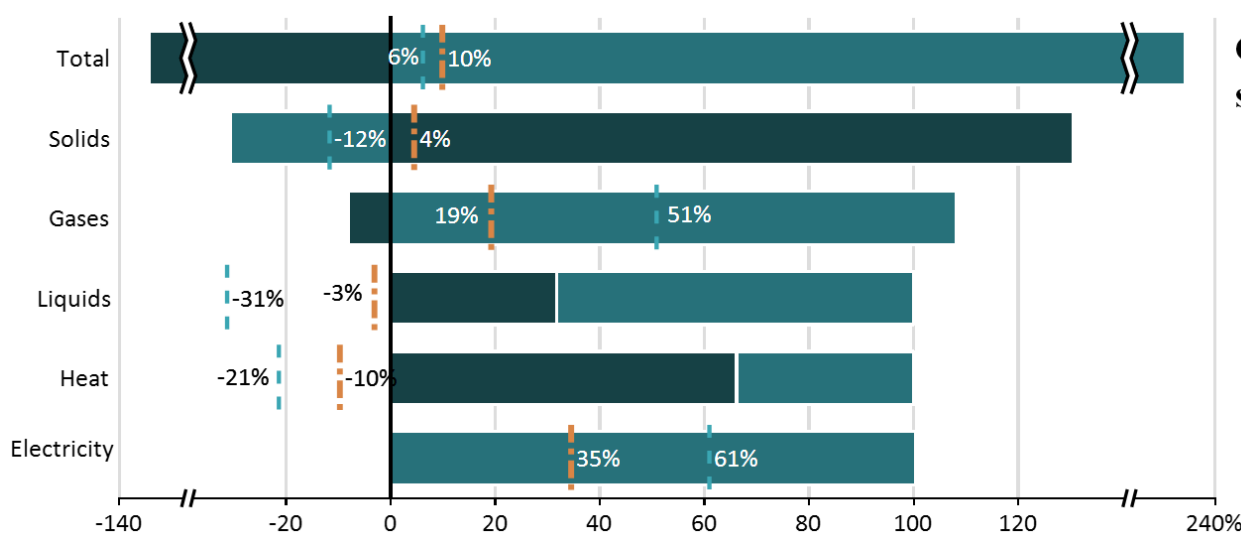

\section{Green Growth scenario}

Direct Effect Contribution 2050

Indirect Effects Contribution 2050

- Total Effects 2030

-. - .Total Effects 2050

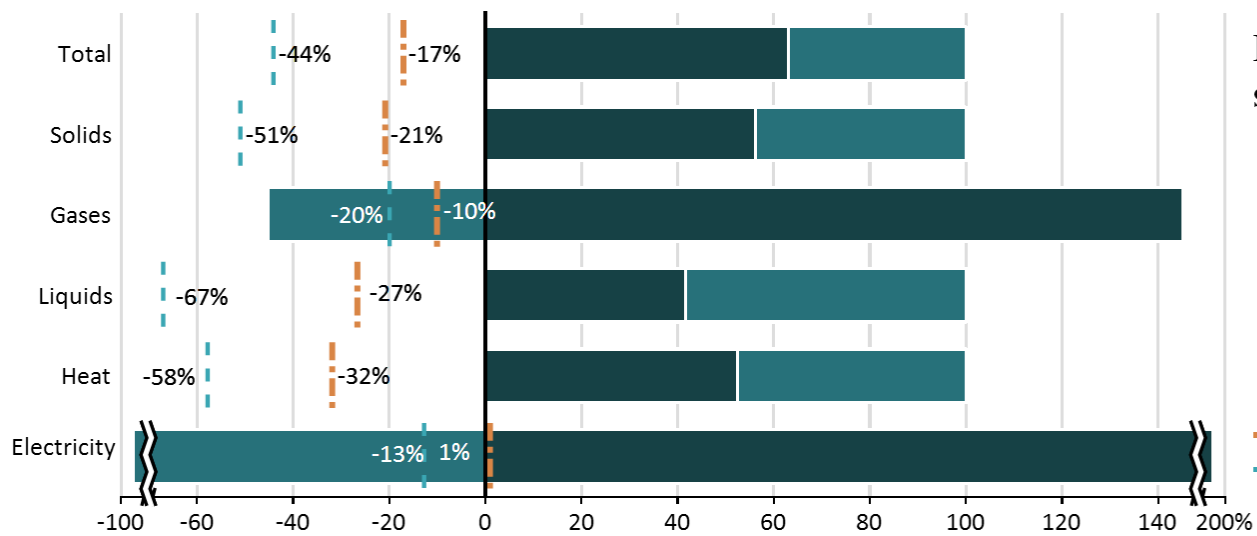

Post-Growth scenario

Indirect Effects Contribution 2050 Direct Effects

Contribution 2050

- "Total Effects 2030 - - . Total Effects 2050

Figure 19. Direct and indirect contribution to energy demand variation by final end-use energy carriers and scenarios. Source: own elaboration.

\subsection{Concluding remarks and Policy Implications}

Within the last few decades, the need to include environmental aspects into macroeconomic modelling has drawn increasing academic attention. Considering that most of the carbon emissions are produced within the energy sector and regarding its nexus with economic 
growth, it makes sense to focus on Energy-Economy-Environmental models. The review of the literature reveals a lack of consideration in simulation models to the role of energy availability and its potential effect on limiting production in the economic system. What is more, there is a theoretical discussion on whether economic growth can be compatible with, or even boost, lowcarbon transitions. Since rapidly tackling climate change while keeping or improving wellbeing imposes an urgent agenda, more accurate outcomes from modelling and discussion on their policy implications is of the utmost importance. According to the IPCC, emissions should plummet from $-41 \%$ to $-72 \%$ by 2050 , with respect to 2010 , in order to make avoiding a world temperature increase of above $2^{\circ} \mathrm{C}$ 'likely'.

The results expose the unfeasibility of economic growth once biophysical constraints have been considered. Although the BAU scenario copes with energy limits at an early stage due to a lack of energy mix transition to renewables; this policy shows itself to be ineffective when the GDP growth rate is increased in the GG scenario. Essentially, the deployment time, diminishing EROEI and sectoral hurdles to switch to renewables collide with the growing energy requirements imposed by GDP growth. Thus, the energy system needs to draw on non-renewable energy resources to meet the increasing energy demand, which eventually becomes higher than the energy availability, resulting in a declining trend of the economic output. It is only after the economic slow-down that emissions start decreasing, but not soon enough to meet climate objectives. Conversely, a planned steady decline in GDP growth displayed by the PG scenario, along with industrial policy fostering less energy-intensive sectors, leads to better climate outcomes (well below $2^{\circ} \mathrm{C}$ ), while completing the energy transition and enhancing income distribution.

The implications for policy-makers lie in the scenario results. Firstly, the differences between the BAU and the other scenarios show that it might be better 'to do something' than 'to do nothing'. Should the energy transition not be undertaken soon with credible, strong policies by the countries, the world might face economic stagnation and then depression in the coming decades. Secondly, and perhaps more importantly, a mere technological energy switch to renewables could be unfeasible if not complemented with huge socioeconomic changes. As shown by the results, the economic costs of keeping GDP growth as the main objective of economic-policy could be too high to be socially affordable. Thus, we believe that economic policy should be redirected to redistributional and industrial policies. In addition, energy demand policies should not only aim at improving energy efficiency, but also designing multidisciplinary demand management policies intended to satisfy human needs by means of collectively less energy-intensive ways. Short distribution channels, a switch from modern to traditional or ecological agriculture and farming, favouring public and collective transport and planning industrial ecology developments, amongst other policies, might contribute to human well-being 
in an energy and GDP declining context. Also, focusing on more labour intensive sectors such as education, health care or social work together with working time reduction policies could be important to address employment in a low-carbon economy.

It certainly raises deep theoretical implications and further challenges for development economics, ecological economics, well-being and economic analysis in general. First, although it becomes ineffective to deliver well-being beyond a certain level of economic growth (Jackson, 2011), most non-developed countries have not yet reached that threshold. Thus, development studies may need to lean towards non-extractivist, post-growth approaches in order to achieve the most meaningful results possible. The reduction of economic output, either planned or unplanned, suggests the need to implement regional redistribution policies to improve the welfare of developing countries. Moreover, economic growth theory should include biophysical boundaries that fit reality better. The MEDEAS model shows that economic growth might be unachievable in the context of the energy challenges that the world urgently needs to tackle. As a consequence, macroeconomic modelling should consider absolute biophysical constraints if more accurate outcomes are to be obtained. Conventional production functions could be failing to capture these absolute restraints by compensating for natural capital depletion with capital accumulation, labour growth, or even the so-called total factors productivity. Therefore, if models only include the environment as theoretical categories -such as 'natural capital' or 'ecosystem services'- which can be eroded but restored, they could be disregarding irreversibility in natural systems and thus obtaining misleading results. Furthermore, there is a lack of high, two-way integration between the economy and the biophysical system in IAMs that MEDEAS could contribute to cover. More complex insights are required to better represent the real world dynamics, subject to irreversibility when the consumption of resources is being assessed.

Finally, in order to improve the accuracy of the economic model, further developments should be addressed in the future. Firstly, the full endogenisation of inequality could enhance the final demand estimation, setting the basis to include the financial structure in the model. The latter will allow the model to analyse the financial requirements of the energy transition by tracking more accurately the investment flows to the energy-related sectors. Secondly, the endogenous A matrix evolution, linked to the energy mix transition and technological change, would be a great step forward in the dynamic representation of the economic structure in the model. This would also contribute to enhance the linkage between the energy mix and energy-related sectors in the IOT. Thirdly, considering this, demand management policies should be measured and then implemented in the model. Thus, an effective decoupling between well-being and GDP growth could be assessed. 


\section{A System Dynamics-Ecological Macroeconomics model: the energy transition in the EU. ${ }^{13}$}

\subsection{Introduction}

The latest IPCC report (IPCC, 2014) highlighted the importance of avoiding a $1.5^{\circ} \mathrm{C}$ increase in temperatures over preindustrial levels. In order to overcome this challenge, the IPCC urges the international community to undertake a huge reduction in greenhouse gases (GHG) emissions as soon as possible. Historically, climate governance efforts have been aimed at a lowcarbon economy via a shift from non-renewable (NRER) to renewable energy resources (RES). Moreover, despite the global nature of the objective and the growing interdependency between economies, climate governance has moved from multilateral -Kyoto Protocol being the most well-known compromise- to unilateral action after the Paris Agreement (Spash, 2016). For this reason, only developed countries are bound to an absolute reduction in GHG emissions. Accordingly, the European Union (EU) has committed to reduce GHG emissions by $80-95 \%$ by 2050 as compared to 1990 levels (European Commission, 2011). As presented in the EU's Energy Roadmap 2050, not only is a replacement of NRER for RER proposed, but also an overall reduction in energy consumption in their decarbonisation scenarios.

Furthermore, after a period of systematically reducing energy consumption from 2011 to 2016, the EU updated its Reference scenario (Ref2016) in a way that only different levels of energy reduction - even with current policies- are considered for the future (Commission, 2016a). This update took place after a few years of energy use decline mostly driven by the economic crisis, but energy use growth started up again in 2016. A set of models is used by the European Union to produce their estimated impacts of the energy transition. The core of this system of interconnected models is the energy model PRIMES (E3MLab, 2014), which is determined by the macroeconomic assumption of general equilibrium adopted by the GEM-E3 model (Institute for Prospective Technological Studies, 2013). In addition to the Reference scenario, different primary energy consumption (PEC) reduction scenarios have been included, such as EUCO+27, EUCO +33 and EUCO+40 with a PEC decrease of 27\%, 33\% and 40\% respectively (E3MLab and IIASA, 2016). They also predict an increase in European energy autonomy, based on a reduced rate of imports over total consumption. Along with this energy consumption and dependency reductions, positive economic growth and employment impacts are to be expected according to

${ }^{13}$ This chapter has been submitted as an article to the journal Ecological Economics on November 2019. Nieto, J., Carpintero, Ó., Lobejón, L. F., et al. 'A System Dynamics-Ecological Macroeconomics model: the energy transition in the EU', Energy Policy. 
the EU reports for both the previous assessment (Cambridge Econometrics, 2013) and the updated one based on the Ref2016 and EUCO scenarios (European Commission, 2016a, 2016b).

The set of models used by the EU are interconnected, mostly in a two-way relationship. However, the economy would be an exception, and this is significantly formulated as 'framework assumptions'. Macroeconomic processes are kept apart from any influence from the rest of the system which is determined by the economy's inputs. As any macroeconomic model based on Computable General Equilibrium (CGE), it explicitly imposes long-term convergence to full employment and full economic potential (Sterman et al., 2012). The results provided by the EU show that the lower the primary energy use, the better the macroeconomic performance achieved in terms of GDP growth and employment will be. These outcomes embrace the idea of decoupling -at least, weak decoupling- between energy consumption and GDP growth, but disregard the potential effects on overall strong decoupling ${ }^{14}$. In fact, a significant proportion of the literature states that the energy transition will imply a net increase in growth and in jobs creation, especially in rich countries (Bowen and Hepburn, 2012; Lehr, Lutz and Edler, 2012; Kander and Stern, 2014).

Nevertheless, a growing body of literature is questioning these paradigms, highlighting the absence of empirical evidence supporting strong decoupling, with weak decoupling only being relevant when focusing on per capita instead of absolute values (Csereklyei and Stern, 2015; Peng, Zhang and Sun, 2016; O’Neill et al., 2017; Wu, Zhu and Zhu, 2018). Similarly, other scholars have pointed out the potential conflict between reducing energy use, meeting environmental goals and the maintenance of employment levels if a -widely defined- degrowth agenda is not adopted (Krausmann et al., 2008; Victor, 2008; Jackson and Victor, 2011; Rodríguez-Huerta, RosasCasals and Sorman, 2017; Antal, 2018).

Our main objective is to analyse such socioeconomic impacts as the expected GDP growth during the European energy transition. More concretely, the effects of different policy assumptions regarding several macroeconomic concerns such as income distribution, labour productivity, working-time reduction and industrial structure shifts are analysed. By comparing our results with those from the European Union's reports, we aim to shed light on the more likely energy transition pathways as well as the more adequate policies for meeting climate goals while still maintaining socioeconomic sustainability. For that purpose, we have built a Post-Keynesian Economics (PKE)-inspired Economy module and an Employment sub-module integrated within

\footnotetext{
${ }^{14}$ Weak decoupling refers to relative reduction in energy used per unit of economic activity (energy/GDP ratio), whereas strong decoupling refers to absolute reduction in energy used and GDP growth simultaneously.
} 
a set of nested Integrated Assessments Models (IAMs) using system dynamics (SD) named MEDEAS (see Figure 20).

The SD methodology has become a relevant tool for economic analysis during the last decade (Radzicki and Tauheed, 2009), drawing the attention of both conventional (Režný and Bureš, 2018) and non-conventional (Victor, 2008; Radzicki, 2009; D’Alessandro, Luzzati and Morroni, 2010; Motesharrei et al., 2014; Bernardo and D’Alessandro, 2016) economic approaches. This methodology, rich in stocks and flows, feedbacks and time delays, allows us to better capture social and biophysical constraints to the economy through non-linear, direct, indirect and multidirectional relationships. As a consequence, we also set as a secondary objective the discussion of the PKE approach under energy constraints. We argue that this methodology is a powerful tool for policy makers to adopt well-informed decisions on energy transitions.

The structure of this article is the following: section 4.2 describes the modelling approach as well as the scenarios and assumptions' description; section 4.3 shows the results of the outcomes through a sequential point of view enabling a better understanding of the policies' effects; section 4.4 discusses these results and the methodology's potential with respect to the literature; finally, section 4.5 summarises the main concluding remarks of the analysis.

\subsection{Methodology}

\subsubsection{General Overview}

MEDEAS is an IAM framework based on System Dynamics and Input-Output Analysis. It is a simulation model, regionally nested and built on dynamically-interrelated modules. As can be seen in Figure 20, the economic activity demands land, water, energy and materials to be transformed into goods and services. After this process, residuals are generated, both material which can be partially recycled- and gaseous, mainly greenhouse gases (GHG). Therefore, MEDEAS follows a socio-metabolic approach coherent with the Ecological Economics paradigm of socioeconomic subjection to the environmental carrying capacity. Conventional economics pictures environment-economy relationships as a source of positive (environmental services, contingent valuation, etc.) and negative (pollution, damage to health, etc.) externalities transversal to the circular flow of income. Ecological Economics, on the other hand, depicts the economic and social processes as embedded in and constrained by the natural systems, of which they are subsystems.

The MEDEAS-World model (Capellán-Pérez et al., 2017) sets the 'landscape' for the Europe model (De Blas et al., 2018) in terms of NRER availability, GHG concentration in the atmosphere and temperature change, as well as the overall world economic activity. These 
outcomes, in turn, affect the MEDEAS-EU model through NRER imports, climate change impacts and the foreign trade balance (Figure 20 and Figure 21). Both energy and labour demand are triggered by a hybrid I-O model, i.e. MEDEAS is demand-led and based on complementarity instead of perfect substitutability, which does not force either equilibrium or the optimization of the productive factors.

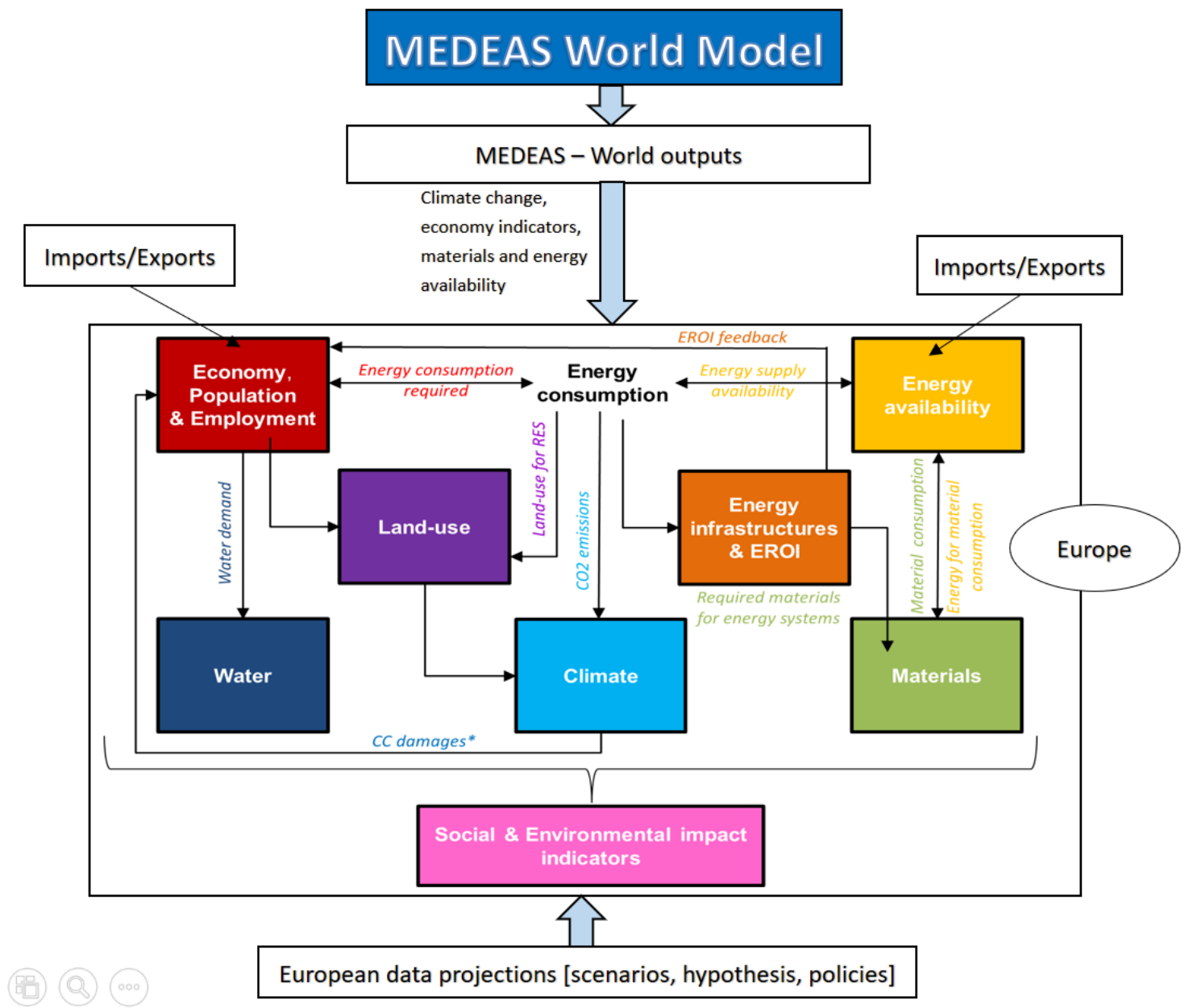

Figure 20. MEDEAS models framework. Source: Own elaboration on the basis of (De Blas et al., 2018).

* The Climate Change damage function has been disabled for this article as a conservative approach in order to shed light just on the energy use reduction effects.

As a consequence, the employment sub-module estimates the hours of work by the skills required to produce each industry output, given the labour intensities -the inverse of labour productivity- and employment in persons, as well as the hours per worker in every industry. Both labour intensities and hours per worker are based on historic observations and then projected according to different scenarios (see section 4.2.3). A simplified influences diagram can be seen in Figure 21. The peculiarity of MEDEAS enabled by the SD approach, is that it includes stocks whose gradual depletion feeds back to other variables in the model in causality loops that force the economy to adapt to resources availability. This allows the model to modulate economic 
growth depending on -among other key variables- energy and labour force availability, feedbacks that are explained in section 4.2.2. The WIOD database (Dietzenbacher et al., 2013) has been used to define the IO framework, together with its socioeconomic (Timmer et al., 2015) and environmental (Genty, 2012) satellite accounts. In addition, the EU-KLEMS database ${ }^{15}$ has been used to extend the socioeconomic variables' time series until 2015. The IO framework used, comprises of 35 different industries (see Appendix 2.A) and a two-region approach with the EU28 as the main territory and the rest of the world (RoW) as the secondary one (see section 4.2.2.1). Appednix 3.C shows a methodology annex on notation, in order to facilitate the understanding of the equations (mostly operations between matrices, vectors and their components) in section 4.2.2.

${ }^{15}$ EU KLEMS is also the database which WIOD Socioeconomic Accounts relies on, so it has been chosen to maintain consistency of the time series and industry disaggregation. See the database in: http://www.euklems.net/ 


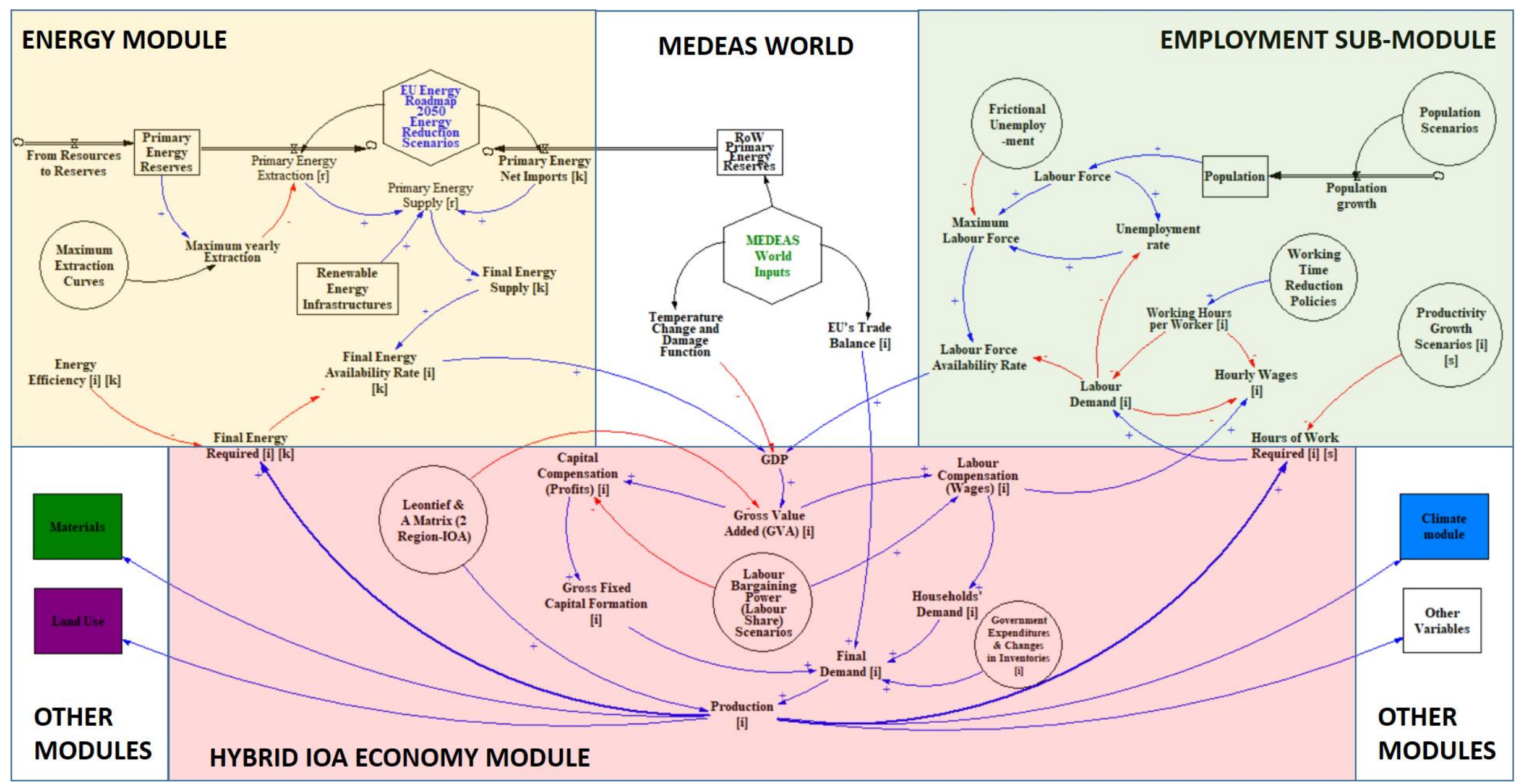

Figure 21. Simplified influences diagram of main interactions between Energy, Economy and Employment.

[i]=industries; [r]=primary energy sources; $[\mathrm{k}]=$ final energy sources; [s]= skills (labour]. Relationships colour code: Red arrow=negative; Blue arrow=positive; Black arrow=variable. Source: own elaboration. 


\subsubsection{The Economy Module}

\subsubsection{Income, Demand and Input-Output Analysis}

System Dynamics has been proven as a relevant methodology for economic analysis, both from conventional and heterodox approaches (Radzicki and Tauheed, 2009). The main advantage of system dynamics modelling consists of its capability to capture the complexity of systems, path-dependency across time and feedbacks (Uehara, Nagase and Wakeland, 2013; CapellánPérez, 2016). Feedbacks are at the core of the Economy module, contributing to stabilize the subsystem and adapting to the biophysical system's boundaries. The Economy module (see Figure 22 ) is demand-led and based on IOA, as well as reliant on expectations and income distribution. Although the module is activated with GDP growth expectations -which does not necessarily match with final demand growth because it includes all the foreign trade-, it is just considered as a mean to produce the inputs that trigger the final demand, the main driver in Input-Output Analysis (IOA); therefore, the core of the MEDEAS Economy module. So, the module's operations start with an exogenous variation in the expected GDP growth grounded on Population and GDP per capita (GDPpc) growth scenarios. Additionally, sectoral income share scenarios enable the estimation of labour and capital compensation:

$$
\boldsymbol{\alpha}^{\text {lab }}=\left[\alpha_{j}^{\text {lab }}\right]=\mathbf{w} \cdot \mathbf{g v a}^{-1}, \boldsymbol{\alpha}^{\text {cap }}=\left[\alpha_{j}^{\text {cap }}\right]=\mathbf{k} \cdot \mathbf{g v a}^{-1} ; \quad j \in 1 \ldots 35 \quad \text { Eq. } 14
$$

With 'i' being the subscript for the 35 industries, $\boldsymbol{\alpha}^{\text {lab }}$ and $\boldsymbol{\alpha}^{\text {cap }}$ the vectors of sectoral labour and capital shares, $\mathbf{w}=\left[w_{j}\right]$ and $\mathbf{k}=\left[k_{j}\right]$ the vectors of sectoral labour and capital compensation - i.e. wages and gross profits- and $\mathbf{g v a}=\left[g v a_{j}\right]$ the sectoral gross value added vector. Therefore, income is easily obtained by solving Eq.1 for $\mathbf{w}$ and $\mathbf{k}$. For the sake of simplicity, the expected GDP growth rate has been taken as the gva`s yearly growth. 


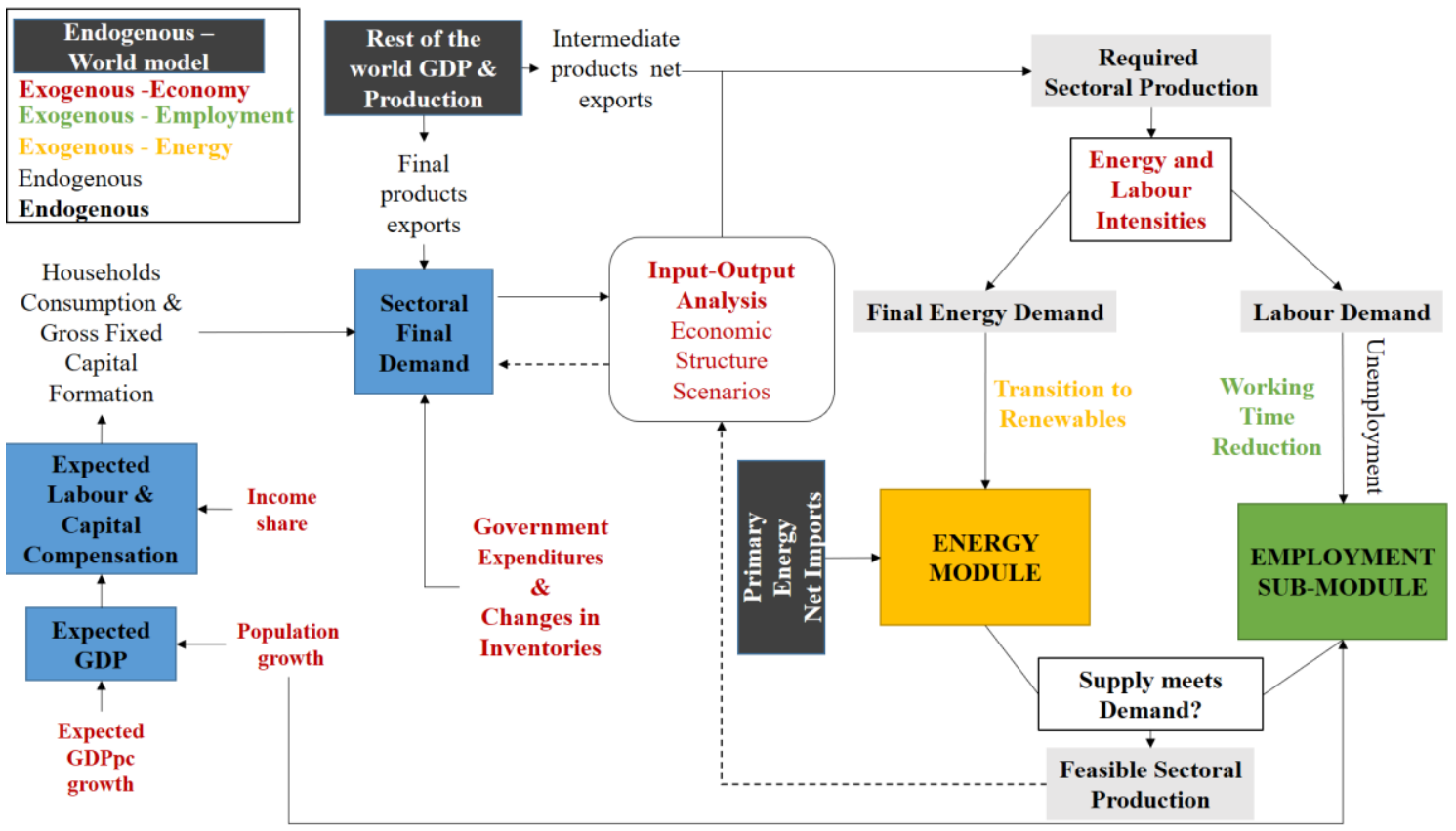

Figure 22. Schematic overview of the Economy module and main interactions.

Source: own elaboration.

Hence, the module's functioning depicts a starting point where employers decide the salaries they are willing to pay in year ' $t$ ', based on the structural income distribution -that could be understood as the labour bargaining power- and the GDP growth expectations. By means of this process, the economic agents know their expected income, which is the main driver of final demand (fd) by different institutional sectors:

$$
\mathbf{f d}=\mathbf{c}+\mathbf{g f c f}+\mathrm{g}+\exp +\text { invent }
$$

With $\mathbf{c}=\left[c_{i}\right]$ standing for sectoral households' consumption, $\mathbf{g f c} \mathbf{c}=\left[g f c f_{i}\right]$ for sectoral Gross Fixed Capital Formation (i.e. real investment), $\mathbf{e x p}=\left[g f c f_{i}\right]$ for the sectoral final products and services exports, $\mathbf{g}=\left[g_{i}\right]$ for sectoral government expenditures and invent $=\left[\right.$ invent $\left._{i}\right]$ for sectoral changes in inventories and valuables. Whereas the latter two are considered a constant proportion of sectoral final demand based on historical data, the rest are estimated with econometric panel data regressions. Although they depend on their relevant explanatory variables, they share a common structure as follows:

$$
\ln \left(\mathrm{Y}_{\mathrm{i}, \mathrm{t}}\right)=\beta_{0}+\beta_{1 i}\left(\operatorname{Sec}_{i}\right)+\beta_{2} \ln \left(\operatorname{Inc} c_{t}\right)+\beta_{3} \ln \left(I n c_{t-1}\right)
$$

$Y_{i, t}$ being the sectoral dependent variable for either $\mathbf{c}$, gfcf or $\exp$ in year $\mathrm{t}, \beta_{0}$ the constant term of the intercept, $\beta_{1 i}$ the variable term of the intercept regarding the different industries, $I n c_{t}$ for the relevant income in year $t$-i.e. labour compensation for $\mathbf{c}$, capital compensation for $\mathbf{g f c f}$ and the rest of the world's (RoW) GDP for exp. In the case of exp, it also depends on the real effective exchange rate. It is important to note that whereas $I n c_{t}$ depends on expectations, its 
lagged value depends on last year's GDP, i.e. it is conditioned by all the modules' feedbacks (energy, employment) and the world economy downstream effect, implying path-dependency. These relevant feedback loops are described in the following sections. Because MEDEAS is a hierarchical, nested set of models, the world's economy performance boosts or slows down the Europe's rate of growth via exp and the intermediate products trade balance calculated through the Input-Output Tables (IOTs). This will enhance or diminish the initial expected GDP growth, implicitly assuming that employers are not able to foresee the world's economic behaviour. IOA is a well-known methodology (Miller and Blair, 2009) based on the complementarity of productive factors and which is able to account for direct and indirect production requirements to satisfy variations in final demand. This framework departs from the basic accountability identity whereby sectoral production is the summation of domestic and foreign intermediate -the inputs that industries need to purchase from others to produce their output- and final demand (see Eq.18). By including invent, it assumes that mismatches between demand and supply are regular in the economy. The specific combination of inputs required from other industries to produce each industry's output is given by the technical coefficient matrix or technological matrix $\mathbf{A}=\left[a_{i j}\right]$, with:

$$
a_{i j}=\frac{z_{i j}}{x_{j}} \quad \mathrm{i}, \mathrm{j} \in\{1 \ldots 70\}
$$

where $a_{i j}$ is the technical coefficient for the intersection between industry ' $\mathrm{i}$ ' -by rowsand ' $\mathrm{j}$ ' - by columns-, $z_{i j}$ is the monetary value of intermediate consumption of industry ' $\mathrm{j}$ ' from industry ' $i$ ', and $x_{j}$ the output produced by industry ' $\mathrm{j}$ '. In a two-region matrix, as in MEDEASEU, intermediate products can be purchased from domestic or foreign industries and therefore, a 70x70 A matrix is used in this article. Although the current state of art in World IOT databases is strong enough to operate with a multi-regional framework, it is not the purpose of this analysis to conduct a consumption-based assessment of the biophysical carriers of domestic production. Therefore, a cleaner yet consistent two-region approach has been adopted to facilitate the understanding of the results. Applying the definition of the A matrix, we can develop the fundamental accountability identity of IOA:

$$
\mathbf{x}=\mathbf{A} \cdot \mathbf{x}+\mathbf{f d} \rightarrow \mathbf{x}=(\mathbf{I}-\mathbf{A})^{-1} \cdot \mathbf{f d} \rightarrow \mathbf{x}=\mathbf{L} \cdot \mathbf{f}
$$

where $\mathbf{x}=\left[x_{j}\right]$ is the sectoral production vector, $\mathbf{I}$ is the identity matrix and $\mathbf{L}=\left[l_{\mathrm{ij}}\right]=$ $(\mathbf{I}-\mathbf{A})^{-1}$ the so-called Leontief matrix measuring the production sensitivity to final demand variations. Extending this to a two-region framework, the European Union's (EU) production is:

$$
\mathbf{x}^{\mathrm{EU}}=\mathbf{L}^{\mathrm{EU}-\mathrm{EU}} \cdot \mathbf{f} \mathbf{d}^{\mathrm{EU}}+\mathbf{L}^{\mathrm{EU}-\mathrm{RoW}} \cdot \mathbf{f} \mathbf{d}^{\mathrm{RoW}}
$$


The superscripts indicate the two regions according to Figure 23 For the sake of simplicity we subsequently refer to the European production $\mathbf{x}^{\mathrm{EU}}$ as simply $\mathbf{x}$. This means that the EU's production is not only dependent on the structural composition of domestic industries, but also on the foreign one's too. Finally, from a demand-side approach, GDP equals ${ }^{16}$ :

$$
\mathrm{GDP}=\sum_{i=1}^{35} g v a_{j}=\sum_{i=1}^{35}\left(f d_{i}^{E U}+z_{i}^{E U-R O W}-z_{i}^{R o W-E U}\right)
$$

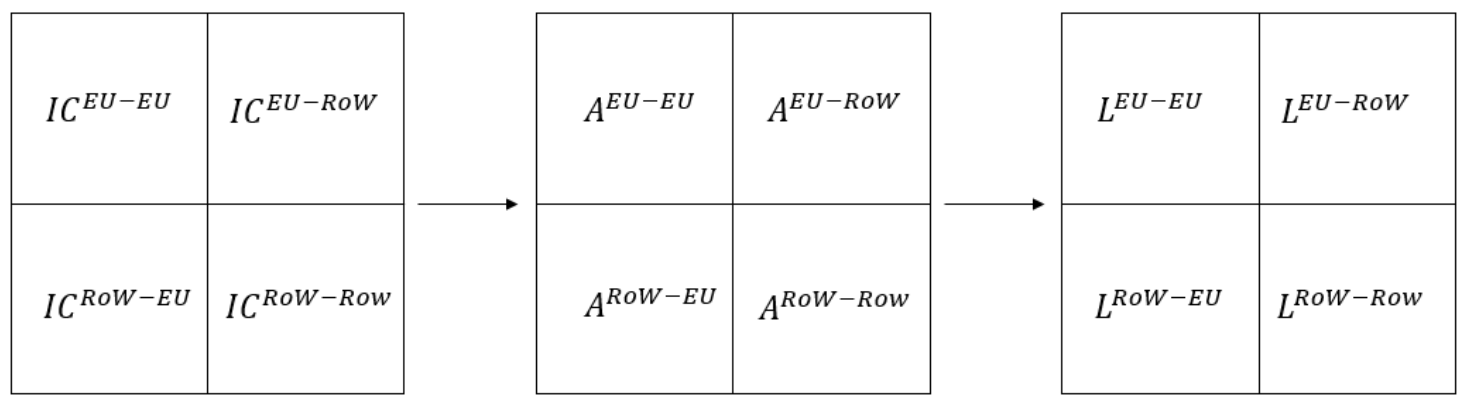

Figure 23. Two-Regions Europe-Rest of the World simplified Input-Output framework.

Source: own elaboration.

\subsubsection{Energy-Economy Feedback}

The energy-economy feedback enables a non-linear, hierarchical energy-economy nexus to be traced whereby, if energy availability is lower than demanded to reach the expected GDP growth, then the actual growth rate will suffer a slowdown. The MEDEAS' Energy module receives the final energy demand from the Economy module and then takes the primary energy resources from the environment and transforms them into final energy as depicted simply in Figure 21. It goes beyond the purpose of this article to thoroughly describe the Energy Module, which is explained in depth in section 2.3 in De Blas et al., (2018). However, in order to provide context for the final energy supply to the economy, it is important to know that it is conditioned by assumptions made on RER installed capacity growth rates, depletion curves of domestic NRER, energy policy' scenarios, and energy efficiency gains (see section 4.2.3). During the transformation process from primary to final energy, it also takes land and materials in order to deploy the energy infrastructures as new capacity is being installed. Final energy is broken down into five different types: solids, liquids, gases, electricity and heat. Each one, in turn, is disaggregated by the primary energy resources that supply them. By operating a hybrid IOA (Leontief, 1970; Miller and Blair, 2009), the final energy demand is estimated by sectors -both direct and indirect requirements- and final energy carriers (Heun, Carbajales-Dale and Haney, 2015). Final energy demand by $k \in 1 \ldots 5$ energy carriers $\mathbf{f e d}=\left[\mathrm{fed}_{k}\right]$ is the sum of the final

${ }^{16}$ GVA and GDP are measured at basic prices, i.e. including taxes less subsidies on production but excluding taxes on products (typically, value added taxes) 
energy demand made by ' $j$ ' $\in 1 \ldots 35$ industries fed_ind $=\left[\right.$ fed_ind $\left._{k}\right]=\sum_{j=1}^{35} f_{-} e d_{-} i n d_{k j}$ and households fed_hh $=\left[f e d_{-} h h_{k}\right]$. The energy coefficients - i.e. energy intensities - are taken from WIOD's historical data and then projected according to scenarios (see section 4.2.3). Both are also split into energy intensities for industries $\mathbf{E}_{-} \mathbf{I N D}=\left[e_{-} i n d_{k j}\right](5 \times 35$ matrix $)$ and for households $\mathbf{e} \_\mathbf{h h}=\left[e_{-} h h_{k}\right]\left(1 \times 35\right.$ vector). Eq. 21 provides the identity whereby fed_ind $_{k j}$ is estimated, Eq.22 the estimation of fed_ind $_{k}$ and Eq.23 the disaggregated estimation of total final energy demand $f e d_{k}$ by energy carriers.

$$
\begin{array}{lr}
e_{-} i n d_{k j}=f e d_{-} i n d_{k j} \cdot x_{j}^{-1} \rightarrow f e d_{-} i n d_{k j}=e_{-} i n d_{k j} \cdot x_{j} & \text { Eq. } 21 \\
\text { fed_ind }_{k}=\sum_{j=1}^{35}\left(e_{-} i n d_{k j} \cdot x_{j}\right) & \text { Eq. } 22 \\
\text { fed }_{k}=\text { fed_h }_{k}+f e d_{-} i n d_{k}=e_{-} h h_{k} \cdot \mathbf{c}+\sum_{j=1}^{35}\left(e_{-} i n d_{k j} \cdot x_{j}\right) & \text { Eq. } 23
\end{array}
$$

Then, the final energy use feu $=\mathbf{f e u}$ ind $+\mathbf{f e u} \_\mathbf{h h}=\left[f e u_{k}\right]=\sum_{j=1}^{35} f e u_{-} i n d_{k j}+$ $f e u_{-} h h_{k}$ is calculated after checking whether the energy system was able to supply all the final energy that was demanded to satisfy the needs of a growing GDP. An assumption has been made that all the possible energy shortages' influence is production-based and therefore, absorbed by industries. Considering this:

$$
\text { feu_ind }_{k j}=\text { fed_ind }_{k j} \cdot \varepsilon ; \quad \varepsilon=\operatorname{Min}\left(1, \frac{f e s_{k}}{\text { fed }_{k}}\right) \quad 0<\varepsilon \leq 1
$$

where $\varepsilon$ is as a shortage coefficient which amounts to either 1 if all total energy carriers are sufficiently supplied including households' demand, i.e. $f e d_{k}=f e s_{k}$ or the fraction representing the relative scarcity otherwise; thus, making the final energy use lower than demanded $\left(\right.$ feu_ind $_{k j}<f e d_{-} i n d_{k j}$ ) for the production requirements of the economy. As there is no assumption of perfect substitutability for neither economic nor energy inputs, the scarcer final energy source (i.e., the minimum quotient for $\varepsilon$ in Eq.11) determines the reduction in the sectoral output. Subsequent periods bring about energy substitution and the energy use reduction per unit of output both in industries and households. Thus, the feasible energy use imposes a new feasible output $\mathbf{f}_{-} \mathbf{x}=\left[f_{-} x_{j}\right]$ by conducting the inverse process as in Eq.21 and then substituting for Eq. 24:

$$
\mathbf{f} \_\mathbf{x}=\overline{\mathbf{E}}_{-} \widehat{I N D}^{-1} \cdot \mathbf{f e u} \text { ind }=\overline{\mathbf{E}}_{-} \widehat{I N D}^{-1} \cdot \mathbf{f e d} \_\mathbf{i n d} \cdot \operatorname{Min}\left(1, \frac{f e s_{k}}{f e d_{k}}\right)
$$

Hence, considering that fed_ind depends on the sectoral output (Eq. 8) that the economy requires to satisfy demand (Eq.5), which in turn depends on expectations and income inequality (Eqs.1-3), the economic output is a function of the final energy intensity, final energy supply, 
domestic economic structure ( $\mathbf{L}^{\mathrm{EU}-\mathrm{EU}}$ ) and final demand (fd), expectations, income inequality and foreign trade $\left(\mathbf{L}^{\mathrm{EU}-\mathrm{RoW}}\right.$ and $\left.\mathbf{e x p}\right)$.

\subsubsection{Employment sub-module and Labour feedback.}

The Employment sub-module is Post-Keynesian, Kaleckian (Kalecki, 1971; Lavoie, 2014) inspired and applied to an IOA framework. According to the Post-Keynesian theory of employment, it is determined by aggregated demand instead of by the relative price of labour, i.e. wages, as Neoclassical Economics states (Hicks, 1968; Boyer and Smith, 2001). Also unlike in Neoclassical Economics, involuntary unemployment is considered, including technological unemployment. According to this situation, a reduction in employment can be expected unless wages increase in step with or more than productivity, so the aggregate demand can offset the relative reduction in labour demand (Nell, 2005). Besides, in the short run, labour cannot be substituted by capital assuming fixed technical coefficients, which is very suitable for the InputOutput methodology used in MEDEAS. WIOD-Socioeconomic Accounts (Timmer et al., 2015) and EUKLEMS have been used and, so working hours per person engaged is the basic unit of analysis. It has been broken down by industries and three labour skills: low, medium and high. Unfortunately, the skills disaggregation is lost for numbers of people employed and working time in order to avoid extremely crude assumptions. The main novelty introduced in this employment model is the inclusion of a feedback loop from labour availability to the GDP growth potential. The process begins like in the energy-economy feedback, because it also follows an IO hybrid approach. According to this, labour demand in hours of work can be expressed as:

$$
\mathbf{h}=\mathbf{Y}^{-1} \cdot \mathbf{x}
$$

with $\mathbf{h}=\left[h_{s j}\right]$ being the labour demand in hours by skills 's' $\in 1 \ldots 3$ (low, medium and high), and sector ' $\mathrm{j}$ '; $\mathbf{Y}=\left[y_{s j}\right]$ the matrix of labour productivity by sectors and skills. This means that $\mathbf{Y}^{-1}$ is the labour intensity measured as the hours of work per unit of output $\left(\frac{h_{s j}}{x_{j}}\right)$. After that, in order to obtain the number of workers required $\mathbf{l d}=\left[l d_{j}\right]$, the total hours of work by sector $h_{j}=$ $\sum_{s=1}^{3} h_{s j}$ is divided by the hours per worker by sector $\mathbf{h p w}=\left[h p w_{j}\right]$ :

$$
l d_{j}=\frac{h_{j}}{h p w_{j}}=\frac{\sum_{s=1}^{3}\left(y_{s j}^{-1} \cdot x_{j}\right)}{h p w_{j}}
$$

Eq. 27

Therefore, the level of employment is a positive function of the aggregated demand and a negative function of productivity. It would also be a negative function of the hours per worker -meaning that a working time reduction (WTR) policy would increase labour demand. Then, hourly wages $\mathbf{h} \_\mathbf{w}=\left[h_{-} w_{j}\right]$ by sector are the result of the following equations: 


$$
w_{j}=h p w_{j} \cdot h_{-} w_{j} \cdot l d_{j} \rightarrow h_{-} w_{j}=\frac{w_{j}}{h p w_{j} \cdot l d_{j}} \rightarrow h_{-} w_{j}=\frac{\alpha_{j}^{\mathrm{lab}} \cdot g v a_{j}}{h p w_{j} \cdot l d_{j}}
$$

From a static perspective, Eq.15 shows a negative relationship between labour demand and hourly wages that, as we shall see in the results and discussion sections, operates differently from a dynamic point of view. It depends on whether it was a change in aggregate demand, productivity or working hours that triggered the labour demand variation (see Figure 21). Additionally, and crucially, it also depends on the initial situation being below or on full employment. All these aspects are discussed in section 4. Finally, as with the energy-economy feedback, if the labour force is not large enough to meet the labour requirements of the GDP growth, total output is cut by the same proportion as the lack in the labour force.

$$
l d_{j}^{\prime}=l d_{j} \cdot \lambda ; \quad \lambda=\operatorname{Min}\left(1, \frac{L F}{L D}\right) ; 0<\lambda \leq 1
$$

where $L F$ represents the total labour force, $\lambda$ the labour availability coefficient and $L D=\sum_{j=1}^{35} l d_{j}$ the total economy-wide labour demand. $L F$ is estimated as a proportion of the population which evolves at the same rate as the 1995-2015 historical observations. Additionally, $L F$ is considered as completely inelastic, an assumption consistent with the Post-Keynesian framework, meaning that we assume that if the labour force is available, all posts demanded by firms are covered. In order to enhance the realism of the outcomes, a $2 \%$ frictional unemployment rate is assumed, so the actually available $L F$ is $2 \%$ lower than that estimated with population growth.

\subsubsection{Definition of scenarios}

The main capability of the MEDEAS model is to estimate the trends that can be expected in the future under different scenarios and policy sets. Here, we distinguish between general assumptions, scenarios and policy targets. All of them are related to variables or parameters that are inputs in the model that affect the outcomes of the simulations differently. Assumptions referred to are arguable, but based on the literature or policy-targets with the explicit intention of evaluation. Scenarios describe different pathways that can be expected in the context of high uncertainty, normally as a combination of coherent assumptions. Policy targets are socioeconomic targets that depend to some extent on the actions of the policymakers in order to assess their potential effects on the system. In this article, we set two different frameworks for scenarios. Firstly, we define a Base scenario on which additional assumptions are added in order to evaluate their cumulative effects. Secondly, we propose three more typical scenarios based on different combinations of assumptions and policies: BAU, Green Growth and Post-Growth. The Base scenario assumes no energy constraints, a good global economic performance, a static economic 
structure (A Matrix) and primary income distribution, as well as productivity growth following the historical trends (see Figure 24 (a) and Appendix 3.A). Subsequent assumptions are added on top of that Base scenario:

i/ Energy Roadmap (ER50): geological limits in domestic extraction are included following the Mohr et al., (2015) and EGW (2013) 'Best Guess' for every primary energy resource's depletion curve. The REF16, EUCO27, EUCO33 and EUCO40 scenarios are imposed as a reduction in the domestic primary energy extraction and also in net imports. This constraint has been applied to all the primary energy resources in the ER50: oil, coal, gas and uranium. Although the EUCO scenarios stop by 2030, they have been projected until 2050 (see Appendix 3.B). Due to statistical discrepancies and a lower disaggregation detail in the PRIMES model, growth rates have been taken and applied to the MEDEAS data projections. Moreover, as a cautionary measure and to give flexibility to the system, a $+25 \%$ primary energy use (both domestic and imported) buffer is allowed for all resources. Energy efficiency follows the current trends in REF16, whereas the EUCO scenarios increase by $27 \%, 33 \%$ and $40 \%$ against the Base scenario, as stated by the EUCO storylines. The undertaking of a rapid transition towards RER will also be considered. Finally, GDP and population growth expectations are the same as those considered in the ER50 reports.

ii/ World Limits (WoLim): a MEDEAS-World scenario using worst-based simulations (Nieto et al., 2019) with energy constraints consistent with the global GDP growth moderation projections (Hawksworth, 2017; Leimbach et al., 2017) is assumed.

iii/ Lower productivity growth (LowProd): as the historical data is suggesting, especially in a context of lower access to highly profitable energy resources (Victor, 2019; Brockway et al., 2019).

iv/ Structural Change (SCh): Different policies are then developed to react to the previous outcomes: industrial policy oriented towards a modern, efficient economic structural change combined with emissions reduction capacity, represented by Germany ${ }^{17}$.

v/ Pro-labour policies (Lab): a working time reduction (WTR) together with an increase in labour bargaining power via raising the labour share and, therefore, total wages.

17 The criteria consisted on selecting a large European country with an efficient economic structure and good emissions reductions indicators (32\% lower than 1990). 
a) Sequential Scenarios

\begin{tabular}{|c|c|c|}
\hline $\begin{array}{l}\text { - World Economy optimistic. (High Growth) } \\
\text { - Static A Matrix. } \\
\text { - Static income distribution. }\end{array}$ & $\begin{array}{l}\text { - Labour productiviy medium growth (historical } \\
\text { average). } \\
\text { - No Energy Roadmap } 2050 .\end{array}$ & se \\
\hline $\begin{array}{l}\text { - World Economy optimistic. (High Growth) } \\
\text { - Static A Matrix. } \\
\text { - Static income distribution. }\end{array}$ & $\begin{array}{l}\text { - Labour productiviy medium growth (historical } \\
\text { average). } \\
\text { - Energy Roadmap } \mathbf{2 0 5 0 .}\end{array}$ & $\begin{array}{l}\text { Energy } \\
\text { Roadmap }\end{array}$ \\
\hline $\begin{array}{l}\text { - World Economy with energy limits (Low Growth). } \\
\text { - Static A Matrix. } \\
\text { - Static income distribution. }\end{array}$ & $\begin{array}{l}\text { - Labour productiviy medium growth (historical } \\
\text { average). } \\
\text { - Energy Roadmap } \mathbf{2 0 5 0 .}\end{array}$ & \\
\hline $\begin{array}{l}\text { - World Economy with energy limits (Low Growth). } \\
\text { - Static A Matrix. } \\
\text { - Static income distribution. }\end{array}$ & $\begin{array}{l}\text { Labour productiviy low growth (current } \\
\text { trends). } \\
\text { - Energy Roadmap } 2050 .\end{array}$ & \\
\hline $\begin{array}{l}\text { - World Economy with energy limits (Low Growth). } \\
\text { - Gradual convergence to Germany's A matrix. } \\
\text { - Static income distribution. }\end{array}$ & $\begin{array}{l}\text { - Labour productiviy low growth (current } \\
\text { trends). } \\
\text { - Energy Roadmap } 2050 .\end{array}$ & \\
\hline $\begin{array}{l}\text { - World Economy with energy limits (Low Growth). } \\
\text { - Gradual convergence to Germany's A matrix. } \\
\text { - Labour share increase. }\end{array}$ & $\begin{array}{l}\text { - Labour productiviy low growth (current } \\
\text { trends). } \\
\text { - Energy Roadmap 2050. } \\
\text { - Working Time Reduction policy. }\end{array}$ & $\begin{array}{l}\text { Labour } \\
\text { Policies (Lab) }\end{array}$ \\
\hline
\end{tabular}

\section{b) Storylines}

\begin{tabular}{|c|c|c|c|}
\hline Variable & BAU & Green Growth & Post-Growth \\
\hline GDP Expectations & SSP2 & SSP1 & Low \\
\hline Population growth & SSP2 & SSP1 & Low \\
\hline A Matrix & Static & Target: Germany & Target: Ad-hoc* \\
\hline Income Distribution & Current trends & Pro-labour & High pro-labour \\
\hline Productivity Growth & Current trends (Low) & Medium & Declining \\
\hline Working Time Reduction & No & No & Yes \\
\hline Renewables Installed Capacity Growth & Low & High & High \\
\hline Energy Efficiency Growth & Ref 2016 (Low) & EUCO33 (High) & EUCO40 (High +$)$ \\
\hline Energy Roadmap TPES restriction & Ref 2016 & EUCO33 & EUCO 40 \\
\hline
\end{tabular}

Figure 24. Sequential (a) and storylines (b) scenarios framework.

* An ad-hoc A matrix favouring the less energy intensive and more labour intensive sectors to the detriment of the more energy intensive and less labour intensive sectors is applied (see Appendix 3.D).

The framework of the other scenarios, i.e. the comprehensive storylines, allow the combination of scenarios and policies according to recognizable, consistent future pathways of the socioeconomic landscape (see Figure 24(b) and Appendix 3.A. These scenarios have been depicted as follows:

1) A BAU scenario based on current trends. The SSP2, also defined as 'Middle of the road' (Riahi et al., 2017) estimates, have been taken for this scenario regarding population and GDP expectations. No structural change is performed through the A Matrix. Also, income 
distribution continues a slow shift towards capital compensation to the detriment of labour share, with no working time reduction policies, although it follows a slow decrease based on historical trends. Productivity growth tends to be lower, as do the change in the energy mix efforts, the increase in energy productivity and the TPES reduction (following REF16).

2) A 'Green Growth' scenario, with an ambitious energy transition in the energy mix, high energy efficiency gains leading to a TPES reduction (EUCO33) combined with relatively higher productivity growth (getting back to the historical average prior to the Eurozone crisis), a transition to an efficient economic structure and high population and GDP expectations growth (according to SSP1, the 'Sustainability' narrative). Income distribution provides a relative increase in the labour share, but no WTR policy is implemented.

3) In the 'Post-Growth' scenario, the energy mix transition is equal to 'Green Growth', but with slightly higher efficiency and a more ambitious TPES reduction (EUCO40). However, unlike the other scenarios, GDP expectations and population growth are lower, primary income distribution shifts greatly to labour and a WTR policy is implemented. Simultaneously, a structural change that encourages the less energy and more labour intensive sectors (and discourages to the opposite ones) via the A matrix is operated (see Appendix 3.D). In order to carry this out, the amount of inputs purchased by all the sectors from different industries is increased or decreased (modifying by rows the technical coefficients of the targeted industries). For instance, agriculture, light industries, electricity and electrical equipment, reparations and retail trade except motor vehicles, health, education, social work and public administration have all been increased; whereas mining, refineries, transport, finance and the retail trade of motor vehicles have been reduced. Also, the efficiency of the electricity sector is improved by reducing the amount of inputs it requires to produce its output. These changes result in an overall reduction of the intermediate consumption's weight on total production.

All these scenarios assume that the World is subject to energy limits according to MEDEAS-W simulations and the same 'Best guess' approach to select the primary energy extraction capacity of the EU28. 


\subsection{Results}

Because one of the objectives of this article is to compare the MEDEAS' results with the ER50 and EUCO scenarios, the variables chosen to be shown are those considered important in this respect. These are GDP and employment as relevant socioeconomic variables and CO2eq emissions as the main climate outcome (Figure 25 for the sequential and Figure 26 for the storyline scenarios). In addition, such energy-related outcomes as the import dependency rate (Net Imports of Primary Energy/TPES) and the RER share on TPES are included (Table 15. Summary of main results: Import Dependency, Renewables share on TPES, GDP, Employment and GHG emissions by Scenarios. Source: own elaboration.).

i/ The first relevant result that can be noticed is that as soon as the TPES reduction is imposed, all the socioeconomic outcomes are worse compared to the Base scenario, but obviously better in terms of climate and energy goals. This suggests a conflict between the combination of environmental and socioeconomic objectives that can be nuanced thanks to different interventions. Through the ER50 scenarios, we can see that the REF16 scenario is able to achieve climate and energy outcomes similar to EUCO 27 and 33, but at a high socioeconomic cost. On the other hand, EUCO40 is the closest to the ER50 climate goals by 2050 with a $67 \%$ reduction with respect to 2010 (72\% compared to 1990), but with similar socioeconomic results to REF16. The import dependency declines and the RER increases as the restrictions to the use of NRER are higher. In fact, both indicators are better in our forecasts compared to the European Union's estimates (Table 15. Summary of main results: Import Dependency, Renewables share on TPES, GDP, Employment and GHG emissions by Scenarios. Source: own elaboration.). Nevertheless, again, this is achieved by incurring low employment outcomes and GDP stagnation (EUCO27 and 33) or collapse (REF16 and EUCO40), and these are only the results of applying the TPES restriction scenarios to the base model.

ii/ World Limits (WoLim): We can distinguish a short-term and a long-term effect. During the first simulation years, the export-intensive sectors reduce their sales. However, because the economy is still growing -though slowly- consumption (c) and investment (gfcf) are able to compensate for the impact of the weakening of sales abroad. Nevertheless, as a consequence of the energy constraint that is assumed, the domestic impulse after 2030 cannot sustain aggregate demand any longer. Consequently, GDP declines, as does the level of employment. Paradoxically, the fall of both indicators after imposing the world limits is less severe in all the scenarios. The fact that the exporting activities are more energy-intensive could explain this counter-intuitive effect. When these sectors' production is capped by the deterioration of the global economic context, energy demand decreases, releasing the economy-wide growth potential. This interesting outcome could unveil the prevalence of 
biophysical constraints to the socioeconomic ones. Furthermore, the overall reduction in commerce also leads to the shrinking of the dependency on imports and a small reduction in the GHG emissions decline as the RER share increases.

iii/ Lower productivity growth (LowProd): as long as it is imposed under primary energy use restrictions, it has no significant effects on GDP, GHG emissions, or energy-related outcomes. It does not matter how productive labour is if the energy inflows required from the productive processes are not delivered. This is the same as stating that a higher productivity growth would not improve the economic situation, given the energy constraints. In fact, under this context, a lower increase in productivity would contribute to significantly enhance the employment outcomes, as can be seen in Figure 25. Despite the positive effect on employment, it is still not enough to steer it closer to the Base, where full-employment is attained. The role of productivity is discussed in section 4 .

iv/ Structural change (SCh): a lower proportion of intermediate inputs $\left(z_{-} i \mathrm{ij}\right)$ are required to produce the same value of output $\left(\mathrm{x} \_\mathrm{j}_{\mathrm{j}}\right)$, resulting in an overall reduction of $\mathrm{a}_{-} \mathrm{ij}$, thus broadening the economy's capacity to produce value added ( $\llbracket g v a \rrbracket \_j$ ). Therefore, final demand is eventually stimulated, leading to an increase in GDP, production and employment. Nevertheless, this also results in higher energy demand in what could be seen as a sort of a 'rebound effect'. Thereby, the increased GDP also triggers -thus, not offset by efficiency gains- a rise in GHG emissions and the dependency on imports.

v/ Pro-Labour policies (Lab): A working time reduction (WTR) policy is gradually implemented, reducing the hpw by $14.28 \%$ (the equivalent reduction from $35 \mathrm{~h}$ to $30 \mathrm{~h}$ ) by the middle of the 2030s, before employment collapses. Simultaneously, there is an increase in the labour share -taken as a proxy variable of the labour bargaining power- in order to maintain the purchasing power of households that sustain aggregate demand during the gradual implementation of the policy, though GDP slightly declines. Employment rises in EUCO27 and EUCO33. However, the energy restriction is so severe in EUCO40 that not even the WTR policy is able to restore the level of employment. Together with the improvement in employment, it also corrects the increase in GHG emissions unleashed by the structural change, thus also achieving an enhancement of the climate goals. 

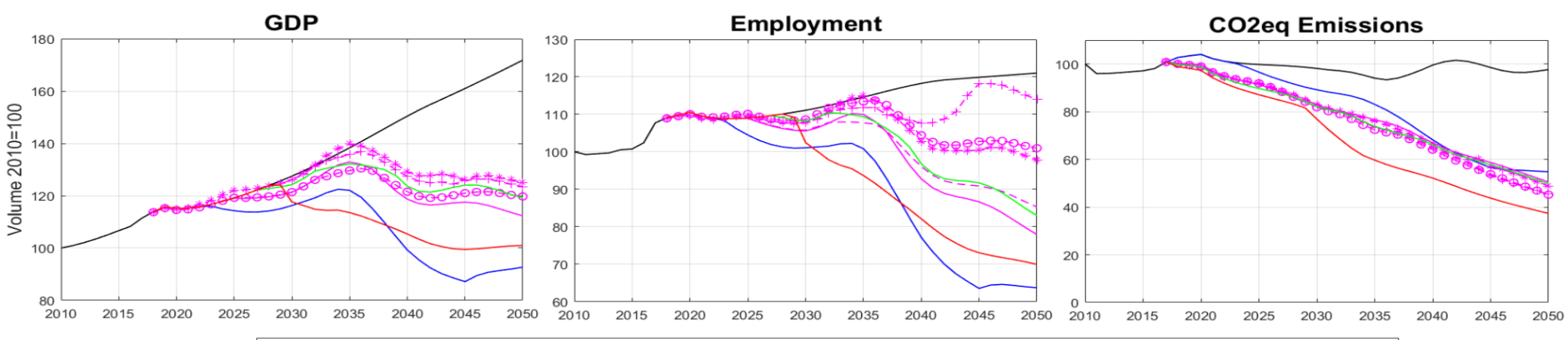

Figure 25. Sequential

scenarios for the Energy

Roadmap 2050. Key

variables.

Source: own elaboration

- Base —REF16 — EUCO27 - - -EUCO27_WoLim - - -EUCO27_LowProd - * -EUCO27_SCh -+-EUCO27_Lab —EUCO33 —EUCO40
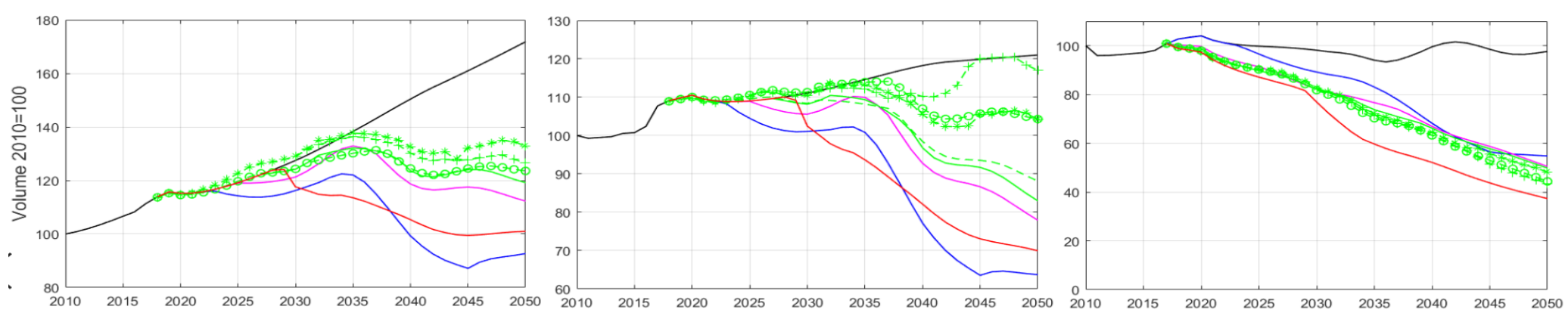

- Base — REF16 — EUCO27 — EUCO33 - - EUCO33_WoLim - - -EUCO33_LowProd -* -EUCO33_SCh -+-EUCO33_Lab —EUCO40
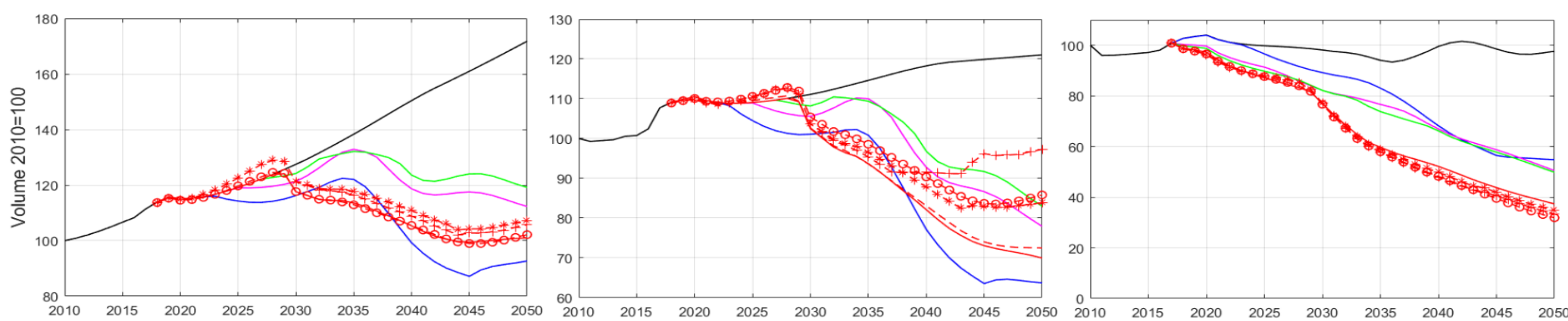

—Base — REF16 - EUCO27 — EUCO33 — EUCO40 - - -EUCO40_WoLim - - -EUCO40_LowProd -* -EUCO40_SCh -+-EUCO40_Lab 
As mentioned before, in addition to the sequential scenarios, a set of three coherent 'storylines' (Business as Usual, Green Growth and Post-Growth) have been assessed as scenarios, which are shown in Figure 26. Storyline scenarios. Main results. Source: own elaboration.:

1) BAU: climate goals are met only after economic collapse. Because the efforts to install new renewables infrastructures are low, all the NRER demand cannot be met via domestic extraction and imports need to increase, leading to an energy shortage if the REF16 estimates are not to be trespassed; even considering the cautionary $25 \%$ buffer applied (see section 2.3). By 2030, the economy is no longer able to cope with the NRER restrictions given the absence of a credible energy mix transition. Despite the increase in the capital share, investment is not able to stimulate aggregate demand, given the containment of salaries and the energy shortage. Therefore, employment demand plummets. Despite the economy's downfall, the GHG emissions reduction by 2050 is higher than the Ref16 and EUCO scenarios (2050 projections), both the estimations from the EU reports and MEDEAS simulations.
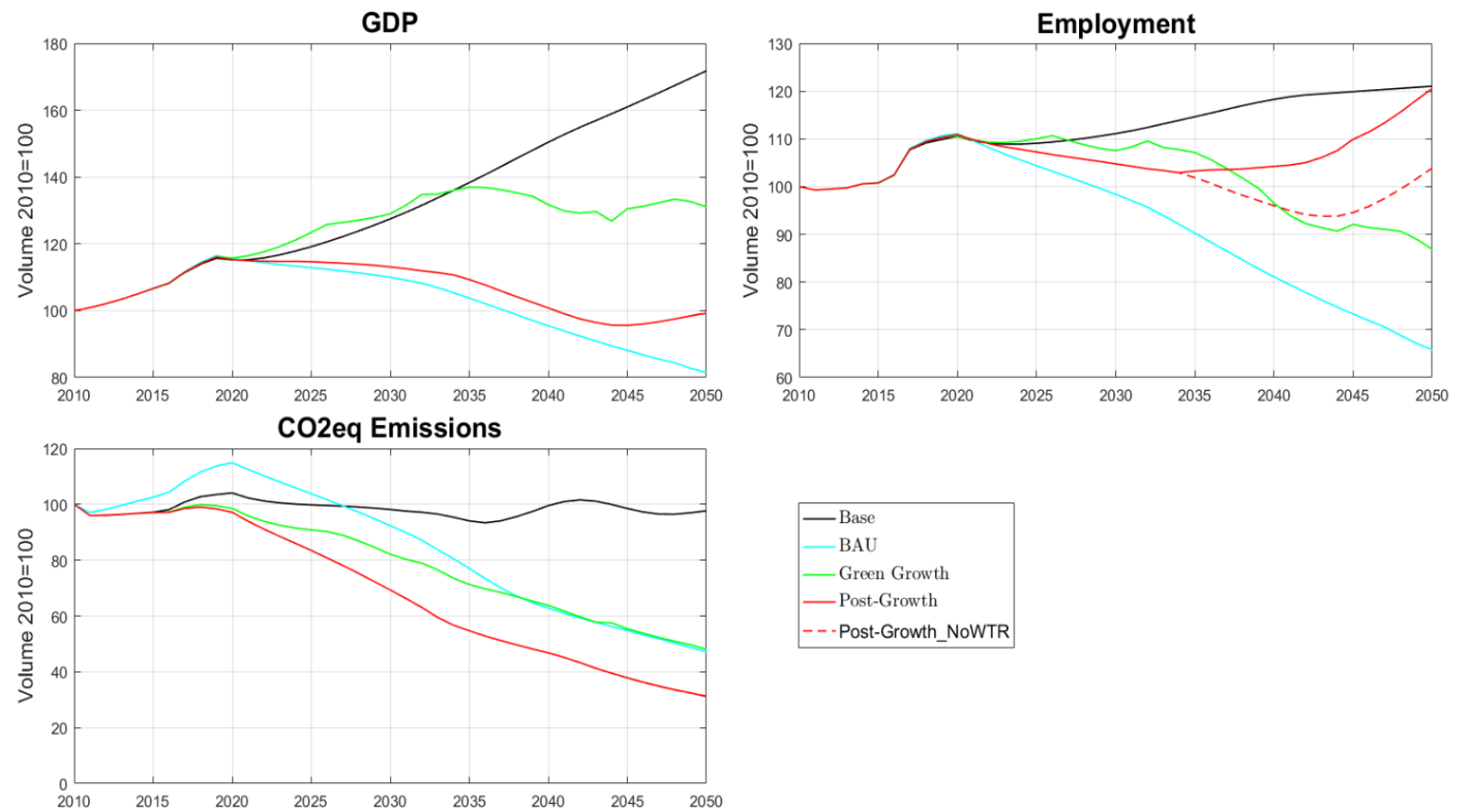

Figure 26. Storyline scenarios. Main results. Source: own elaboration.

2) Green Growth: technological change -represented by an intense increase in energy efficiency and the gradual transition towards a more efficient A matrix- and a shift in the energy mix reduce environmental pressures. Nevertheless, an increased productivity growth consistent with the scenario storyline, the higher GDP and population growth expectations impose a pressure to the energy system that hinders the energy transition. The high energy demand required to satisfy an increased aggregate demand -also bolstered by a rise in the labour 
share- at an early stage of the energy transition makes it difficult to deploy the new RER infrastructures on time. As a consequence, the RER share on TPES is similar to that in REF16, EUCO27 and EUCO33, leading to the noncompliance of GHG emissions reduction by 2050 . Nevertheless, due to enhanced capacity of the economic system, GDP and employment values are better than in these scenarios, yet not enough to avoid economic downturn by 2035 and stagnation after 2040 .

3) Post-Growth: This scenario reduces the import dependency rate to $30 \%$, has the higher RER share on TPES (54\%) -apart from the collapse-led reduction in BAU-, higher employment rates and is the only scenario - except BASE- that barely meets climate goals: 24.7 with $2010=100$, i.e., $79 \%$ with respect to 1990 . On the negative side, GDP would be slightly lower than 2010, meaning that the EU28 would need to deal with a declining GDP soon if climate targets are to be met. An additional variant has been included (Post-Growth_noWTR) to isolate the effects of a rise in the labour share from the working time reduction policy under energy constraints. A reduction in the level of employment is observed in comparison to the scenario that includes the WTR policy. 


\begin{tabular}{|c|c|c|c|c|c|c|c|c|c|c|c|c|c|}
\hline & & \multicolumn{3}{|c|}{$\begin{array}{c}\text { Import Dependency } \\
(\%)\end{array}$} & \multicolumn{3}{|c|}{$\begin{array}{c}\text { RER share on TPES } \\
(\%)\end{array}$} & \multicolumn{2}{|c|}{$\begin{array}{c}\text { GDP } \\
(2010=100) \\
\end{array}$} & \multicolumn{2}{|c|}{$\begin{array}{c}\text { Employment } \\
(2010=100\end{array}$} & \multicolumn{2}{|c|}{$\begin{array}{c}\text { GHG emissions } \\
(2010=100)\end{array}$} \\
\hline & & 2010 & 2030 & 2050 & 2010 & 2030 & 2050 & 2030 & 2050 & 2030 & 2050 & 2030 & 2050 \\
\hline \multirow{4}{*}{$\begin{array}{l}\text { Energy Roadmap } \\
2050\end{array}$} & Ref 2016 & \multirow{24}{*}{50.2} & 56.6 & 57.6 & \multirow{24}{*}{11.4} & 9.7 & 23.6 & \multirow{4}{*}{129.4} & 174.7 & \multirow{4}{*}{\multicolumn{2}{|c|}{ 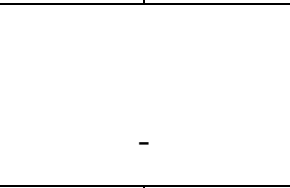 }} & 76.5 & 61.72 \\
\hline & EUCO+27 & & 54.3 & $58.4 *$ & & \multirow{3}{*}{19.6} & \multirow{3}{*}{$27.8 *$} & & \multirow{3}{*}{$158.8 *$} & & & 70.0 & $40.0^{*}$ \\
\hline & EUCO+33 & & 52.6 & $55.0 *$ & & & & & & & & 67.3 & $34.6^{*}$ \\
\hline & EUCO+40 & & 51.8 & $53.4 *$ & & & & & & & & 62.4 & $24.8^{*}$ \\
\hline \multirow{20}{*}{$\begin{array}{c}\text { MEDEAS - } \\
\text { Europe } \\
\text { estimates }\end{array}$} & Base & & 50.8 & 55.3 & & 20.0 & 29.7 & 127.5 & 171.8 & 111.1 & 121.0 & 98.2 & 97.7 \\
\hline & REF16 & & 49.3 & 40.0 & & 22.7 & 42.4 & 116.2 & 92.7 & 101.1 & 63.7 & 89.2 & 54.8 \\
\hline & EUCO27 & & 47.7 & 39.6 & & 23.8 & 42.3 & 121.3 & 112.3 & 105.6 & 77.9 & 82.1 & 50.5 \\
\hline & WoLim & & 47.3 & 37.9 & & 24.2 & 44.2 & 121.4 & 119.7 & 105.8 & 85.3 & 81.9 & 45.2 \\
\hline & Prod & & 47.4 & 37.9 & & 24.2 & 44.2 & 121.4 & 119.7 & 108.7 & 101.0 & 81.9 & 45.2 \\
\hline & SCh & & 47.8 & 39.9 & & 23.9 & 42.3 & 126.0 & 125.0 & 107.8 & 97.9 & 82.9 & 48.9 \\
\hline & Lab & & 47.8 & 38.5 & & 24.2 & 43.6 & 126.0 & 123.5 & 107.8 & 114.0 & 82.9 & 45.4 \\
\hline & EUCO33 & & 47.8 & 39.4 & & 24.0 & 42.8 & 124.2 & 119.2 & 108.2 & 83.0 & 82.2 & 49.8 \\
\hline & WoLim & & 47.9 & 38.0 & & 24.0 & 44.5 & 124.3 & 123.6 & 108.4 & 88.2 & 81.8 & 44.4 \\
\hline & Prod & & 47.8 & 38.1 & & 24.1 & 44.5 & 124.3 & 123.6 & 111.3 & 104.3 & 81.8 & 44.4 \\
\hline & SCh & & 48.0 & 40.1 & & 24.0 & 42.4 & 129.0 & 132.8 & 110.4 & 104.2 & 82.7 & 48.3 \\
\hline & Lab & & 48.0 & 37.8 & & 24.0 & 44.6 & 129.0 & 126.7 & 110.4 & 117.0 & 82.7 & 43.6 \\
\hline & EUCO40 & & 46.1 & 30.7 & & 25.2 & 50.4 & 117.6 & 101.0 & 102.5 & 70.0 & 76.9 & 37.3 \\
\hline & WoLim & & 47.2 & 30.6 & & 25.3 & 51.8 & 117.7 & 102.2 & 102.7 & 72.5 & 76.7 & 31.9 \\
\hline & Prod & & 47.2 & 30.4 & & 25.3 & 51.9 & 117.7 & 102.2 & 105.4 & 85.8 & 76.7 & 31.9 \\
\hline & SCh & & 47.5 & 30.8 & & 25.1 & 50.5 & 121.1 & 107.3 & 103.7 & 83.9 & 77.2 & 34.8 \\
\hline & Lab & & 47.5 & 30.8 & & 25.1 & 50.4 & 121.1 & 105.8 & 103.7 & 97.3 & 77.2 & 33.4 \\
\hline & BAU & & 46.0 & 29.6 & & 22.0 & 57.4 & 110.0 & 81.5 & 98.4 & 65.8 & 92.4 & 47.2 \\
\hline & $\begin{array}{c}\text { Green } \\
\text { Growth }\end{array}$ & & 48.8 & 40.4 & & 23.6 & 42.2 & 129.0 & 131.1 & 107.5 & 86.8 & 82.1 & 48.1 \\
\hline & $\begin{array}{c}\text { Post- } \\
\text { Growth }\end{array}$ & & 45.4 & 30.0 & & 26.1 & 54.6 & 113.1 & 99.2 & 104.8 & 120.6 & 69.3 & 31.1 \\
\hline
\end{tabular}

Table 15. Summary of main results: Import Dependency, Renewables share on TPES, GDP, Employment and GHG emissions by Scenarios. Source: own elaboration.

*Linear projection. 


\subsection{Discussion}

Modelling complex systems means taking uncertainty and complexity into account. The scenarios-based analysis allows uncertainty to be dealt with transparently. In fact, the sequential scenarios' outcomes can be seen as the likely pathways under different policy or scenario assumptions. Whereas it is common in the literature to introduce different variants -or scenariosin order to assess their marginal effect on the results, in this article, these variants are cumulative, which would offer a more complete picture. There are two reasons why we consider this a more appropriate approach. Firstly, because in the real world, policies and structural conditioners -the landscape in transitions terminology (Geels, 2002)- tend to operate simultaneously and not individually. Secondly, because dominance hierarchies can thus be revealed between the different hypotheses, as described below. These scenarios were set in the first place because this paper aims to test the effects of energy restrictions on the economy.

On the other hand, system dynamics is an appropriate methodology to deal with complex systems It is able to allow the examination of the propagation of disturbances in the system, taking feedback loops, time lags and stock-flow relationships into account. This also fits well with the ecological economics theoretical framework (Constanza and and, 1997; Farley and Daly, 2003) whereby in a planet with finite stocks of resources, the socioeconomic system is limited to the boundaries imposed by the environment. Its metabolic standpoint, in turn, enables an understanding of sustainability transitions aligned with the socio-metabolic approach (Krausmann et al., 2008; M Fischer-Kowalski, 2011). According to this approach, transitions to sustainability are bounded to 'the energy system a society depends upon', subject to lock-in situations or system collapse (Tainter, 1988, 2011), or tipping points in earth systems (Lenton et al., 2008). MEDEAS is able to take this into consideration, fully integrating the economy and the biophysical systems. Models and policy-makers should not disregard the two-way, subordinated relationship between the socioeconomic system and the environment.

\subsubsection{An ecological macroeconomics contribution to Post-Keynesian theory}

Simulation, demand-led models have proven their worth in Integrated Assessment Modelling (Scrieciu, Rezai and Mechler, 2013). At the same time, ecological macroeconomics models (Rezai, Taylor and Mechler, 2013; Taylor, Rezai and Foley, 2016; Hardt and O'Neill, 2017) have contributed to that body of literature increasingly grounded in Keynesian and PostKeynesian Economics (PKE) (Kaldor, 1957; Lavoie, 2014; Cahen-Fourot and Lavoie, 2016). The MEDEAS' Economy module and Employment sub-module inspiration in PKE can be summarised in the three following characteristics: i/ the level of employment is determined by the aggregate demand -and based on IOA, i.e. the complementarity of productive factors; ii/ labour 
demand is not determined by wages but, if anything, aggregate demand is a positive function of wages; iii/ labour demand is not systematically converging towards equilibrium with labour supply: involuntary unemployment is considered and technological unemployment play an important role. All of them are consistent with a Kaleckian approach to employment and subject to revision when analysed under biophysical constraints.

Although the model is built according to these principles, in the context of energy restrictions, a rise in wages could lose its effectiveness to increase the labour demand. As can be seen in the Post-Growth_noWTR scenario (Figure 26) employment falls despite the increase in the labour share. Figure 27 represents a (for the sake of the argument) simplified version of the Kaleckian employment model, inspired in Lavoie (2014 According to this model, the labour demand is a positive function of the real wages, as an increase in them represents a stimulus to aggregate demand. Therefore, a rise in those real wages $(w / p)$, from $(w / p)_{0}$ to $(w / p)_{1}$, would imply a movement up along the labour demand curve, resulting in an increase in the level of employment from $\mathrm{L}_{0}$ to $\mathrm{L}_{1}$. However, beyond full employment $\left(\mathrm{L}_{\mathrm{FE}}\right)$, an increase in real wages above $(\mathrm{w} / \mathrm{p})_{\mathrm{FE}}$ would be ineffective.

What the results of this article suggest is that the energy supply constraints could act as a reducer of the full capacity of the economy regardless of the labour supply, i.e. even below the level of full employment. As so, the same real wages increase would only be able to increase the level of employment from $\mathrm{L}_{0}$ to $\mathrm{L}_{2}$, capping the real wages up to a maximum of $(w / p)_{2}$. This way, the environment would be a determinant of the economy's boundaries, just as Ecological Economics states. Accordingly, the sustainability approach of this theoretical framework would be fully operating in this extended model, as energy would be acting as an absolute restriction. Not a relative one, since it is not possible to avert its consequences by substituting energy by neither manufactured capital (through investments increasing aggregate demand) nor labour, as an aggregate neoclassical production function would allow. Rather, the complementarity of the energy inputs to produce the economic throughput would drive the economy's full potential leftwards in Figure 27, i.e. reducing it. 


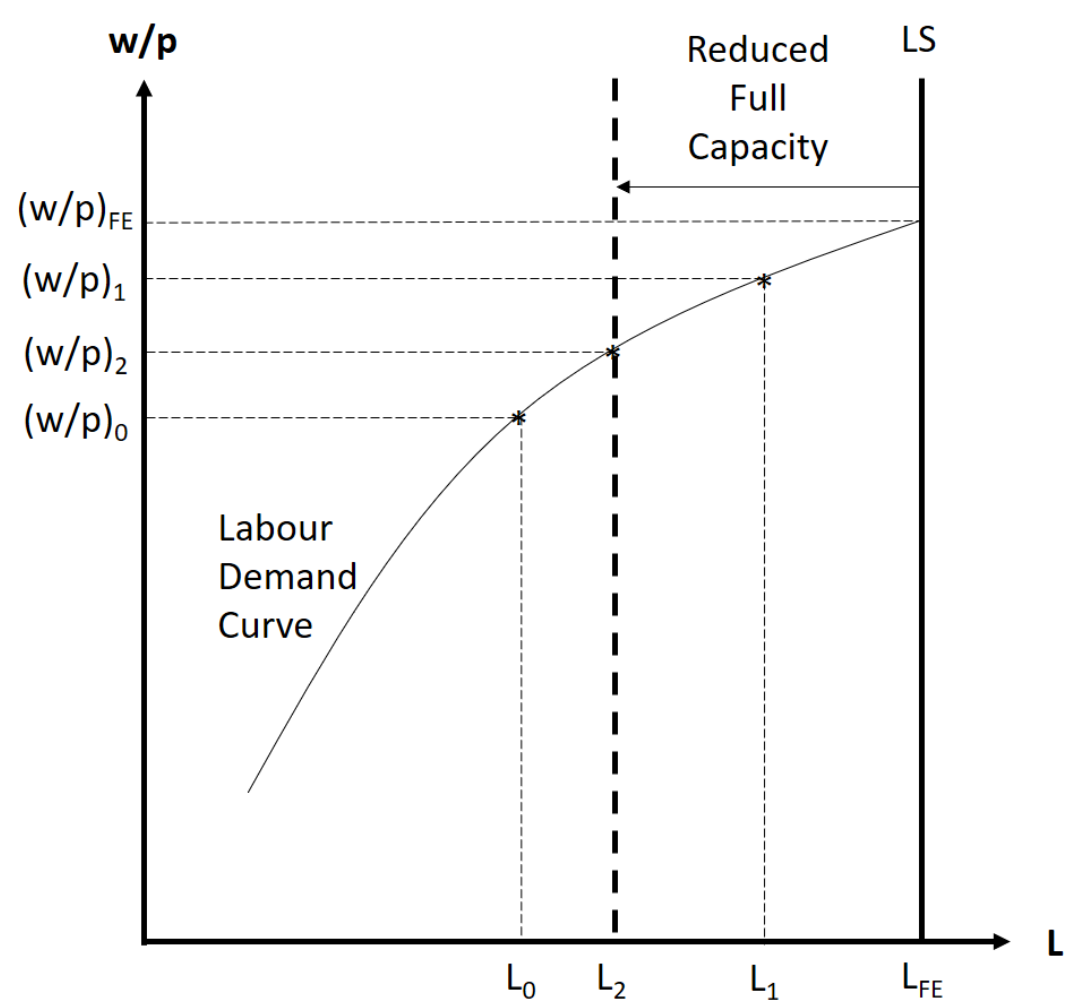

Figure 27. Kaleckian employment model extended with energy supply constraints. Source: own elaboration.

Hence, a paradox emerges, since the initial status as a wage-led economy (Bhaduri, 2007; Lavoie and Stockhammer, 2013), i.e. wages being the main driver of the aggregate demand increases instead of profits, is rejected after imposing energy constraints. Moreover, as the Green Growth scenario shows, not even an exogenous increase in aggregate demand would be able to maintain the level of employment, as it would face the same reduced full capacity. Nevertheless, the application of a working time reduction (WTR) policy could help the level of employment to rise. In effect, the results of the pro-labour policies (Lab) in section 3 show a negligible response on GDP, which may suggest a lowering of the full capacity threshold of the economy. PKE states that a working time reduction policy, to be successful in increasing the level of employment, must raise wages at the same or a higher proportion than productivity growth in order to maintain aggregate demand (Nell, 2005). In Figure 27, once in $\mathrm{L}_{2}$, a WTR policy could potentially avoid the energy-restricted full capacity and get back to $\mathrm{L}_{1}$, as long as salaries increase to $(\mathrm{w} / \mathrm{p})_{1}$. Conversely, if salaries still remain at $(w / p)_{2}$, employment would not be able to recover, as the effective demand would not have been stimulated.

Therefore, it could be expected that expanding the level of employment becomes increasingly difficult if energy use is restricted. However, according to our results, a WTR policy could contribute to increasing the level of employment under energy constraints if a considerable socioeconomic change is undertaken, such as the one defined in the Post-Growth scenario. 
Moreover, a higher labour share, combined with WTR, may have the ability to reinforce disposable income and reduce income inequality.

Regarding the role of productivity and technological unemployment, the MEDEAS approach can also supplement PKE with new insights. According to the Kaleckian employment model, an increase in productivity can result in a reduction in the level of employment if it is not accompanied by a greater increase in salaries. In fact, because salaries have lost their ability to expand aggregate demand under energy constraints, higher productivity growth is very likely to reduce the level of employment. Moreover, productivity plays a contradictory role in modern capitalist economies in what Jackson and Victor (2011) called the 'productivity trap'. Certainly, in a profit-seeking economy where capital owners need to compete in order to avoid an interruption of the accumulation process, there is a natural incentive to increase productivity so their labour costs are reduced.

On the other hand, productivity growth also implies a reduction in the labour requirements to produce the same output, as well as a constraint to aggregate demand if wages do not increase at least at the same rate. The authors explore the potential to maintain jobs while reducing carbon emissions by applying a working time reduction policy and an industrial policy oriented towards favouring the more labour-intensive sectors in the UK. Our results in the Post-Growth scenario would confirm that study, now generalized to the EU28 and even forecasting a potential increase in employment. In fact, a shift towards a low-productivity growth regime is a phenomenon that is already taking place: a reduction in overall productivity growth has been observed since the late 1970s in the OECD countries (this would also justify the LowProd assumption and its integration in the BAU scenario). Given the historically tight link between access to high-quality energy resources and productivity growth, in a context of lower energy use and the transition to less power density sources, the fall in productivity growth may continue (Jackson, 2019).

As captured by the MEDEAS labour feedback, if the labour requirements to increase GDP are higher than the available labour force, then GDP growth will be lower than expected. Therefore, population or productivity growth can contribute to easing this pressure. Considering the ageing of the population, as well as the decline in population growth rates, the two most likely options for the EU in the future may be the following: Firstly, increasing productivity sufficiently to avoid this situation, but not by enough to escape the 'productivity trap'. Then again, as long as the full potential of the economy may be capped by the energy restrictions -as shown in our results-, labour productivity growth may be ineffective to reinforce GDP growth. Secondly, it could actually be more likely, since productivity growth rates are steadily falling, as is already happening in particular EU economies, for instance Germany, where there are calls to increase its 
labour force once the stagnation of productivity growth has completely settled in. Of course, this may well be unevenly distributed across the EU countries.

\subsubsection{A realistic methodology to assess energy transition scenarios.}

The set of models used by the European Commission to develop the REF16 scenario are interconnected, but only the economy is left as a 'framework assumption', based on the Computable General Equilibrium (CGE) model GEM-E3. The EUCO scenarios were created using PRIMES with the Ref2016 as the starting point and, after that, two other modelling exercises were undertaken to assess their potential macroeconomic impacts. The GEM-E3 (Pollit, 2016) model shows an improvement of both GDP and employment as energy restrictions get harsher -when financing is loan-based instead of based on self-financing. The E3ME (Pollit, 2014) modelling describes a similar situation, with GDP 2.2\%-4.4\% and employment $1.4 \%-2.1 \%$ higher in the EUCO+40 as compared to the EUCO+27 by 2030. However, MEDEAS follows a different methodology, whereby not only the environment is influenced by the economy, but the environment also conditions the economy. In fact, the conditioning power of the environment over the economy is so strong that some policies lose all or part of their capacity under energy constraints, as explained before. As can be seen in section 3, the stricter the TPES reduction, the more difficult it is for the economy to maintain macroeconomic stability. Not even applying major energy efficiency gains does the economy receive sufficient energy inflows and, therefore, a slowdown or even a downturn of GDP occurs. Furthermore, because employment is determined by aggregate demand, the level of employment falls in the reduced energy consumption scenarios.

The basic hypothesis underlying conventional models is that energy consumption will be reduced by as much as energy efficiency grows. This paradigm underestimates the presence of rebound effects (Blake, 2005; Polimeni et al., 2015; Duarte, Mainar and Sánchez-Chóliz, 2013) and energy availability limits. In MEDEAS, the rebound effect is implicitly considered. Because energy scarcity hinders economic growth, the higher the energy efficiency gains are, the longer the accumulation progress can last. Therefore, energy efficiency gains increase the potential aggregate demand, which eventually leads to higher energy consumption. This is what explains the ability to grow faster in the EUCO and Green growth scenarios as compared to REF16 at an early stage. But then, the intensified pressure on natural resources, triggered by the higher demand, interrupts economic growth. This may show the importance of the adequate accountability of both the direct and indirect effects of the necessary energy efficiency targets.

Furthermore, as expressed in the previous sub-section, MEDEAS is able to capture the systemic hierarchy dependencies. Moreover, its granular framework, based on Input-Output Analysis, enables the emergence of situations that would remain hidden in aggregated models. The systemic hierarchies have already been explained in the previous subsection, since economic 
incentives lose their effectiveness if energy availability is insufficient to supply the productive process. This reveals the subjection of the society and the economy to the biophysical restrictions. The lack of integration of the different components of the system in Integrated Assessment modelling could lead to the overestimation of the capability of the economy to absorb large energy use reductions, as well as huge energy efficiency gains. For instance, the set of models used by the European Union presents a unidirectional link between the economy and the environment. According to this, the economy is virtually autonomous and the environment plays a passive role as a same-level subsystem that only receives impacts from the economy. To the best of our knowledge, this is very common in IAM, which may be leading to unrealistic outcomes that could mislead the policymakers' future decisions.

All the scenarios simulated present a fundamental conflict between environmental and social objectives. Nevertheless, favouring less energy-intensive sectors, along with the more labour-intensive sectors, in the Post-Growth scenario (see section 3) was crucial to reconciling environmental and social objectives. Industrial policy has been ruled out in practice over the last few decades. The results of this article suggest that it may be a relevant tool of economic policy for a successful energy transition. This conflict is well represented by the Green growth scenario, which also poses a challenging paradox: despite the great efforts to unfold a renewable energy transition, along with rapid energy efficiency gains, would require massive energy inflows that, at the early stage of the transition, must be provided partially by NRER. This fact is especially intense under a high GDP and productivity growth regime. Not even an industrial policy aimed at converging with a modern, efficient, emissions-reducer structure like Germany's is able to offset this tendency. As a result, the import dependency in the Green growth scenario is similar to that in the MEDEAS REF16 estimate (40\%), yet much lower than the EU Ref2016 estimate by 2050 (56\%). Similarly, the GHG emissions do not decrease enough to meet the climate goals (55\% with respect to 2010 , i.e., $61 \%$ over 1990). Moreover, this scenario could not avoid a decrease in employment, which could potentially be corrected by WTR policy.

\subsection{Conclusions}

The energy transition that the European Union is decided to undertake, described in its Energy Roadmap 2050, is not without its challenges. In order to cope with them, an important and serious modelling effort has been done. At an early stage of the Roadmap (in 2013), the European Union unveiled a first report anticipating the main results to be expected under different hypotheses. The first 'Reference' scenario, i.e., expressing current trends without energy transition objectives after 2020, forecasted a net increase in energy consumption by 2050 . 
However, the Eurozone crisis changed the 'current trends' and, after that, a new 'Reference' scenario was released in 2016. In addition, the EUCO scenarios were also released in order to explore further energy reduction and more ambitious transition pathways. In this new version, following the new 'current trends', the 'Reference' scenario forecasted a net reduction of energy consumption in 2050. However, only one year later, energy consumption resumed its tendency to grow. The European Union's scenarios predict that the energy transition will boost economic growth and employment creation. However, the results obtained from MEDEAS-Europe are suggesting that such energy use reductions may well be harming key socioeconomic indicators in the absence of further policies.

Insufficient integration of the economic system, and the resources that the economy rely on, can lead to modelling results that are not able to account for the limits that the former imposes on the latter. Should this be disregarded, the one-way relationship from the economy to society and the environment, inevitably leads to socioeconomic outputs being improved as energy use is downsized. The optimization hypothesis as the cornerstone of the economic process guarantees equilibrium - in the long-run in the worst case- and therefore full employment, while continued economic growth drives employment unequivocally up. MEDEAS-Europe contributes to filling this gap by adopting an ecological economics approach, whereby the economy is a subsystem of the biophysical system and the society. Thus, a deficient energy supply to what is required from the economy to maintain a certain GDP growth would reduce the economy's full capacity. As a consequence, this investigation shows that, despite the high energy efficiency gains applied to all the Energy Roadmap scenarios, the forecasted socioeconomic outputs are unlikely to be achieved. Moreover, the climate goals would only be reached at great socioeconomic costs. In fact, under reduced energy use scenarios, monetary demand stimulus may no longer be effective to sustain employment creation -as the Keynesian and Post-Keynesian literature states. In this context, the inherent trend of the market-based economic systems to increase labour productivity would potentially deepen employment destruction.

In general terms, all the MEDEAS-EU28 scenarios present a trend that implies a reduction in the dependence on imports -except Base-, the GHG emissions and an increase in the RER share. However, in REF16, this has more to do with NRER depletion and reduced capability to import, and not due to an adequate energy transition. EUCO40 is unable to cope with such a steep energy use reduction while avoiding economic downturn, which eventually leads to the reduction of dependency and environmental impacts. It can be seen that the ER2050 might be overestimating GDP growth in all their scenarios and, as a consequence, without any intervention to stimulate employment, labour demand would strongly decline. Structural change towards an increased economic efficiency would be able to 'buy time' in terms of GDP growth, but without industrial policy aimed at decreasing the importance of the energy-intensive sectors and 
increasing the less-energy intensive ones, this would lead to additional environmental impacts. In fact, if the EUCO scenarios are projected to 2050, this effect would be ineffective after the 2030s. Therefore, pro-labour policies may be required to sustain employment along with meeting the environmental goals.

As a result of the above, only a self-defined Post-Growth scenario is able to cope with the shift to renewables and the energy use reduction transition, while maintaining employment and achieving a substantial emissions reduction (70\%). This would call into question the feasibility of policy agendas committing to net zero by 2040, without a detailed socioeconomic shift plan. The results attained in the PG scenario are caused by the structural change steering the economy towards labour-intensive and less energy-intensive sectors, as well as a reduction in the GDP growth expectations. In order to compensate for this, an increase in salaries accompanying a working time reduction (WTR) policy lets employment recover. This highlights the importance of the Post-Keynesian standpoint, whereby a WTR policy should be aligned with a wage increase that outpaces productivity growth if employment is to be maintained. Actually, reducing the proportion of intermediate inputs to produce economic output could contribute to reducing the material and energy inputs required from the economy. However, if these pro-labour policies are not undertaken, employment would not be likely to react. For instance, an increase in the labour bargaining power (or the labour share) could avert the appropriation of the increase in income since gross value added has been broadened by reducing the intermediate consumption to produce one unit of output- by the capital-owners, which could lead to higher inequality and reduced aggregate demand -given that salary-earners are more keen on spending, proportionally, than capital-owners. Thus, this could contribute to the main challenge of this narrative: the decoupling of human well-being from economic growth. 


\section{Conclusion}

Climate scientists have warned about the complex processes which the elevation of the global temperatures lead to. This complexity is the result of the existence of non-linear dynamics, presenting positive, reinforcing feedbacks between them. Moreover, these are subject to considerable inertia, which makes its reversion increasingly difficult. A sound example of this situation is the liberation of huge quantities of methane as a consequence of the permafrost melting in Northern latitudes. Therefore, the escalation of global temperatures is faster than predicted, thus making accelerating tipping-points or even no-return points more likely to be reached. Naturally, this implies that achieving the IPCC targets to avoid an increase of $1.5 \mathrm{C}-2 \mathrm{C}$ in the global average temperature in time would require an even greater effort than previously envisaged. In order to evaluate whether the global community is committed to undertaking sufficient actions to tackle climate change, this thesis has contributed to answering the research questions outlined in the introduction section. This conclusion section includes the main findings of this thesis, its policy and theory implications and, finally, its limitations and future developments.

\subsection{Main Findings}

The Intended Nationally Determined Contributions (INDCs) are the documents submitted by countries to comply with the Paris Agreement. Accordingly, the INDCs required at least a voluntary commitment describing: $\mathrm{i} /$ the emissions reduction target; ii/ the set of policies to attain that target; iii/ the means to finance and implement that set of policies. Therefore, the main findings of this research, addressing Objective 1 of the thesis, are the following:

- Overall, no significant socioeconomic transformations are detailed in the INDCs. The sustainability transition would be a combination of capital investment and green technologies, which would eventually lead to "inclusive economic growth". This would build on a "Green Growth" narrative.

- The implementation of all the policies would require at least (since not all the countries reported financial carriers) 5,423 bn US \$, equivalent to 7.3\% of global GDP in 2017. $41.4 \%$ of the financial requirements are conditional to the reception of foreign North-South support.

- The voluntary, unilateral approach of the Paris Agreement leads to incoherencies between policies, e.g., a huge reliance on forestation (it is the third most mentioned policy in $42 \%$ of the INDCs, mainly in Lower-Income countries) and fostering biofuels (18\% of all INDCs 
mention it, especially in Low-income countries where cropland is normally placed, and HigherIncome countries where they are typically transformed and consumed).

- According to the information from the INDCs, their full implementation would imply a $19.3 \%$ increase in emissions by 2030 compared to the $2005-2015$ average). The application of only the unconditional commitments would raise global emissions by $25.8 \%$. If no policies are applied (Baseline or Business as usual), emissions would increase by $31.5 \%$.

- All scenarios would entail, should their trajectories be projected to 2050, a global temperature increase of $3^{\circ}-4^{\circ} \mathrm{C}$, meaning that the Paris Agreement would not be able to attain its objectives, not even if all the resulting commitments are fully put into practice.

Having once set that the overwhelming majority of the INDCs would correspond with a Green Growth narrative, this is framed as a transition scenario in the global MEDEAS model. As previously said, the main novelty is the construction from scratch of an Economy module based on IOA subject to biophysical (energy-related) restraints. Together with the 'Green-Growth' scenario, a no-policies or 'Business as Usual' (BAU) and an alternative 'Post-Growth' (PG) scenario -adding socioeconomic transformations to the energy transition- were simulated. The following findings address Objective 2 of this thesis:

- The inclusion of energy restrictions grounded in literature -such as those grounded in literature-based Hubbert curves- provide significantly different results from those that disregard energy limits.

- $\quad$ Also taking into account indirect effects allows a high proportion of energy use carriers of the economic activity that otherwise would remain hidden to be captured. Depending on the scenario and the type of energy, the proportion of total variation explained by indirect carriers can be 2-4 times the variation explained by direct effects.

- If no energy limits are considered, as long as GDP growth is not gradually slowed down, climate goals would not be attained. Conversely, if energy limits are imposed, GHG emissions reduction would be driven by an involuntary GDP degrowth. There would be a conflict between GDP growth and climate targets, even considering high energy efficiency gains.

- $\quad$ The 'energy trap' would be captured by the model, as well as the rebound effect of energy efficiency. In the GG scenario, a high-demand economic system, at an early stage of the energy transition, entails fossil fuel consumption while the renewable technologies are deployed. Moreover, energy efficiency can avoid energy scarcity, allowing a longer period of GDP growth, which eventually increases energy demand.

- Only a Post-Growth scenario would be able to significantly reduce GHG emissions and avoid mismatches between energy demand and supply. 
Finally, Chapter 3 contributes to addressing Objectives 2 and 3. After obtaining global results, they can be used as inputs for the European model. Here, a new Employment sub-module is built to evaluate the socioeconomic impacts of the European energy transition and compare the outcomes with results from the European Commission-supported models. Whereas in these models the economy operates autonomously and produces environmental impacts as a consequence (externalities), in MEDEAS the economy dimension receives feedbacks from the environment, determining the productive process. Thus, the Energy Roadmap 2050 primary energy use reduction objectives have been taken as energy constraints to domestic extraction and imports, besides the regular geological restrictions to extraction. These are the main findings:

- $\quad$ The energy reduction projected by the European Energy Roadmap 2050 would entail important GDP losses and employment destruction even though high energy efficiency gains are applied.

- Systemic hierarchies are revealed, as once the energy demand cannot be met by energy supply, higher productivity growth or a better global socioeconomic context would not be able to change the fact that not all the economic output could be produced.

- A clear conflict emerges to achieve, simultaneously, the environmental, social and economic (GDP) objectives.

- The greater import dependency reduction and renewables share on energy mix scenarios, except Post-Growth, are driven by involuntary GDP reduction.

- If energy use is constrained, social and climate objectives are only met when combining transition to renewables and energy efficiency, with deep socioeconomic transformations, such as: planned reduction in GDP growth, turn to a low productivity growth scenario, industrial policies stirring labour-intensive and less energy-intensive sectors, increase in the labour share and reduction of the working time.

- Demand-side stimuli may lose their effectiveness when energy supply is not able to meet the demand.

\subsection{Policy and theory Implications}

From a methodological point of view, the modelling approach that consists in combining Input-Output Analysis (IOA) and System Dynamics (SD) has been revealed as a powerful IAM tool. As shown in Chapter 3, the high relevance of indirect energy carriers of final demand -for some energy resources, even higher than the direct carriers- suggests the great value of IOA in assessing energy demand management policies in the future. Furthermore, SD provides dynamism to a methodology which has been widely criticized for being static. The capability of SD for considering feedback loops and tipping points, in this case related with energy resources 
stocks depletion, adds depth to the classic hybrid energy-extended IOA. The combination of these methodologies and the increasing availability of reliable worldwide IO databases offers a promising path for an integrated assessment modelling grounded in the Ecological Economics framework.

Moreover, in the light of the findings of this thesis, policy implications can be drawn. The shift from multilateralism (Kyoto Protocol) to unilateralism (Paris Agreement) is an obstacle to tackling climate change. Although the Paris Agreement's main target is containing the global temperature rise, its reliance on the voluntary, unaudited commitments of the parties involved is an obstacle to meeting that target. A rigorous global climate governance to cope with climate change on time would be targeted at halting fossil fuel combustion. This would involve multilateral agreements such as an Oil Depletion Protocol (Heinberg, 2006) or leaving fossil fuels underground (McGlade and Ekins, 2015). The former would require an understanding between exporting and importing countries, as it would imply a gradual reduction in both figures. The latter would entail a negotiation between the same parties, involving both the public and private fossil fuel reserves' owners. Only a realistic approach to the problem, i.e., aimed at the multilateral cooperation required to reduce fossil fuels consumption, would effectively address the problem.

Otherwise, the common target of shifting to a greener energy mix combined with energy efficiency gains would face contradictions. First, the rebound effect would eventually drive energy demand up. For this reason, the 'energy trap' would lead to higher fossil fuel combustion during the earlier stages of the sustainability transition. Moreover, energy efficiency is subject to thermodynamics that are being approached, especially at the device level, meaning that these energy gains may be reducing potential growth in the near future. The objective would be to maintain - or even increase in the least developed countries- energy services, while final energy is reduced with such policies as car-sharing, promoting public collective transport to the detriment of private vehicles, supporting local economy and short distribution channels, agroecology, urban planning aimed at reducing transport requirements, etc. Efficient economies have typically been linked to productivity growth, including the analysis of the Environmental Kuznets Curve (Stern, 2003; Huang, Hwang and Yang, 2008; Peng, Zhang and Sun, 2016). However, increasing labour productivity when the energy limits have been reached may be of no use, as this thesis suggests. In addition, it plays a contradictory role, as productivity gains are a necessity in capitalist economies, but at the same time, they are a means of employment destruction, as the 'productivity trap' posits (Jackson and Victor, 2011). In fact, according to this thesis' results, in an economy which already has energy restraints, focusing on labour intensity reductions (i.e., labour productivity gains) could either harm employment or, at best, be useless. On the other hand, industrial policies can also be very relevant in this regard. 
Industrial policy has been neglected by policymakers during the preceding three decades. The de-industrialization of developed countries, as well as the reliance of free markets to efficiently allocate resources among sectors and agents, has put industrial policy aside. Nevertheless, the massive and rapid structural change that the energy transition involves has brought industrial policy back to the limelight. In this thesis, two different avenues have been explored in this regard: i/ increasing overall efficiency to reduce the amount of inputs (i.e., material carriers) required to produce the output of all sectors; and ii/ a combination of industrytargeted policies to stir up or discourage some sectors. The former strategy is able to initially reduce the material carriers of production, avoiding energy constraints for a longer period. However, at the same time, it broadens the gross value added (should the mark-up remain constant) which eventually encourages demand, more or less depending on the evolution of the primary income shares. As a result, material carriers are higher in the end. The second strategy would favour the less energy-intensive sectors and the more labour-intensive ones, to the detriment of the more energy-intensive (especially those relying on fossil fuels) and less labourintensive ones. As a result, the energy carriers are downscaled and employment is maintained, as the energy use reduction may reduce the potential of economies. This highlights the importance of the composition of the economic structure, which needs to be regarded in addition to its scale. A combination of both strategies would also be convenient under certain circumstances.

In order to compensate for a reduced energy input to the economy, potentially downsizing its scale, an increase in the labour share could alleviate the worst social consequences. The labour share has been gradually decreasing at global level since 1995, whereas in Europe it remains stagnated. It is worth distinguishing between the different consequences that may be expected at different stages, since it is not exempt from contradictions. As labour income is more likely spent than saved, increasing its share would lead to a demand-side impulse to the investments required for the energy transition at an early stage. Nevertheless, for the same reason, it could eventually worsen the 'energy trap', since all the consumption (energy and non-energy) would entail fossil fuel energy carriers. But if applied, once energy constraints hit the real economy or under a planned low-GDP growth regime, it can only contribute to improve equality and ease the negative impacts of the energy shortage, although aggregate demand would remain unchanged. This contradicts the Kaleckian employment model, which states that below full employment, a wages increase would bolster the aggregate demand, resulting in a higher level of employment -as according to PKE, employment is determined by the aggregate demand of goods and services-. This feature is also guaranteed in MEDEAS with the labour feedback (see section 4.2.2.3.); so the novelty lies in MEDEAS being able to capture this exception below full employment. The reason is that a reduced amount of energy flows to the economy would diminish its potential capacity, even though the economy is not operating in full employment. 
In such a situation, a working time reduction policy would solidify the likelihood of maintaining social stability by creating employment when GDP growth is no longer able to deliver new jobs. It is important that wages are kept at least aligned with productivity growth since, otherwise, the WTR policy would eventually lead to a reduction in the level of employment. Moreover, a reduced working time would also result in an improvement in sustainable consumption, since a significant proportion of unsustainable consumption can be linked to the reduction of leisure time. In addition, lower working time would contribute to regaining the preceding decades' labour productivity growth that had mostly been absorbed by profits.

As a final remark, it is worth mentioning the degrowth debate. First of all, the only scenarios able to succeed in meeting climate goals were those implying a long-term planned reduction of GDP. Moreover, employment would be more likely to be maintained in this same scenario. Therefore, it has been revealed as the most effective one at reconciling sustainability, both in an environmental and social way. However, in Kate Raworth's (2017) Doughnut Economics framework, it would be the most likely to fall below ecological ceilings and above social foundations. Nevertheless, at least two considerations could be made. Firstly, that GDP degrowth alone is insufficient to achieve these outcomes: structural change, reduction of inequality, working time reduction and other policies are also required. Thus, Post-Growth rather than Degrowth would more precisely represent the kind of narratives and policies underlying these scenarios. In fact, these socioeconomic variables must be combined with other energy-side measures to be effective: energy use reduction and demand-side energy efficiency. As such, it is not that GDP growth should be explicitly pursued -as it is in this thesis, due to model construction constraints- but just a consequence of a less material-intensive economy. Secondly, despite the positive outcomes achieved under the Post-Growth narratives, it is still uncertain how well welfare can be decoupled from GDP growth. For this purpose, it will be crucial to decouple human need satisfaction from energy use, as underpinned by Brand-Correa and Steinberger (2017).

This is especially relevant for the least developed countries. In this thesis, we have verified the righteous demand from these countries to boost economic growth while they complete their sustainability transitions. In Kicking away the ladder, Ha-Joon Chang (2002) explained how developed countries modernized their structure by applying protectionist measures and afterwards embraced free trade, depriving the rest of the world of the former policies to develop their countries. Consequently, the Post-Growth agenda does not imply an indiscriminate reduction of economic output. Instead, a regional balancing through a reduction in the developed countries and an increase in those countries where achieving widespread welfare is required. It has been proved that beyond a threshold, GDPpc growth is not able to deliver significant further welfare improvements. Therefore, through a cooperative approach, regional equality should be looked for in order to undertake a fair sustainability transition. 


\subsection{Limitations and future development.}

The core of this thesis lies in the construction from scratch of a new economy module, integrated a well disaggregated, highly integrated IAM. As such, this is a work in progress which awaits further developments in the near future that will address its main current limitations.

First, the endogeneization of the technical coefficients matrix to make it consistent with the large structural change simulated. Although the method used in this thesis is consistent with the literature and cautious enough to avert unrealistic outcomes, endogeneizing part, or the totality, of this change would greatly improve the model. Second, labour demand lacks endogenous behavioural change. When too low (approaching full-employment) or too high unemployment rates are reached, an internal reaction is expected in the economy. Thus, endogenous productivity change and/or a predator-prey model involving the employment rate and the labour share, could be applied following the Goodwin model (Goodwin, 1967). Thirdly, despite the many advantages of using WIOD, the incoming future developments rely, as far as possible, on a sectoral structure with a higher disaggregation of the primary and final energy sectors. Fourthly, the capability for extending the income representation in the analysis from primary to disposable income, will allow a much deeper assessment of the role of inequality in the energy transition. On the same basis, it would contribute a more accurate description of the composition of households, e.g., by income group, gender, age, urban or rural, etc. Finally, the financial dimension is lacking in this thesis. This would imply the capability to assess the financial carriers of the energy transition, which agents are more effective to finance it (public or private sector) and how (debt, taxes, increase in money supply, etc). Applying a Stock-Flow-Consistent model (Lavoie, 2012) to MEDEAS would ensure the financial consistency of the outcomes and enable these research questions to be answered. All these improvements will be carried out within the framework of the European project H2020-LC-CLA-2018-2 (821105) "Low-carbon society: an enhanced modelling tool for the transition to sustainability" (LOCOMOTION). 


\section{References}

Aguilera, R. F. (2014) 'Production costs of global conventional and unconventional petroleum', Energy Policy. Elsevier, 64, pp. 134-140. doi: 10.1016/J.ENPOL.2013.07.118.

Alcamo, J., Leemans, R. and Kreileman, E. (1998) Global change scenarios of the 21st century: results from the IMAGE 2.1 model. Tarrytown, N.Y.: Pergamon.

Alig, R. Adams, D., McCarl, B., Callaway, J.M., Winnet, S.. (1997) 'Assessing Effects of Mitigation Strategies for Global Climate Change with an Intertemporal Model of the U.S. Forest and Agriculture Sectors', Environmental and Resource Economics. Kluwer Academic Publishers, 9(3), pp. 259-274. doi: 10.1023/A:1026409105660.

Altieri, M. A. (1995) Agroecology: the science of sustainable agriculture. Westview Press.

Andersson, J. and Lindroth, M. (2001) 'Ecologically unsustainable trade', Ecological Economics, 37, pp. 113-122.

Antal, M. (2018) 'Post-growth strategies can be more feasible than techno-fixes: Focus on working time', The Anthropocene Review, p. 2053019618794212. doi: $10.1177 / 2053019618794212$.

ASPO (2008) Newsletter(february).

Atteridge, A. (2011) Will Private Finance Support Climate Change Adaptation in Developing Countries? Stockholm.

Ayres, R. and Warr, B. (2009) The Economic Growth Engine. Edward Elgar Publishing. doi: $10.4337 / 9781848445956$.

Badgley, C. et al. (2007) 'Organic agriculture and the global food supply', Renewable Agriculture and Food Systems, 22(2), pp. 86-108. doi: 10.1017/S1742170507001640.

Bardi, U. (2011) The limits to growth revisited. Springer.

Barlas, Y. (1996) 'Formal aspects of model validity and validation in system dynamics', System Dynamics Review. John Wiley \& Sons, Ltd, 12(3), pp. 183-210. doi: 10.1002/(SICI)1099-1727(199623)12:3<183::AID-SDR103>3.0.CO;2-4.

Bastin, G. and Cassiers, I. (2013) Modelling the balanced transition to a sustainable economy. Available at: http://sites.uclouvain.be/econ/DP/IRES/2013014.pdf. 
Batra, R., Beladi, H. and Frasca, R. (1998) 'Environmental pollution and world trade', Ecological Economics, 27, pp. 171-182.

Berg, M., Hartley, B. and Richters, O. (2015) 'A stock-flow consistent input-output model with applications to energy price shocks, interest rates, and heat emissions', New Journal of Physics. IOP Publishing, 17(1), p. 015011. doi: 10.1088/1367-2630/17/1/015011.

Bernardo, G. and D’Alessandro, S. (2014) 'Transition to sustainability? Feasible scenarios towards a low-carbon economy', MPRA Paper. University Library of Munich, Germany. Available at: https://ideas.repec.org/p/pra/mprapa/53746.html (Accessed: 24 June 2019).

Bernardo, G. and D’Alessandro, S. (2016) 'Systems-dynamic analysis of employment and inequality impacts of low-carbon investments', Environmental Innovation and Societal Transitions, 21(Supplement C), pp. 123-144. doi: 10.1016/j.eist.2016.04.006.

Bhaduri, A. (2007) 'On the dynamics of profit-led and wage-led growth', Cambridge Journal of Economics. Narnia, 32(1), pp. 147-160. doi: 10.1093/cje/bem012.

Blake, A. (2005) 'Jevons’ paradox’, Ecological Economics, 54, pp. 9-21.

De Blas, I. et al. (2018) European Model: MEDEAS Model and IOA implementation at European geographical level. Barcelona, Spain. Available at: http://medeas.eu/system/files/documentation/files/Deliverable 4.1 \%28D13\%29_Global Model.pdf.

Bouwman, A., Kram, T. and Goldewijk, K. K. (2006) Integrated modelling of global environmental change: an overview of IMAGE 2.4. Bilthoven: Netherlands Environmental Assessment Agency.

Bowen, A. and Hepburn, C. J. (2012) Prosperity with Growth: Economic Growth, Climate Change and Environmental Limits. Rochester, NY. Available at: https://papers.ssrn.com/abstract=2575804 (Accessed: 17 April 2018).

Boyer, G. R. and Smith, R. S. (2001) 'The Development of the Neoclassical Tradition in Labor Economics', ILR Review, 54(2), pp. 199-223. doi: 10.1177/001979390105400201.

BP, (2016). BP Statistical Review of World Energy June 2016, Statistical Review of World Energy. British Petroleum.

Brand-Correa, L. I. and Steinberger, J. K. (2017) 'A Framework for Decoupling Human Need Satisfaction From Energy Use', Ecological Economics. Elsevier, 141, pp. 43-52. doi: 10.1016/J.ECOLECON.2017.05.019. 
Briens, F. (2015) 'Investigating Pathways to Post-Growth Economies Through Prospective Macroeconomic Modeling: Vision and Scenarios for France.', in. Leeds.

Brockway, P. E. et al. (2019) 'Estimation of global final-stage energy-return-oninvestment for fossil fuels with comparison to renewable energy sources', Nature Energy. Nature Publishing Group, 4(7), pp. 612-621. doi: 10.1038/s41560-019-0425-z.

de Bruyn, S. M. and van der Bergh, J. C. J. M. . O. (1998) 'Economic growth and emissions: Reconsidering the empirical basis of environmental Kuznets curves.', Ecological Economics, 25, pp. 161-175.

Buchner, B., Falconer, A., Hervé-Mignucci, M., Trabacchi, C., and Brinkman, M., 2011 (2011) The Landscape of Climate Finance.

Buchner, B. K. et al. (2015) Global Landscape of Climate Finance 2015. San Francisco: Climate Policy Initiative.

Cahen-Fourot, L. and Lavoie, M. (2016) 'Ecological monetary economics: A postKeynesian critique', Ecological Economics. Elsevier, 126, pp. 163-168. doi: 10.1016/J.ECOLECON.2016.03.007.

Calvin, K. et al. (2013) 'Implications of simultaneously mitigating and adapting to climate change: initial experiments using GCAM', Climatic Change, 117(3), pp. 545-560. doi: 10.1007/s10584-012-0650-y.

Cambridge Econometrics (2013) Employment Effects of selected scenarios from the Energy roadmap 2050. F inal report for the European Commission (DG Energy). Cambridge, UK. Available at: https://ec.europa.eu/energy/sites/ener/files/documents/2013_report_employment_effects_roadm ap_2050_1.pdf.

Cambridge Econometrics (2014) E3ME Technical Manual, Version 6.0. Cambridge, UK. doi: http://www.camecon.com/EnergyEnvironment/EnergyEnvironmentEurope/ModellingCapability /E3ME/E3MEManual.aspx.

Campiglio, E., Godin, A. and Kinsella, S. (2015) 'The Economic Implications of the Transition to a Low-Carbon Energy System: A Stock-Flow Consistent Model'. Presentation at the 11th Biennial Conference of the European Society for Ecological Economics, Leeds, 30/0603/07 2015 .

Capellán-Pérez, I., Mediavilla, M., de Castro, C., Carpintero, Ó., Miguel, L.J. (2014) 
'Fossil fuel depletion and socio-economic scenarios: An integrated approach', Energy, 77, pp. 641-666. doi: 10.1016/j.energy.2014.09.063.

Capellán-Pérez, I. Mediavilla, M., de Castro, C., Carpintero, Ó., Miguel, L.J. (2015) 'More growth? An unfeasible option to overcome critical energy constraints and climate change', Sustain Sci, 10(3), pp. 397-411. doi: 10.1007/s11625-015-0299-3.

Capellán-Pérez, I. et al. (2017) Global Model: MEDEAS- World Model and IOA implementation at global geographical level. Available at: https://www.medeas.eu/system/files/documentation/files/Deliverable 4.1\%28D13\%29_Global Model.pdf.

Capellán-Pérez, Í. (2016) Development and Application of Environmental Integrated Assessment Modelling towards Sustainability. University of País Vasco.

Carpintero, Ó. (2003) 'Los costes ambientales del sector servicios y la nueva economía: Entre la “desmaterialización” y el “efecto rebote”., Economía Industrial, 352, pp. 59-76.

Carpintero, Ó. (2005) El metabolismo de la economía española. Recursos naturales y huella ecológica (1955-2000). Madrid: Economía vs Naturaleza.

Carpintero, Ó. and Riechmann, J. (2013) 'Pensar la transición: enseñanzas y estrategias económico-ecológicas', Revista de Economía Crítica, 16, pp. 45-107. Available at: http://revistaeconomiacritica.org/node/670.

Carpintero, O. (2019): "Economía para la sostenibilidad", en: J.M Enriquez; C. Duce y Luis J. Miguel (eds.): Repensar la sostenibilidad. Barcelona: Icaria (en prensa).

de Castro, C. et al. (2011) 'Global wind power potential: Physical and technological limits', Energy Policy. (Sustainability of biofuels), 39(10), pp. 6677-6682. doi: 10.1016/j.enpol.2011.06.027.

de Castro, C., Mediavilla, M., Miguel, L.J., Frechoso, F.. (2013) 'Global solar electric potential: A review of their technical and sustainable limits', Renewable and Sustainable Energy Reviews, 28, pp. 824-835. doi: 10.1016/j.rser.2013.08.040.

de Castro, C., Carpintero, Ó., Frechoso, F., Mediavilla, M., Miguel, L.J. (2014) ‘A topdown approach to assess physical and ecological limits of biofuels', Energy, 64, pp. 506-512. doi: 10.1016/j.energy.2013.10.049.

Chang, H.-J. (2002) Kicking away the ladder : development strategy in historical perspective. Anthem. 
Cole, H. S. D., Freeman, C., Jahoda, M., Pavitt, K.L.R. (1973) Models of Doom. A Critique of the Limits to Growth. New York: Universe Books. doi: 10.2307/1531545.

Cole, M. A. (2004) 'US environmental load displacement: examining consumption, regulations and the role of NAFTA', Ecological Economics. Elsevier, 48(4), pp. 439-450. doi: 10.1016/J.ECOLECON.2003.10.016.

Constanza, R. and and, C. P. (1997) The development of Ecological Economics. Cheltenham: Edward Elgar.

Cordier, M. Uehara, T., Weih, J., Hamaide, B. (2017) 'An Input-output Economic Model Integrated Within a System Dynamics Ecological Model: Feedback Loop Methodology Applied to Fish Nursery Restoration', Ecological Economics, 140, pp. 46-57. doi: 10.1016/j.ecolecon.2017.04.005.

Costanza, R. (1989) 'What is ecological economics?', Ecological Economics, 1(1), pp. 1-7. doi: 10.1016/0921-8009(89)90020-7.

Costanza, R. (1991) Ecological Economics: The Science and Management of Sustainability. Revised ed. New York: Columbia University Press.

Côte, R. and Liu, C. (2016) 'Strategies for reducing greenhouse gas emissions at an industrial park level: a case study of Debert Air Industrial Park, Nova Scotia', Journal of Cleaner Production, 114, pp. 352-361.

Creutzig, F. et al. (2016) 'Beyond Technology: Demand-Side Solutions for Climate Change Mitigation', Annual Review of Environment and Resources, 41(1), pp. 173-198. doi: 10.1146/annurev-environ-110615-085428.

Csereklyei, Z. and Stern, D. I. (2015) 'Global energy use: Decoupling or convergence?', Energy Economics, 51, pp. 633-641. doi: 10.1016/j.eneco.2015.08.029.

D'Alessandro, S. et al. (2018) EUROGREEN Model of Job Creation in a Post-Growth Economy. Available at: https://degrowth.org/2018/10/29/eurogreen-an-ecologicalmacroeconomic-model-to-test-degrowth-policies/.

D’Alessandro, S., Luzzati, T. and Morroni, M. (2010) 'Energy transition towards economic and environmental sustainability: feasible paths and policy implications', Journal of Cleaner Production, 18(4), pp. 291-298. doi: 10.1016/j.jclepro.2009.10.015.

D’Alisa, G., Kallis, G. and Federico, D. (2014) Degrowth: A Vocabulary for a New Era. 1 edition. New York; London: Routledge. 
Dafermos, Y., Nikolaidi, M. and Galanis, G. (2017) 'A stock-flow-fund ecological macroeconomic model', Ecological Economics, 131, pp. 191-207. doi: 10.1016/j.ecolecon.2016.08.013.

Dagoumas, A. S. and Koltsaklis, N. E. (2019) 'Review of models for integrating renewable energy in the generation expansion planning', Applied Energy. Elsevier, 242, pp. 1573-1587. doi: 10.1016/J.APENERGY.2019.03.194.

Dale, M., Krumdieck, S. and Bodger, P. (2012) 'Global energy modelling - A biophysical approach (GEMBA) part 1: An overview of biophysical economics', Ecological Economics, 73, pp. 152-157. doi: 10.1016/j.ecolecon.2011.10.014.

Daly, H. (1968) 'On economics as a life science', Journal of Political Economy, 76(3), pp. 392-406.

Daly, H. E. (1973) Toward a steady-state economy. W.H. Freeman.

Daly, H. E. (1990) 'Toward some operational principles of sustainable development', Ecological Economics. Elsevier, 2(1), pp. 1-6. doi: 10.1016/0921-8009(90)90010-R.

Dietz, R. and O’Neill, D. (2013) Enough Is Enough: Building a Sustainable Economy in a World of Finite Resources. 1 edition. San Francisco: Berrett-Koehler Publishers.

Dietzenbacher, E. Los, B., Stehrer, R., Timmer, M., de Vries, G. (2013) 'The construction of world input-output tables in the wiod project', Economic Systems Research, 25(1), pp. 71-98. doi: 10.1080/09535314.2012.761180.

Di Donato, M., Lomas, P. L. and Carpintero, Ó. (2015) 'Metabolism and Environmental Impacts of Household Consumption: A Review on the Assessment, Methodology, and Drivers', Journal of Industrial Ecology, 19(5), pp. 904-916. doi: 10.1111/jiec.12356.

Dowlatabadi, H. (1998) 'Sensitivity of climate change mitigation estimates to assumptions about technical change.', Energy Economics, 20, pp. 473-493. doi: 10.1016/S0140-9883(98)00009-7.

Duarte, R., Mainar, A. and Sánchez-Chóliz, J. (2013) 'The role of consumption patterns, demand and technological factors on the recent evolution of $\mathrm{CO} 2$ emissions in a group of advanced economies', Ecological Economics. Elsevier, 96, pp. 1-13. doi: 10.1016/J.ECOLECON.2013.09.007.

E3MLab (2014) PRIMES model. Detailed model description. Athens, Greece. https://ec.europa.eu/clima/sites/clima/files/strategies/analysis/models/docs/primes_model_20132014_en.pdf. Available at: 
https://ec.europa.eu/clima/sites/clima/files/strategies/analysis/models/docs/primes_model_20132014_en.pdf.

E3MLab and IIASA (2016) Technical report on Member State results of the EUCO policy scenarios. Available at: https://ec.europa.eu/energy/sites/ener/files/documents/20170125__technical_report_on_euco_scenarios_primes_corrected.pdf.

EEA (1997) Towards Sustainable Development for Local Authorities. Approaches, Experiences and Sources. Copenhagen, Denmark. Available at: https://www.eea.europa.eu/publications/GH-07-97-191-EN-C/page001.html.

den Elzen, M. G. J., Hof, A. F. and Roelfsema, M. (2011) 'The emissions gap between the Copenhagen pledges and the $2{ }^{\circ} \mathrm{C}$ climate goal: options for closing and risks that could widen the gap', Global Environmental Change, 21(2), pp. 733-743.

Erickson, P., Lazarus, M. and Spalding-Fecher, R. (2014) 'Net climate change mitigation of the Clean Development Mechanism', Energy Policy. Elsevier, 72, pp. 146-154. doi: 10.1016/J.ENPOL.2014.04.038.

European Commission (2011) A Roadmap for Moving to a Competitive Low Carbon Economy in 2050. Brussels: European Comission.

European Commission (2016a) EU reference scenario 2016: energy, transport and GHG emissions: trends to 2050. Luxembourg. https://trid.trb.org/view.aspx?id=1423568. Available at: https://trid.trb.org/view.aspx?id=1423568 (Accessed: 28 November 2018).

European Commission (2016b) Commission staff working document impact assessment Accompanying the document Proposal for a Directive of the European Parliament and of the Council amending Directive 2012/27/EU on Energy Efficiency. Brussels, Belgium. https://eurlex.europa.eu/legal-content/EN/TXT/PDF/?uri=CELEX:52016SC0405\&from=EN. Available at: https://eur-lex.europa.eu/legalcontent/EN/TXT/PDF/?uri=CELEX:52016SC0405\&from=EN.

Eurostat (2001): Economy -wide material flow accounts and development indicators. A methodological guide. Luxembourg.

Ewers, R. and Rodrigues, A. (2008) 'Estimates of reserve effectivenessare confounded by leakage', Trends in Ecology and Evolution, 23, pp. 113-116.

EWG (2013) Fossil and Nuclear Fuels - the Supply Outlook. (No. 2013/03/18 LBST).

Farley, J. and Daly, H. E. (2003) Ecological Economics: Principles and Applications. 1 
edition. Washington: Island Press.

Fiddaman, T. S. (2002) 'Exploring policy options with a behavioral climate-economy model', System Dynamics Review. doi: 10.1002/sdr.241.

Fischer-Kowalski, Marina (2011) 'Analyzing sustainability transitions as a shift between socio-metabolic regimes', Environmental Innovation and Societal Transitions, 1(1), pp. 152-159. doi: https://doi.org/10.1016/j.eist.2011.04.004.

Fischer-Kowalski, M (2011) 'Analyzing sustainability transitions as a shift between socio-methabolic regimes', Environmental Innovation and Societal Transitions., 1, pp. 152 159.

Fischer-Kowalski, M. and Haberl, H. (2007) Socioecological transitions and global change: trajectories of social metabolism and land use. Edward Elgar.

Fontana, G. and Sawyer, M. (2016a) 'Towards post-Keynesian ecological macroeconomics', Ecological Economics. Elsevier, 121, pp. 186-195. doi: 10.1016/J.ECOLECON.2015.03.017.

Fontana, G. and Sawyer, M. (2016b) 'Towards post-Keynesian ecological macroeconomics', Ecological Economics. Elsevier, 121, pp. 186-195. doi: 10.1016/J.ECOLECON.2015.03.017.

Forrester, J. (1971) World Dynamics, Futures. doi: 10.1016/0016-3287(73)90052-9.

Forrester, J. W., Low, G. W. and Mass, N. J. (1974) 'The debate on World Dynamics: A response to Nordhaus', Policy Sciences. Kluwer Academic Publishers, 5(2), pp. 169-190. doi: 10.1007/BF00148039.

Fouquet, R. (2016) 'Historical energy transitions: Speed, prices and system transformation', Energy Research \& Social Science, 22, pp. 7-12. doi: 10.1016/j.erss.2016.08.014.

Foxon, T. J. (2017) Energy and Economic Growth: Why we need a new pathway to prosperity. 1 edition. Abingdon, Oxon ; New York, NY: Routledge.

Freeman, C. and C. Pérez (1988) 'Structural Crises of Adjustment, Business Cycles and Investment Behavior', in G. Dossi, et al. (ed.) Technical Change and Economic Theory. London: Pinter, pp. 39-62.

Gao, Y. (2016) 'China's response to climate change issues after Paris Climate Change Conference', Advances in Climate Change Research. (Including special topic on Sino-India 
monitor on NDCs), 7(4), pp. 235-240. doi: 10.1016/j.accre.2016.10.001.

Geels, F. (2002) 'Technological transitions as evolutionary reconfiguration processes: a multi-level perspective and a case-study', Research Policy, 8/9(31), pp. 1257-1274.

Geels, F. W. (2011) 'The multi-level perspective on sustainability transitions: Responses to seven criticisms', Environmental Innovation and Societal Transitions. Elsevier, 1(1), pp. 24-40. doi: 10.1016/J.EIST.2011.02.002.

Genty, A. (2012) 'Final database of environmental satellite accounts: technical report on their compilation'. WIOD Deliverable 4.6, Documentation. Available at: http://www.wiod.org/publications/source_docs/Environmental_Sources.pdf.

Georgescu-Roegen, N. (1971) The Entropy Law and the Economic Process. Harvard University Press.

Georgescu-Roegen, N. (1975) 'Dynamic models and economic growth', World Development, 3(11), pp. 765-783. doi: 10.1016/0305-750X(75)90079-0.

Gliessman, S. R. (2015) Agroecology: the ecology of sustainable food systems.

Godin, A. (2012) 'Guaranteed Green Jobs: Sustainable Full Employment', Levy Economics Institute Working Paper No. 722. doi: 10.2139/ssrn.2060326.

Gómez-Plana, A., González-Eguino, M. and Rodrigues, R. (2019) ‘Energy-EconomicEnvironmental models: a survey', in Anil Markandya, Ibon Galarraga, M. G.-E. (ed.) Handbook of Sustainable Energy. Edgard Elgar Publishing.

González-Eguino, M., Capellán-Pérez, Í., Arto, Í., Ansuategui, A., Markandya, A. (2017) 'Industrial and terrestrial carbon leakage under climate policy fragmentation', Climate Policy. Taylor \& Francis, 17(sup1), pp. S148-S169. doi: 10.1080/14693062.2016.1227955.

Goodwin, R. M. (1967) 'A growth cycle’, in FeinsteinC.H. (ed.) Capitalism and Economic Growth. Cambridge: Cambridge University Press, pp. 54-58.

de Graaf, T. (2017) 'Is OPEC dead? Oil exporters, the Paris agreement and the transition to a post-carbon world', Energy Research \& Social Science, 23, pp. 182-188. doi: 10.1016/j.erss.2016.10.005

Grubb, M. (1993) 'The Costs of Limiting Fossil-Fuel CO2 Emissions: A Survey and Analysis', Annual Review of Energy and the Environment, (18), pp. 397-478. doi: 10.1146/annurev.energy.18.1.397.

de Haan, M. (2001) 'A Structural Decomposition Analysis of Pollution in the 
Netherlands', Economic Systems Research, 13(2), pp. 181-196. doi:

http://dx.doi.org/10.1080/09537320120052452.

Haberl, H., Fischer-Kowalski, M., Kraussman, F., Martínez-Alier, J., Winiwarter, V. (2011) 'A Socio-metabolic Transition towards Sustainability?', Challenges for Another Great Transformation, 19, pp. 1-14.

Hall, Charles A S and Klitgaard, K. (2012) Energy and the Wealth of Nations: Understanding the Biophysical Economy. New York: Springer-Verlag. Available at: //www.springer.com/us/book/9781441993984 (Accessed: 17 April 2018).

Hall, Charles A. S. and Klitgaard, K. A. (2012) Energy and the wealth of nations : understanding the biophysical economy. Springer.

Hall, C. A. S., Lambert, J. G. and Balogh, S. B. (2014) 'EROI of different fuels and the implications for society', Energy Policy, 64, pp. 141-152. doi: 10.1016/j.enpol.2013.05.049.

Hardt, L. and O’Neill, D. W. (2017) 'Ecological Macroeconomic Models: Assessing Current Developments', Ecological Economics, 134, pp. 198-211. doi: 10.1016/j.ecolecon.2016.12.027.

Hawksworth, J. (2017) The Long ViewHow will the global economic order change by2050? Available at: https://www.pwc.com/gx/en/world-2050/assets/pwc-the-world-in-2050full-report-feb-2017.pdf.

Hein, E. and Ochsen, C. (2003) 'Regimes of Interest Rates, Income Shares, Savings and Investment: A Kaleckian Model and Empirical Estimations for some Advanced OECD Economies', Metroeconomica, 54(4), pp. 404-433. doi: 10.1111/1467-999X.00173.

Heinberg, R. (2006) The oil depletion protocol : a plan to avert oil wars, terrorism, and economic collapse. New Society Pub.

Heinberg, R. (2007) Peak everything. New Society Publishers.

Heinberg, R. (2014) Fracking: el bálsamo milagroso. Barcelona: Icaria.

Henckens, M. L. C. M, van Ierland, E.C., Driessen, P.P.J., Worrell, E. (2016) 'Mineral resources: Geological scarcity, market price trends, and future generations', Resources Policy. Pergamon, 49, pp. 102-111. doi: 10.1016/J.RESOURPOL.2016.04.012.

Heun, M., Carbajales-Dale, M. and Haney, B. (2015) Beyond GDP: National Accounting in the Age of Resource Depletion. Springer.

Hicks, J. R. (1968) The Theory of Wages. Macmillan. 
Höhne, N. et al. (2012) 'National GHG emissions reduction pledges and $2^{\circ} \mathrm{C}$ : comparison of studies', Climate Policy. Routledge , 12(3), pp. 356-377. doi: $10.1080 / 14693062.2011 .637818$.

Holt, R. P. F., Pressman, S. and Spash, C. L. (2009) Post Keynesian and ecological economics : confronting environmental issues. Edward Elgar.

Hoogwijk, M. M. (2004) On the global and regional potential of renewable energy sources. Utrecht: Proefschrift Universiteit Utrecht.

Hook, M. and Hirsch R. y Aleklett, K. (2009) 'Giant oil field decline rates and their influence on world oil production', Energy Policy, 37(6), pp. 2262-2272.

Hook M. y Aleklett, K. (2008) 'A decline rate study of Norwegian oil production', Energy Policy, 36(11), pp. 4262-4271.

Hourcade, J.-C. et al. (2001) 'Global, regional, and national costs and ancillary benefits of mitigation', in Davidson, O., Swart, R., and Pan, J. (eds) Climate Change 2001: Mitigation. Cambridge, UK: Cambridge University Press, pp. 499-559. Available at: https://orbit.dtu.dk/en/publications/global-regional-and-national-costs-and-ancillary-benefits-ofmitigation(36a8441a-6cc3-4258-bb5a-ef463f0d2210).html (Accessed: 4 September 2019).

Huang, B.-N., Hwang, M. J. and Yang, C. W. (2008) 'Causal relationship between energy consumption and GDP growth revisited: A dynamic panel data approach', Ecological Economics, 67(1), pp. 41-54. doi: 10.1016/j.ecolecon.2007.11.006.

Hubbert, M. King (1956) 'Nuclear energy and the fossil fuels', in Drilling and Production Practice 1956.

Hubbert, M K (1956) Nuclear Energy and the Fossil Fuels.

IEA (2010) World Energy Outlook 2010. Paris. Available at: https://www.iea.org/newsroom/news/2010/november/world-energy-outlook-2010.html.

IEA (2016) 'World Energy Outlook 2016', IEA. Paris, France: International Energy Agency.

IEA (2017). Energy Technology Perspectives 2017. Catalysing Energy Technology Transformations. International Energy Agency.

IEA (2019) IEA World Energy Statistics and Balances, World Energy Statistics and Balances. Database. Paris, France.

Institute for Prospective Technological Studies (2013) GEM-E3 model documentation. 
Available at: https://publications.europa.eu/en/publication-detail/-/publication/1d556dc6-d1034b1a-8787-37ea26f2b33f/language-en (Accessed: 11 March 2019).

IPCC (2014) IPCC Fifth Assessment Synthesis Report. Geneva.

IPCC (2014): Climate Change 2014: Mitigation of Climate Change. Contribution of Working Group III to the Fifth Assessment Report of the Intergovernmental Panel on Climate Change [Edenhofer, O., R. Pichs-Madruga, Y. Sokona, E. Farahani, S. Kadner, K. Seyboth, A. Adler, I. Baum, S. Brunner, P. Eickemeier, B. Kriemann, J. Savolainen, S. Schlömer, C. von Stechow, T. Zwickel and J.C. Minx (eds.)]. Cambridge University Press, Cambridge, United Kingdom and New York, NY, USA. Available at: https://www.ipcc.ch/site/assets/uploads/2018/02/ipcc_wg3_ar5_full.pdf

IPCC (2018): Summary for Policymakers. In: Global Warming of $1.5^{\circ} \mathrm{C}$. An IPCC Special Report on the impacts of global warming of $1.5^{\circ} \mathrm{C}$ above pre-industrial levels and related global greenhouse gas emission pathways, in the context of strengthening the global response to the threat of climate change, sustainable development, and efforts to eradicate poverty [Masson-Delmotte, V., P. Zhai, H.-O. Pörtner, D. Roberts, J. Skea, P.R. Shukla, A. Pirani, W. Moufouma-Okia, C. Péan, R. Pidcock, S. Connors, J.B.R. Matthews, Y. Chen, X. Zhou, M.I. Gomis, E. Lonnoy, T. Maycock, M. Tignor, and T. Waterfield (eds.)]. In Press. https://www.ipcc.ch/site/assets/uploads/sites/2/2019/05/SR15_SPM_version_report_LR.pdf

Ivner, J. and Broberg, S. (2015) 'Effect of the use of industrial excess heat in district heating on greenhouse gas emissions: A systems perspective', Resources, Conservation and Reciclyng, 100, pp. 81-87.

Jackson, T. (2009) Prosperity without growth: Economics for a finite planet, Prosperity without Growth: Economics for a Finite Planet. London: Earthscan. doi: $10.4324 / 9781849774338$.

Jackson, T. (2011) Prosperity without Growth: Economics for a Finite Planet. Reprint ed. London; Washington, DC: Routledge.

Jackson, T., Drake, B., Victor, P., Kratena, K., Sommer, M.. (2014) 'Foundations for an Ecological Macroeconomics: literature review and model development', WWWforEurope Working Paper no 65.

Jackson, T. (2019) 'The Post-growth Challenge: Secular Stagnation, Inequality and the Limits to Growth', Ecological Economics, 156, pp. 236-246. doi:

10.1016/j.ecolecon.2018.10.010.

Jackson, T. and Victor, P. (2011) 'Productivity and work in the "green economy": Some 
theoretical reflections and empirical tests', Environmental Innovation and Societal Transitions, 1(1), pp. 101-108. doi: 10.1016/j.eist.2011.04.005.

Jackson, T. and Victor, P. A. (2015) 'Does credit create a "growth imperative"? A quasi-stationary economy with interest-bearing debt', Ecological Economics. Elsevier, 120, pp. 32-48. doi: 10.1016/J.ECOLECON.2015.09.009.

Jackson, T. and Victor, P. A. (2016) 'Does slow growth lead to rising inequality? Some theoretical reflections and numerical simulations', Ecological Economics, 121, pp. 206-219. doi: 10.1016/j.ecolecon.2015.03.019.

Jacobsson S. y Bergek, A. (2011) 'Innovation system analyses and sustainabilty transitions: Contributions and suggestions for research', Environmental Innovation and Societal Transitions, 1, pp. 41-57.

James, D. E., Jansen, H. M. A. and Opschoor, J. B. (1978) Economic Approaches to Environmental Problems. Amsterdam: Elsevier North Holland.

Jayasuriya, R. T. (2015) 'Natural resource scarcity - classical to contemporary views', Journal of Natural Resources Policy Research. Penn State University Press, pp. 221-245. doi: 10.1080/19390459.2015.1048964.

Kainuma, M. (2003) Climate policy assessment: Asia-Pacific integrated modeling. Tokyo: Springer.

Kaldor, N. (1957) ‘A Model of Economic Growth.’, The Economic Journal, 67(268), pp. 591-624.

Kalecki, M. (1971) Selected Essays on the Dynamics of the Capitalist Economy 19331970. Cambridge: Cambridge University Press.

Kander, A. and Stern, D. I. (2014) 'Economic growth and the transition from traditional to modern energy in Sweden', Energy Economics, 46, pp. 56-65. doi: 10.1016/j.eneco.2014.08.025.

Kemfert, C. (2005) 'Induced technological change in a multi-regional, multi-sectoral, integrated assessment model (WIAGEM): Impact assessment of climate policy strategies.', Ecological Economics, 54, pp. 293-305. doi: 10.1016/j.ecolecon.2004.12.031.

Kemp-Benedict, E. (2014a) Shifting to a Green Economy: Lock-In, Path Dependence and Policy Options. Available at: http://www.seiinternational.org/mediamanager/documents/Publications/SEI-WP-2014-08-Brown-greencapital.pdf. 
Kemp-Benedict, E. (2014b) 'The inverted pyramid: A neo-Ricardian view on the economy-environment relationship', Ecological Economics. Elsevier, 107, pp. 230-241. doi: 10.1016/J.ECOLECON.2014.08.012.

Kemp, R. and Schot J. y Hoogma, R. (1998) 'Regime Shifts to Sustainability Through Processes of Niche Formation: The Approach os Strategic Niche Management', Technology Analysis \& Strategic Management, 10(2), pp. 175-195.

Kerschner, C. (2010) 'Economic de-growth vs. steady-state economy', Journal of Cleaner Production. (Growth, Recession or Degrowth for Sustainability and Equity?), 18(6), pp. 544-551. doi: 10.1016/j.jclepro.2009.10.019.

King, J. E. (John E. (2002) A history of post Keynesian economics since 1936. E. Elgar.

Kiuila, O. (2018) 'Decarbonisation perspectives for the Polish economy', Energy Policy, 118, pp. 69-76. doi: 10.1016/j.enpol.2018.03.048.

Kondrat'ev, N. D. (1984) The long wave cycle. Richardson \& Snyder.

Kratena, K. et al. (2013) Fully Interregional Dynamic Econometric Long-term InputOutput Model for the EU27. Luxembourg: Publications Office of the European Union.

Krausmann, F., Fischer-Kowalski, M., Schandl, H., Eisenmenger, N. (2008) 'The Global Sociometabolic Transition. Past and Present Metabolic Profiles and Their Future Trajectories.', Journal of Industrial Ecology, 12, pp. 637-656.

Krausmann, F., Lauk, C., Haas, W., Wiedenhofer, D.. (2018) 'From resource extraction to outflows of wastes and emissions: The socioeconomic metabolism of the global economy, 1900-2015', Global Environmental Change, 52, pp. 131-140. doi: 10.1016/j.gloenvcha.2018.07.003.

Kronenberg, T. (2010) 'Finding common ground between ecological economics and post-Keynesian economics', Ecological Economics. Elsevier, 69(7), pp. 1488-1494. doi: 10.1016/J.ECOLECON.2010.03.002.

Lacal Arantegui, R. and Jäger-Waldau, A. (2018) 'Photovoltaics and wind status in the European Union after the Paris Agreement', Renewable and Sustainable Energy Reviews, 81, pp. 2460-2471. doi: 10.1016/j.rser.2017.06.052.

Lachman, D. A. (2013) 'A survey and review of approaches to study transitions', Energy Policy, 58, pp. 269-276.

Ladyman, J., Lambert, J. and Wiesner, K. (2013) 'What is a complex system?', 
European Journal for Philosophy of Science. Springer Netherlands, 3(1), pp. 33-67. doi: 10.1007/s13194-012-0056-8.

Laherrère, J. (2006) 'Oil and gas, what future? Presented at the Groningen annual Energy Convention', in. Groningen, Netherlands.

Laherrère, J. (2010) 'Peak Oil and Energy Security. Presented at the Segundo Simposio ASPO Argentina', in. Buenos Aires, Argentina.

Lange, S. (2018) Macroeconomics Without Growth: Sustainable Economies in Neoclassical, Keynesian and Marxian Theories. Marburg: Metropolis Verlag.

Lavoie, M. (1995) 'Interest Rates in Post-Keynesian Models of Growth and Distribution', Metroeconomica, 46(2), pp. 146-177. doi: 10.1111/j.1467-999X.1995.tb00375.x.

Lavoie, M. (2012) The Stock-Flow Consistent Approach. Palgrave Macmillan. Available at: https://www.palgrave.com/br/book/9780230293113 (Accessed: 11 February 2019).

Lavoie, M. (2014) Postkeynesian Economics: New Foundations. Chentelham: Edward Elgar.

Lavoie, M. and Stockhammer, E. (2013) "'Wage-led growth: concepts, theories and policies", Basingstoke Lavoie, M. and E. Stockhammer (2013a), , in M. Lavoie and E. Stockhammer, : Palgrave Macmillan, pp. 13-39.', in Wage-led Growth: An Equitable Strategy for Economic Recovery. Basingstoke: Palgrave Macmillan, pp. 13-39.

Lawn, P. (2004) 'How well are resource prices likely to serve as indicators of natural resource scarcity?', International Journal of Sustainable Development, 7(4), p. 369. doi: 10.1504/IJSD.2004.006416.

Lehr, U., Lutz, C. and Edler, D. (2012) 'Green jobs? Economic impacts of renewable energy in Germany', Energy Policy, 47, pp. 358-364. doi: 10.1016/j.enpol.2012.04.076.

Leimbach, M. et al. (2017) 'Future growth patterns of world regions - A GDP scenario approach - ScienceDirect', Global Environmental Change, 42, pp. 215-225. doi: https://doi.org/10.1016/j.gloenvcha.2015.02.005.

Lenton, T. M. et al. (2008) 'Tipping elements in the Earth's climate system', Proc. Natl. Acad. Sci. U.S.A., 105(6), pp. 1786-1793. doi: 10.1073/pnas.0705414105.

Leontief, W. (1970) 'Environmental Repercussions and the Economic Structure: An Input-Output Approach', The Review of Economics and Statistics, 52(3), pp. 262-271. doi: 
$10.2307 / 1926294$.

Leontief, W. (1976) The structure of American economy, 1919-1939: an empirical application of equilibrium analysis. International Arts and Sciences Press.

Leontief, W. and Duchin, F. (1986) The future impact of automation on workers. Oxford University Press. Available at: https://econpapers.repec.org/bookchap/oxpobooks/9780195036237.htm (Accessed: 24 June 2019).

Leontief, W. (1936) 'Quantitative Input and Output Relations in the Economic Systems of the United States', The Review of Economics and Statistics. doi: 10.2307/1927837.

Leung, D. Y., Caramanna, G. and Maroto-Valer, M. (2014) 'An overview of current status of carbon dioxide carbon capture and storage technologies', Renewable and Sustainable Energy Reviews, 39, pp. 426-443.

Liobikienè, G. and Butkus, M. (2017) 'The European Union possibilities to achieve targets of Europe 2020 and Paris agreement climate policy', Renewable Energy. Pergamon, 106, pp. 298-309. doi: 10.1016/J.RENENE.2017.01.036.

Lund, J.W., Boyd, T.L., (2015). Direct Utilization of Geothermal Energy 2015 Worldwide Review, in: Proceedings World Geothermal Congress 2015. Presented at the World Geothermal Congress 2015, Melbourne, Australia, p. 31.

Markaard, J., Raven, R. and Truffer, B. (2012) 'Sustainability transitions: An emerging field of research and its prospects', Research Policy, 41, pp. 955-967.

Martínez-Alier, J. (1991) 'Ecological Perception, Environmental Policy and Distributional Conflicts: Some lessons from History', in Costanza, R. (ed.) Ecological Economics.The Science and Management of Sustainabilit. New York: Columbia University Press, pp. 119-120.

Mason, L., Prior, T., Mudd, G., Giurco, D. (2011) 'Availability, addiction and alternatives: three criteria for assessing the impact of peak minerals on society', Journal of Cleaner Production. Elsevier, 19(9-10), pp. 958-966. doi: 10.1016/J.JCLEPRO.2010.12.006.

Masui, T. Hanaoka, T., Hikita, S., Kainuma, M. (2006) 'Assessment of $\mathrm{CO}_{3}$ Reductions and Economic Impacts Considering Energy-Saving Investments', The Energy Journal, 27, pp. 175-190. Available at: http://www.jstor.org/stable/23297062 (Accessed: 29 June 2017).

McGinnis, R., Meadows, D.H., Meadows, D.L., Randers, J., Behren, W. (1973) 'The Limits to Growth: A Report for the Club of Rome's Project on the Predicament of Mankind.', 
Demography. Pan Books, 10(2), p. 295. doi: 10.2307/2060820.

McGlade, C. and Ekins, P. (2015) 'The geographical distribution of fossil fuels unused when limiting global warming to $2{ }^{\circ} \mathrm{C} '$, Nature, 517(7533), pp. 187-190. doi: 10.1038/nature14016.

Meadows, D. H., Meadows, D.L., Randers, J., Behrens III, W. (1972) The Limits to growth; a report for the Club of Rome's project on the predicament of mankind. Universe Books. Available at: https://www.clubofrome.org/report/the-limits-to-growth/ (Accessed: 10 September 2019).

Meadows, D. H., Meadows, D. L. and Randers, J. (1992) Beyond the limits: global collapse or a sustainable future. Post Mills: Chelsea Green.

Meadows, D. H. and Randers, J. (2013) Limits to Growth: The 30-Year Update. White River Junction, Vt: Chelsea Green Publishing Co.

Meadows, D. H., Randers, J. and Meadows, D. L. (2002) The limits to growth : the 30year update. Chelsea Green Publishing Company.

Melillo, J. M., Richmond, T. and Yohe, G. W. (2014) Climate Change Impacts in the United States: The Third National Climate Assessment. Washington DC: US.

Miller, R. E. and Blair, P. D. (2009) Input-Analysis. Foundations and Extensions. Cambridge, UK: Cambridge University Press.

Mohr, S. H., Wang, J., Ellem, G., Ward, J., Giurco, D. (2015) 'Projection of world fossil fuels by country', Fuel, 141, pp. 120-135. doi: 10.1016/j.fuel.2014.10.030.

Moriarty, P. and Honnery, D. (2016) 'Can renewable energy power the future?', Energy Policy, 93, pp. 3-7.

Morita, T. Jiang, K., Masui, T., Matsuoka, Y., Rana, A.. (2003) 'Long-term Scenarios based on AIM Model', in Climate Policy Assessment. Tokyo: Springer, pp. 17-36.

Muñoz, P., Strohmaier, R. and Roca, J. (2011) 'On the North-South trade in the Americas and its ecological asymmetries', Ecological Economics. Elsevier, 70(11), pp. 19811990. doi: 10.1016/J.ECOLECON.2011.05.012.

Muradian, R., O’Connor, M. and Martinez-Alier, J. (2002) 'Embodied pollution in trade: estimating the "environmental load displacement" of industrialised countries', Ecological Economics. Elsevier, 41(1), pp. 51-67. doi: 10.1016/S0921-8009(01)00281-6.

Murray, B. C., McCarl, B. A. and Lee, H.-C. (2004) 'Estimating Leakage from Forest 
Carbon Sequestration Programs', Land Economics. University of Wisconsin Press, 80(1), pp. 109-124. doi: $10.2307 / 3147147$.

Naqvi, S. A. A. (2015) Modeling Growth, Distribution, and the Environment in a StockFlow Consistent Framework. Available at: http://econpapers.repec.org/paper/feuwfeppr/y_3a2015_3am_3a2_3ad_3a0_3ai_3a18.htm (Accessed: 5 April 2017).

Naredo, J. M. (1987) La economía en evolución. Madrid: Sigl XXI.

Naredo, J. M. (2010) Raíces económicas del deterioro ecológico y social : más allá de los dogmas. Siglo XXI de España Editores, S.A. Available at: https://www.casadellibro.com/libro-raices-economicas-del-deterioro-ecologico-y-social-masalla-de-1-os-dogmas/9788432314278/1654863 (Accessed: 27 September 2019).

Nell, E. J. (2005) The General Theory of Transformational Growth: Keynes After Sraffa. Cambridge University Press.

Nieto, J. and Carpintero, Ó. (2016) 'Evaluación de planes de transición energética hacia sociedades postcarbono', in. Universidad Complutense de Madrid, Madrid, pp. 632-660. Available at: http://webs.ucm.es/info/ec/jec15/10t3.pdf.

Nieto, J., Carpintero, Ó. and Miguel, L. J. (2018) 'Less than $2{ }^{\circ} \mathrm{C}$ ? An EconomicEnvironmental Evaluation of the Paris Agreement', Ecological Economics. doi: 10.1016/j.ecolecon.2017.10.007.

Nilsson, S. and Schopfhauser, W. (1995) 'The carbon-sequestration potential of a global afforestation program', Climatic Change, 30, pp. 267-293.

Nordhaus, W. D. (1973) 'World Dynamics: Measurement Without Data', The Economic Journal, 83(332), p. 1156. doi: 10.2307/2230846.

Nordhaus, W. D. (1992) 'Lethal models', Brookings Papers on Economic Activity. Economic Studies Program, The Brookings Institution, 23(2), pp. 1-59. Available at: https://econpapers.repec.org/article/binbpeajo/v_3a23_3ay_3a1992_3ai_3a1992-2_3ap_3a160.htm (Accessed: 11 September 2019).

Norgaard, R. B. (1990) 'Economic indicators of resource scarcity: A critical essay’, Journal of Environmental Economics and Management. Academic Press, 19(1), pp. 19-25. doi: 10.1016/0095-0696(90)90057-6.

O’Neill, B. C. et al. (2017) 'The roads ahead: Narratives for shared socioeconomic pathways describing world futures in the 21st century', Global Environmental Change, 42, pp. 
169-180. doi: 10.1016/j.gloenvcha.2015.01.004.

O’Neill, D. W., Fanning, A.L., Lamb, W.F., Steinberger, J.K. (2018) 'A good life for all within planetary boundaries', Nature Sustainability. Nature Publishing Group, 1(2), pp. 88-95. doi: 10.1038/s41893-018-0021-4.

Odum, H. T. (1971) Environment, Power, and Society. New York: Wiley-Interscience.

Ortego, A., Valero, A. and Valero, A. (2016) 'Stock in use in the urban mobility system. Life Cycle Assessment and Other Assessment Tools for Waste Management and Resource Optimization. An exergy approach', 2016, pp. 5-10.

Palmer, G. (2018) ‘A Biophysical Perspective of IPCC Integrated Energy Modelling', Energies, 11(4), p. 839. doi: 10.3390/en11040839.

Pan, H. (2006) 'Dynamic and endogenous change of input-output structure with specific layers of technology', Structural Change and Economic Dynamics, 17(2), pp. 200-223. doi: 10.1016/j.strueco.2005.05.003.

Pasinetti, L. L. (2007) Keynes and the Cambridge Keynesians : a 'revolution in economics' to be accomplished. Cambridge University Press.

Patzek, T. W. (2004) 'Thermodynamics of the Corn-Ethanol Biofuel Cycle', Critical Reviews in Plant Sciences. Taylor \& Francis Group , 23(6), pp. 519-567. doi: 10.1080/07352680490886905.

Pellow, D. N. and Park, L. S.-H. (2002) The Silicon Valley of dreams : environmental injustice, immigrant workers, and the high-tech global economy. New York University Press.

Peng, S., Zhang, W. and Sun, C. (2016) “"Environmental load displacement” from the North to the South: A consumption-based perspective with a focus on China', Ecological Economics, 128, pp. 147-158. doi: 10.1016/j.ecolecon.2016.04.020.

Peters, J. C. (2017) 'Natural gas and spillover from the US Clean Power Plan into the Paris Agreement', Energy Policy, 106, pp. 41-47. doi: 10.1016/j.enpol.2017.03.039.

Pimentel, D., Patzek, T. and Cecil, G. (2007) 'Ethanol production: energy, economic and environmental losses', Rev Environ Contam Toxicol, 189, pp. 25-41.

Polimeni, J. M. Mayumi, K., Giampetro, M., Alcott, B. (2015) The Jevons' paradox and the myth of resource efficiency improvements.

Pollit, H. (2014) 'Technical Manual, Version 6.0’. Cambridge Econometrics. Available at: https://www.camecon.com/wp-content/uploads/2016/09/E3ME-Manual.pdf. 
Pollit, H. (2016) Summary of E3ME Modelling. Cambridge. Available at: https://ec.europa.eu/energy/sites/ener/files/documents/20161219__technical_report_on_macroeconomic_results_e3me.pdf.

Pollitt, H. et al. (2010) A scoping study on the macroeconomic view of sustainability Final report for the European Commission. Cambridge, UK.

Pretty, J., Morison, J. I. . and Hine, R. . (2003) 'Reducing food poverty by increasing agricultural sustainability in developing countries', Agriculture, Ecosystems \& Environment. Elsevier, 95(1), pp. 217-234. doi: 10.1016/S0167-8809(02)00087-7.

Prior, T., Giurco, D., Mudd, G., Mason, L., Behrisch, J.(2012) 'Resource depletion, peak minerals and the implications for sustainable resource management', Global Environmental Change. Pergamon, 22(3), pp. 577-587. doi: 10.1016/J.GLOENVCHA.2011.08.009.

Radzicki, M. J. (2009) 'System Dynamics and Its Contribution to Economics and Economic Modeling', in Complex Systems in Finance and Econometrics. New York, NY: Springer New York, pp. 727-737. doi: 10.1007/978-1-4419-7701-4_39.

Radzicki, M. J. and Tauheed, L. (2009) 'In Defense of System Dynamics: A Response to Professor Hayden', Journal of Economic Issues, 43(4), pp. 1043-1061. doi: 10.2753/JEI0021-3624430411.

Raftery, A. E. Zimmer, A., Frierson, D.M.W., Startz, R., Liu, P. (2017) 'Less than $2{ }^{\circ} \mathrm{C}$ warming by 2100 unlikely', Nature Climate Change, 7(9), pp. 637-641. doi: $10.1038 /$ nclimate 3352 .

Raveendran, S. P. (2013) 'The role of CCS as a mitigation technology and challenges to its commercialization'. Massachusetts Institute of Technology. Available at: https://dspace.mit.edu/handle/1721.1/81127 (Accessed: 30 October 2019).

Raworth, K. (2017) Doughnut Economics: Seven Ways to Think Like a 21st-Century Economist. London: Random House Business.

Raworth, K. (2018) Doughnut Economics: Seven Ways to Think Like a 21st-Century Economist. Random House Business.

Reynolds, D. B. (1999) 'The mineral economy: how prices and costs can falsely signal decreasing scarcity', Ecological Economics. Elsevier, 31(1), pp. 155-166. doi: 10.1016/S09218009(99)00098-1.

Reynolds, D. B. (2014) 'World oil production trend: Comparing Hubbert multi-cycle 
curves', Ecological Economics. Elsevier, 98, pp. 62-71. doi:

10.1016/J.ECOLECON.2013.12.016.

Rezai, A. and Stagl, S. (2016) 'Ecological macroeconomics: introduction and review.', Ecological Economics, 121, pp. 181-185.

Rezai, A., Taylor, L. and Mechler, R. (2013) 'Ecological macroeconomics: An application to climate change', Ecological Economics. (New Climate Economics), 85, pp. 6976. doi: 10.1016/j.ecolecon.2012.10.008.

Režný, L. and Bureš, V. (2018) 'Adding Feedbacks and Non-Linearity to the Neoclassical Growth Model: A New Realm for System Dynamics Applications', Systems, 6(2), p. 8. doi: 10.3390/systems6020008.

Riahi, K. et al. (2017) 'The Shared Socioeconomic Pathways and their energy, land use, and greenhouse gas emissions implications: An overview', Global Environmental Change. Pergamon, 42, pp. 153-168. doi: 10.1016/J.GLOENVCHA.2016.05.009.

Rockström, J. et al. (2009) 'Planetary boundaries: Exploring the safe operating space for humanity', Ecology and Society, 14(2). doi: 10.5751/ES-03180-140232.

Rodríguez-Huerta, E., Rosas-Casals, M. and Sorman, A. H. (2017) ‘A societal metabolism approach to job creation and renewable energy transitions in Catalonia', Energy Policy, 108, pp. 551-564. doi: 10.1016/j.enpol.2017.06.024.

Rogelj, J. et al. (2016) 'Paris Agreement climate proposals need a boost to keep warming well below $2{ }^{\circ} \mathrm{C}^{\prime}$, Nature, 534(7609), pp. 631-639. doi: 10.1038/nature18307.

Rosenbaum, E. (2015) 'Zero growth and structural change in a post Keynesian growth model', Journal of Post Keynesian Economics, 37(4), pp. 623-647. doi: 10.1080/01603477.2015.1050334.

Rotmans, J. et al. (2011) 'More evolution than revolution: transition management in public policy', Foresight, 3(1), pp. 15-31.

Rotmans, J., Kemp, R. and van Asselt, M. (2001) 'More evolution than revolution: transition management in public policy', Foresight. MCB UP Ltd, 3(1), pp. 15-31. doi: 10.1108/14636680110803003.

Sakai, M., Brockway, P., Barrett, J., Taylor, P. (2018) 'Thermodynamic Efficiency Gains and their Role as a Key "Engine of Economic Growth", Energies. Multidisciplinary Digital Publishing Institute, 12(1), p. 110. doi: 10.3390/en12010110. 
Schneider, S. H. (1997) 'Integrated assessment modeling of global climate change: Transparent rational tool for policy making or opaque screen hiding value-laden assumptions?', Environmental Modeling and Assessment, 2, pp. 229-249. doi: 10.1023/A:1019090117643.

Scrieciu, S., Rezai, A. and Mechler, R. (2013) 'On the economic foundations of green growth discourses: the case of climate change mitigation and macroeconomic dynamics in economic modeling', WENE, 2(3), pp. 251-268. doi: 10.1002/wene.57.

Sers, M. R. and Victor, P. A. (2018) 'The Energy-emissions Trap', Ecological Economics. Elsevier, 151, pp. 10-21. doi: 10.1016/J.ECOLECON.2018.04.004.

Seufert, V., Ramankutty, N. and Foley, J. A. (2012) 'Comparing the yields of organic and conventional agriculture', Nature, 485(7397), pp. 229-232. doi: 10.1038/nature11069.

Sgouridis, S., Csala, D. and Bardi, U. (2016) 'The sower's way: quantifying the narrowing net-energy pathways to a global energy transition', Environmental Research Letters. IOP Publishing, 11(9), p. 094009. doi: 10.1088/1748-9326/11/9/094009.

Shafik, N. (1994) 'Economic development and environmental quality: an econometric analysis.', Oxford Economic Papers, 46, pp. 757-773.

SHC (2016). Solar Heat Worldwide. Markets and Contribution to the Energy Supply 2014. Solar Heating \& Cooling Programme IEA.

Shishlov, I., Morel, R. and Bellassen, V. (2016) 'Compliance of the Parties to the Kyoto Protocol in the first commitment period', Climate Policy. Taylor \& Francis, 16(6), pp. 768-782. doi: 10.1080/14693062.2016.1164658.

Sommer, M. and Kratena, K. (2017) 'The Carbon Footprint of European Households and Income Distribution', Ecological Economics. Elsevier B.V., 136, pp. 62-72. doi: 10.1016/j.ecolecon.2016.12.008.

Spash, C. L. (2016) 'The political economy of Paris Agreement on human induced climathe change: a brief guide.', Real-World Economics Review, 75, pp. 67-75. Available at: http://www.paecon.net/PAEReview/issue75/Spash75.pdf.

Steen-Olsen, K, Weinzettel, J., Cranston, G., Ercin, A., Hertwich, E. (2012) ‘Carbon, land, and water footprint accounts for the European Union: Consumption, production, and displacements through international trade', Environmental Science \& Technology, 20(46), pp. 10883-10891.

Steffen, B. W. and Rockström, J. (2015) 'Planetary boundaries: Guiding human development on a changing planet', Science, 347(6223). doi: 10.1126/science.1259855. 
Stehfest, E. et al. (2009) 'Climate benefits of changing diet', Climatic Change, 95(1-2), pp. 83-102. doi: 10.1007/s10584-008-9534-6.

Stehfest, E. van Vuuren, D., Bowman, A., Kram, T. (2014) Integrated assessment of global environmental change with IMAGE 3.0: Model description and policy applications. Netherlands Environmental Assessment Agency (PBL).

Sterman, J. (2000) Business dynamics : systems thinking and modeling for a complex world. Irwin/McGraw-Hill.

Sterman, J. et al. (2012) 'Climate interactive: the C-ROADS climate policy model', System Dynamics Review. John Wiley \& Sons, Ltd, 28(3), pp. 295-305. doi: 10.1002/sdr.1474.

Stern, D. I. (1997) 'Limits to substitution and irreversibility in production and consumption: A neoclassical interpretation of ecological economics', Ecological Economics, 21(3), pp. 197-215. doi: 10.1016/S0921-8009(96)00103-6.

Stern, D. I. (2003) 'International Society for Ecological Economics Internet Encyclopaedia of Ecological Economics. The Environmental Kuznets Curve'. Available at: http://citeseerx.ist.psu.edu/viewdoc/summary?doi=10.1.1.557.802 (Accessed: 22 October 2019).

Stern, D. I. (2004) 'The Rise and Fall of the Environmental Kuznets Curve', World Development. Pergamon, 32(8), pp. 1419-1439. doi: 10.1016/J.WORLDDEV.2004.03.004.

Stern, D. I. (2011) 'The Role of Energy in Economic Growth',. doi: 10.2139/SSRN.1878863.

Stockhammer, E., Onaran, Ö. and Ederer, S. (2009) 'Functional income distribution and aggregate demand in the Euro area', Cambridge J Econ, 33(1), pp. 139-159. doi: 10.1093/cje/ben026.

Tainter, J. (1988) The Collapse of Complex Societies. Cambridge: Cambridge University Press.

Tainter, J. (2011) 'Energy, complexity, and sustainability: A historical perspective’, Environmental Innovation and Societal Transitions(, 1, pp. 89-95.

Tapia-Granados J. A., I. E. L. and Carpintero, O. (2012) 'Climate change and the world eonomy: short-run determinants of atmospheric CO2', Environmental Science and Policy, 21, pp. 50-62.

Tapia Granados, J. A., Ionides, E. L. and Carpintero, Ó. (2012) 'Climate change and the world economy: short-run determinants of atmospheric CO2', Environmental Science \& Policy. 
Elsevier, 21, pp. 50-62. doi: 10.1016/J.ENVSCI.2012.03.008.

Taylor, L., Rezai, A. and Foley, D. K. (2016) 'An integrated approach to climate change, income distribution, employment, and economic growth', Ecological Economics, 121, pp. 196-205. doi: 10.1016/j.ecolecon.2015.05.015.

Thorgeirsson, H. (2015) 'Paris and the Path to Climate Neutrality', in Arctic Frontiers Conference on Climate and Energy. Tromso, Norway: High North Research Centre for Climate and the Environment.

Timmer, M, Dietzenbacher, E., Los, B., Stehrer, R., de Vries, G. (2015) ‘An Illustrated User Guide to the World Input-Output Database: the Case of Global Automotive Production', Review of International Economics, 23(3), pp. 575-605. Available at:

http://econpapers.repec.org/article/blareviec/v_3a23_3ay_3a2015_3ai_3a3_3ap_3a575-605.htm (Accessed: 29 June 2017).

Toth, F. L. (2005) 'Coupling Climate and Economic Dynamics: Recent Achievements and Unresolved Problems', in The Coupling of Climate and Economic Dynamics, Advances in Global Change Research. Springer, New York, pp. 35-68. doi: 10.1007/1-4020-3425-3_2.

Uehara, T., Nagase, Y. and Wakeland, W. (2013) 'Integrating Economics and System Dynamics Approaches for Modeling an Ecological-Economic System', Systems Science Faculty Publications and Presentations. Available at: http://pdxscholar.library.pdx.edu/sysc_fac/63.

UNEP (2010) The Emissions Gap Report: Are the Copenhagen Accord Pledges Sufficient to Limit Global Warming to $2{ }^{\circ} \mathrm{C}$ or $1.5^{\circ} \mathrm{C}$ ? A preliminary assessment.

UNFCCC (2016) ‘The Paris Agreement'. Paris, France.

Victor, P. A. (2008) Managing Without Growth: Slower by Design, Not Disaster. Cheltenham, UK ; Northampton, MA: Edward Elgar Publishing.

Victor, Peter A and Rosenbluth, G. (2007) 'Managing without growth', Ecological Economics, 61(2), pp. 492-504. doi: 10.1016/j.ecolecon.2006.03.022.

Victor, Peter A. and Rosenbluth, G. (2007) 'Managing without growth', Ecological Economics. Elsevier, 61(2-3), pp. 492-504. doi: 10.1016/J.ECOLECON.2006.03.022.

Viola, E. (2016) 'The structural limits of the Paris Agreement and the need of a global coalition for deep de-carbonization', in Wilhite, H. and HansenA. (eds) Will the Paris agreement save the world? An analysis and critique of the governance roadmap set out in COP21. Oslo: Oslo Academy of Global Governance, pp. 47-56. 
van Vuuren, D. P., Kok, M.T.J., Girod, B., Lucas, P.L., de Vries, B. (2012) 'Scenarios in Global Environmental Assessments: Key characteristics and lessons for future use', Global Environmental Change. Pergamon, 22(4), pp. 884-895. doi:

10.1016/J.GLOENVCHA.2012.06.001.

Wagner, M. (2008) 'The carbon Kuznets curve: A cloudy picture emitted by bad econometrics?', Resource Energy and Economics, 30, pp. 388-408.

Wen, Z. and Meng, X. (2015) 'Quantitative assessment of industrial symbiosis for the promotion of circular economy: a case study of the printed circuit boards industry in China's Suzhou New District', Journal of Cleaner Production, 90, pp. 211-219.

Wiseman, J., Edwards, T. and Luckins, K. (2013) 'Post carbon pathways: A metaanalysis of 18 large-scale post carbon economy transition strategies.', Environmental Innovation and Societal Transitions, 8, pp. 76-93.

Wu, Y., Zhu, Q. and Zhu, B. (2018) 'Comparisons of decoupling trends of global economic growth and energy consumption between developed and developing countries', Energy Policy, 116, pp. 30-38. doi: 10.1016/j.enpol.2018.01.047.

Yu, F., Han, F. and Cui, Z. (2015) 'Reducing carbon emissions through industrial symbiosis: a case study of a large enterprise group in China', Journal of Cleaner Production, 103, pp. 811-818.

Zittel, W. and Schindler, J. (2006) Uranium Resources and Nuclear Energy. Ottobrunn/Achen: Energy Watch Group. 


\section{Supplementary Materials}

\section{Appendix 1. Methodological appendix for INDCs revision}

The heterogeneity of the data in the INDCs has forced us to make a series of hypotheses which are summarized in the Methodology section and are set out in detail here.

The policies, classified using codes, have been recorded country by country, grouped in the sectors described above. To carry out the analysis, and to establish comparisons, the proportion of countries adopting each policy over the total number of countries providing information has been calculated. This reduces the analysis to 126 of the 161 INDCs submitted (representing 188 countries). In order to estimate the interest of each group of countries by income, we have calculated the mean of these proportions in each sector.

As for funding, we have collected the data offered in the INDCs in dollars. Although the base varies in some of them, in most of them there is no mention of this aspect, so the quantities expressed in dollars are subject to this limitation. To calculate the percentage of external support required by the INDCs that do not explicitly provide this information, we have assumed that it would be distributed uniformly, the proportion being that which represents the conditional reduction in emissions over the total reduction in emissions (conditional + unconditional).

We have calculated the variation in emissions of the INDCs in relation to the intensity of emissions in the following manner: having defined the intensity of emissions as

$$
\text { A.1. } \quad I=\frac{E}{G D P}
$$

the following equation is solved:

$$
\text { A.2. } \quad \frac{\left(\left(I_{2030} * G D P_{2030}\right)-\left(I_{B Y} * G D P_{B Y}\right)\right)}{\left(I_{B Y} * G D P_{B Y}\right)} * 100=\Delta E \text {. }
$$

Where $\mathrm{I}_{2030 / \mathrm{BY}}$ is the intensity of emissions in 2030 and the base year respectively; $G D P_{2030 / B Y}$ is the GDP in 2030 and the base year respectively; and $\Delta E$ is the percentage variation 
of the emissions. Both China and India present their data in this way and require additional hypotheses. They have had to use the projections of the GDP for the year 2030 of the OECD.

In the case of the INDCs that apply a reduction on a BAU scenario, the procedure was as follows: applying arbitrary emissions of 100, the problem was solved using the following equation:

$$
\text { A.3 } \frac{((100 *(1+\triangle B A U) *(1-\triangle P R O P))-100)}{100}=\Delta E \text {. }
$$

Where $\triangle B A U$ is the percentage variation of emissions in the Business as usual (BAU) scenario; $\triangle P R O P$ is the proposed percentage reduction in emissions on the BAU scenario (conditional and unconditional, depending on the case); and $\Delta E$ is the percentage variation in the emissions. BAU scenario refers to the emissions in the horizon year if policies were not applied, usually based on historical emissions trends.

With a conservative supposition, we have assumed that the INDCs which propose a reduction range will finally achieve the upper bound.

Regarding the policies analysis, we have to differentiate three analyses: policies at world level, policies at regional level, and sectoral-regional analysis.

Policies at world level are assessed throughout the number of countries using each policy over total countries, according to eq. A4:

$$
\text { A4. } \quad \alpha_{W}=\frac{\sum P_{i}}{N}
$$

Being subscript i each policy, regardless the sector and $\sum P_{i}$ the number of countries using each policy $\left(P_{i j}\right)$ considered and $\mathrm{N}$ the total number of countries. Top 15 policies are shown in Table 8. For the regional level, an analogous calculation is made:

$$
\text { A5. } \alpha_{r}=\frac{\sum P_{i, r}}{N_{r}}
$$

Where the numerator represents the same as in A4 but for region (income group) $r$. The denominator is the number of countries in region r. Figure 8 shows the deviation from each top 15 policy share by income group to the world average, namely: $\alpha_{r}-\alpha_{W}$. Finally, we take the arithmetical mean of $\alpha_{r}$ and $\alpha_{W}$ by sector:

A6. $\quad \alpha_{j, W}=\frac{\sum \alpha_{W}}{N_{j}} ; \quad \alpha_{j, r}=\frac{\sum \alpha_{r}}{N_{j}}$

With $N_{j}$ being the number of policies in each sector $\mathrm{j}$. By proceeding this way, we obtain an approximation to the relative importance of each sector in the different regions and in the 
world. Finally, analogously to Figure 8, Figure 9 shows the deviation from each region to world:

$\alpha_{j, r}-\alpha_{j, W}$

\begin{tabular}{|l|l|}
\hline Income group & Contries \\
\hline Low income & $\begin{array}{l}\text { Afganisthan, Benin, Burkina Faso, Burundi, Cambodia, Central African Rep., Chad, Comores, DR of Congo, Eritrea, } \\
\text { Ethiopia, Gambia, Guinea, Guinea Bissau, Liberia, Madagascar, Malawi, Mali, Mozambique, Nepal, Niger, Rwanda, } \\
\text { Sierra Leone, Somalia, South Sudan, Tanzania, Togo, Uganda, Zimbabue. }\end{array}$ \\
\hline Lower-Middle & $\begin{array}{l}\text { Armenia, Bangladesh, Bhutan, Bolivia, Cameroon, Cape Verde, Congo, Djibouti, Egypt, El Salvador, Georgia, Ghana, } \\
\text { Guayana, India, Indonesia, Ivory Coast, Kenya, Kiribati, Lao, Lesotho, Mauritania, Morocco, Myanmar, Nigeria, Papua } \\
\text { New Guinea, Samoa, Senegal, Solomon Islands, Sri Lanka, St. Tome, Sudan, Tajikistan, Vanuatu, Vietnam, Yemen, } \\
\text { Zambia. }\end{array}$ \\
\hline High & $\begin{array}{l}\text { Algeria, Angola, Azerbaijan, Belarus, Belize, Bosnia-Herzegovina, Brazil, China, Costa Rica, Cuba, Dominica, Ecuador, } \\
\text { Fiji, Gabon, Grenada, Jamaica, Jordan, Kazajstan, Lebanon, Marshall Islands, Mauritius, Mongolia, Namibia, Palau, } \\
\text { Paraguay, South Africa, St Kitts, St Lucia, Surinam, Thailand, Tonga, Tunez, Turkey, Tuvalu. }\end{array}$ \\
\hline OECD & $\begin{array}{l}\text { Antigua and Barbuda, Argentina, Bahamas, Barbados, Brunei, Equatorial Guinea, Monaco, Oman, Qatar, San Marino, } \\
\text { Saudi Arabia, Seychelles, St.Vincent\&Grenadines, U.A.E., Uruguay, Venezuela. }\end{array}$ \\
\hline Australia, Canada, Chile, EU28, Iceland, Israel, Japan, Korean Rep., New Zealand, Norway, Switzerland, USA.
\end{tabular}




\title{
Appendix 2. MEDEAS-World analysis
}

\author{
Appendix 2.A. List of industries
}

Table 16. List of industries

\begin{tabular}{|c|c|c|c|}
\hline \multicolumn{4}{|c|}{ Sectors } \\
\hline 1 & $\begin{array}{l}\text { Agriculture, Hunting, Forestry and } \\
\text { Fishing }\end{array}$ & 18 & Construction \\
\hline 2 & Mining and Quarrying & 19 & $\begin{array}{l}\text { Sale, Maintenance and Repair of Motor } \\
\text { Vehicles and Motorcycles; Retail sail of fuel }\end{array}$ \\
\hline 3 & Food, Beverages and Tobacco & 20 & $\begin{array}{l}\text { Wholesale Trade and Commission Trade, } \\
\text { Except of Motor Vehicles and Motorcycles }\end{array}$ \\
\hline 4 & Textiles and Textile Products & 21 & $\begin{array}{l}\text { Retail Trade, Except of Motor Vehicles and } \\
\text { Motorcycles; Repair of Household goods }\end{array}$ \\
\hline 5 & Leather, Leather and Footwear & 22 & Hotels and Restaurants \\
\hline 6 & Wood and Products of Wood and Corks & 23 & Inland Transport \\
\hline 7 & Pulp, Paper, Printing and Publishing & 24 & Water Transport \\
\hline 8 & Coke, Refined Petroleum and Nuclear fuel & 25 & Air Transport \\
\hline 9 & Chemicals and Chemical Products & 26 & $\begin{array}{l}\text { Other Supporting and Auxiliary Transport } \\
\text { Activities; Activities of Travel Agencies }\end{array}$ \\
\hline 10 & Rubber and Plastics & 27 & Post and Telecommunications \\
\hline 11 & Other Non-Metallic Mineral & 28 & Financial Intermediation \\
\hline 12 & Basic Metals and Fabricated Metal & 29 & Real Estate Activities \\
\hline 13 & Machinery, Nec & 30 & $\begin{array}{l}\text { Renting of M\&Eq and Other Business } \\
\text { Activities }\end{array}$ \\
\hline 14 & Electrical and Optical Equipment & 31 & $\begin{array}{l}\text { Public Admin and Defence; Compulsory } \\
\text { Social Security }\end{array}$ \\
\hline 15 & Transport Equipment & 32 & Education \\
\hline 16 & Manufacturing, Nec.; Recycling & 33 & Health and Social Work \\
\hline 17 & Electricity, Gas and Water supply & 34 & $\begin{array}{l}\text { Other Community, Social and Personal } \\
\text { Services }\end{array}$ \\
\hline & & 35 & Private Households with Employed Persons \\
\hline
\end{tabular}

Source: Own compilation on the basis of WIOD (Dietzenbacher et al., 2013) 


\section{Appendix 2.B. Target matrices for the World model.}

BAU- Gradually evolving from 2020 to 2050 at historical rates, limited to maintain the consistency of accounting balances. The historical average growth rate of every component of the A matrix is estimated, i.e. 1225 rates. Then every A matrix component $a_{i j}$ is projected applying its average growth rate. This can lead to inconsistencies that have been avoided:

1- Total intermediate inputs proportion being higher than 1 or lower than zero. For this purpose, 1 and 0 were set as maximum and minimum for this proportion respectively.

2- Total intermediate inputs proportion being high or low enough to reduce or increase gross value added in an unrealistic way. Gross value added proportion over sectoral output can only be $1 / 3$ higher or lower than its initial value.

For instance, sector 2 has an intermediate inputs' share of 0.318 as its last observed value and starts declining after 2020. It only decreases 0.275 by 2050 with a gross value added share 0.725. Otherwise it could have led to gross value added being $95 \%$ of total output or even lower than zero. Nevertheless, the most common situation is technical coefficients going higher and therefore, reducing the economy's capability to create gross value added out of production. This system allows the BAU scenario continue its current trajectory avoiding gross value added to shrink.

Green growth- Denmark A Matrix (last observation). The Denmark's IOT was transformed into a one-region matrix, incorporating intermediate inputs from imports to the purchases made by Denmark's sectors domestically. Additionally, exports have been considered as domestic sales. This way, we can evaluate the economic performance of the global economy (where imports are equal to exports) if its sectoral trade flows had the same structure as Denmark, one of the most important countries in terms of domestic sustainability, and a European, modern and efficient country. 
Post-growth- Ad-hoc matrix fostering less energy-intensive sectors and improving the efficiency of the energy producing sector. Method: increasing sales weights (row coefficients) and reducing purchases weights (column coefficients), respectively, by a factor (see Figure A.3). By affecting the technical coefficients by rows, the implicit assumption is that every sector will purchase more (or less) intermediate products or services from the sector that is being modified. For instance, if we want to evaluate in this scenario a situation whereby all the economy is going to transit to electrification, is to be expected that all industries will increase their purchases from sector 17 (see Appendix A.1.). This would imply that the proportion in which sectors will use products from sector 17 over their total output will be higher. As a consequence, row 17 of the technical coefficients matrix is multiplied by 1.40 factor. Analogously, by predicting a less materialintensive future within the Post-Growth scenario, a $10 \%$ reduction in intermediate consumption is operated by multiplying by a 0.90 factor by columns. These row and column factors can be seen broken down by sectors below the target matrix. 


\section{Table 17. BAU final A matrix (World level) and different year's sum of columns (share of intermediate products on total output)}

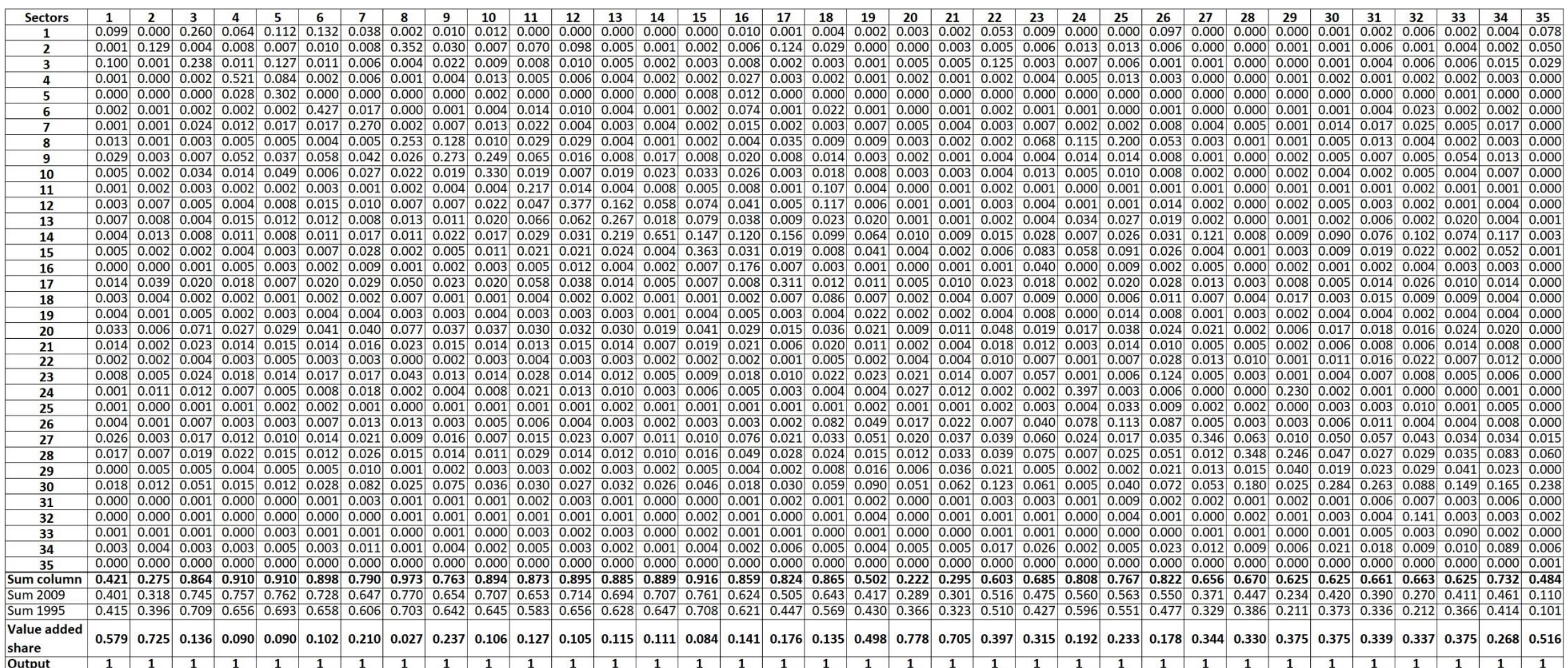

Own elaboration. 


\section{Table 18. Green growth scenario target A matrix (World level)}

\begin{tabular}{|c|c|c|c|c|c|c|c|c|c|c|c|c|c|c|c|c|c|c|c|c|c|c|c|c|c|c|c|c|c|c|c|c|c|c|c|}
\hline Sectors & 1 & 2 & 3 & 4 & 5 & 6 & 7 & 8 & 9 & 10 & 11 & $\frac{12}{000}$ & 13 & 14 & 15 & 16 & 17 & 18 & 19 & 20 & 21 & 22 & 23 & 24 & 25 & 26 & 27 & 28 & 29 & 30 & 31 & 32 & 33 & 34 & 35 \\
\hline & 0.089 & \begin{tabular}{|l|}
0.001 \\
\end{tabular} & 0.326 & \begin{tabular}{|l|}
0.014 \\
0
\end{tabular} & & & \begin{tabular}{|c|}
0.000 \\
0
\end{tabular} & & \begin{tabular}{|c|c|}
0.002 \\
001
\end{tabular} & 0.000 & 0.001 & 0.000 & 0.000 & & 0.000 & 0.005 & 0.014 & \begin{tabular}{|l|}
0.008 \\
\end{tabular} & 0.000 & \begin{tabular}{|c|c|}
0.000 \\
\end{tabular} & 0.000 & $0.048 \mathrm{C}$ & 0.001 & 0.000 & 0.000 & 0.001 & \begin{tabular}{|l|}
0.000 \\
\end{tabular} & \begin{tabular}{|c|c|}
0.000 \\
\end{tabular} & 0.000 & & 0.009 & 0.005 & & & 0.000 \\
\hline 2 & 0.001 & \begin{tabular}{|l|}
0.052 \\
\end{tabular} & \begin{tabular}{|l|}
0.000 \\
\end{tabular} & $\mid$\begin{tabular}{|l|}
$\mid$ \\
\end{tabular} & 0.000 & \begin{tabular}{|l|}
0.000 \\
\end{tabular} & \begin{tabular}{|l|}
0.000 \\
\end{tabular} & 0.560 & \begin{tabular}{|l|l|}
0.001 \\
\end{tabular} & \begin{tabular}{|l|l|}
0.001 \\
\end{tabular} & 0.022 & 0.001 & 0.000 & \begin{tabular}{|l|}
0.000 \\
\end{tabular} & \begin{tabular}{|l|l|}
0.000 \\
\end{tabular} & \begin{tabular}{|l|}
0.000 \\
\end{tabular} & \begin{tabular}{|c|}
0.146 \\
\end{tabular} & \begin{tabular}{|l|}
0.003 \\
\end{tabular} & \begin{tabular}{|l|}
0.000 \\
\end{tabular} & \begin{tabular}{|l|l|}
0.000 \\
\end{tabular} & \begin{tabular}{|l|l|} 
\\
\end{tabular} & $0.000 \mathrm{C}$ & \begin{tabular}{|l|l|l|l|}
0.000 \\
\end{tabular} & $\mid 0.000$ & & \begin{tabular}{|l|}
0.000 \\
\end{tabular} & $\mid 0.000$ & \begin{tabular}{|c|}
0.000 \\
\end{tabular} & 0.000 & $000 \mathrm{C}$ & 0.000 & 0.000 & 000 & 0.000 & 0.000 \\
\hline 3 & 0.071 & 0.002 & 0.123 & \begin{tabular}{|l|} 
\\
\end{tabular} & 0.047 & 0.001 & 0.003 & - 0.000 & & 0.004 & 0.003 & 0.001 & 0. & & 0.000 & 0 & $01 \mid$ & 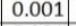 & 0.002 & 005 & .00 & $0.217 \mid \mathrm{C}$ & \begin{tabular}{|l|}
0.002 \\
\end{tabular} & \begin{tabular}{|l|l|} 
& 0.000 \\
\end{tabular} & & 0.004 & .001 & 001 & & & 0.003 & 0.002 & & 0.005 & .000 \\
\hline 4 & 0.000 & \begin{tabular}{|l|l|}
0.000 \\
\end{tabular} & 0.000 & 0.097 & 0.006 & 001 & 0.001 & 0.000 & & 0.002 & 0.003 & & & & 0.0 & & & & & & & & & 0. & & & & & & & 0.001 & 000 & & .001 & 000 \\
\hline 5 & & & 0.000 & 0.001 & 0.031 & & 0.000 & 0.000 & & & 0.000 & & & & & & & & & & & & & & & & & & & & & 500 & & & 500 \\
\hline 6 & & 0.001 & \begin{tabular}{|l|l|} 
\\
\end{tabular} & & 0.0 & & 0.001 & 0.000 & & 0.0 & 0.005 & & & 0.002 & 0.002 & & & \begin{tabular}{|l|}
0.046 \\
\end{tabular} & & & & & \begin{tabular}{|l|}
0.001 \\
\end{tabular} & & & & & & & & 000 & 500 & & 001 & 000 \\
\hline 7 & & 0.0 & \begin{tabular}{|l|l|}
0.013 \\
\end{tabular} & \begin{tabular}{|l|}
0.007 \\
\end{tabular} & 0.007 & & \begin{tabular}{|l|}
0.218 \\
\end{tabular} & 0.000 & & \begin{tabular}{|l|l|}
0.016 \\
\end{tabular} & \begin{tabular}{|l|}
0.013 \\
\end{tabular} & & & & 0.001 & 0.013 & & \begin{tabular}{|l|}
0.001 \\
\end{tabular} & & & & & & & & & & & & & 0.008 & 508 & & 012 & .000 \\
\hline 8 & & & 0.005 & & 0.007 & & 0.002 & & & & & & & 01 & & & & & & & & & \begin{tabular}{|l|l|}
0.042 \\
\end{tabular} & & & & & & & & 0.003 & 002 & & & 000 \\
\hline 9 & & & 0.011 & & 0.0 & 0.012 & \begin{tabular}{|l|}
0.016 \\
\end{tabular} & 0.012 & & & \begin{tabular}{|l|l|}
0.024 \\
\end{tabular} & & & 0.0 & & & & & & & & & & & & & & & & & & & & 11 & .000 \\
\hline & & 0.0 & 0.010 & & 0.00 & $\begin{array}{l}0.010 \\
\end{array}$ & 0.006 & 0.002 & & & $\begin{array}{ll}0.012 \\
\end{array}$ & & & & & & & & & & & & & & & & & & & & & & & & .000 \\
\hline & & 0.0 & 0.001 & 0.0 & 0.000 & & \begin{tabular}{|l|l|}
0.000 \\
\end{tabular} & & & & 0.065 & & & & & & & & & & & & & & & & & & & & & & & & .000 \\
\hline 12 & & & 0.010 & 0.0 & 0.008 & 0.062 & & & & & 0.036 & & & & & & & & & & & & & & & & & & & & & & & & .000 \\
\hline 13 & 0.004 & \begin{tabular}{|l|l|}
0.014 \\
\end{tabular} & \begin{tabular}{|l|}
0.006 \\
\end{tabular} & & 0.006 & \begin{tabular}{|l|}
0.010 \\
\end{tabular} & 0.005 & 0.004 & \begin{tabular}{|l|}
0.008 \\
\end{tabular} & & 0.011 & & & \begin{tabular}{|l|}
0.040 \\
\end{tabular} & 222 & & & & & & & & \begin{tabular}{|l|}
0.007 \\
\end{tabular} & & & & & & & & & & & & .000 \\
\hline 14 & 0.002 & 0.012 & - 0.006 & 0.0 & 0.004 & 0.015 & \begin{tabular}{|c|c|} 
\\
\end{tabular} & 0.00 & & & 0.021 & 0.0 & & 0.215 & 0.022 & & & & 0.033 & & & & \begin{tabular}{|l|}
0.007 \\
\end{tabular} & & & & & & & & & & & & .000 \\
\hline 15 & & & & & & 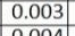 & 0.001 & 0.00 & & & 0.003 & 0.00 & & \begin{tabular}{|c|}
0.004 \\
\end{tabular} & \begin{tabular}{|c|c|}
0.025 \\
\end{tabular} & \begin{tabular}{|l|l|}
0.002 \\
020
\end{tabular} & & \begin{tabular}{|l|l|}
0.004 \\
\end{tabular} & & & & & \begin{tabular}{|l|l|}
0.011 \\
\end{tabular} & & & & & & & & & & & & .000 \\
\hline 16 & & & & 0.0 & & 0.004 & & 0.000 & 2.002 & & 0.011 & 0.02 & & 0.002 & 0.002 & 0.035 & $\frac{0.00}{0.02}$ & 0.004 & & & & & 0.002 & & & & & & & & & & & & .000 \\
\hline 17 & & & & 0.005 & 0.002 & |.007| & 0.005 & 0.128 & | & & 0.011 & 0.007 & & 0.002 & 0.002 & & & & & & & & \begin{tabular}{|l|}
0.006 \\
\end{tabular} & & & & & & & & & & & & .000 \\
\hline 18 & 0.006 & & 0.003 & 0.002 & & & 0.003 & \begin{tabular}{|l|l|} 
\\
\end{tabular} & 0.005 & & 0.006 & 0.004 & & \begin{tabular}{|l|l|}
0.004 \\
\end{tabular} & 0.001 & & & & 0.00 & & & & & & & & & & & & 221 & & & & \\
\hline 19 & 0.006 & \begin{tabular}{|l|l|}
0.004 \\
\end{tabular} & 0.009 & \begin{tabular}{|l|}
0.015 \\
\end{tabular} & 0.012 & \begin{tabular}{|l|}
0.015 \\
\end{tabular} & 0.005 & \begin{tabular}{|l|l|} 
\\
\end{tabular} & \begin{tabular}{|l|}
0.006 \\
\end{tabular} & \begin{tabular}{|l|}
0.011 \\
\end{tabular} & 0.010 & 0.012 & & 0.010 & \begin{tabular}{|l|}
0.003 \\
\end{tabular} & 0.013 & 0.002 & \begin{tabular}{|l|l|}
0.014 \\
\end{tabular} & & 0.0 & & & \begin{tabular}{|l|}
0.031 \\
\end{tabular} & & & & & & & & & & & 44 & \\
\hline 20 & 0.038 & 0.0 & 0.080 & \begin{tabular}{|l|}
0.138 \\
\end{tabular} & 0.130 & \begin{tabular}{|l|l|}
0.124 \\
\end{tabular} & \begin{tabular}{|l|l|}
0.044 \\
\end{tabular} & 0.021 & \begin{tabular}{|l|}
0.064 \\
\end{tabular} & 0.0 & \begin{tabular}{|l|}
0.073 \\
\end{tabular} & 0.101 & 0.113 & \begin{tabular}{|l|}
0.082 \\
\end{tabular} & \begin{tabular}{|l|}
0.030 \\
\end{tabular} & 0.108 & 0.021 & \begin{tabular}{|l|}
0.091 \\
\end{tabular} & \begin{tabular}{|l|}
0.054 \\
\end{tabular} & 0.0 & 0.0 & 4 & \begin{tabular}{|l|}
0.025 \\
\end{tabular} & \begin{tabular}{|l|l|} 
\\
\end{tabular} & & & & & & & 019 & & & & \\
\hline 21 & 0.019 & \begin{tabular}{|c|}
0.011 \\
0.001
\end{tabular} & \begin{tabular}{|c|}
0.038 \\
0.002
\end{tabular} & \begin{tabular}{|l|}
0.064 \\
0.002
\end{tabular} & $\begin{array}{l}0.046 \\
0.003\end{array}$ & \begin{tabular}{|c|}
0.061 \\
0.002
\end{tabular} & \begin{tabular}{|c|}
0.021 \\
0.002
\end{tabular} & 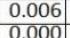 & \begin{tabular}{|c|}
0.027 \\
0.011
\end{tabular} & \begin{tabular}{|l|}
0.046 \\
0.003
\end{tabular} & \begin{tabular}{|c|}
0.038 \\
0.002
\end{tabular} & \begin{tabular}{|c|c|c|}
0.048 \\
0.003
\end{tabular} & & \begin{tabular}{|l|}
0.041 \\
0
\end{tabular} & 0.014 & 0.0 & 0.006 & \begin{tabular}{|l|}
0.048 \\
0
\end{tabular} & \begin{tabular}{|c|}
0.028 \\
0005
\end{tabular} & 0.007 & 0.005 & 0.034 & \begin{tabular}{|l|}
0.011 \\
\end{tabular} & 0.006 & 0.006 & $|0.005|$ & 0.016 & 0.002 & J.001 & UU8 & 0.010 & 0.004 & 011 & 0.011 & 0.000 \\
\hline$\frac{22}{23}$ & $\frac{0.000}{0.002}$ & \begin{tabular}{|l|}
0.001 \\
0.192
\end{tabular} & \begin{tabular}{|l|}
0.002 \\
0.022
\end{tabular} & \begin{tabular}{|l|}
0.002 \\
0.014
\end{tabular} & $\mid \begin{array}{c}0.003 \\
0.019\end{array}$ & \begin{tabular}{|l|}
0.002 \\
0.019
\end{tabular} & \begin{tabular}{|c|}
0.002 \\
0.014
\end{tabular} & $\begin{array}{l}0.000 \\
0.013\end{array}$ & \begin{tabular}{|c|}
0.011 \\
0.010
\end{tabular} & \begin{tabular}{|c|}
0.003 \\
0.018 \\
\end{tabular} & \begin{tabular}{|l|}
0.002 \\
0.042
\end{tabular} & \begin{tabular}{|c|}
0.003 \\
0.010
\end{tabular} & & \begin{tabular}{|l|}
0.002 \\
0.004
\end{tabular} & \begin{tabular}{|c|}
0.001 \\
0.002
\end{tabular} & \begin{tabular}{|l|}
0.002 \\
0.026 \\
\end{tabular} & $\begin{array}{c}0.001 \\
0.003\end{array}$ & \begin{tabular}{|c|}
0.001 \\
0.007
\end{tabular} & \begin{tabular}{|c|}
0.005 \\
0.012
\end{tabular} & \begin{tabular}{|c|c|}
0.007 \\
0.063
\end{tabular} & & \begin{tabular}{|l|l|}
0.001 \\
\end{tabular} & \begin{tabular}{|l|l|}
0.145 \\
\end{tabular} & \begin{tabular}{|l|}
0.013 \\
\end{tabular} & & 0.02 & 0.011 & & & & & 0.014 & & & $\begin{array}{l}0.000 \\
0.000\end{array}$ \\
\hline & & \begin{tabular}{|l|}
0.000 \\
\end{tabular} & \begin{tabular}{|l|}
0.000 \\
\end{tabular} & & & & & & & & \begin{tabular}{|c|}
0.000 \\
\end{tabular} & & & \begin{tabular}{|l|}
0.000 \\
\end{tabular} & 0.000 & \begin{tabular}{|l|}
0.000 \\
\end{tabular} & & \begin{tabular}{|l|}
0.000 \\
\end{tabular} & 0.0 & & & & \begin{tabular}{|l|}
0.001 \\
\end{tabular} & 0.002 & & 0 & 0.000 & & & & & & & & \begin{tabular}{|l|l|} 
\\
\end{tabular} \\
\hline & & & 0.000 & & & & $\overline{01}$ & & & & 0.001 & & & & & & & & & & & & & & & & & & & & & & & & \\
\hline & & & & & & & & & & & 0.004 & & & & & & & & & & & & & & & & & & & & & & & & \\
\hline & & & 0.006 & & & & & & & & 0.0 & & & & & & & & & & & & & & & & & & & & & & & & \\
\hline 28 & & & 0.0 & .0 & & & & & & & & & & & & & & & & & & & & & & & & & & & & & & & \\
\hline & & & 0.0 & & & & & & & & & & & & & & & & & & & & & & & & & & & & & & & & \\
\hline 30 & & & 8.0 & & & & & & & & & & & & & & & & & & & & & & & & & & & & & & & & \\
\hline 31 & & .0 & .001 & .00 & & & 0.0 & & & & 0.0 & & & & & & & & & & & & & & & & & & & & & & & & \\
\hline 32 & & & 1.0 & & & & & & & & 0.0 & & & & & & & & & & & & & & & & & & & & & & & & \\
\hline 33 & & & 0.0 & .0 & 0.0 & & & & & & 0.0 & & & & & & & & & & & & & & & & & & & & & & & & \\
\hline 34 & & & 0.0 & .0 & & & & & & & & & & & & & & & & & & & & & & & & & & & & & & & \\
\hline 35 & .000 & $\mid 0.000$ & \begin{tabular}{|l|l|}
0.000 \\
\end{tabular} & 0.000 & 0.0 & 0.0 & 0.00 & 0.06 & $\overline{0.0}$ & $\mid$\begin{tabular}{|l|}
0.000 \\
\end{tabular} & 0.0 & & & & 0.0 & & & & & & & & & & & & & & & & & & & & \\
\hline & & & & & & & & & & & & & & & & & & & & & & & & & & & & & & & & & & & \\
\hline & & & & & & & & & & & & & & & & 52 & & & & & & & & 5 & & & & & & & & & & & .110 \\
\hline um 1995 & 0.41 & | 0.396 & $\mid 0.709$ & $\mid 0.656$ & 0.693 & \begin{tabular}{|c|}
0.658 \\
\end{tabular} & \begin{tabular}{|l|}
0.606 \\
\end{tabular} & \begin{tabular}{|l|l|}
0.703 \\
\end{tabular} & 0.642 & $\mid$ & \begin{tabular}{|l|}
0.583 \\
\end{tabular} & 0.656 & 0.628 & $\mid$ & 0.708 & 0.621 & $0.447 \mid$ & $\mid$ & $|0.430|$ & . & 0.520 & 0.310 & 0.427 & 0.596 & & 0.477 & 0.32 & 0.380 & 0.211 & 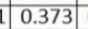 & 0.336 & 0.212 & $\mid$ & \begin{tabular}{|l|}
0.414 \\
\end{tabular} & 0.101 \\
\hline Value added & 0.612 & $0.517 \mid$ & 0.237 & $\mid 0.430$ & 0.443 & 0.396 & 0.493 & 0.201 & 0.491 & 0.430 & \begin{tabular}{|l|}
0.499 \\
\end{tabular} & 0.358 & 0.322 & 0.435 & 0.809 & $\mid$\begin{tabular}{|l|}
$\mid$ \\
\end{tabular} & 0.584 & 0.358 & 0.557 & 0.590 & 0.663 & \begin{tabular}{|c|c|}
3 & 0.359
\end{tabular} & $0.467 \mid$ & 0.238 & 0.495 & 0.474 & 0.602 & 0.701 & 0.681 & $\begin{array}{ll}1 & 0.462 \\
\end{array}$ & 611 & 0.746 & $|0.679|$ & .4475 & 1.000 \\
\hline Output & 1 & 1 & 1 & 1 & 1 & 1 & 1 & 1 & 1 & 1 & 1 & 1 & 1 & 1 & 1 & 1 & 1 & 1 & 1 & 1 & 1 & 1 & 1 & 1 & 1 & 1 & 1 & 1 & 1 & 1 & 1 & 1 & 1 & 1 & 1 \\
\hline
\end{tabular}

Own elaboration from WIOD (Dietzenbacher et al., 2013) 
Table 19. Post growth scenario A matrix (World level)

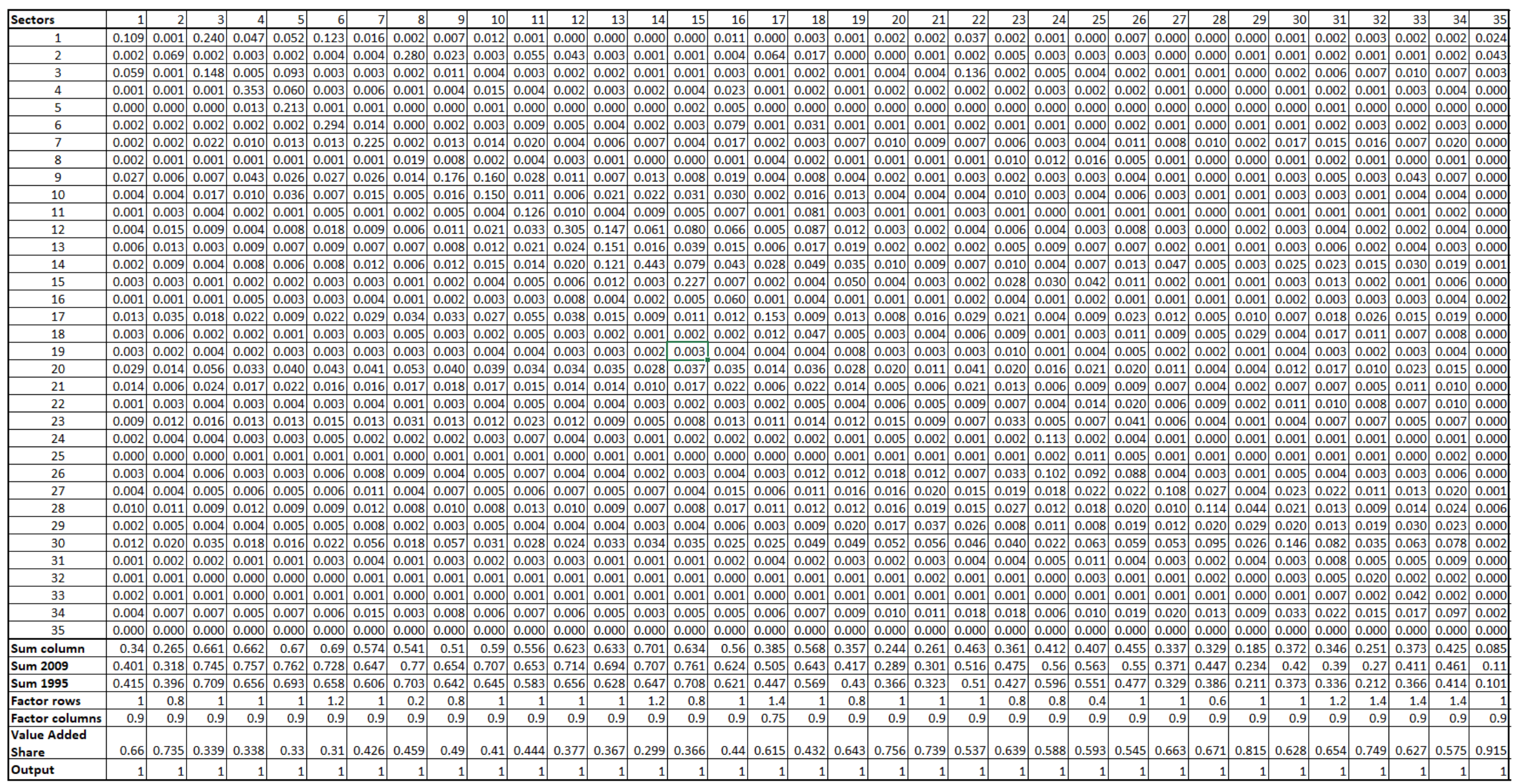

Own elaboration 


\section{Appendix 2.C. Direct and indirect effects}

Input-Output Analysis (IOA) allows the sectoral production required to satisfy an exogenous variation in demand to be calculated. As we already know, IOA encompasses the set of inputs that each industry needs from the others in order to produce its output (technical coefficients). Thus, by means of this structure, the variation in final demand not only triggers a direct reaction in economic output, but also an indirect one, regarding the cross-industry demand for intermediate products. Hence, IOA lets us separate the total effects of a variation in final demand between direct effects and indirect effects on production. As the total production (on the demand side) equals the row sum of sectoral intermediate consumption, plus sectoral final demand, both figures would represent indirect and direct effects, respectively. Moreover, by using energy coefficients (i.e., energy intensities), we can obtain energy carriers from each effect. Since MEDEAS-World takes household energy consumption separately (Eq.10), additional arrangements must be made to correctly track the energy carriers of direct effects. Therefore, considering that $\mathrm{fd}=\mathrm{x}-\mathrm{Z}$, the indirect and direct energy carrier effects are calculated as follows:

$$
\mathbf{D E}^{\mathbf{k i}}=\hat{\mathbf{e}}^{\mathbf{k i}} \cdot\left(\mathbf{x}^{\prime}-\mathbf{r}^{\prime}\right)+\widehat{\mathbf{h h}_{-}} \mathbf{e}^{\mathbf{k i}} \cdot \mathbf{c} \quad \text { Eq. C. } 1
$$

$$
\mathbf{I} \mathbf{E}^{\mathbf{k i}}=\hat{\mathbf{e}}^{\mathbf{k i}} \cdot \mathbf{r}^{\prime}
$$

where $\mathbf{D E}^{\mathbf{k i}}$ and $\mathbf{I E}^{\mathbf{k i}}$ are both direct and indirect energy carrier effects, $\mathbf{r}^{\prime}$ is the row vector of the row's sum of intermediate consumption by industry ' $i$ ' $\left(\sum_{j=1}^{35} z_{i j}\right), \hat{\mathbf{e}}^{\mathbf{k i}}$ is the energy intensities by sector and $\widehat{\mathbf{h h}} \mathbf{e}^{\mathbf{k i}}$ household energy intensity (both intensities' diagonal matrices equal to those in section 3.1.4 since sectors ' $\mathrm{i}$ ' $=$ sectors ' $\mathrm{j}$ '), $\mathbf{c}$ stands for the households' demand for industry i's products and $\mathbf{x}^{\prime}$ the row vector of economic output. In order to check the validity of Eqs. A.1 and A.2, let us define the total effects (TE ${ }^{\mathrm{ki}}$ ) as the sum of both:

$$
\mathbf{T E} \mathbf{E}^{\mathbf{k i}}=\hat{\mathbf{e}}^{\mathbf{k i}} \cdot\left(\mathbf{x}^{\prime}-\mathbf{r}^{\prime}\right)+\widehat{\mathbf{h h}}_{\mathbf{e}}^{\mathbf{k i}} \cdot \mathbf{c}+\hat{\mathbf{e}}^{\mathbf{k i}} \cdot \mathbf{r}^{\prime} \quad \text { Eq. C. } 3
$$

and then, operating:

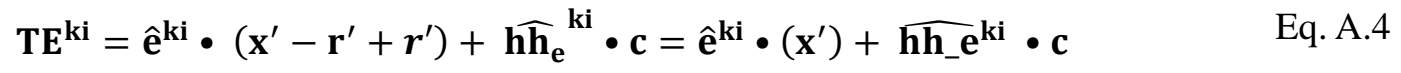

which, considering that $\mathbf{x}$ ' $=\mathbf{x}$ and sectors ' $\mathrm{i}$ ' and ' $\mathrm{j}$ ' are equal but by rows and columns respectively, exactly equals Eq.10. 
Appendix 2.D. World Economy module views

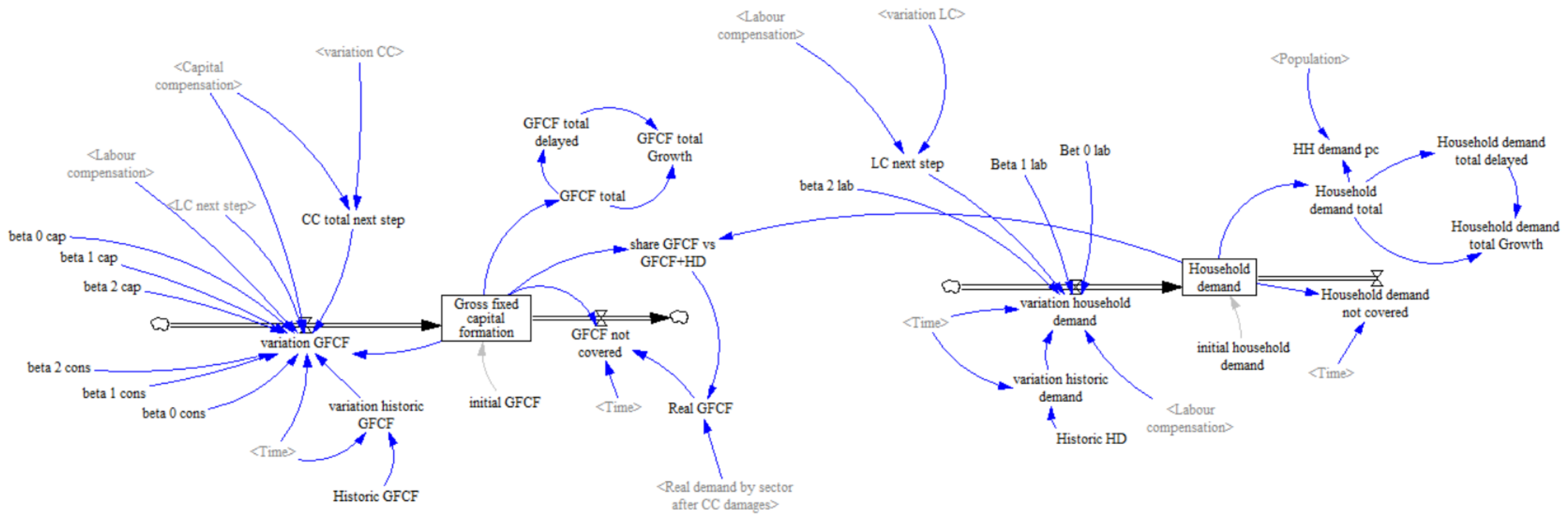

Figure 28. 'DEM-ECON. Investment and Households' View in MEDEAS-World. 


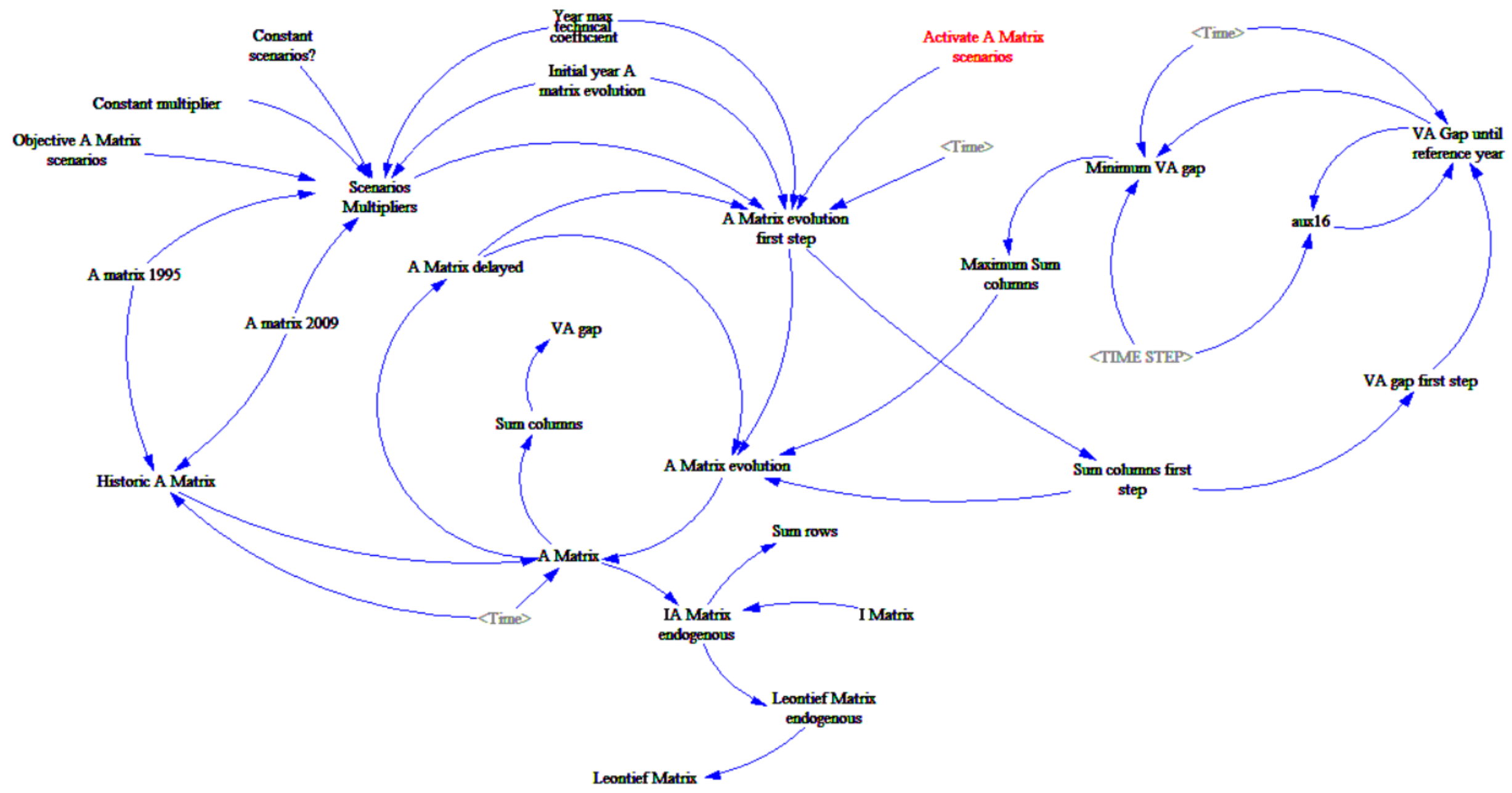

Figure 29. 'ECON. Economic structure - A matrix evolution' view in MEDEAS-World. 


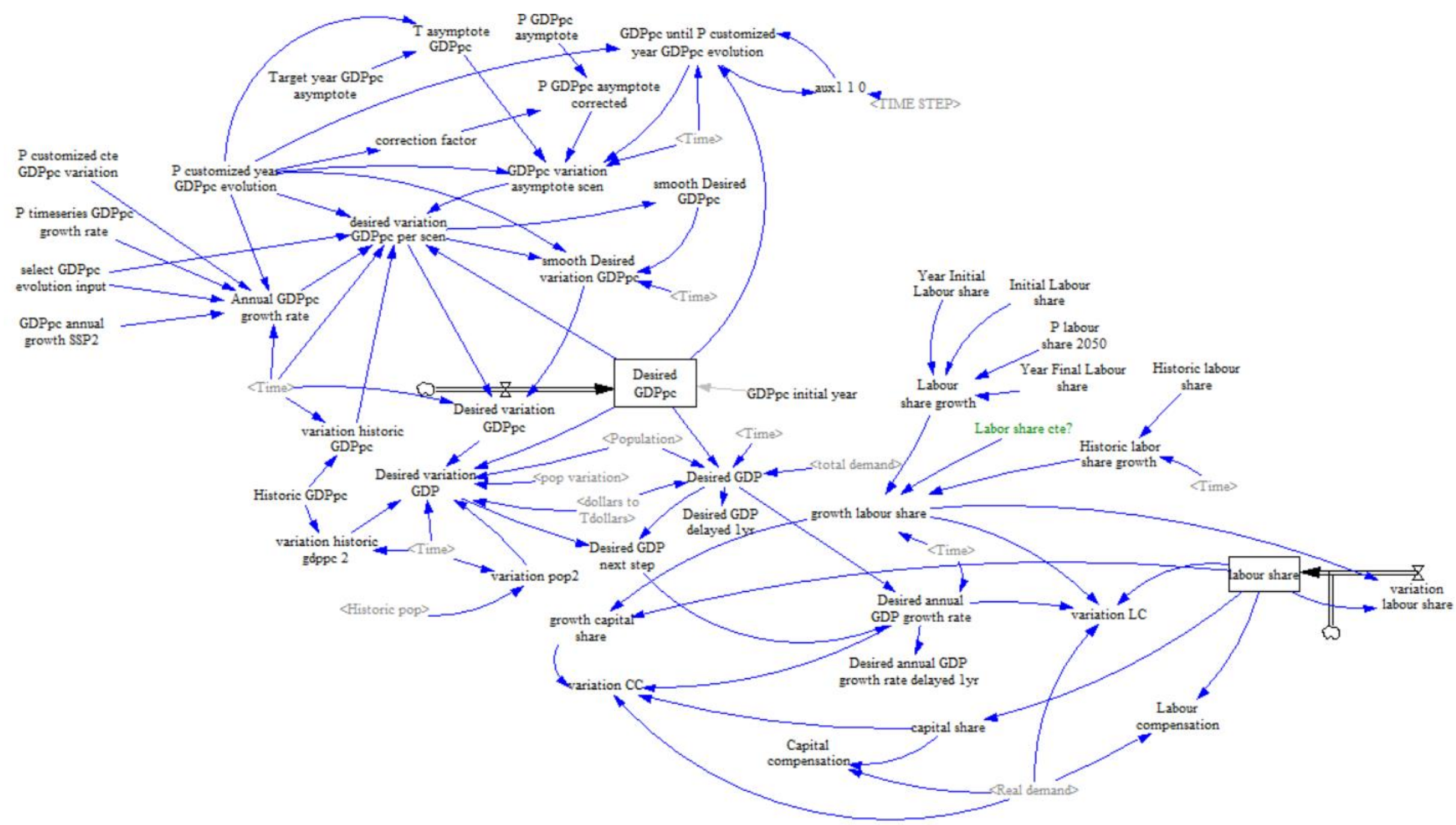

Figure 30. 'DEM ECON - Income. Labour and capital compensation' view in MEDEAS-World. 


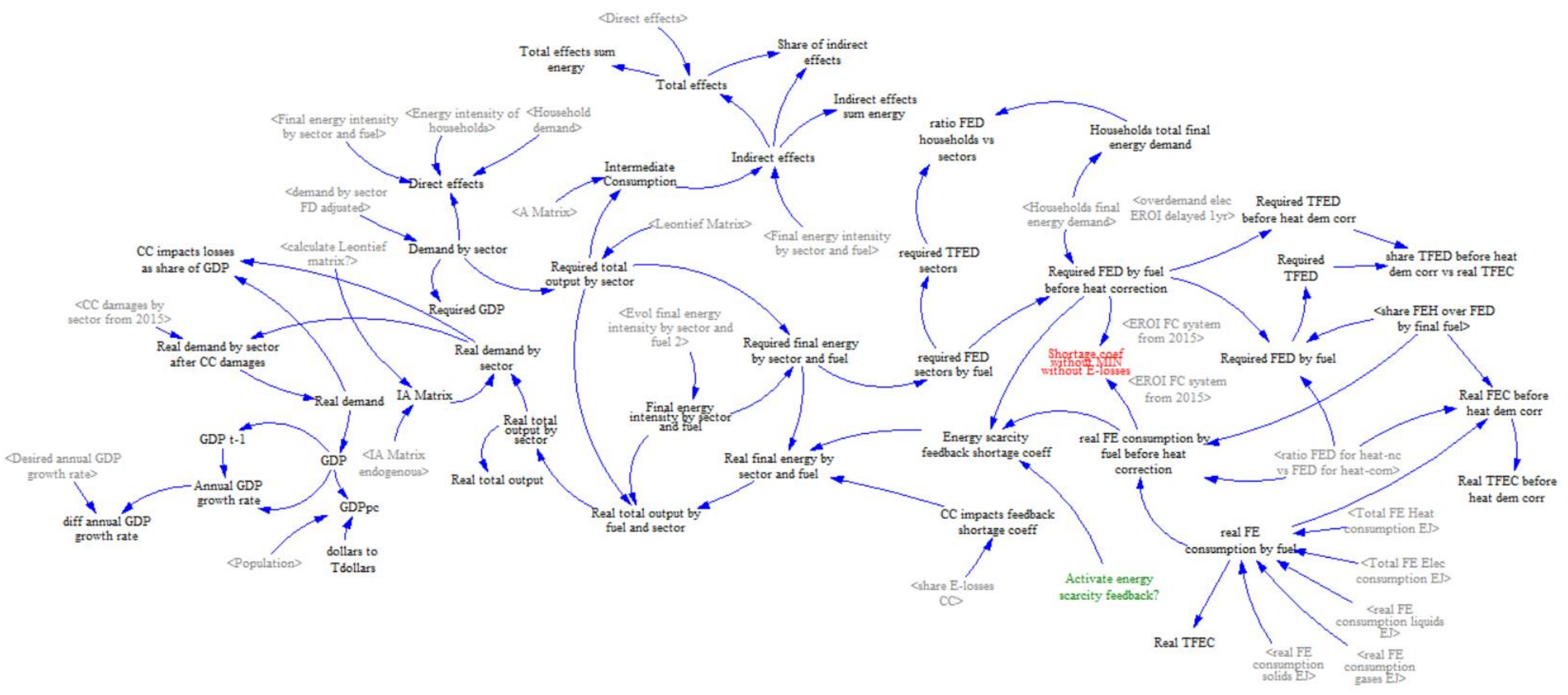

Figure 31. 'ECON. Confrontation demand with limits' view in MEDEAS-World. 


\section{Appendix 3. MEDEAS-Europe analysis}

\section{Appendix 3.A. Scenarios Assumptions}

Table 20. Detailed scenarios summary for European model.

\begin{tabular}{|c|c|c|c|c|c|c|c|c|c|c|c|c|}
\hline Variable & $\mathbf{B A U}$ & \multicolumn{2}{|c|}{ REF16 } & \multicolumn{2}{|c|}{ EUCO27 } & \multicolumn{2}{|c|}{ EUCO33 } & \multicolumn{2}{|c|}{ EUCO40 } & $\begin{array}{l}\text { Green } \\
\text { Growth }\end{array}$ & Post-Growth & Comments \\
\hline $\begin{array}{l}\text { GDP } \\
\text { Expectations }\end{array}$ & $\begin{array}{l}1.57 \% \\
(\mathrm{SSP} 2)\end{array}$ & \multicolumn{2}{|c|}{$\begin{array}{l}1.44 \% \\
(\mathrm{ER} 2050)\end{array}$} & \multicolumn{2}{|c|}{$\begin{array}{l}1.44 \% \\
(\mathrm{ER} 2050)\end{array}$} & \multicolumn{2}{|c|}{$\begin{array}{l}1.44 \% \\
(\text { ER2050) }\end{array}$} & \multicolumn{2}{|c|}{$1.44 \%$ (ER2050) } & $1.88 \%$ (SSP1) & $0.94 \%$ & $\begin{array}{l}\text { Post-Growth: below } \\
\text { BAU }\end{array}$ \\
\hline $\begin{array}{l}\text { Population } \\
\text { growth } \\
\text { (yearly } \\
\text { change) }\end{array}$ & $\begin{array}{l}0.14 \% \\
\text { (SSP2) }\end{array}$ & \multicolumn{2}{|c|}{$\begin{array}{l}0.08 \% \\
(\mathrm{ER} 2050)\end{array}$} & \multicolumn{2}{|c|}{$\begin{array}{l}0.08 \% \\
(\mathrm{ER} 2050)\end{array}$} & \multicolumn{2}{|c|}{$\begin{array}{l}0.08 \% \\
(\text { ER2050) }\end{array}$} & \multicolumn{2}{|c|}{$0.08 \%($ ER2050) } & $0.19 \%$ (SSP1) & $0.10 \%$ & $\begin{array}{l}\text { Post-Growth: below } \\
\text { BAU }\end{array}$ \\
\hline A Matrix & Static & \multicolumn{2}{|l|}{ Static } & \multicolumn{2}{|c|}{$\begin{array}{l}\text { Static } \\
\text { SCh: } \\
\text { Germany } \\
\text { (Target) }\end{array}$} & \multicolumn{2}{|c|}{$\begin{array}{l}\text { Static } \\
\text { SCh: } \\
\text { Germany } \\
\text { (Target) }\end{array}$} & \multicolumn{2}{|c|}{$\begin{array}{l}\text { Static } \\
\text { SCh: Germany } \\
\text { (Target) }\end{array}$} & $\begin{array}{l}\text { Target: } \\
\text { Germany }\end{array}$ & Target: Ad-Hoc & $\begin{array}{l}\text { See Supplementary } \\
\text { Material. }\end{array}$ \\
\hline $\begin{array}{c}\text { Income } \\
\text { Distribution } \\
\text { Target } \\
\text { (Labour } \\
\text { share) }\end{array}$ & $55 \%$ & \multicolumn{2}{|c|}{$57 \%$} & \multicolumn{2}{|c|}{$57 \%$} & \multicolumn{2}{|c|}{$57 \%$} & \multicolumn{2}{|c|}{$57 \%$} & $\begin{array}{c}60 \% \\
(+\mathrm{Lab})\end{array}$ & $65 \%$ & $\begin{array}{l}\text { BAU: current trends, } \\
\text { slow decline. } \\
\text { Taxes on products } \\
\text { constant at } 10 \% \text {. }\end{array}$ \\
\hline $\begin{array}{l}\text { Global GDP } \\
\text { Growth }\end{array}$ & $+\mathrm{WoLim}=-1.17 \%$ & \multicolumn{8}{|c|}{$\begin{array}{c}\text { Base: } 3.14 \% \\
+ \text { WoLim: } 1.56 \%\end{array}$} & $\begin{array}{l}\text { +WoLim: } \\
1.56 \%\end{array}$ & +WoLim: $0.29 \%$ & $\begin{array}{l}\text { Delivered by } \\
\text { MEDEAS-World } \\
\text { simulations (Nieto et al. } \\
\text { 2019). }\end{array}$ \\
\hline \multirow{2}{*}{$\begin{array}{l}\text { Energy } \\
\text { Efficiency } \\
\text { Growth }\end{array}$} & \multirow{2}{*}{ REF16 } & 2030 & 2050 & 2030 & 2050 & 2030 & 2050 & 2030 & 2050 & \multirow{2}{*}{ EUCO33 } & \multirow{2}{*}{ EUCO40 } & \multirow{2}{*}{$\begin{array}{l}\text { Average of all sectors } \\
\text { and energy sources. } \\
\text { Compared to } 2010 .\end{array}$} \\
\hline & & $31 \%$ & $61 \%$ & $68 \%$ & $123 \%$ & $75 \%$ & $135 \%$ & $87 \%$ & $159 \%$ & & & \\
\hline
\end{tabular}




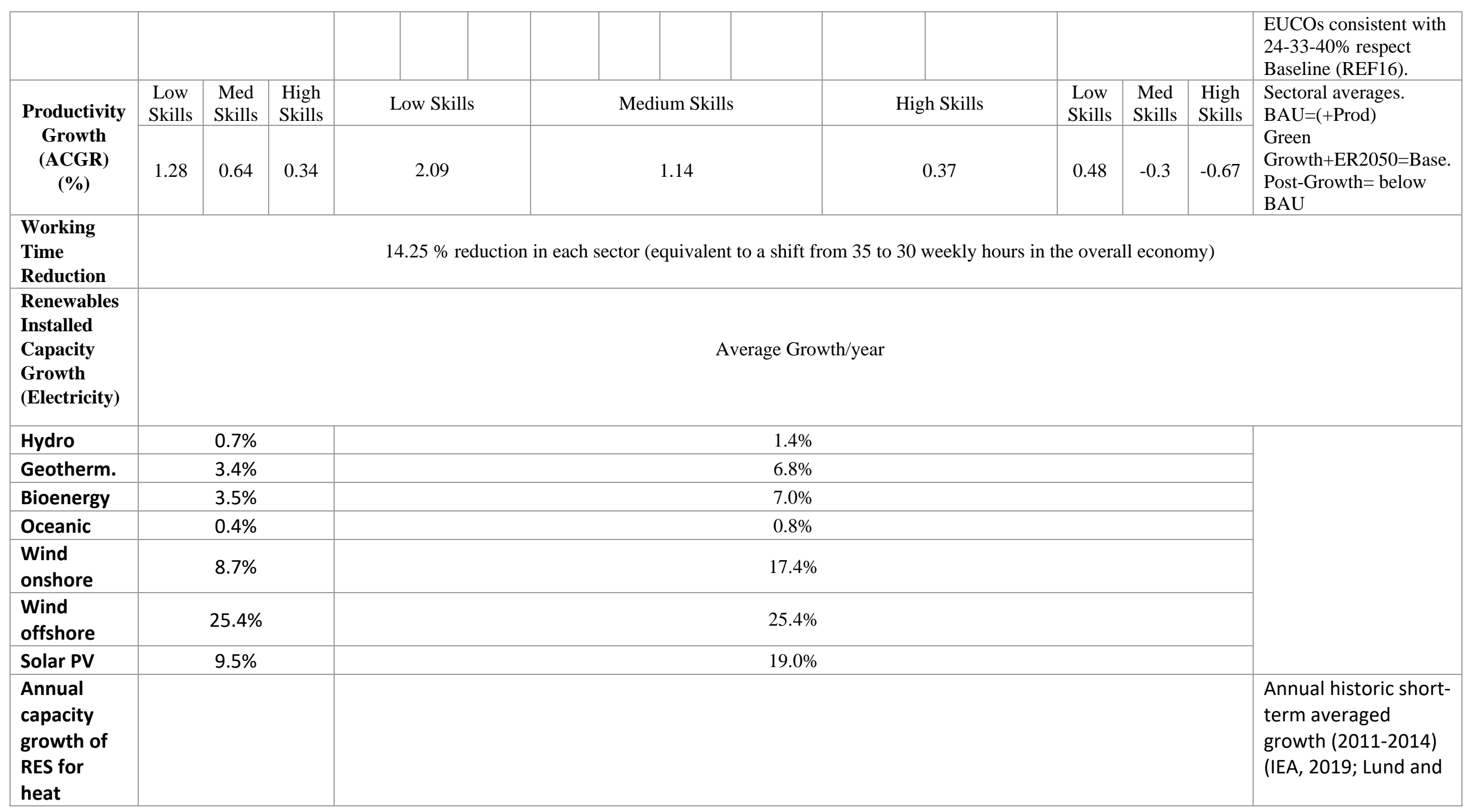




\begin{tabular}{|c|c|c|c|}
\hline $\begin{array}{l}\text { Solar } \\
\text { thermal }\end{array}$ & $7 \%$ & $14 \%$ & \multirow[t]{2}{*}{$\begin{array}{l}\text { Boyd, 2015; SHC, } \\
\text { 2016) }\end{array}$} \\
\hline Geothermal & $5.10 \%$ & $10.20 \%$ & \\
\hline \multicolumn{3}{|l|}{ Bioenergy } & \multirow{5}{*}{$\begin{array}{l}\text { (IEA ETP, 2017) and } \\
\text { annual historic short- } \\
\text { term averaged } \\
\text { growth of } \\
\text { conventional biofuels } \\
(2012-2015) \text { (BP, } \\
2016)\end{array}$} \\
\hline $\begin{array}{l}2^{\text {nd }} \quad \text { Gen } \\
\text { cropland }\end{array}$ & $4 \%$ & $8 \%$ & \\
\hline $\begin{array}{l}3^{\text {rd }} \quad \text { Gen } \\
\text { cropland } \\
\text { (starting } \\
\text { 2025) }\end{array}$ & $4 \%$ & $8 \%$ & \\
\hline $\begin{array}{l}\text { Residues } \\
\text { (starting } \\
\text { 2025) }\end{array}$ & $11 \%$ & $20 \%$ & \\
\hline Biogas & $15 \%$ & $30 \%$ & \\
\hline \multicolumn{4}{|l|}{$\begin{array}{l}\text { Non- } \\
\text { renewable } \\
\text { energies } \\
\text { depletion } \\
\text { curves* }\end{array}$} \\
\hline Oil & \multicolumn{3}{|c|}{ (Mohr et al., 2015), Conventional: High; Unconventional: Best Guess } \\
\hline Natural gas & \multicolumn{3}{|c|}{ (Mohr et al., 2015), Conventional: High; Unconventional: Best Guess } \\
\hline Coal & \multicolumn{3}{|c|}{ (Mohr et al., 2015), Best Guess } \\
\hline Uranium & \multicolumn{3}{|c|}{ (EWG, 2013) } \\
\hline
\end{tabular}


Appendix 3.B. Energy Roadmap 2050: Primary energy use reduction targets to 2030 and projections to 2050.
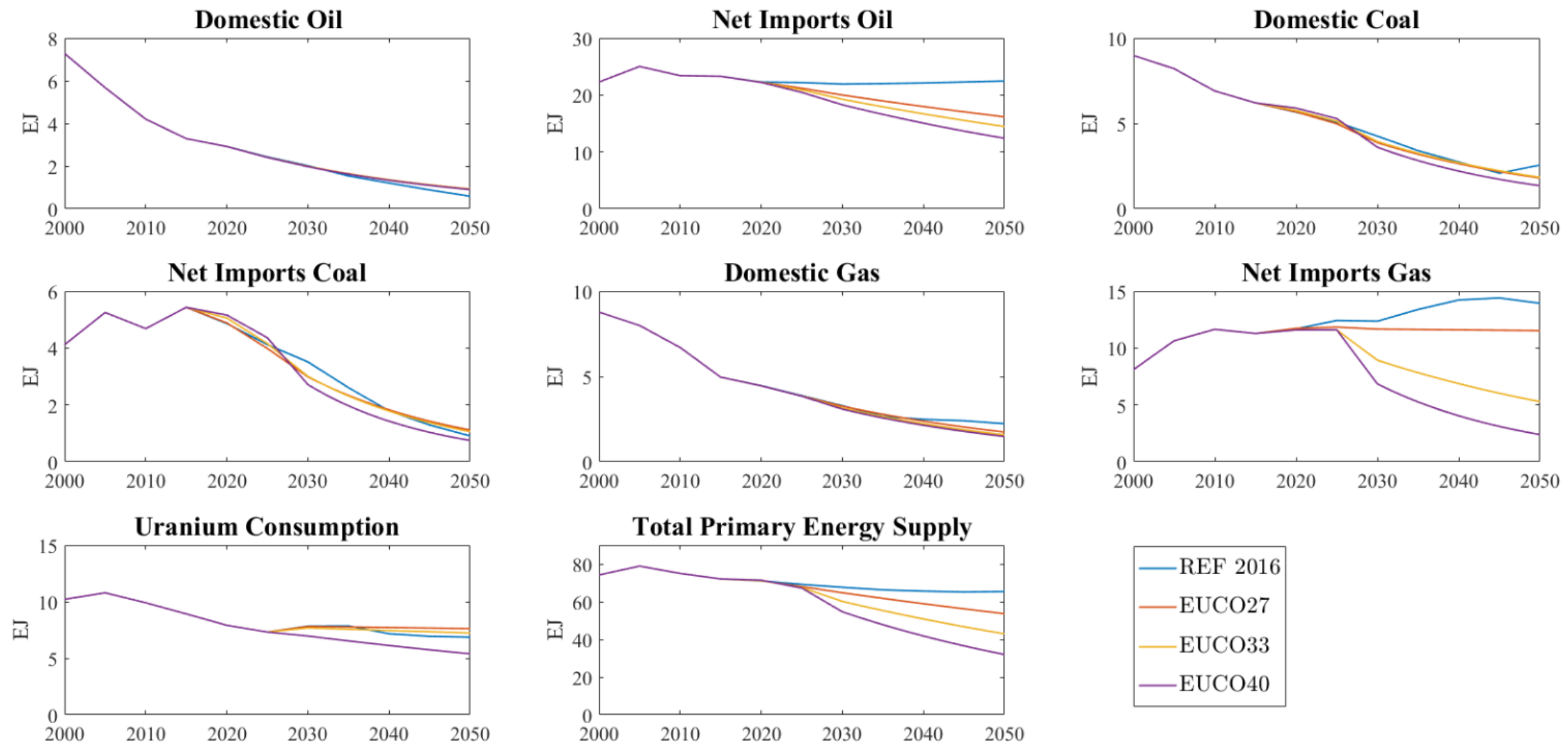

Figure 32. Ref2016 and EUCO scenarios. Primary Energy production and net imports pathways and projections.

Source: Own elaboration on the basis of European Commission (2016a, 2016b) 


\section{Appendix 3.C. Methodology annex on notation.}

The MEDEAS Economy module (and Employment sub-module) relies on Input-Output Analysis and therefore, matrix notation has been employed. Here, we describe the notation used in section 2 of Methodology.

Matrices have been noted with capital, boldface letters, e.g. A for the ixj technical coefficients matrix.

Vectors have been noted with lowercase, boldface letters, e.g. $\mathbf{x}$ for the sectoral production vector.

Vector or matrix components are noted with lowercase letters in italics and have subscripts to indicate their dimensions, e.g. $z_{i j}$ or $x_{j}$ for the intermediate demand between sectors 'i' and 'j'.

A matrix or vector component in brackets represents how that matrix or vector is composed, e.g. $\mathbf{A}=\left[a_{i j}\right]$ means that $\mathbf{A}$ matrix is formed by $a_{i j}$ components.

Although matrix and vectors are normally represented by only one letter as in A matrix, we have noted matrices and vectors with more than one letter as in e.g. fed or LD to provide clarity to the methodology narration.

Finally, given the two-dimensional nature of matrices and the fact that the IOA represents the interactions between all sectors, these have been noted with different subscripts depending on the role of the economic variable.

Subscript ' $\mathrm{i}$ ' is used for all the sectoral demand, or use-side such as final demand $\left(f d_{i}\right)$ and its components (eq.2) or intermediate sales in the IOT $\left(z_{i j}\right)$.

Subscript ' $\mathrm{j}$ ' is used for all the sectoral supply-side variables such as production $\left(x_{j}\right)$,

energy and labour intensities $\left(e_{j}\right.$ and $\left.y_{j}{ }^{-1}\right)$, gross value added $\left(g v a_{j}, w_{j}\right.$ and $\left.k_{j}\right)$, intermediate purchases $\left(z_{i j}\right)$, and also the energy or labour requirements of production $\left(f e d_{-} i n d_{k j}, h_{s j}\right.$ or $\left.l d_{j}\right)$. 
Appendix 3.D. Target matrices for the European model.

Table 21. Main changes in target matrices

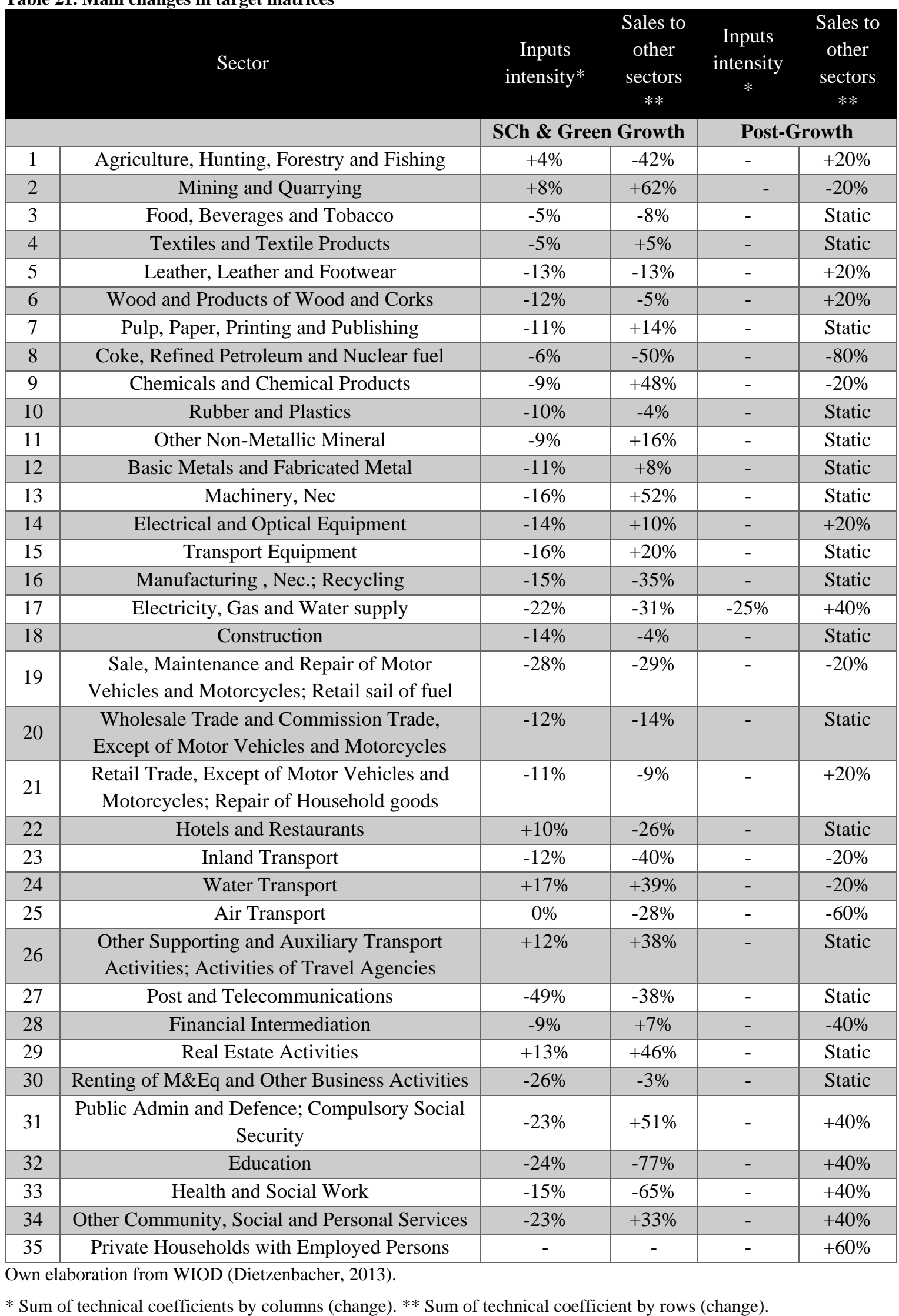


Note: The figures for SCh \& Green Growth are the result of transition towards a Germany-like A matrix. The Post-Growth figures are modelling options selected for the purpose of this article. 
